\title{
Investigation of lubricant oil consumption and its contribution to particulate matter emissions
}

\author{
Sam George \\ West Virginia University
}

Follow this and additional works at: https://researchrepository.wvu.edu/etd

\section{Recommended Citation}

George, Sam, "Investigation of lubricant oil consumption and its contribution to particulate matter emissions" (2008). Graduate Theses, Dissertations, and Problem Reports. 2859.

https://researchrepository.wvu.edu/etd/2859

This Dissertation is protected by copyright and/or related rights. It has been brought to you by the The Research Repository @ WVU with permission from the rights-holder(s). You are free to use this Dissertation in any way that is permitted by the copyright and related rights legislation that applies to your use. For other uses you must obtain permission from the rights-holder(s) directly, unless additional rights are indicated by a Creative Commons license in the record and/ or on the work itself. This Dissertation has been accepted for inclusion in WVU Graduate Theses, Dissertations, and Problem Reports collection by an authorized administrator of The Research Repository @ WVU.

For more information, please contact researchrepository@mail.wvu.edu. 
Investigation of Lubricant Oil Consumption and its Contribution to Particulate Matter Emissions

Sam George

Dissertation submitted to the College of Engineering and Mineral Resources at West Virginia University in partial fulfillment of the requirements for the degree of

\author{
Doctor of Philosophy \\ in \\ Mechanical Engineering
}

\begin{abstract}
Mridul Gautam, Ph.D., Chair Nigel N. Clark, Ph.D.

Gregory J. Thompson, Ph.D.

Scott W. Wayne, Ph.D.
\end{abstract}

Department of Mechanical and Aerospace Engineering

Michael H. McMillian, PhD.

National Energy Technology Laboratory (NETL)

Morgantown, West Virginia

2008

Keywords: Lubricant Oil, Hydrogen, Lubricant Oil Consumption, Elemental Carbon, Organic Carbon 


\section{ABSTRACT \\ Investigation of Lubricant Oil Consumption and its Contribution to Particulate Matter Emissions}

\section{Sam George}

The global objective of this study was to determine lubricant oil consumption as a function of engine operating conditions, and determine its contribution to particulate matter (PM) emissions in a hydrogen-fueled engine. Hydrogen offers a promising alternative for internal combustion engines owing to its clean burning properties. The success of gaseousfueled engines lies in the development and use of specially formulated and well researched lubricating oils as these oils are the only source of carbon emissions in hydrogen-fueled engines. The lubricant oil consumption can be determined in a hydrogen-fueled engine by measuring the carbonaceous emissions. This study determined lubricant oil consumption as a function of engine speed, equivalence ratio, and boost for hydrogen-fueled engine operation. The oil consumption data was fitted using multiple linear regression analysis. Elemental Carbon/Organic Carbon analysis, trace metals analysis, ions analysis, and particle size distributions at various steady state operating conditions were also performed to have an understanding of lubricant contribution to particulate emissions. The lubricant oil consumption was also measured using trace metal markers such as $\mathrm{Ca}$ and $\mathrm{Zn}$. Oil consumption models would help in calculating ash accumulation in exhaust after-treatment devices like diesel particulate filters (DPF). The oil consumption was found to be well correlated to engine operating conditions. The particulate matter was found to be almost completely organic carbon, and the synthetic oil derived organic fraction was found to be lower in spite of its higher volatility for the conditions tested. It was found that the trace metal marker method for oil consumption determination was not a suitable method as a result of the different rates of consumption of base stocks versus additives. The particle size distributions in the case of hydrogen-fueled operation were found to be in the same order of magnitude as a diesel engine. The particle size distributions and number concentrations were found to be more influenced by the engine operating conditions and amount of oil consumed, and was not influenced by the difference in the oil volatility or the nature of the base stock (synthetic versus mineral) for the conditions tested in this study. 


\section{ACKNOWLEDGEMENTS}

First and foremost, I would like to thank my advisor, Dr. Mridul Gautam, for the unending support, invaluable advice, and guidance provided throughout my graduate study. He has been a good friend and advisor all along.

I also thank Dr. Nigel Clark, Dr. Greg Thompson, and Dr. Scott Wayne for being on my advisory committee, and providing me the necessary guidance and suggestions. I would also like to thank Dr. Michael McMillian who was also on my advisory committee and has been extremely helpful in providing valuable technical suggestions and feedback throughout the project at the National Energy Technology Laboratory (NETL), Morgantown, West Virginia.

The project at NETL would not have been a reality without the support of Mike, Steven Richardson, John Ontko, Doug Horton, and Tod Worstell, among many others. Special thanks are due to John for the technical advice with all statistical issues. I also extend my gratitude to Jacinto Solano for his help during the entire study.

Last but not the least, I would like to thank my entire family for their support, prayers, and motivation throughout my graduate study. Special thanks are due to my wife, Simi, for her

tireless efforts and help in the preparation of this document. I also wish to remember and dedicate all my work to my late Mom, and my late brother, Sajan, who would have been extremely proud of this day. 


\section{TABLE OF CONTENTS}

ABSTRACT ii

ACKNOWLEDGEMENTS iii

LIST OF TABLES vii

LIST OF FIGURES viii

NOMENCLATURE $\mathrm{xi}$

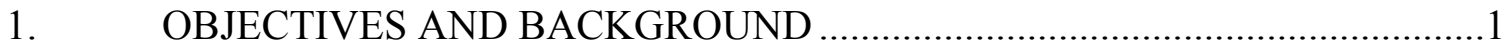

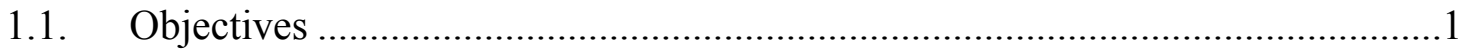

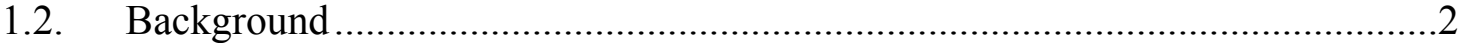

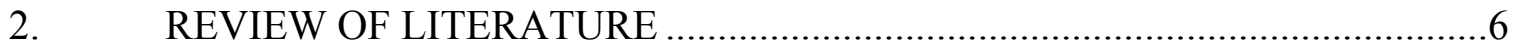

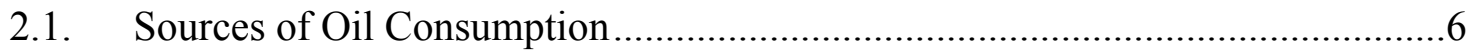

2.2. Lubricant Oil Consumption Studies...............................................................

2.3. Lubricant Oil Consumption Measurement Using Trace Metals Analysis ...........9

2.4. Hydrogen Combustion Studies ....................................................................10

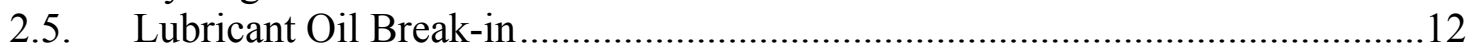

3. EXPERIMENTAL EQUIPMENT AND PROCEDURES ………....................14

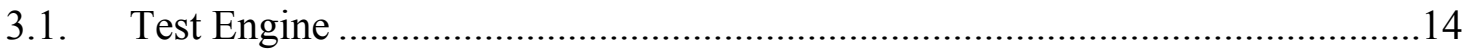

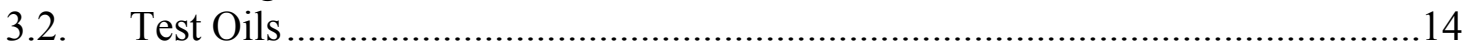

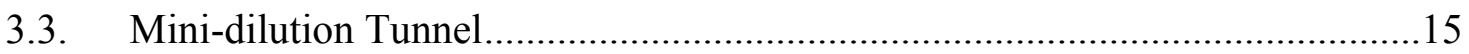

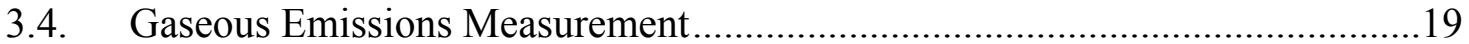

3.4.1. Hydrocarbon Analyzer.......................................................................

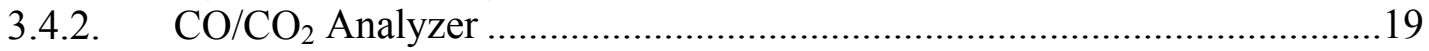

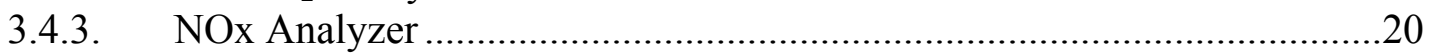

3.5. Scanning Mobility Particle Sizer (SMPS) ………………………………....20

3.6. Elemental Carbon/Organic Carbon (EC/OC), Ions, Trace Metals Analyses.....21

3.7. High Speed Data Acquisition System............................................................22

3.8. Low Speed Data Acquisition System .............................................................22

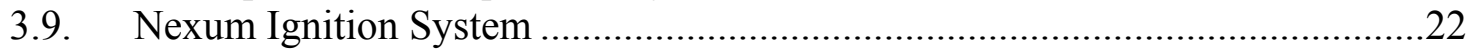

4. EXPERIMENTAL AND ANALYSIS PROCEDURES ………………..............

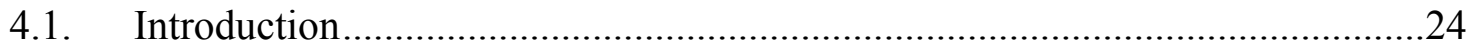

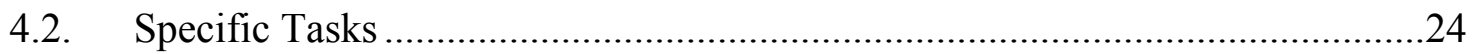

4.3. Test Matrix for Lubricant Oil Consumption Measurement (Pre-mixed Hydrogen/Air Operation) .25 
4.4. Test Matrix for EC/OC, Ions, and Trace Metals Analyses ..............................26

4.5. Maximum Thermal Efficiency Timing Test..............................................27

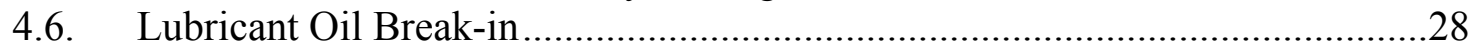

4.7. Carbon Balance Oil Consumption Calculation (g/bhp-hr) .............................29

4.8. Overview of Statistical Tools Used for Analysis.............................................. 31

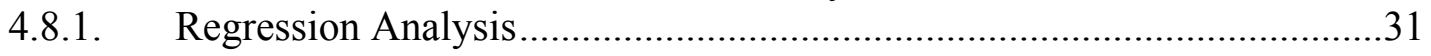

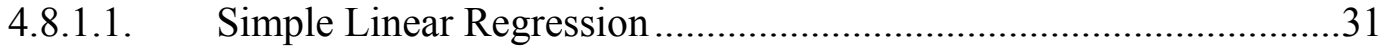

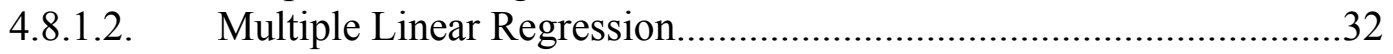

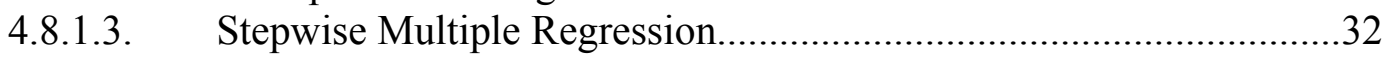

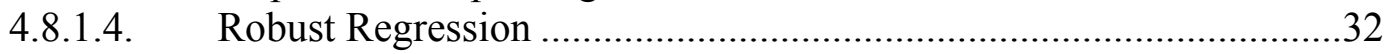

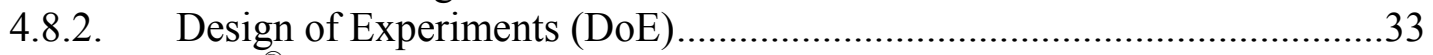

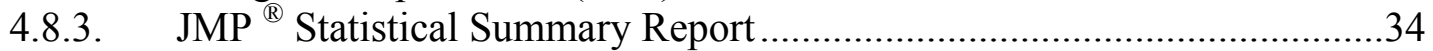

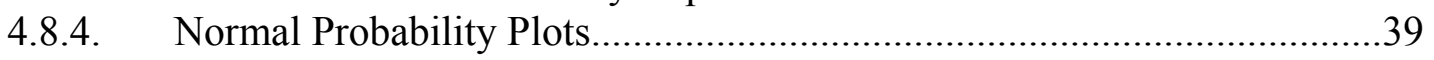

4.8.5. Box Plots ...................................................................................... 40

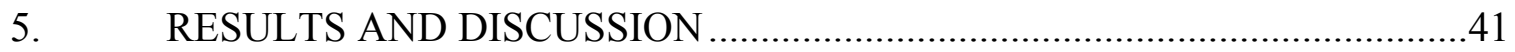

5.1. Oil Consumption Analysis (Carbon Balance Method) ..................................42

5.1.1. Brake-specific Oil Consumption Analysis (Carbon Balance Method)......44

5.1.2. Time-specific Oil Consumption Analysis (Carbon Balance Method).......53

5.1.3. Influence of Combustion Parameters on Oil Consumption .......................58

5.1.4. Influence of Engine Operating Conditions, and Combustion Parameters on Oil Consumption Sources ..............................................73

5.2. Elemental Carbon/ Organic Carbon (EC/OC), Trace Metals Analysis .............74

5.3. PM Concentrations and Size Distribution Analysis......................................83

5.3.1. Brake-specific Particle Size Distribution Results ...................................83

5.3.2. Particle Size Distribution (Motoring versus Combustion)........................95

5.3.3. Particle Surface Area Distribution Analysis ............................................99

5.4. Lubricant Oil Aging: Effects on Lubricant Properties...................................105

6. CONCLUSIONS AND RECOMMENDATIONS ....................................107

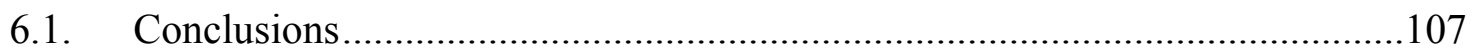

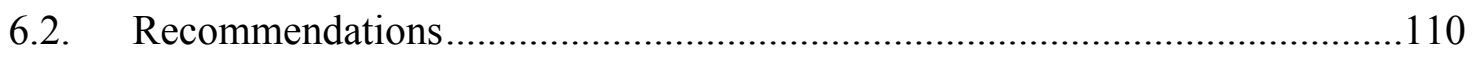

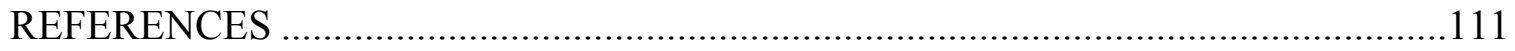

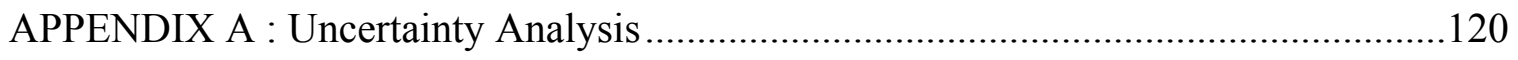

A1 C-balance OilCconsumption Calculation : Uncertainty ..............................120

A2 Dilution Ratio Calculation : Uncertainty .................................................122

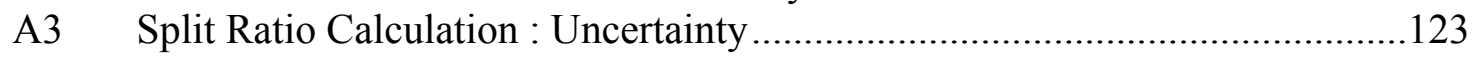

APPENDIX B : Lubricant Oil Consumption Analysis - Experiment Matrix and Data...124

APPENDIX C : Brake-specific Gaseous Emissions $\left(\mathrm{CO}_{2}, \mathrm{CO}\right.$, THC, and NOx) Data ..125 
APPENDIX D : Elemental Carbon (EC)/Organic Carbon (OC), Ions, Trace Metals Analysis: Procedure and Data from Desert Research Institute (DRI) ..126

D1 Thermal/Optical Carbon Analysis Method (EC/OC Analysis)[85]..................126

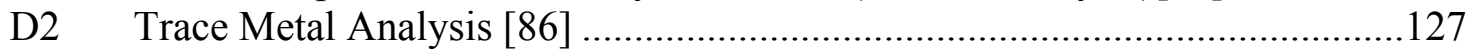

D3 Ions Analysis (Ion Chromatography) [88] ..................................................129

APPENDIX E : Particle Size Distribution Data: Experimental Data with Error Bars....135 


\section{LIST OF TABLES}

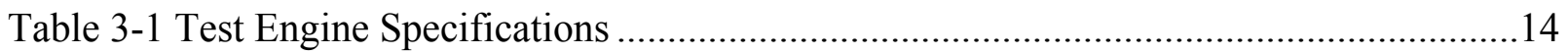

Table 3-2 Properties of Test Oils .......................................................................................... 15

Table 4-1 Test Matrix for Premixed Hydrogen/Air Operation ............................................26

Table 4-2 Test Matrix for EC/OC, and Trace Metals Analysis .............................................27

Table 4-3 Maximum Thermal Efficiency (MTE) Spark Timing Used for the Test Points ........27

Table 5-1 Steady-state Test Points Denoted by State Numbers ..............................................42

Table 5-2 Brake-specific Oil Consumption (g/bhp-hr) Results for the Test Oils.....................43

Table 5-3 Combustion Parameters Data for the Operating States Tested for the Test Oils .......59

Table 5-4 Exhaust Temperature Data for the Operating States Tested for the Test Oils ..........60

Table 5-5 Effects of Combustion Parameters and Oil Consumption as a Result of Increasing Speed, Phi, and Boost................................................................. 71

Table 5-6 Effects of Engine Operating Conditions, and Combustion Parameters on Sources

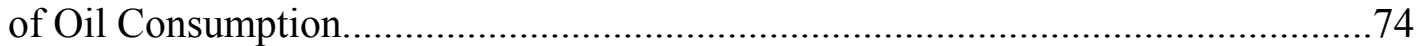

Table 5-7 Comparison of Oil Consumption (C-balance, Organic Fraction, Ca-balance, Zn-

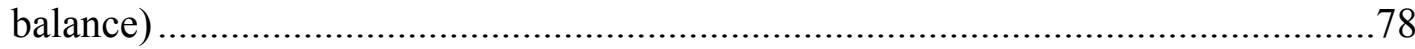

Table 5-8 Particle Number Statistics for the Operating States .............................................92

Table 5-9 Comparison of Integrated Particle Number, Exhaust Temperatures, and Maximum Cylinder Pressures (Combustion vs Motoring) ......................................99

Table 5-10 Lubricant Oil Properties at Various Testing Intervals........................................106

Table D1 EC/OC Results : Raw Data From DRI ............................................................. 130

Table D2 Trace Metals Results : Raw Data From DRI ..................................................131

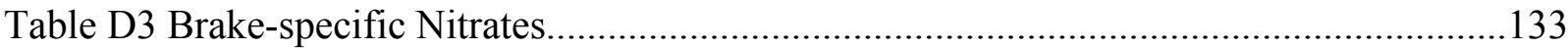

Table D4 Ions Analysis Results : Raw Data From DRI ....................................................133

Table D5 Trace Metals Analysis : Elements and Corresponding Symbols .............................134

Table D6 Operating State Numbers and Corresponding Filter IDs .....................................134 


\section{LIST OF FIGURES}

Figure 1-1 Comparison of Toxic Air Contaminants from a CNG Engine [3] ..........................4

Figure 1-2 Transit Bus Steady State Operation at $35 \mathrm{mph}$ (Vehicle with a WVU-ECS PM

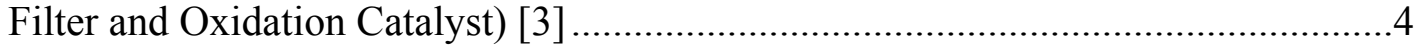

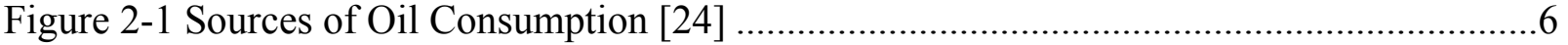

Figure 3-1 Schematic of Engine Test Facility .................................................................. 17

Figure 3-2 Schematic of Mini-tunnel Layout ..................................................................... 18

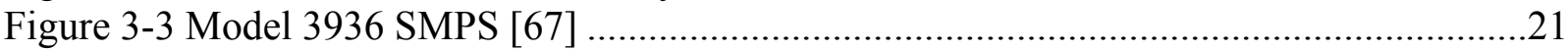

Figure 3-4 Typical Setup of Nexum Ignition System [68] .............................................23

Figure 4-1 Faced Central Composite Design for Premixed Hydrogen/Air Operation ..............25

Figure 4-2 Face-centered Central Composite Design..............................................................33

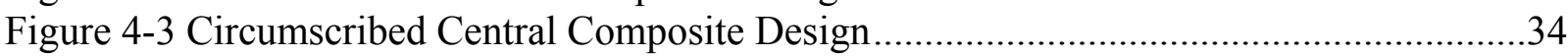

Figure 4-4 Inscribed Central Composite Design ................................................................34

Figure 4-5 Typical JMP Statistical Summary Report .........................................................35

Figure 5-1 Normal Probability Plot of Brake-specific Oil Consumption Data for the Test

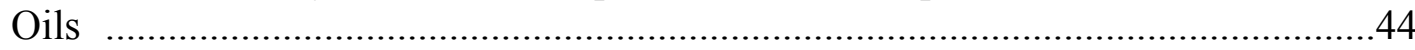

Figure 5-2 Box Plot of Brake-specific Oil Consumption Data for the Test Oils.....................45

Figure 5-3 Comparison of Step-wise Regression Model vs. Robust Regression Model...........49

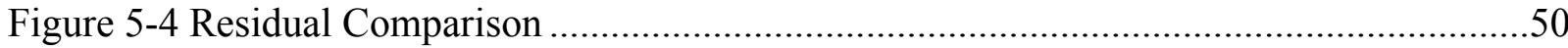

Figure 5-5 Quadratic Brake-specific Oil Consumption (g/bhp-hr) Model ..............................51

Figure 5-6 Quadratic Brake -specific Oil Consumption Model : Constant Speed Steps............52

Figure 5-7 Quadratic Brake-specific Oil Consumption Model : Constant Phi Steps ................52

Figure 5-8 Quadratic Brake-specific Oil Consumption Model : Constant Boost Steps .............52

Figure 5-9 Quadratic Time-specific Oil Consumption (g/hr) Model......................................56

Figure 5-10 Quadratic Time -specific Oil Consumption (g/hr) Model: Constant Speed Steps..57

Figure 5-11 Quadratic Time -specific Oil Consumption (g/hr) Model: Constant Phi Steps ......57

Figure 5-12 Quadratic Time -specific Oil Consumption (g/hr) Model: Constant Boost Steps ..57

Figure 5-13 Correlation between Combustion Duration and Boost .....................................72

Figure 5-14 Normal Probability Plot (Organic Fraction Data for Mineral Oil and Synthetic

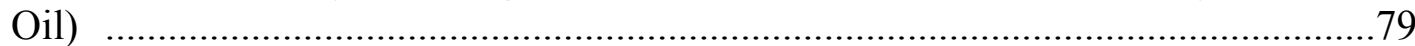

Figure 5-15 Box Plot (Organic Fraction Data for Mineral Oil and Synthetic Oil)...................79

Figure 5-16 Normal Probability Plot (Brake-specific Ca: Mineral Oil and Synthetic Oil)........80

Figure 5-17 Box Plot (Brake-specific Ca: Mineral Oil and Synthetic Oil) ..............................81

Figure 5-18 Normal Probability Plot (Brake-specific Zn: Mineral Oil and Synthetic Oil).......81

Figure 5-19 Box Plot (Brake-specific Zn: Mineral Oil and Synthetic Oil) .............................82

Figure 5-20 Comparison of Calculated Oil Consumption Values (Mineral Oil and Synthetic

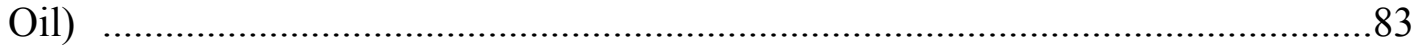

Figure 5-21 Lognormal Probability Plot of Particle Number Data..........................................85

Figure 5-22 Brake-specific Particle Number Distribution (Mineral Oil): Speed $=15 \mathrm{rps}$.........86

Figure 5-23 Brake-specific Oil Consumption, OC Fraction, Particle \# (Mineral Oil): Speed

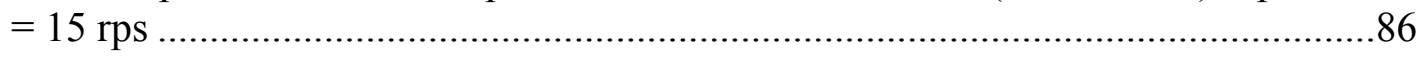

Figure 5-24 Brake-specific Particle Number Distribution (Synthetic Oil): Speed $=15$ rps.......87

Figure 5-25 Brake-specific Oil Consumption, OC Fraction, Particle \# (Synthetic Oil):

$$
\text { Speed }=15 \mathrm{rps}
$$


Figure 5-26 Brake-specific Particle Number Distribution (Mineral Oil): Speed $=22.5 \mathrm{rps} \ldots . . .88$

Figure 5-27 Brake-specific Oil Consumption, OC Fraction, Particle \# (Mineral Oil): Speed $=22.5 \mathrm{rps}$ .88

Figure 5-28 Brake-specific Particle Number Distribution (Synthetic Oil): Speed = 22.5 rps ....89

Figure 5-29 Brake-specific Oil Consumption, OC Fraction, Particle \# (Synthetic Oil):

Speed $=22.5 \mathrm{rps}$ .89

Figure 5-30 Brake-specific Particle Number Distribution (Mineral Oil): Speed $=30$ rps .........90

Figure 5-31 Brake-specific Oil Consumption, OC Fraction, Particle \# (Mineral Oil): Speed $=30 \mathrm{rps}$

Figure 5-32 Brake-specific Particle Number Distribution (Synthetic Oil): Speed = 30 rps.......91

Figure 5-33 Brake-specific Oil Consumption, OC Fraction, Particle \# (Synthetic Oil):

Speed $=30 \mathrm{rps}$ .91

Figure 5-34 Comparison of Oil-specific Particle Number : Speed $=15$ rps..........................94

Figure 5-35 Comparison of Oil-specific Particle Number : Speed $=22.5$ rps.........................94

Figure 5-36 Comparison of Oil-specific Particle Number: Speed = 30 rps..........................95

Figure 5-37 Particle Size Distribution (Motoring): Constant Boost $=40 \mathrm{kPa} \ldots \ldots \ldots \ldots \ldots \ldots \ldots \ldots . . . . . . . . . . . . .66$

Figure 5-38 Particle Size Distribution: Constant Boost $=40 \mathrm{kPa}, \mathrm{Phi}=0.33 \ldots \ldots \ldots \ldots \ldots \ldots \ldots \ldots . . . . . . \ldots 6$

Figure 5-39 Particle Size Distribution (Motoring): Constant Speed = 22.5 rps ......................97

Figure 5-40 Particle Size Distribution: Constant Speed = 22.5 rps, Phi = 0.33 ......................97

Figure 5-41 Particle Surface Area Distribution (Mineral Oil): Speed $=15 \mathrm{rps} \ldots \ldots \ldots \ldots \ldots \ldots \ldots . . . . . . . .100$

Figure 5-42 Particle Surface Area Distribution (Synthetic Oil): Speed = $15 \mathrm{rps}$.................100

Figure 5-43 Comparison of Integrated Particle Surface Area (Mineral vs. Synthetic): Speed

$=15 \mathrm{rps}$

Figure 5-44 Particle Surface Area Distribution (Mineral Oil): Speed = 22.5 rps ..................101

Figure 5-45 Particle Surface Area Distribution (Synthetic Oil): Speed = $15 \mathrm{rps}$ 102

Figure 5-46 Comparison of Integrated Particle Surface Area (Mineral vs. Synthetic): Speed $=22.5 \mathrm{rps}$

Figure 5-47 Particle Surface Area Distribution (Mineral Oil): Speed = 30 rps ......................103

Figure 5-48 Particle Surface Area Distribution (Synthetic Oil): Speed = 30 rps ..................103

Figure 5-49 Comparison of Integrated Particle Surface Area (Mineral vs. Synthetic): Speed $=30 \mathrm{rps}$

Figure D 1 The Principle of XRF and the typical XRF Detection Arrangement [87] 128

Figure E1 Particle Size Distribution: Mineral Oil (Speed=15 rps, Phi=0.28, Boost=20 kPa)..135 Figure E2 Particle Size Distribution: Mineral Oil (Speed=15 rps, Phi=0.28, Boost=60 kPa)..135 Figure E3 Particle Size Distribution: Mineral Oil (Speed=15 rps, Phi=0.33, Boost=40 kPa)..136 Figure E4 Particle Size Distribution: Mineral Oil (Speed=15 rps, Phi=0.38, Boost=20 kPa)..136 Figure E5 Particle Size Distribution: Mineral Oil (Speed=15 rps, Phi=0.38, Boost=60 kPa)..137 Figure E6 Particle Size Distribution: Synthetic Oil (Speed=15 rps, Phi=0.28, Boost=20 $\mathrm{kPa})$ 137

Figure E7 Particle Size Distribution: Synthetic Oil (Speed=15 rps, Phi=0.28, Boost=60 $\mathrm{kPa})$ 138

Figure E8 Particle Size Distribution: Synthetic Oil (Speed=15 rps, Phi=0.33, Boost=40 $\mathrm{kPa})$ 138

Figure E9 Particle Size Distribution: Synthetic Oil (Speed=15 rps, Phi=0.38, Boost=20 
$\mathrm{kPa})$ 139

Figure E10 Particle Size Distribution: Synthetic Oil (Speed=15 rps, Phi=0.38, Boost=60 $\mathrm{kPa})$

Figure E11 Particle Size Distribution: Mineral Oil (Speed=22.5rps, $P h i=0.28$, Boost $=20$ $\mathrm{kPa})$ .140

Figure E12 Particle Size Distribution: Mineral Oil (Speed=22.5rps, $P h i=0.33$, Boost $=20$ $\mathrm{kPa})$

Figure E13 Particle Size Distribution: Mineral Oil (Speed $=22.5 \mathrm{rps}, \mathrm{Phi}=0.33$, Boost $=40$ $\mathrm{kPa})$

Figure E14 Particle Size Distribution: Mineral Oil (Speed $=22.5 \mathrm{rps}, \mathrm{Phi}=0.33$, Boost $=60$ $\mathrm{kPa})$

Figure E15 Particle Size Distribution: Mineral Oil (Speed=22.5rps, Phi $=0.38$, Boost $=40$ $\mathrm{kPa})$

Figure E16 Particle Size Distribution: Synthetic Oil (Speed=22.5rps, Phi=0.28, Boost $=40 \mathrm{kPa}$ ).

Figure E17 Particle Size Distribution: Synthetic Oil (Speed=22.5rps, Phi=0.33, Boost $=20 \mathrm{kPa}$ ).

Figure E18 Particle Size Distribution: Synthetic Oil (Speed=22.5rps, Phi=0.33, Boost $=40 \mathrm{kPa}$ ).....

Figure E19 Particle Size Distribution: Synthetic Oil (Speed=22.5rps, Phi=0.33, Boost $=60 \mathrm{kPa}$ ).

Figure E20 Particle Size Distribution: Synthetic Oil (Speed=22.5rps, Phi=0.38, Boost $=40 \mathrm{kPa}$. .144

Figure E21 Particle Size Distribution: Mineral Oil (Speed=30 rps, Phi=0.28, Boost=20 kPa) 145 Figure E22 Particle Size Distribution: Mineral Oil (Speed=30 rps, Phi $=0.28$, Boost $=60 \mathrm{kPa}$ ) 145 Figure E23 Particle Size Distribution: Mineral Oil (Speed=30 rps, Phi $=0.33$, Boost $=40 \mathrm{kPa}$ ) 146 Figure E24 Particle Size Distribution: Mineral Oil (Speed=30 rps, Phi $=0.38$, Boost $=20 \mathrm{kPa}$ ) 146 Figure E25 Particle Size Distribution: Mineral Oil (Speed=30 rps, Phi=0.38, Boost=60 kPa) 147 Figure E26 Particle Size Distribution: Synthetic Oil (Speed=30 rps, Phi=0.28, Boost=20 $\mathrm{kPa})$ .147

Figure E27 Particle Size Distribution: Synthetic Oil (Speed=30 rps, Phi=0.28, Boost $=60$ $\mathrm{kPa})$ .148

Figure E28 Particle Size Distribution: Synthetic Oil (Speed $=30 \mathrm{rps}, \mathrm{Phi}=0.33$, Boost $=40$ $\mathrm{kPa})$ .148

Figure E29 Particle Size Distribution: Synthetic Oil (Speed=30 rps, Phi=0.38, Boost=20 $\mathrm{kPa})$

Figure E30 Particle Size Distribution: Synthetic Oil (Speed=30 rps, Phi=0.38, Boost=60 $\mathrm{kPa})$

Figure E31 Particle Size Distribution: Motoring Condition (Speed=15 rps, Boost=40 kPa)...150 Figure E32 Particle Size Distribution: Motoring Condition (Speed=22.5 rps, Boost $=40 \mathrm{kPa}$ ) 150 Figure E33 Particle Size Distribution: Motoring Condition (Speed=30 rps, Boost $=40 \mathrm{kPa}$ )...151 Figure E34 Particle Size Distribution: Motoring Condition ( $\mathrm{Speed}=22.5 \mathrm{rps}$, Boost $=20 \mathrm{kPa}$ ) 151 Figure E35 Particle Size Distribution: Motoring Condition (Speed=22.5 rps, Boost=40 kPa) 152 Figure E36 Particle Size Distribution: Motoring Condition (Speed=22.5 rps, Boost=60 kPa) 152 


\section{NOMENCLATURE}

\begin{tabular}{|c|c|}
\hline bhp & Brake-horsepower \\
\hline bhp-hr & Brake-horsepower-hour \\
\hline BMEP & Brake Mean Effective Pressure \\
\hline BTDC & Before Top Dead Center \\
\hline $\mathrm{Ca}$ & Calcium \\
\hline $\mathrm{CA}$ & Crank Angle \\
\hline CARB & California Air Resources Board \\
\hline CFR & Code of Federal Regulations \\
\hline $\mathrm{CH}_{4}$ & Methane \\
\hline CMD & Count Median Diameter \\
\hline $\mathrm{CNG}$ & Compressed Natural Gas \\
\hline $\mathrm{CO}$ & Carbon Monoxide \\
\hline $\mathrm{CO}_{2}$ & Carbon Dioxide \\
\hline $\mathrm{COV}$ & Coefficient of Variance \\
\hline $\mathrm{DC}$ & Direct Current \\
\hline DPF & Diesel Particulate Filter \\
\hline DRI & Desert Research Institute \\
\hline $\mathrm{EC} / \mathrm{OC}$ & Elemental Carbon/Organic Carbon \\
\hline EPA & Environmental Protection Agency \\
\hline ESC & European Stationary Cycle \\
\hline EUDC & Extra Urban Driving Cycle \\
\hline GC-FID & Gas Chromatography - Flame Ionization Detector \\
\hline GSD & Geometric Standard Deviation \\
\hline $\mathrm{H}_{2}$ & Hydrogen \\
\hline $\mathrm{HC}$ & Hydrocarbon \\
\hline HFID & Heated Flame Ionization Detector \\
\hline $\mathrm{IC}$ & Ion Chromatography \\
\hline IDI & Indirect-injection \\
\hline IMEP & Indicated Mean Effective Pressure \\
\hline $\mathrm{Mg}$ & Magnesium \\
\hline NDIR & Non-dispersive Infrared \\
\hline NETL & National Energy Technology Laboratory \\
\hline NO & Nitric Oxide \\
\hline $\mathrm{NO}_{2}$ & Nitrogen Dioxide \\
\hline NOx & Oxides of Nitrogen \\
\hline $\mathrm{O}_{2}$ & Oxygen \\
\hline
\end{tabular}




$\begin{array}{ll}\text { OC } & \text { Oxidation Catalyst } \\ \text { OH } & \text { Hydroxyl radical } \\ \text { P } & \text { Phosphorus } \\ \text { PAH } & \text { Polycyclic Aromatic Hydrocarbon } \\ \text { PM } & \text { Particulate Matter } \\ \text { ROHR } & \text { Rate of Heat Release } \\ \text { SAE } & \text { Society of Automotive Engineers } \\ \text { SMPS } & \text { Scanning Particle Mobility Sizer } \\ \text { SO }_{2} & \text { Sulfur Dioxide } \\ \text { SOF } & \text { Soluble Organic Fraction } \\ \text { TAN } & \text { Total Acid Number } \\ \text { TBN } & \text { Total Base Number } \\ \text { THC } & \text { Total Hydrocarbons } \\ \text { ULEV } & \text { Ultra Low Emissions Vehicle } \\ \text { US } & \text { United States } \\ \text { VOC } & \text { Volatile Organic Compound } \\ \text { XRF } & \text { X-ray Fluorescence } \\ \text { ZDDP } & \text { Zinc Dialkyl- Dithio- Phosphate } \\ \text { Zn } & \text { Zinc }\end{array}$




\section{OBJECTIVES AND BACKGROUND}

\subsection{Objectives}

The global objective of this study was to determine the lubricant oil consumption as a function of engine operating conditions, and its contribution to particulate matter emissions in a hydrogen fueled engine; hence, contribute to the understanding of lubricant oil consumption characteristics in general.

The activities performed towards the objective are listed below:

i) Lubricant oil consumption was analyzed as a function of engine operating conditions, such as speed, load (equivalence ratio), and boost for hydrogen-fueled operation. The lubricant oil consumption was measured using the carbonaceous emissions measurements, details of which are provided later. The gaseous and particulate emissions were monitored as function of engine operating parameters, such as speed, equivalence ratio, and boost in the case of premixed hydrogen-air fueled operation. The in-cylinder pressure characteristics were also recorded to understand the influence of combustion parameters such as, combustion duration, maximum cylinder pressure, and start of combustion on oil consumption.

ii) Elemental carbon/organic carbon (EC/OC) analysis, ions analysis, and trace metals analysis of engine particulate matter (PM), were performed along with the lubricant oil analysis in order to understand the composition of lubricant derived PM emissions. Simultaneous measurement of particle size distributions at the various steady state engine operating conditions were also performed to help understand the nanoparticle forming precursors in lubricant oils.

iii) The lubricant oil consumption measured using trace metal markers was compared with that obtained using the carbon balance method. This was an attempt to check the feasibility of using trace metal markers for lubricant consumption measurement in the case of engines operating on carbon-based fuels such as diesel, gasoline, and CNG.

iv) Particle number concentrations, size distributions, and particle surface area distributions were calculated for the various steady-state conditions tested. This helped to understand the contribution of lubricant oil consumption to nanoparticle formation. Soluble organic fraction (SOF) extracted from PM samples were analyzed for mutagenic activity in a 
separate study performed simultaneously with this study. The dependence of mutagenicity effects on particle surface area distributions obtained was correlated to the findings of the mutagenicity study to determine whether any relation existed between particle size and surface distribution characteristics, and degree of mutagenicity.

v) The effect of lubricant oil ageing on oil properties was determined by oil analyses of the test oil samples which were taken at regular intervals during the course of testing.

\subsection{Background}

The need for lower exhaust emissions to comply with stringent emissions regulations for heavy-duty diesel engines has led to research in alternative, non-petroleum based fuels. Engine exhaust PM is a complex mixture consisting of several compounds of which many are carcinogenic, and have been classified as toxics [1]. PM emissions have long been a major concern, and especially in light of the 2007 US Environmental Protection Agency (EPA) standard of $0.01 \mathrm{~g} / \mathrm{bhp}-\mathrm{hr}[2]$. The soot or PM and eventually its inhalation have been reported to be mainly responsible for the carcinogenic effect.

Hydrogen is being considered as a promising alternative fuel for internal combustion engines owing to its clean burning properties resulting in reduced regulated emissions and global warming potential. The success of gaseous fueled engines lies in the development and use of specially formulated and well researched lubricating oils. The pyrolized oil can enter the combustion chamber through blow-by from the crankcase, through seepage past the valve guide seals, and/or from the positive crankcase ventilation system (that is, through the intake manifold).

It is well established that engines operating on gaseous fuels emit high levels of lubricantoil derived toxic pollutants [3]. Development of advanced lubricating oils for gaseous-fueled engines should include development of specially formulated additive packages that will not poison the exhaust after-treatment systems, and help prevent pre-ignition. Understanding lubricant oil consumption as a function of engine operating conditions helps in determining the expected lubricant consumption for a given engine if its typical duty cycle is known. The knowledge of lubricant contribution to particulate matter will help in developing better lubricant formulations that would reduce particulate emissions, and also increase the durability and performance of the engine and exhaust after-treatment devices. 
Studies [4-7] conducted in the past on hydrogen fueled engines have reported negligible amounts of carbonaceous emissions and high levels of NOx emissions. Hydrogen fueled engines can suffer from many of the same drawbacks that are typical of natural gas engines. Hydrogen fueled engines can have high levels of lubricant derived nanoparticle and toxics emissions similar to CNG fueled engines. Figure 1-1 shows the results from a recent study on a Cummins C8.3G + CNG engine (ULEV standards) powering a transit bus [3]. The use of the PM trap and oxidation catalyst (depicted as "Novel After-treatment" in the figure), which were developed by West Virginia University (WVU) and Emissions Control Systems (ECS) showed that toxic pollutants were reduced to levels comparable to those in the background. Figure 1-2 shows that the lubricant oil derived nanoparticle emissions were also reduced to background levels. However, the long term effects of lubricant oil derived products of combustion on the exhaust after-treatment systems is not very encouraging [3]. Hence, attempts have to be made to minimize the deleterious impact of lubricant oil derived products by reducing oil consumption. EC/OC analysis, trace metals analysis, and particle size distribution measurements along with lubricant oil consumption measurement with hydrogen fueled operation gives a good understanding of the lubricant derived nanoparticle and toxics emissions. Findings related to lubricant oil consumption in a hydrogen fueled engine can to a certain extent, be extended to natural gas and diesel engines as well. However, it should be noted that the composition of the manufacturer- recommended oils may be different for different engines, especially diesel fueled engines when compared to gaseous-fueled engines.

Lubricant oil consumption measurement is commonly performed using radioactive tracer techniques, sulfur tracer method, gravimetric method or using chemical kinetics based models which incorporate ring dynamics and piston design parameters. The lubricant oil consumption can be determined from the measurement of carbon (measured as $\mathrm{CO}_{2}, \mathrm{CO}$, and THC) bearing exhaust emissions from a hydrogen-fueled engine as these would be produced solely due to the oxidation of lubrication oil. This method of lubricant oil consumption measurement has been found to yield accurate results compared to other conventional methods, such as tracer techniques [4-7]. 


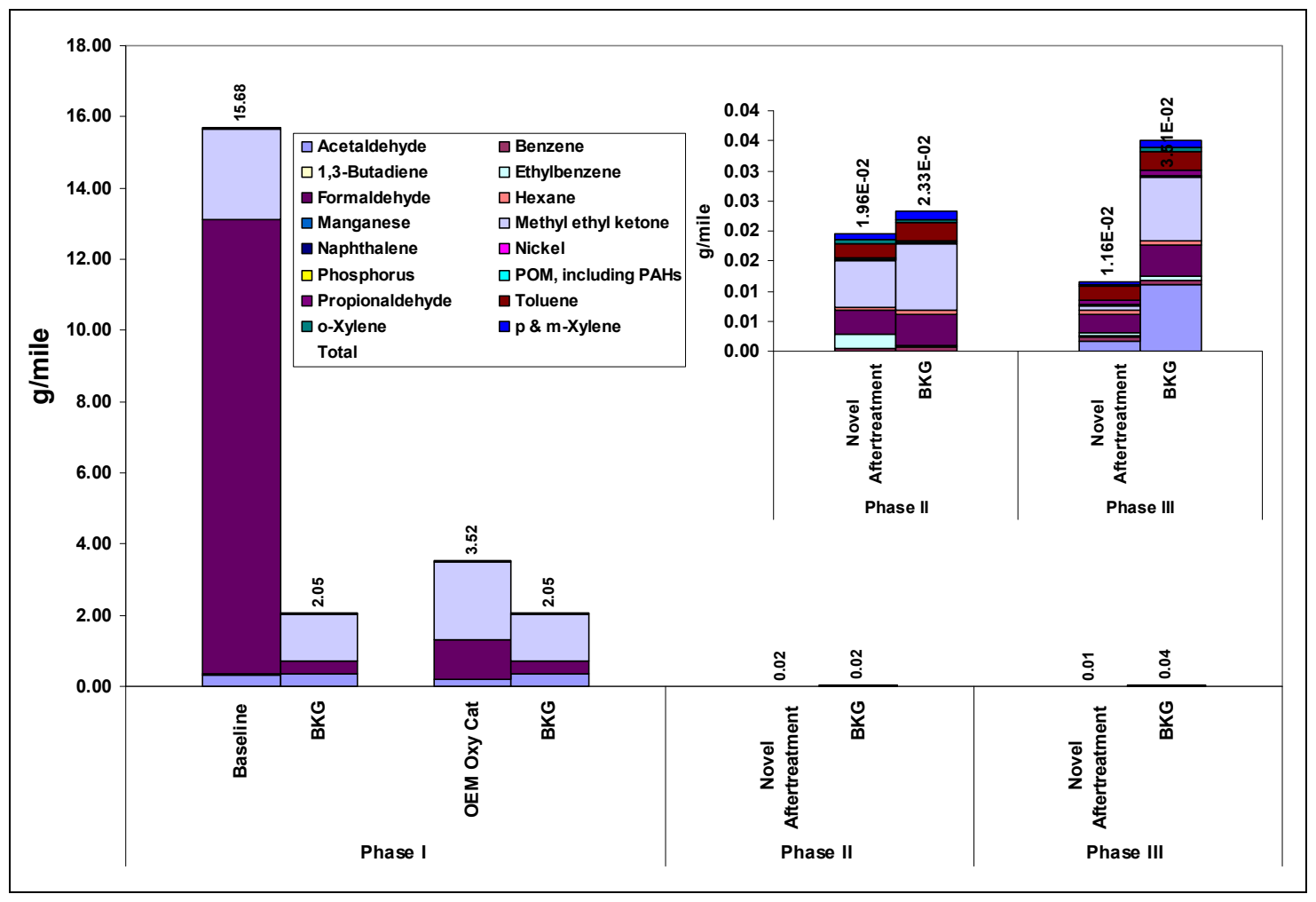

Figure 1-1 Comparison of Toxic Air Contaminants from a CNG Engine [3]

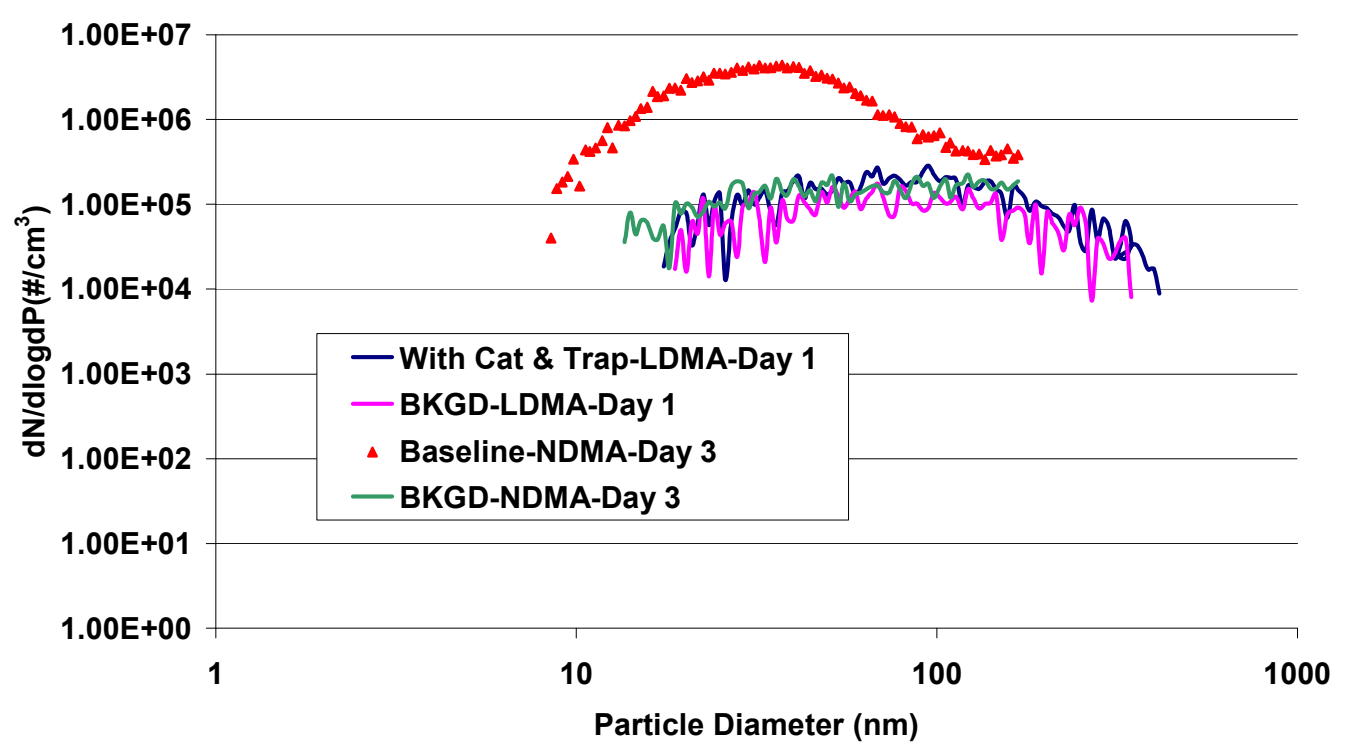

Figure 1-2 Transit Bus Steady State Operation at 35 mph (Vehicle with a WVU-ECS PM Filter and Oxidation Catalyst) [3] 
Mutagenicity studies have been used as an indicator of potential health risks associated with particulate emissions [8-20]. The classification of diesel exhaust as a toxic air contaminant by California Air Resources Board (CARB) [21] and USEPA's note regarding the mutagenic potential of the soluble organic fraction (SOF) of diesel PM $[8,22]$ have promoted the use of natural gas among other alternative fuels. But, there have been a limited number of studies [812] on the mutagenic potencies of CNG derived PM and it was found to be similar to the range observed in gasoline and diesel emission samples. Okamoto et al. [11] found higher mutagenic activity without an oxidation catalyst as compared to the configuration with an oxidation catalyst for a 2000 DDC Series 50G CNG fueled engine. As mentioned earlier, results from a recent study [3] found that the use of a PM trap and oxidation catalyst reduced toxic pollutants to levels comparable to those in the background. The lubricant oil derived nanoparticle emissions were also reduced to background levels. Considering both these studies [3,11], the nanoparticle emissions with a greater total surface area could be considered as a potential contributor to mutagenic activity. This study recorded nanoparticle size distributions at the steady-state conditions for which mutagenic activity were determined. Mutagenicity of PM samples was determined in a separate though simultaneously conducted study, the findings of which were used to relate particle surface area and particulate matter derived mutagenicity effects [23]. 


\section{REVIEW OF LITERATURE}

This chapter comprises a review of literature related to studies performed in the past on lubricant oil consumption measurement using carbon and sulfur balance, hydrogen-fueled engines, trace metals balance method for lubricant oil consumption measurement, and lubricant break-in methods.

\subsection{Sources of Oil Consumption}

The possible sources of oil consumption are illustrated in Figure 2-1 [24]. The pistonring-liner system would include the evaporation from the cylinder walls, oil throw off from the top land as a result of inertia forces due to the varying engine speeds. Reverse gas flows into the combustion chamber through the top ring gap may occur, when gas pressures between the top ring and second ring exceed the combustion chamber pressure depending on the engine cycle [25]. This reverse flow may also transport oil into the combustion chamber.

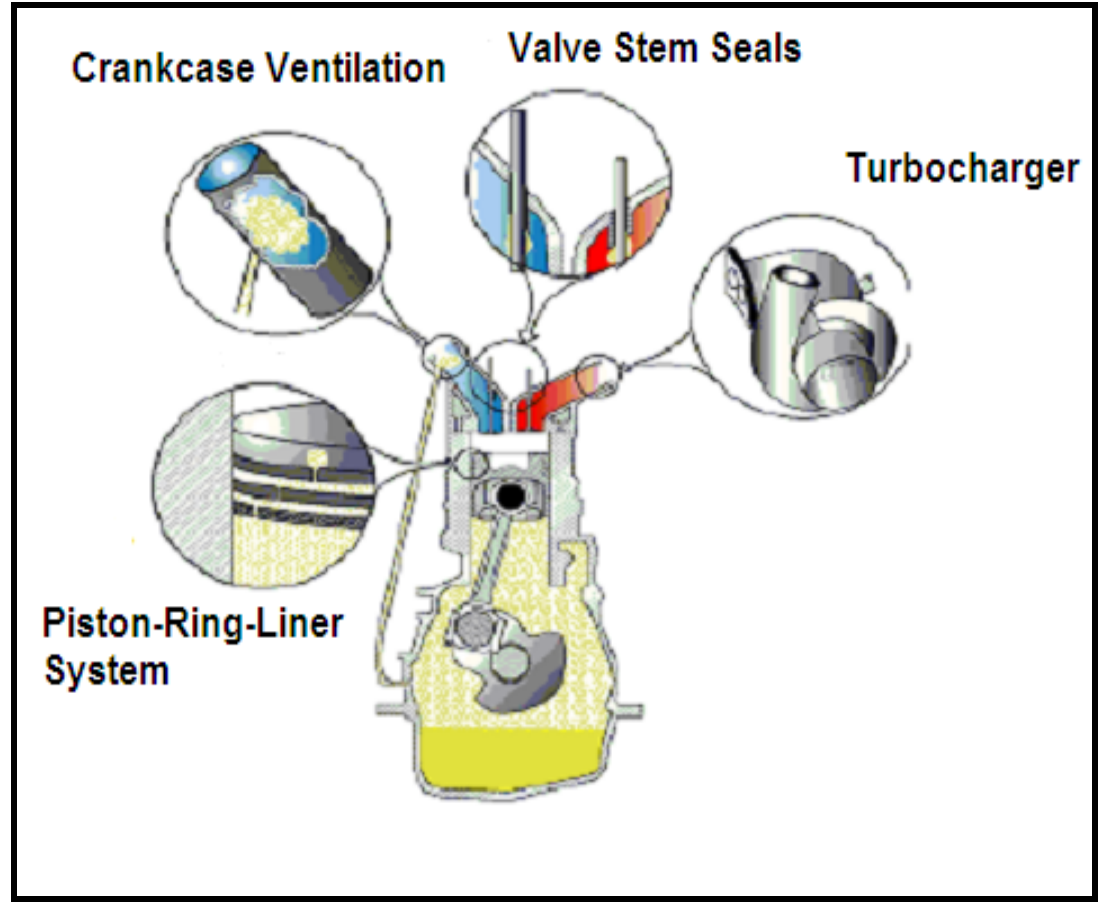

Figure 2-1 Sources of Oil Consumption [24]

Crankcase ventilation results in blowby gases carrying oil mist into the combustion chamber through the intake air system. In the case of turbocharged engines, the leakage past the 
turbocharger seals also contributes to the total oil consumption depending on engine operating conditions. The leakage past valve stem guides occurs when the intake manifold pressures are significantly low. The combustion from the different sources depends on the engine operating conditions, and typically the piston-ring-liner system makes the largest contribution to the total oil consumption.

In this study the test engine did not have a turbocharger or a positive crankcase ventilation system. The piston-ring-liner system and leakage past the valve stem guides were the major oil consumption sources. The possible effect of engine operating conditions and combustion parameters on the various sources is discussed in Section 5.1.4.

\subsection{Lubricant Oil Consumption Studies}

Lubricant oil consumption measurement is commonly performed using radioactive tracer techniques, sulfur tracer method, gravimetric method or using chemical kinetics based models which incorporate ring dynamics and other piston design parameters. Gravimetric methods require several hours of operation to obtain oil consumption data at a single operating point, and radioactive tracer techniques are expensive and involve safety issues. Sulfur tracer technique, using high sulfur lubricant oil and an ultra-low sulfur fuel is one of the most common methods used by various researchers to study lubricant consumption in diesel engines. The lubricant oil consumption can be studied in a hydrogen fueled engine by measuring the carbonaceous emissions.

Furuhama et al. [6,7] used a hydrogen fueled engine to study the effects of engine operating conditions, piston ring gap, alignment of piston pin, and top land clearance on engine oil consumption. They had an oxidation catalyst in the sampling stream so as to convert all carbon compounds to $\mathrm{CO}_{2}$. They assumed carbon fraction in the lubricant oil as 0.86 and calculated the oil consumption rate. It was found that oil consumption increased greatly with increase in intake manifold vacuum and also increased with load. It was also found that approximately $10 \%$ of total lubricant oil consumed in the engine became hydrocarbons whereas the remaining consumed oil was burned completely.

Ariga et al. [26] used the sulfur dioxide $\left(\mathrm{SO}_{2}\right)$ tracer technique to measure real-time total oil consumption and unburned oil consumption in a diesel engine. They found that both total and unburned oil consumption increased with speed and load. Unburned oil consumption 
showed some peaks at intermediate speed, high load condition. To measure the total oil consumption, the exhaust sample was completely oxidized in an external furnace, and for unburned oil consumption, the sample was first filtered so that all particulate matter including oil aerosols was removed and only the gas flowed through the sample line to the $\mathrm{SO}_{2}$ detector. In the latter case the detector gave the burned oil consumption, which when subtracted from the total gave the unburned oil consumption.

Several lubricant oil consumption studies at the Massachusetts Institute of Technology's Sloan Automotive Laboratory [25,27-29] have used the $\mathrm{SO}_{2}$-based diagnostic system to measure the engine oil consumption in diesel engines. Miller [27] studied the relationship between lubricant oil derived particulate emission rate and lubricant oil consumption. He found that the oil-derived soluble organic fraction (SOF) was highest at the high speed-low load condition, and found an approximately linear relationship between engine oil consumption and the amount of oil derived SOF. Lubricant oil consumption was found to increase with decrease in intake air pressure, whereas the lubricant derived SOF first increased and then decreased.

Froelund et al. [30] used a $\mathrm{SO}_{2}$-tracer technique referred to as Real-Time Oil consumption (RTOC)-III, to measure oil consumption for transient and steady-state engine condition. The engine-to-engine variability in oil consumption and the effect of two different ring packs were studied at various operating conditions. They found low engine-to-engine and ring pack-to-ring pack variability in both steady state as well as transient oil consumption. Froelund et al. [31] used the same technique in measuring oil consumption from an EMD 16$645 \mathrm{E}$ locomotive diesel engine. They found that oil consumption increased with engine speed, load factor, and also found that the oil consumption relative to fuel consumption ranged from $0.20 \%-0.40 \%$ for that particular engine. They had a day-to-day repeatability within $\pm 10 \%$ from the average and claimed the estimated overall accuracy of the RTOC technique to be approximately $\pm 10 \%$.

Li et al. [32] studied oil combustion in a spark ignited hydrogen engine. The oil consumption was measured by determining the $\mathrm{CO}$ and $\mathrm{CO}_{2}$ concentrations in the exhaust. Oil consumption was found to increase with increasing equivalence ratio, whereas compression ratio was found to have little effect on oil consumption. The oil consumption was found to increase suddenly and rapidly at the onset of knock and the additional lubricant oil consumed was found 
to be burned completely.

\subsection{Lubricant Oil Consumption Measurement Using Trace Metals Analysis}

The traditional drain and weight method for lubricant consumption measurement takes several hours for satisfactory measurement, and is more practical in the case of lubricant oil consumption measurement required over several hours of operation. In the case of oil consumption measurement over standard steady-state tests or transient tests over short periods of time, the measurement would be inaccurate and one would need to rely on radio-tracer techniques for meaningful data in the case of diesel engines or other engines operating on carbonaceous fuels. Lubricant oil consumption measurement using trace metals balance, that is, a mass balance between the trace metals $(\mathrm{Ca}, \mathrm{Zn}$, or $\mathrm{Mg})$ in the lubricating oil and particulate mass has been used in some studies [33-36]. Although these studies did report the oil consumption data, the methodology was not compared against a more accurate method for reliability of the data.

In the proposed study the lubricant oil consumption measurement using trace metal balance will be compared with the carbon balance method based measurement for different operating conditions.

Andrews et al. [33] studied the relationship between the lubricant oil consumption and the unburned lubricant oil fraction in a Perkins 4-236 naturally aspirated, direct injection diesel engine. The lubricant oil consumption was determined from a $\mathrm{Ca}$ mass balance, and the unburned oil emission was determined by thermogravimetric analysis (TGA) of the particulate. The lubricant oil combustion efficiency was determined based on the measurement of the unburnt fraction and the total lubricant consumption. The assumptions used were that $\mathrm{Ca}$ compounds are well distributed through the distillation range of the lubricant oil, and that $\mathrm{Ca}$ would be found in both the burned and unburned fractions proportionate to the total lubricant oil consumed.

Cooke [34] showed that the Ca concentration in lubricant oil is independent of lubricant oil ageing, however Elamir et al. [35] have found that the Ca content decreased by approximately $20 \%$ over a 150 hour ageing test.

The proposed study intends to analyze the variation in lubricant properties including trace metal concentrations over a 50 hour period to study the effects of oil ageing on its properties. 
Stetter et al. [36] measured the oil consumption in a Cummins N-14 single cylinder research engine using the trace metals in the particulate mass. They calculated oil consumption using both $\mathrm{Ca}$ and $\mathrm{Zn}$ concentrations measured in the particulate and in the oil and found good agreement between the two measurements. Their data indicated that the oil consumption for the steady-state testing done was approximately an order of magnitude below oil consumption found in the literature for transient test operation. Whether or not the lower magnitude of oil consumption observed in the study was a result of the steady-state conditions or a result of the inaccuracies in oil consumption measured using trace metals balance is not clear.

\subsection{Hydrogen Combustion Studies}

There have been several studies conducted in the past on hydrogen fueled engines to determine the engine combustion parameters [4-7, 37-52]. Most of the studies reported negligible amounts of carbonaceous emissions and high levels of NOx emissions. Pre-ignition or backfire is considered to be one of the greatest issues in a spark-ignited hydrogen-fueled engine $[4,37,38]$. This is a result of the low minimum ignition energy required for hydrogen as compared to gasoline. Intake manifold backfire at higher equivalence ratios limits the power output from an external mixture formation hydrogen engine; hence, it is an obstacle for the use of hydrogen as an automotive fuel. The backfire limiting equivalence ratio at a boost pressure of $60 \mathrm{kPa}$ for the test engine used in this study was 0.45 . Therefore, the highest equivalence ratio $(\Phi)$ chosen for the test matrix was 0.38 . The low minimum ignition energy $(0.02 \mathrm{~mJ}$ at $\Phi=1)$, the wide flammability limits $(0.21<\Phi<7.34)$, and small surface quenching distance of the hydrogenair mixture all contribute to backfire [39]. There are several published studies [39-46] related to the backfire mechanisms and methods to avoid backfire, but none of them succeeded in completely avoiding the backfire in an external mixture formation hydrogen engine. Some of the reasons for backfire found in the literature are:

- surfaces of the exhaust valve as an ignition source [39]

- combustion chamber hot spots due to their high local temperatures [39]

- spark plug electrode as a source of ignition [40,41]

- the electrical energy remaining in the ignition system (spark plug cable) after the ignition, which gets discharged during the intake stroke resulting in backfire [40]

- the moderately burning flame at the piston top land as a source of ignition, according to 
measurement of $\mathrm{OH}$ radicals [42]

- catalytic effects of some materials coming in contact with the fuel-air charge in the combustion chamber by which ignition can occur at decreased temperatures [47]

- presence of deposits caused by pyrolysis of lubricating oil which act as ignition sources $[48,49]$

- near stoichiometric fuel-air equivalence or advanced spark timing, which results in increased wall temperature of the combustion chamber, hence, becomes a source of ignition [50]

Studies have also shown that pre-ignition or knock tend to increase the oil consumption. Li et al. [4] have observed that knock in an engine can cause significantly higher oil consumption than encountered during normal combustion. The smaller quenching distance of hydrogen, which varies with air/fuel ratio, implies that flames may enter crevices, more closely approach cylinder walls, and contribute to the observed oil consumption [4].

Further, accelerated hydrogenation of lubricant oils in the presence of a wide variety of metals, which are available in the oil, has recently emerged [51]. There is detailed, empirical, understanding of the interaction of higher hydrocarbons with hydrogen within the refining industries. A decrease in kinematic viscosity at $100^{\circ} \mathrm{C}$ and breakdown of lubricating and wearresisting additives after limited, but unspecified, testing times was reported.

The onset of knock may be avoided under any set of operating conditions by reducing the equivalence ratio for lean mixture operation, lowering compression ratio and retarding the spark timing [37]. The oil consumption also would be reduced as a result of decreased equivalence ratios, but the decreased equivalence ratio would also mean reduced power output. The broad flammability limit helps in running the hydrogen fueled engine very lean, but it was found that unburned hydrogen in the exhaust increased rapidly for equivalence ratios less than 0.25 . The NOx emissions were found to be a function of equivalence ratio. The broad flammability and burn rate range helps in controlling the $\mathrm{H}_{2}$ engine similar to a gasoline engine where the fuel/air ratio is constant and desired torque is a function of both fuel and air flow, and also similar to a diesel engine where air is unthrottled and desired torque is a function of fuel flow [38].

Miller et al. [52] investigated the formation of combustion generated particles derived from lubricating oil in the absence of soot by examining emissions from a hydrogen-fueled 
Caterpillar 3304 diesel engine modified for operation with hydrogen. They also studied the dependence of number concentration and size distribution of lubricant derived particles on engine operating conditions. For the study, a portion of the raw exhaust was cooled and diluted using an ejector-type dilutor to approximately 10:1 dilution ratio. EC/OC concentrations and particle morphology were also studied apart from the particle number and size distributions. They found that the particle mean diameter and mass were very low compared to most internal combustion engines, but the number and the resulting surface area were substantial. The elemental carbon emissions were found to be extremely low whereas the organic carbon was found to be comparable to a diesel engine of similar size. It was also found that the metal-tocarbon ratio for most particles were higher compared to diesel engines.

\subsection{Lubricant Oil Break-in}

The effect of lubricating oil age on emissions has been reported in several studies [53-59]. Dowling [53] reported that emissions from the same engine running on the same oil varied as it aged which he attributed to the evaporation of the volatile basestock fraction, shearing of the polymer and viscosity increase as a result of soot loading and oxidation. Emissions were found to stabilize after a certain period (1000-2000 km depending on oil). Tests conducted on a Volkswagen Passat passenger car fitted with a 1.6L turbocharged IDI diesel engine with a prototype oil, resulted in $\mathrm{CO}$ rising from its initial value and NOx declining until both stabilized after around $2000 \mathrm{~km}$. The vehicle was driven on a test track and was tested on the chassis dynamometer at specified intervals. HC and PM emissions followed similar patterns, both declining from their initial values quickly reaching a minimum and then increased until it stabilized around $2000 \mathrm{~km}$. Tests conducted using a different oil resulted in the emissions stabilizing after around $1000 \mathrm{~km}$. Based on these findings, subsequent tests were conducted after ageing the oil for 20 hours at $50 \%$ of full load in the case of heavy duty oils and onroad driving of 1600 miles for passenger cars.

Andrews et al. [54] found similar variations in $\mathrm{HC}$ and PM from tests conducted on a small 0.220 liter Petter IDI single cylinder diesel engine over 120 hours of operation with emissions monitored every 20 hours. Fuel dilution of the lubricant oil was found to increase uniformly with time and reached about $10 \%$ after 120 hours. CO and NOx were not influenced by the ageing of the oil. The $\mathrm{HC}$ emissions were high from the fresh oil which declined to a 
minimum after 50 hours and then rose again. The authors attributed this to the lubricant oil volatility effects. The lubricating oil has a lower volatile fraction which is vaporized but not burnt and results in the initial high $\mathrm{HC}$ emissions. This fraction of the lubricant oil is lost after about 50 hours and the subsequent rise is attributed to fuel dilution resulting in a new volatile fraction of the lubricant oil. The particulate emissions also showed a similar trend. The PM emissions reduced initially by about $25 \%$ after 50 hours of operation and then rose steadily, which is again due to the fuel dilution of the lubricant oil. The higher volatility of the aged oil with fuel dilution results in more lubricant oil burning and a greater fraction of lubricant oil generated carbon.

Laurence et al. [55] and Froelund et al. [56] suggest a 5 hour lubricant oil break-in corresponding to 200-300 miles of field test using a high temperature steady state engine operation, based on studies [57-59] which suggest that most volatility reduction in fresh oil occurs during the first 10-20 hours of operation.

Andersson et al. [60,61] followed a detailed oil change and conditioning procedure throughout their test matrix to ensure repeatability and consistency of test procedures. After each oil change, the heavy-duty engine was operated continuously at ESC Mode 10 for 60 minutes, and the light-duty vehicle was subjected to three EUDC cycles. This ensured high temperature operation and enabled removal of any volatile hydrocarbon and sulfate compounds in the catalyst and exhaust systems, and also served to precondition the dilution system.

A similar lubricant oil break-in procedure was followed in the Advanced Petroleum-Based Fuels- Diesel Emissions Control (APBF-DEC) study done by the National Renewable Energy Laboratory (NREL) [62]. The current study followed the APBF study's procedure for lubricant oil break-in and is discussed in further detail in Section 4.6. 


\section{EXPERIMENTAL EQUIPMENT AND PROCEDURES}

The study was done at the Reciprocating Engines Laboratory at the US Department of Energy's National Energy Technology Laboratory (NETL) facility in Morgantown, West Virginia. The laboratory had a single cylinder engine test bed which was used to implement the test matrix for this study.

\subsection{Test Engine}

The test engine was a single cylinder Ricardo Proteus research engine. The engine specifications are given in Table 3.1.

Table 3-1 Test Engine Specifications

\begin{tabular}{|l|l|}
\hline Engine Manufacturer & Ricardo \\
\hline Displacement & 1.997 liters $\left(122.4 \mathrm{in}^{3}\right)$ \\
\hline Bore x Stroke & $0.13 \mathrm{~m} \times 0.15 \mathrm{~m}$ \\
\hline Engine Strokes per Cycle & Four \\
\hline Compression Ratio & $13.3: 1$ \\
\hline Ignition & Spark Ignited \\
\hline Number of Valves & Two \\
\hline Piston Bowl Configuration & Toroidal Combustion Bowl \\
\hline Fuel Induction & Premixed Fuel-Air \\
\hline
\end{tabular}

The engine was previously used for diesel fuel research and was modified for spark ignited hydrogen and natural gas fueled operation, prior to the start of the current study. Engine start-up and load were controlled by a 420-V, $100 \mathrm{hp}(75 \mathrm{~kW})$, DC dynamometer. Figure 3.1 shows the schematic of the engine test facility. The intake air source for the engine and dilution air source for the mini-dilution tunnel was filtered, dried, preheated and pressurized site air. The boost pressure was varied by regulating the site air and hence turbocharger conditions were simulated.

\subsection{Test Oils}

Two different lubricant oils were tested in the current study. Table 3.2 gives the properties of the synthetic and mineral oil formulations that were used for this study. The oil properties were analyzed at the Valvoline Product Development Laboratory. The synthetic oil was a commercially available Amsoil SAE (20W-40) Synthetic Natural Gas Engine Oil. The 
mineral oil was supplied by Valvoline.

Table 3-2 Properties of Test Oils

\begin{tabular}{|l|c|c|}
\hline Oil Type & Mineral & Synthetic \\
\hline Kinematic Viscosity @ $100^{\circ} \mathrm{C}$, cSt (ASTM D-445) & 15.01 & 13.97 \\
\hline Kinematic Viscosity @ 40 ${ }^{\circ} \mathrm{C}$, cSt (ASTM D-445) & 140 & 103 \\
\hline Viscosity Index (ASTM D-2270) & 106 & 133 \\
\hline Noack Volatility, \% weight loss (g/100g) (DIN 51581) & 2.68 & 4.17 \\
\hline Ash Content (ASTM D-874), \% & 0.37 & 0.43 \\
\hline Pour Point ${ }^{\circ} \mathrm{C}\left({ }^{\circ}\right.$ F) (ASTM D 97) & $-27(-17)$ & $-48(-54)$ \\
\hline Carbon, wt.\% (ASTM D 5291) & 85.56 & 85.41 \\
\hline Hydrogen, wt.\% (ASTM D 5291) & 13.86 & 14.22 \\
\hline Calcium, wt.\% (D 5185) & 0.112 & 0.118 \\
\hline Phosphorus, wt.\% (D 5185) & 0.022 & 0.019 \\
\hline Zinc, wt.\% (D 5185) & 0.03 & 0.03 \\
\hline Sulfur, wt.\% (D 5185) & 0.079 & 0.075 \\
\hline
\end{tabular}

\subsection{Mini-dilution Tunnel}

A partial flow or mini-dilution tunnel designed and previously used by McMillian [16] was used for exhaust conditioning and subsequent total particulate sample collection and particle size distribution measurements. The mini-tunnel system was reconfigured for dilution ratio measurement for hydrogen fueled operation. The mini-tunnel was constructed using a 3.25 inch $(82.6 \mathrm{~mm})$ ID schedule 10 type 316 stainless steel. As mentioned earlier, filtered, dried, temperature controlled and pressurized site air was used for dilution. Dilution air entered the inlet end of the tunnel circumferentially at four equidistant points. This configuration helped in obtaining efficient mixing and a uniform flow prior to reaching the particulate sample filter. The tunnel had electric heat tracing and was well insulated for maintaining constant wall temperature and minimizing thermophoretic losses. The particulate sample filter face temperature was maintained below $125^{\circ} \mathrm{F}\left(51.7^{\circ} \mathrm{C}\right)$. The maximum and minimum filter temperatures were recorded during each sampling period.

A $0.75 \mathrm{inch}(19 \mathrm{~mm})$ stainless steel tube inserted into the engine exhaust flow sampled the engine exhaust which was transferred into the mini-tunnel via a 0.25 inch $(6.3 \mathrm{~mm})$ stainless steel flexible transfer pipe. The length of the transfer line was maintained as short as possible 
and walls were well insulated to minimize any sample losses, particularly diffusion and thermophoretic deposition to the tube walls. Two micromotion Coriolis flow meters, Model CMF010 and Model CMF025, were used for recording dilution air flow and the total tunnel flow, respectively. Coriolis flow meters provide direct mass flow measurements and had a gas flow measurement accuracy of $\pm 0.35 \%$ of the flow for the mass flow used in this study (approximately $3 \mathrm{~g} / \mathrm{s}$ ). Exhaust sample was drawn through the dilution tunnel by a KNF Neuberger twin head diaphragm pump rated at 300 liters per minute free flow. The pump was placed upstream of the flow meter because of the pressure drop that results across the Coriolis meter. The leak rate for the KNF Neuberger pump was certified by the manufacturer at less than 0.005 Torr-liter/sec. The dilution ratio in the tunnel was calculated based on the dilution air flow and the total tunnel flow. Emissions based dilution ratio measurement and control was not feasible for hydrogen fueled operation because of the low raw emissions and undetectable levels of diluted emissions. The accuracy of the Coriolis flow meters helped in determining and controlling dilution ratios at desired levels. The sampling lines downstream of the particulate filters had electric heat tracing till the Coriolis meter measuring the total flow so as to prevent any condensation prior to flow measurement. 


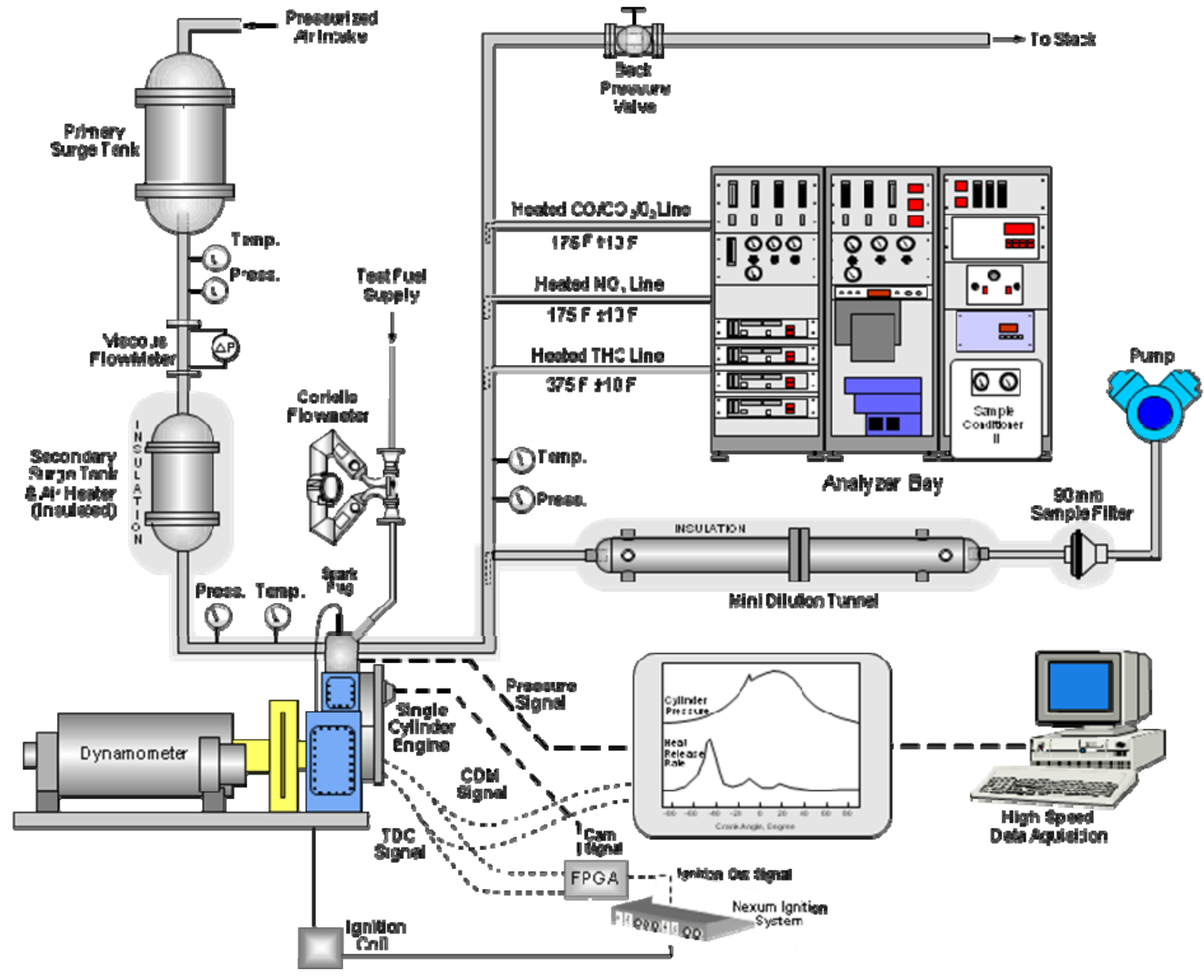

Figure 3-1 Schematic of Engine Test Facility 


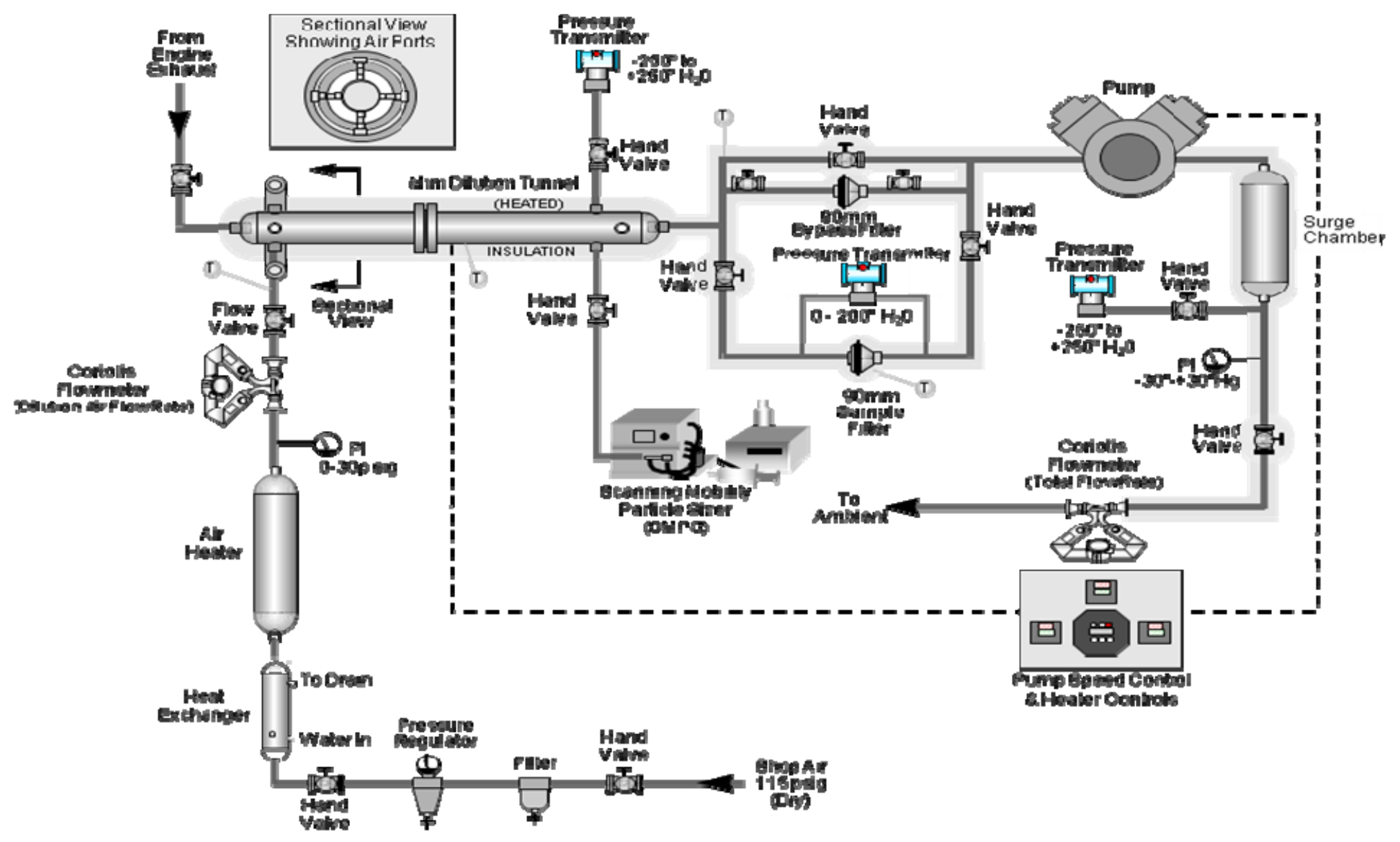

a

Figure 3-2 Schematic of Mini-tunnel Layout 


\subsection{Gaseous Emissions Measurement}

A gas analysis bench was used to measure the concentration of raw gaseous components in the exhaust gas stream of the engine. The gas analysis bench consisted of the following major components: THC analyzer, $\mathrm{CO}_{2}$ analyzer, $\mathrm{CO}$ analyzer, and a $\mathrm{NOx}$ analyzer. Three heated stainless steel probes inserted into the raw engine exhaust obtained the samples for THC, $\mathrm{CO} / \mathrm{CO}_{2}$, and NOx analysis. Each probe was inserted to a depth of 1.5" (38 mm) in the 4" (101 $\mathrm{mm}$ ) exhaust line. These probes were connected to heated lines, which transferred the gaseous samples to their respective analyzers. The hydrocarbon line and probe were maintained at a wall temperature of $191^{\circ} \mathrm{C} \pm 5.5^{\circ} \mathrm{C}\left(375^{\circ} \mathrm{F} \pm 10^{\circ} \mathrm{F}\right)$ to prevent the higher molecular weight hydrocarbons from condensing out on the walls and other surfaces in the sampling stream. The other system probes and lines were kept at $79^{\circ} \mathrm{C} \pm 5.5^{\circ} \mathrm{C}\left(175^{\circ} \mathrm{F} \pm 10^{\circ} \mathrm{F}\right)$ at the wall, in order to prevent water condensation, which would have affected the measurements by the analyzers.

\subsubsection{Hydrocarbon Analyzer}

The hydrocarbon analyzer was a Horiba FIA-236 heated flame ionization detector (HFID), which operates on the following principle. The sensor is a burner where a regulated flow of sample gas flows through a flame produced by regulated flows of air and a pre-mixed hydrogen/helium fuel gas. Polarized electrodes then collect the ions that are produced causing current to flow through the associated electronic measuring circuitry. The current flow is proportional to the rate at which carbon atoms enter the burner. It had a repeatability of $\pm 1 \%$ of full scale, zero and span drift of $\pm 1 \%$ of full scale per 8 hours [63].

\subsection{2. $\mathrm{CO} / \mathrm{CO}_{2}$ Analyzer}

The sample for $\mathrm{CO}$, and $\mathrm{CO}_{2}$, analysis passed through a Baldwin Environmental Model 20410 thermoelectric sample gas conditioner from the heated sample line. The sample conditioner lowered the sample dew point to $+5^{\circ} \mathrm{C}\left(41^{\circ} \mathrm{F}\right)$. The reported soluble gas removal rates as percent of inlet gas concentration were NO: $0 \%$ loss, $\mathrm{NO}_{2}:<2 \%$ loss, $\mathrm{CO}: 0 \%$ loss, and $\mathrm{CO}_{2}:<1 \%$ loss. The $\mathrm{CO}$ and $\mathrm{CO}_{2}$ analyzers were Horiba Model VIA-510 Non-Dispersive Infrared (NDIR) analyzers. NDIR analyzers use the exhaust gas species being measured to detect itself by the principle of selective absorption, in which the infrared energy of a particular wavelength, specific to a certain gas, will be absorbed by that gas. Infrared energy of other 
wavelengths will be transmitted by that gas, just as the absorbed wavelength will be transmitted by other gases. The Horiba VIA-510 has a reproducibility of $\pm 0.5 \%$ of full scale reading $( \pm 1 \%$ of full scale when $\mathrm{CO}, \mathrm{CO}_{2}$ are $<100 \mathrm{ppm}$ ), a zero and span drift of $\pm 1.0 \%$ of full-scale per 24 hours [64].

The $\mathrm{CO}_{2}$ in the inlet air was monitored using a California Analytical Model 601 NDIR analyzer. A sample line was run directly from the site air line into the analyzer inlet through a flow meter. It was important to measure the background $\mathrm{CO}_{2}$, since the $\mathrm{CO}_{2}$ emissions resulting from the hydrogen fueled operation are close to background levels. The Model 601 had a repeatability of $\pm 1 \%$ of full scale, linearity of $0.5 \%$ of full scale, zero and span drift of $<1 \%$ of full scale per 24 hours [65].

\subsubsection{NOx Analyzer}

The NOx analyzer used was a Thermo Environmental Model 42C High Level chemiluminescent analyzer. The analyzer was capable of determining the concentration of either $\mathrm{NO}$ or $\mathrm{NO}+\mathrm{NO}_{2}(\mathrm{NOx})$. The NOx mode was used in this study. The sample from the heated line passed through a Horiba Model COM11, $\mathrm{NO}_{2}$ to $\mathrm{NO}$ converter. The sample then passed through a Baldwin Model 8210 sample conditioner which removed water from the sample stream before it entered the analyzer. The sample $\mathrm{NO}$ was quantitatively converted into $\mathrm{NO}_{2}$ by gas-phase oxidation with molecular ozone, which was generated inside the analyzer by an ozone generator that was supplied with room air routed through a desiccant. When this reaction takes place, approximately $10 \%$ of the $\mathrm{NO}_{2}$ molecules are elevated to an electronically excited state followed by immediate reversion to the non-excited state accompanied by a photon emission. The instrument response is proportional to the total NO in the original sample plus the NO produced by the dissociation of $\mathrm{NO}_{2}$. The response time $\left(\mathrm{T}_{90}\right)$ of the instrument was 5 seconds. Both, repeatability and linearity were less than $\pm 1 \%$ of full scale reading. The zero drift was less than $0.05 \mathrm{ppm}$ in 24 hours, and span drift is less than $\pm 1 \%$ of full scale reading in 24 hours [66].

\subsection{Scanning Mobility Particle Sizer (SMPS)}

A SMPS system was used for recording the particle size distributions at the various steady state operating conditions. Figure 3.3 shows the Model 3936 SMPS used in this study. 


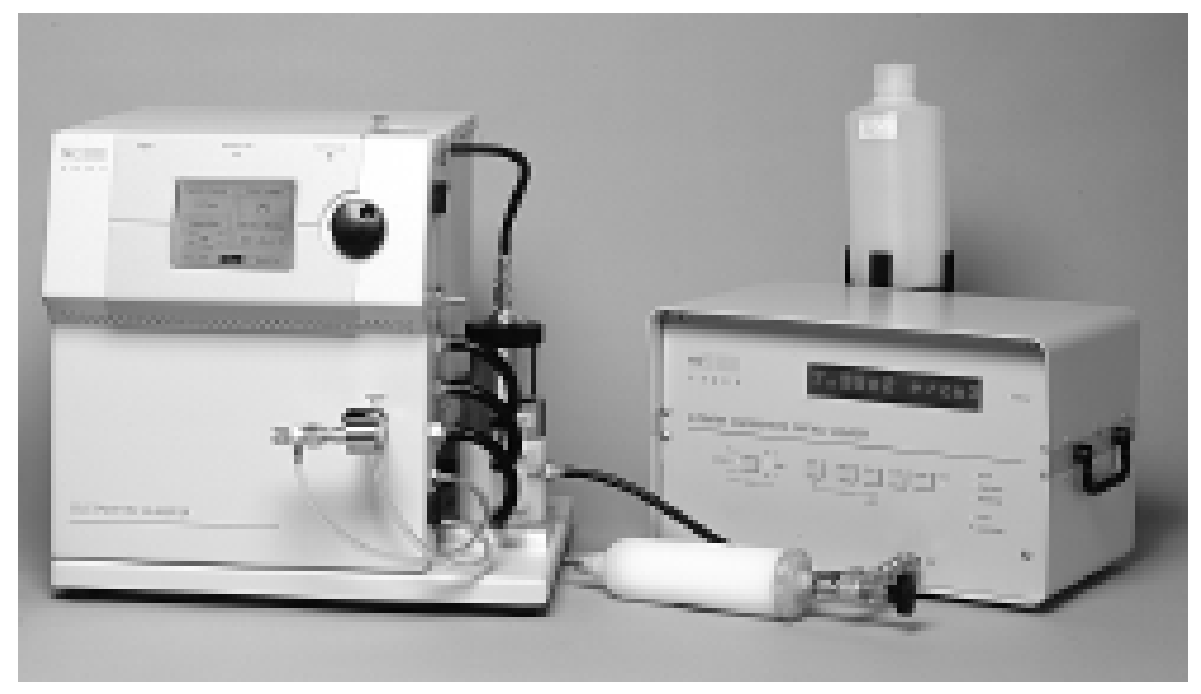

Figure 3-3 Model 3936 SMPS [67]

The SMPS uses an electrical mobility detection technique. The major components of the system are: the impactor and differential mobility analyzer (DMA) which together constitutes the Model 3080 electrostatic classifier (EC), the Model 3025 condensation particle counter (CPC), and the data acquisition system. The EC classifies the particles according to their electrical mobility and the CPC counts the particle numbers in each size bin. The detailed theory of operation of the SMPS can be found in the instrument manual [67]. The diluted sample was transferred via a heated line from the mini-tunnel to the classifier inlet. For the configuration used in this study, the particle size range measured was $15 \mathrm{~nm}$ to $660 \mathrm{~nm}$.

\subsection{Elemental Carbon/Organic Carbon (EC/OC), Ions, Trace Metals Analyses}

EC/OC analysis, ions analysis, and trace metals analysis were performed by Desert Research Institute (DRI). The EC/OC analysis was performed using the thermal/optical reflectance (TOR) method. Particulate samples were collected on $90 \mathrm{~mm}$ pre-fired quartz filters for EC/OC analysis. The particulate phase inorganic ions (water soluble nitrate, sulfate, chloride, etc.) analyses were performed by extracting the quartz filters and subsequent Ion Chromatographic analysis of the extracts. Filter face velocities during particulate sampling were kept within the range of $35-45 \mathrm{~cm} / \mathrm{s}$. The filter face temperature was held at approximately $47^{\circ} \mathrm{C}$, and dilution ratios were held approximately at a constant ratio of $12: 1$ for this study.

The trace metals analysis was performed using X-Ray Fluorescence (XRF) method. Particulate samples for this was collected on $90 \mathrm{~mm}$ Teflon-membrane filters. A brief description of the DRI procedures for the above analyses is included in Appendix D. 


\subsection{High Speed Data Acquisition System}

An AVL GU21D uncooled Gallium orthophosphate $\left(\mathrm{GaPO}_{4}\right)$ rapid response piezoelectric pressure transducer was used to obtain pressure signals. $\mathrm{GaPO}_{4}$ is highly stable at high temperatures. An AVL 3066 piezo amplifier conditions the output from the transducer. The amplifier gain error (accuracy) was $< \pm 0.1 \%$ and had a linearity of $< \pm 0.01 \%$ of full scale output. The piezoelectric transducer was ranged at 200 bar with a linearity of $< \pm 0.3 \%$ of full scale reading. The cyclic temperature drift and indicated mean effective pressure (IMEP) stability of the transducer over a 10 hour test period was less than \pm 0.4 bar and $2 \%$, respectively. AVL's "Indicom" software was used for data acquisition purpose. Engine speed and crank angle $\left({ }^{\circ} \mathrm{CA}\right)$ position were measured using an AVL 364C high precision optical encoder mounted on the crankshaft end. AVL's "Concerto" combustion analysis software package was used for post processing of the data. The parameters that were analyzed were IMEP, IMEP COV, start of combustion, combustion duration, and maximum pressure.

\subsection{Low Speed Data Acquisition System}

A Paragon TNT system was used for all low speed data acquisition. The Paragon system acquired signals from the various instruments (analyzers, flow meters, pressure transmitters, temperature indicators) and converted them to engineering units. Paragon TNT provides open links to third party software such as Excel spreadsheets, statistical analysis packages, etc. through dynamic data exchange (DDE). Microsoft Excel was used to communicate with the DDE subsystem in Paragon and obtain data in real time. The time averaged test data was recorded and saved in Excel files for later analysis.

\subsection{Nexum Ignition System}

A Nexum programmable ignition system was used to control the spark ignition in this study. This system allows the operator to manually adjust the spark characteristics (peak current, sustaining current, current decay rate, duration, etc.) from the dynamometer control console. The major advantage of this approach is the ability to rapidly reconfigure the spark while the engine is running, which makes it possible to conduct back-to-back comparisons between candidate spark configurations under virtually identical operating conditions. Figure 3.4 shows a typical setup of the ignition system. 


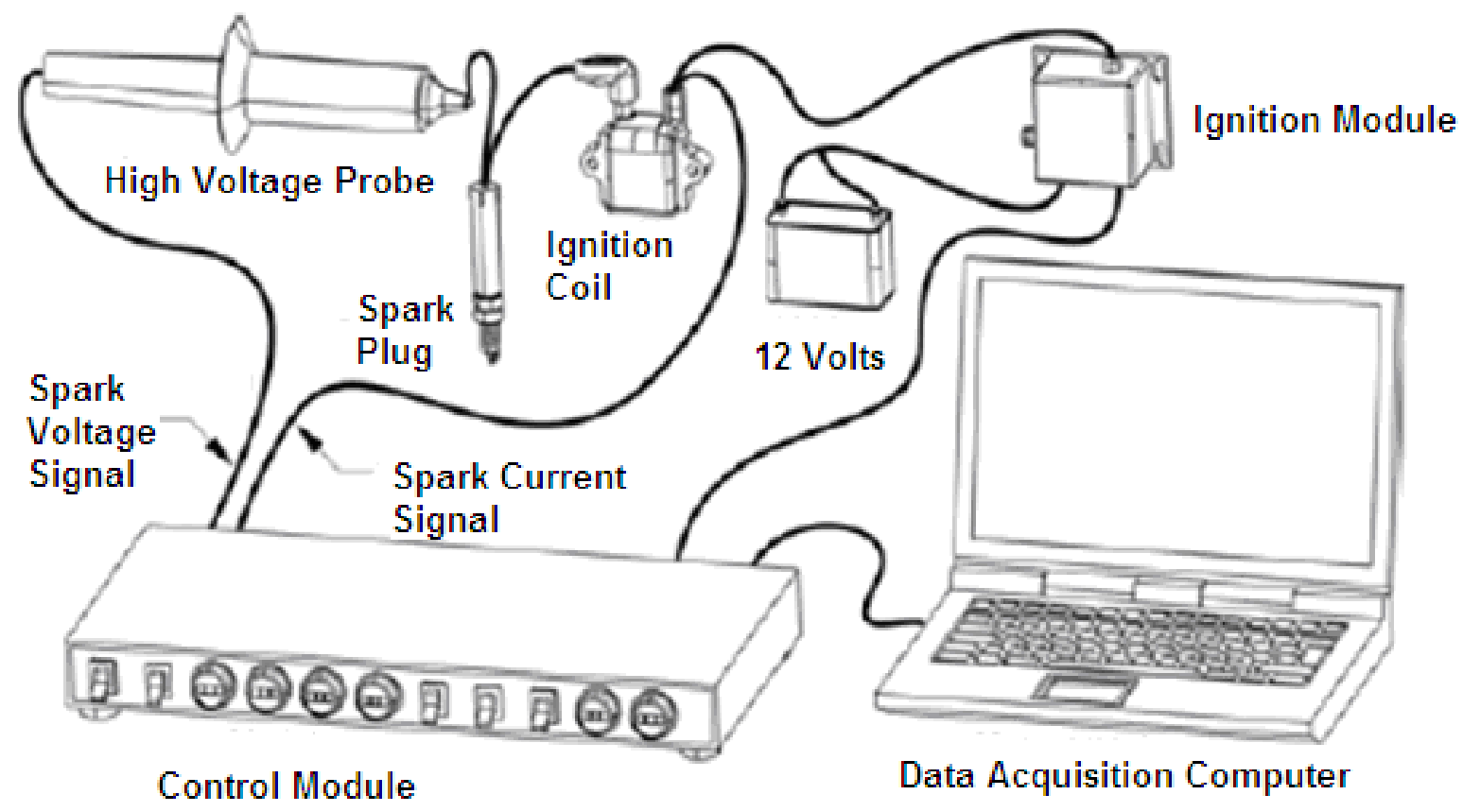

Figure 3-4 Typical Setup of Nexum Ignition System [68] 


\section{EXPERIMENTAL AND ANALYSIS PROCEDURES}

\subsection{Introduction}

The global objective of this study was to determine the lubricant oil consumption and its contribution to particulate emissions as a function of engine operating conditions in a hydrogen fueled engine. The study determined the effects of engine operating conditions such as, engine speed, equivalence ratio, boost, combustion duration, and lubricant oil volatility, on oil consumption; hence, its contribution to particulate matter emissions.

\subsection{Specific Tasks}

The specific tasks that were performed are listed below:

i) Measured the gaseous, and particulate emissions as a function of engine operating parameters like equivalence ratio (load), engine speed, and boost, in the case of premixed hydrogen-air fueled operation.

ii) Performed EC/OC analysis, and trace metals analysis for selected operating points in the test matrix for hydrogen fueled operation.

iii) Analyzed lubricant consumption as a function of engine operating conditions, and lubricant oil volatility. The lubricant oil consumption was measured using the carbonaceous emissions measurements.

iv) Determined contribution of lubricant oil towards organic fraction of particulate matter.

v) Determined lubricant oil consumption using trace metal markers such as $\mathrm{Ca}$, and $\mathrm{Zn}$, so as to determine the viability of using trace metal markers for lubricant oil consumption measurement for engines using carbon based fuels.

vi) Measured in-cylinder pressure signals; hence, determined lubricant oil consumption dependence on combustion duration, maximum cylinder pressure, and start of combustion.

vii) Determined particle number concentrations, size distributions, and particle surface area distributions for the various steady-state conditions so as to determine the variation of particle size distributions with variations in lubricant oil consumption.

viii) Determined if any relation exists between particle surface distribution characteristics and degree of mutagenicity for the test conditions considered for this study. 
ix) Determined the effect of lubricant oil ageing on lubricant oil consumption, and lubricant properties.

\subsection{Test Matrix for Lubricant Oil Consumption Measurement (Pre-mixed Hydrogen/Air Operation)}

"Equivalence Ratio" will be referred to as "Phi" throughout the remainder of the document. The lubricant oil consumption for the pre-mixed hydrogen/air operation was measured at three levels of engine speed, phi, and boost. The backfire limiting phi at a boost pressure of $60 \mathrm{kPa}$ for the test engine was 0.45 . Therefore, the highest equivalence ratio chosen for the test matrix was 0.38 . Table $4-1$ shows the test matrix that was used for the premixed hydrogen/air operation. The tests were performed for two lubricant oil formulations. It was necessary to keep the number of tests to a minimum possible, but at the same time adequate enough for statistical analysis. Central composite designs are response surface designs that aid in fitting full quadratic models [69,70]. Figure 4-1 shows the faced central composite design that was used and Table 4-1 shows the actual test matrix. The black solid dots represent the complete test matrix. The nine points represented by both a dot and a square were the conditions at which particulate matter samples were collected for EC/OC, and trace metals analyses.

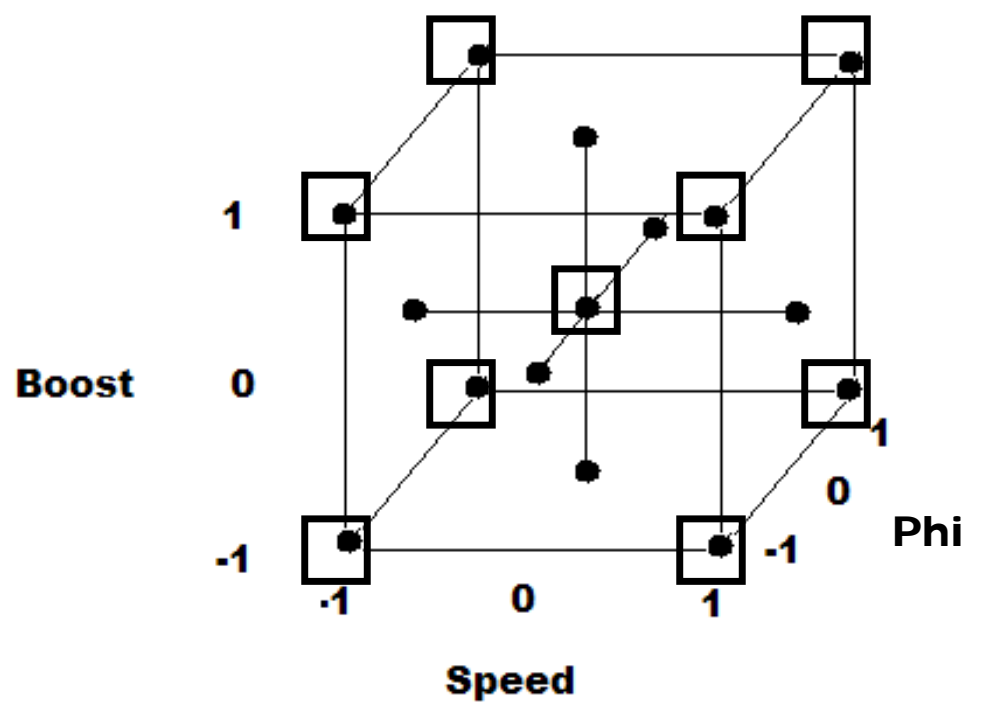

Figure 4-1 Faced Central Composite Design for Premixed Hydrogen/Air Operation 
Table 4-1 Test Matrix for Premixed Hydrogen/Air Operation

\begin{tabular}{|c|c|c|c|}
\hline Phi & 900 & 1350 & 1800 \\
\hline 0.28 & $\begin{array}{l}20 \mathrm{kPa} \\
60 \mathrm{kPa}\end{array}$ & $40 \mathrm{kPa}$ & $\begin{array}{l}20 \mathrm{kPa} \\
60 \mathrm{kPa}\end{array}$ \\
\hline 0.33 & $40 \mathrm{kPa}$ & $\begin{array}{l}20 \mathrm{kPa} \\
40 \mathrm{kPa} \\
60 \mathrm{kPa}\end{array}$ & $40 \mathrm{kPa}$ \\
\hline 0.38 & $\begin{array}{l}20 \mathrm{kPa} \\
60 \mathrm{kPa}\end{array}$ & $40 \mathrm{kPa}$ & $\begin{array}{l}20 \mathrm{kPa} \\
60 \mathrm{kPa}\end{array}$ \\
\hline
\end{tabular}

The boost levels of $20 \mathrm{kPa}, 40 \mathrm{kPa}$, and $60 \mathrm{kPa}$ were the values at which the site air regulator was set. The actual intake manifold pressure corresponding to these set values were approximately $14 \mathrm{kPa}, 34 \mathrm{kPa}$, and $54 \mathrm{kPa}$, respectively. The actual values measured for speed, and phi for the test conditions were within $\pm 3 \%$ of the set values. The actual measured data for speed, phi, and boost were used for the oil consumption analysis. In-cylinder pressure signals were recorded at all operating points which helped in determining combustion duration, and peak pressures. The gaseous emissions and particle size distributions were also recorded at all the points. Particulate matter emissions and potential mutagenicity in the case of pre-mixed hydrogen operation were investigated as part of a complementary study, which was simultaneously performed by Solano [23].

\subsection{Test Matrix for EC/OC, Ions, and Trace Metals Analyses}

The test matrix for obtaining samples for EC/OC analysis, and trace metals analysis was a subset of the matrix shown in Table 4-1, and is also represented in Figure 4-1. Table 4-2 shows the actual EC/OC analysis test matrix. 
Table 4-2 Test Matrix for EC/OC, and Trace Metals Analysis

\begin{tabular}{|c|c|c|c|}
\hline Phi $\quad \begin{array}{c}\text { Speed } \\
(\text { rpm) }\end{array}$ & 900 & 1350 & 1800 \\
\hline 0.28 & $\begin{array}{l}20 \mathrm{kPa} \\
60 \mathrm{kPa}\end{array}$ & & $\begin{array}{l}20 \mathrm{kPa} \\
60 \mathrm{kPa}\end{array}$ \\
\hline 0.33 & & $40 \mathrm{kPa}$ & \\
\hline 0.38 & $\begin{array}{l}20 \mathrm{kPa} \\
60 \mathrm{kPa}\end{array}$ & & $\begin{array}{l}20 \mathrm{kPa} \\
60 \mathrm{kPa}\end{array}$ \\
\hline
\end{tabular}

\subsection{Maximum Thermal Efficiency Timing Test}

The steady-state tests for all the above mentioned matrices were conducted at maximum thermal efficiency (MTE) spark timing. MTE was determined at each operating point, by varying spark timing around an expected optimum, and recording thermal efficiency once the engine emissions had stabilized. The stabilization time was kept constant for all tests using a stop watch. The oil and coolant temperatures were also maintained constant during all tests. Thermal efficiency was then plotted as a function of spark timing and a second-order curve was fitted. This curve was used to determine the spark timing for MTE. The MTE spark timing used for the various steady-state conditions tested is shown in Table 4-3.

Table 4-3 Maximum Thermal Efficiency (MTE) Spark Timing Used for the Test Points

\begin{tabular}{|c|c|c|c|}
\hline Speed (rps)/Coded Speed & Phi/Coded Phi & Boost (kPa)/Coded Boost & $\begin{array}{c}\text { MTE Timing } \\
\text { (oBTDC) }\end{array}$ \\
\hline $15 /-1$ & $0.28 /-1$ & $20 /-1$ & 27 \\
\hline $15 /-1$ & $0.28 /-1$ & $60 /+1$ & 24 \\
\hline $15 /-1$ & $0.33 / 0$ & $40 / 0$ & 20 \\
\hline $15 /-1$ & $0.38 /+1$ & $20 /-1$ & 16 \\
\hline $15 /-1$ & $0.38 /+1$ & $60 /+1$ & 13 \\
\hline $22.5 / 0$ & $0.28 /-1$ & $40 / 0$ & 25 \\
\hline $22.5 / 0$ & $0.33 / 0$ & $20 /-1$ & 21 \\
\hline $22.5 / 0$ & $0.33 / 0$ & $40 / 0$ & 20 \\
\hline $22.5 / 0$ & $0.33 / 0$ & $60 /+1$ & 19 \\
\hline $22.5 / 0$ & $0.38 /+1$ & $40 / 0$ & 15 \\
\hline $30 /+1$ & $0.28 /-1$ & $20 /-1$ & 27 \\
\hline $30 /+1$ & $0.28 /-1$ & $60 /+1$ & 24 \\
\hline $30 /+1$ & $0.33 / 0$ & $40 / 0$ & 20 \\
\hline $30 /+1$ & $0.38 /+1$ & $20 /-1$ & 16 \\
\hline $30 /+1$ & $0.38 /+1$ & $60 /+1$ & 13 \\
\hline
\end{tabular}




\subsection{Lubricant Oil Break-in}

The need to break-in fresh lubricant oil has already been discussed in Section 2.4. The lubricant oil used for this study was subjected to a break-in following the procedure adopted by a previous study [62]. Multiple oil flushes, followed by a 3 hour break-in at maximum speed, phi, and boost condition was performed. The procedure [62] was as follows:

1. Drained previous test oil.

2. Removed oil filter and replaced.

3. Engine was filled with fresh test oil.

4. Started engine and brought to operating temperature.

5. Stopped engine and allowed to cool down.

6. Drained oil ( $1^{\text {st }}$ Flush).

7. Removed oil filter and replaced.

8. Refilled engine with fresh oil.

9. Started engine and brought to operating temperature.

10. Stopped engine and allowed to cool down.

11. Drained oil ( $2^{\text {nd }}$ Flush).

12. Removed oil filter and replaced.

13. Refilled engine with fresh test oil.

14. Started engine and brought to operating temperature.

15. Ran engine at maximum speed, phi, and boost condition for 3 hours.

16. Brought engine to idle and prepared for steady-state tests. 


\subsection{Carbon Balance Oil Consumption Calculation (g/bhp-hr)}

The brake-specific oil consumption (g/bhp-hr) based on carbon balance was calculated using the following equation,

$$
\dot{m}_{\text {oil }}=\frac{3600}{m_{c}^{*} W}\left[K w\left\{\left(\frac{\left[C O_{2}\right]}{10^{6}} V_{e x h} \rho_{C O_{2}} \frac{M W_{c}}{M W_{C O_{2}}}\right)+\left(\frac{[C O]}{10^{6}} V_{e x h} \rho_{C O} \frac{M W_{c}}{M W_{C O}}\right)\right\}+\left(\frac{[T H C]}{10^{6}} V_{e x h} \rho_{T H C} \frac{M W_{c}}{M W_{T H C}}\right)\right]
$$

\section{Equation 4-1}

$m_{c}=$ Carbon mass fraction of the oil,

$W=$ Power, bhp

$\left[\mathrm{CO}_{2}\right],[\mathrm{CO}],[\mathrm{THC}]=$ Concentrations of $\mathrm{CO}_{2}, \mathrm{CO}, \mathrm{THC}$ in the exhaust, ppm

$V_{\text {exh }}=$ Exhaust volumetric flow $\left(\mathrm{m}^{3} / \mathrm{sec}\right)$ at $20^{\circ} \mathrm{C}$ and $101.3 \mathrm{kPa}$ pressure, and is given by,

$$
V_{\text {exh }}=\frac{m_{a}+m_{f}}{\rho_{\text {air }}}
$$

\section{Equation 4-2}

where, $m_{a}=$ Intake air flow rate, $\mathrm{g} / \mathrm{s}$

$$
m_{f}=\text { Fuel (hydrogen) mass flow rate, } \mathrm{g} / \mathrm{s}
$$$$
\rho_{\text {air }}=\text { Density of air at } 20^{\circ} \mathrm{C} \text { and } 101.3 \mathrm{kPa}=1204 \mathrm{~g} / \mathrm{m}^{3}
$$

$\rho_{i}=$ Density of exhaust components, $i=\mathrm{CO}_{2}, \mathrm{CO}, \mathrm{THC}$

$M W_{i}=$ Molecular weight, $i=\mathrm{C}, \mathrm{CO}_{2}, \mathrm{CO}$

$M W_{T H C}=$ Relative molecular weight (that is, ratio of total molecular weight of all elements to $\left.12 * M W_{C}\right)$

The molecular weights and densities were obtained from the NIST website [71], and the Code of Federal Regulations [72] respectively. 


$$
\begin{aligned}
& \mathrm{MW}_{\mathrm{C}}=12.0107, \mathrm{MW}_{\mathrm{CO} 2}=44.0095, \mathrm{MW}_{\mathrm{CO}}=28.0101, \mathrm{MW}_{\mathrm{THC}}=13.0186, \rho_{C O 2}=1830 \mathrm{~g} / \mathrm{m}^{3}, \\
& \rho_{C O}=1164 \mathrm{~g} / \mathrm{m}^{3}, \rho_{T H C}=574.6 \mathrm{~g} / \mathrm{m}^{3}
\end{aligned}
$$

$m_{c}$, the mass fraction of carbon for the oil samples collected were analyzed by Southwest Research Institute using the ASTM D5291 analysis procedure. The results of the analysis are included in Table 5-6. The uncertainty analysis for Equation 4-1 is presented in Appendix A.

The power output (bhp) for a given test was calculated as,

$$
W=\frac{2 \pi N T}{60000} * 1.34
$$

where, $N=$ Speed, rpm

$$
T=\text { Torque, } \mathrm{Nm}
$$

$1.34=$ Conversion factor for conversion of $\mathrm{kW}$ to $\mathrm{hp}$

$K w$ in Equation 4.1 is the dry to wet correction factor, and was calculated as

$K w=1-M_{\mathrm{H}_{2} \mathrm{O}}$

where, $M_{\mathrm{H}_{2} \mathrm{O}}=$ Mole fraction of $\mathrm{H}_{2} \mathrm{O}$, and is given by,

$$
M_{H_{2} O}=\frac{2 \phi}{\phi+4.76}
$$

The above expression can be obtained from a hydrogen combustion equation involving " $a$ " moles of $\mathrm{H}_{2}$ and $\phi<1$.

$$
a H_{2}+\frac{a}{2 \phi}\left(O_{2}+3.76 N_{2}\right) \rightarrow a H_{2} O+\frac{a(1-\phi)}{2 \phi} O_{2}+\frac{3.76 a}{2 \phi} N_{2}
$$




\subsection{Overview of Statistical Tools Used for Analysis}

This section comprises a brief review of the statistical tools and terms used for the presentation of results in Chapter 5.

\subsubsection{Regression Analysis}

Regression analysis is a statistical tool to determine a relationship between a set of variables or factors and a response. It aids in finding the statistical significance of each factor on the response, and the effects of interaction of variables. The dependent variables (or response) are modeled as a function of the independent variables (or factors).

\subsubsection{Simple Linear Regression}

In a simple linear regression model, the relation between one factor and a single response is estimated. For example, if $x_{i}$ represents " $\mathrm{n}$ " factor data points, and $y_{i}$ represents the corresponding response data, then $y_{i}$ can be expressed as,

$$
y_{i}=\beta_{0}+\beta_{1} x_{i}+\varepsilon_{i} ; \mathrm{i}=1, \ldots \ldots, \mathrm{n},
$$

where, $\beta_{0}$ and $\beta_{1}$ are called the parameters which need to be estimated in order to model the above relation and $\varepsilon_{i}$ is the random error term. The estimated model can be represented as,

$$
\hat{y_{i}}=\hat{\beta}_{0}+\hat{\beta}_{1} x_{i}+e_{i}
$$

where "^" denotes that the terms are estimates. $e_{i}$ is the residual associated with the model and is given by, $e_{i}=y_{i}-\hat{y}_{i}$.

The most common method of estimation of parameters is by minimizing the sum of squares of the residuals (SSE), where, $\mathrm{SSE}=\sum_{i=1}^{n} e_{i}^{2}$.

The mathematical equations associated with the calculation can be found in any advanced statistical text book. References [70,73] also provide further details and references. 


\subsubsection{Multiple Linear Regression}

Multiple linear regression is an extension of simple linear regression. In this case, the relation between multiple independent variables (factors) and a dependent variable (response) is modeled. In the current study, multiple linear regression was employed to estimate the oil consumption model.

The multiple linear regression, in particular for the current study can be represented as, $y_{i}=\beta_{0}+\beta_{1} x_{1 i}+\beta_{2} x_{2 i}+\beta_{3} x_{3 i}+\beta_{12} x_{1 i} x_{2 i}+\beta_{13} x_{1 i} x_{3 i}+\beta_{23} x_{2 i} x_{3 i}+\beta_{11} x_{1 i}{ }^{2}+\beta_{22} x_{2 i}{ }^{2}+\beta_{33} x_{3 i}{ }^{2}+\varepsilon_{i}$.

With respect to the current study, $y_{i}$ is the oil consumption data, $x_{1}, x_{2}$, and $x_{3}$ are speed, phi, and boost respectively. $\beta_{12}, \beta_{13}$ and $\beta_{23}$ are interaction parameters, and $\beta_{11}, \beta_{22}$ and $\beta_{33}$ are the parameters for the quadratic effects.

The parameters are estimated in a similar fashion as in simple linear regression, the only difference being that the number of equations to solve increase depending on the number of factors; hence, involves matrix computation.

\subsubsection{Stepwise Multiple Regression}

Stepwise regression can be based on a forward elimination procedure or a backward elimination procedure. In the case of forward elimination procedure, the model starts with only the intercept term. In the succeeding steps, each factor is added one at a time, and the significance of each of the variables in the model is determined. The variables with p-value above a certain threshold are eliminated and the model is refitted without the eliminated variables. In the case of backward elimination procedure, the model starts with all the variables, and eliminates variables with p-values higher than the threshold and refits the model at each step. The forward elimination procedure was used in the current study as it was the default procedure in the JMP® software [73].

\subsubsection{Robust Regression}

Robust regression models are less sensitive to outliers. The method involves weighting of data points. The initial iteration weights all data points equally and fits a model. In subsequent 
iterations, data points resulting in large residuals or potential outliers are given less weight compared to the rest of the data points and the model is re-fitted. This method is particularly useful in data sets where some outliers skew the fitted model significantly.

\subsubsection{Design of Experiments (DoE)}

Design of experiments is a systematic method of analyzing a process. The tests are designed in a way that most of the information pertaining to the process can be determined with minimum test time and resources. The effects of factors, their interaction, and quadratic effects can be determined based on the number of factors, test points and design chosen.

Central Composite Designs (CCDs) are among the most popular models in DoE. Figures 5-50 through 5-52 [69] show the three types of CCDs, face-centered, circumscribed, and inscribed designs. All three designs are efficient in determining full quadratic models.

The inscribed and circumscribed methods use five levels of each factor for the experiments. In the current study, the operating window considered was not wide enough for five factor levels due to the backfire limiting equivalence ratio of the engine. The face centered design which uses three levels for each factor was appropriate for the objective of the study.

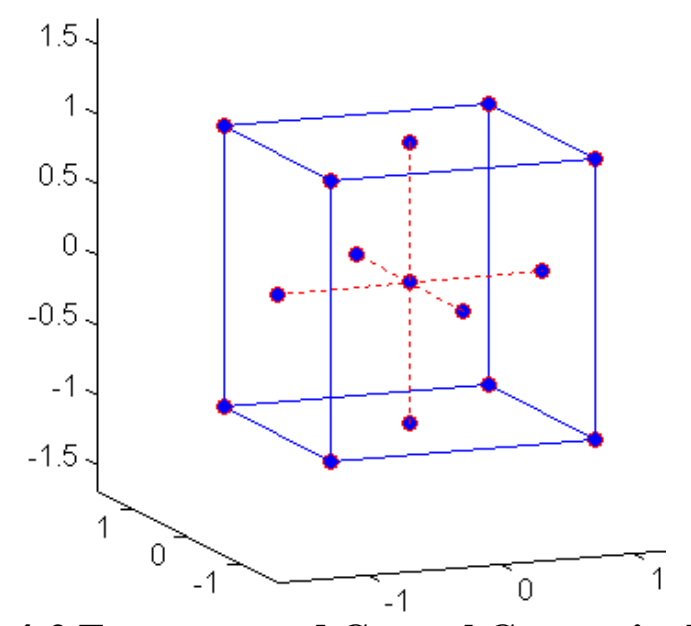

Figure 4-2 Face-centered Central Composite Design 


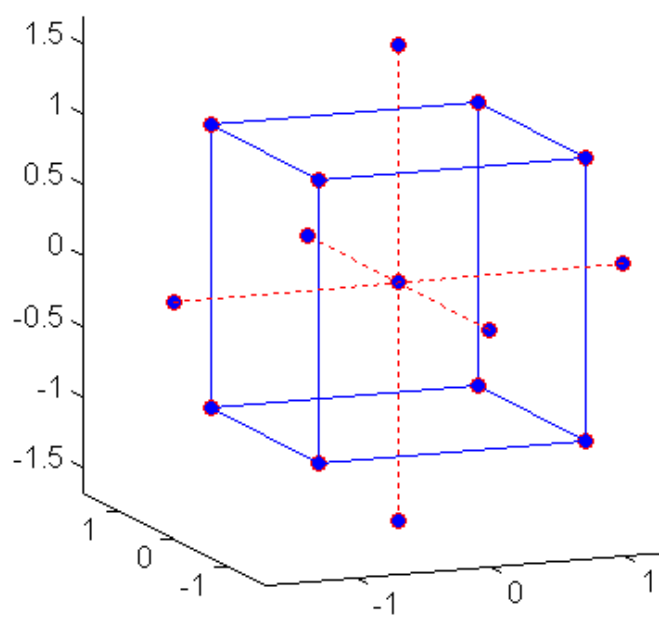

Figure 4-3 Circumscribed Central Composite Design

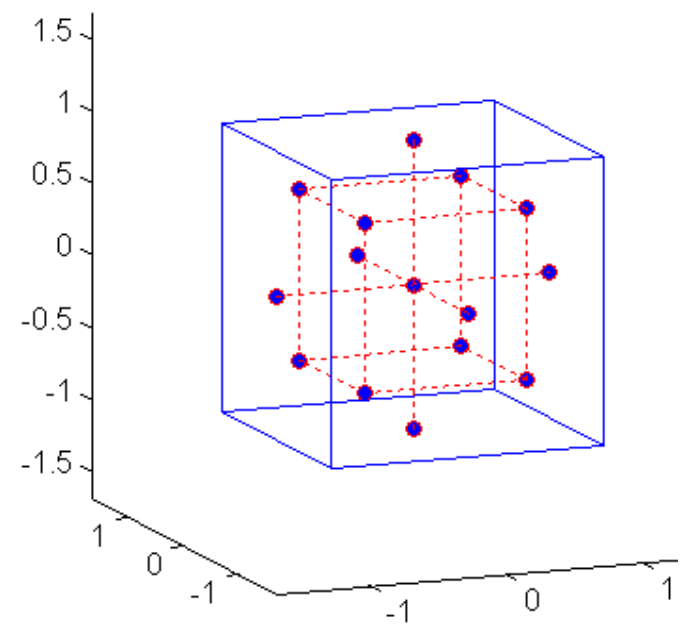

Figure 4-4 Inscribed Central Composite Design

\subsubsection{JMP ${ }^{\circledR}$ Statistical Summary Report}

The JMP ${ }^{\circledR}$ statistical analysis software from SAS (Statistical Analysis Institute) was used for the regression analysis in this study. Figure 4-5 shows an example of a typical JMP ${ }^{\circledR}$ statistical analysis report for a multiple linear regression analysis. 
Figure 4-5 Typical JMP Statistical Summary Report

Whole Model Actual by Predicted Plot

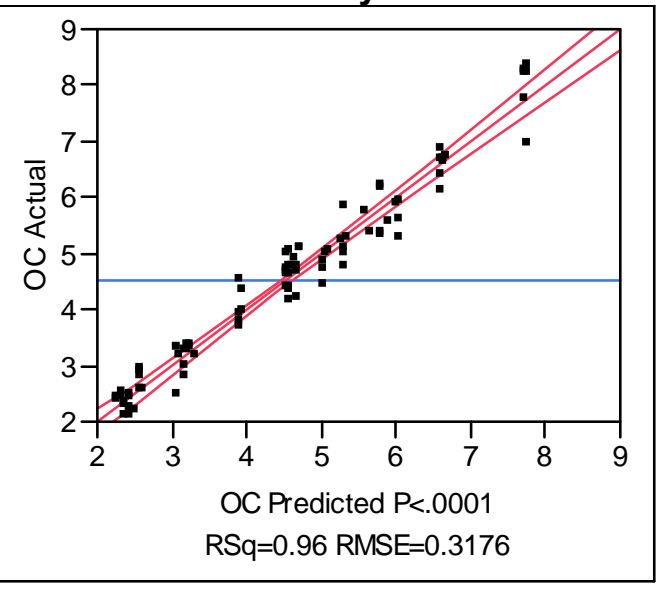

\section{Summary of Fit}

RSquare

RSquare Adj

Root Mean Square Error

Mean of Response

Observations (or Sum Wgts)

0.964542

0.961515

0.317621

4.531778

90

Analysis of Variance

$\begin{array}{lrr}\text { Source } & \text { DF } & \text { Sum of Squares } \\ \text { Model } & 7 & 225.03113 \\ \text { Error } & 82 & 8.27239 \\ \text { C. Total } & 89 & 233.30352\end{array}$

\section{Lack Of Fit}

Source

Lack Of Fit

Pure Error

Total Error

$\begin{array}{rr}\text { DF } & \text { Sum of Squares } \\ 43 & 3.8381236 \\ 39 & 4.4342667 \\ 82 & 8.2723902\end{array}$

Mean Square
0.089259
0.113699
1

2

\section{Parameter Estimates}

\section{Term}

Intercept

Speed $(15,30)$

Phi $(0.28,0.38)$

Boost $(14,54)$

Speed*Phi

Speed*Boost

Speed*Speed

Phi*Phi

Estimate
4.568629
1.7662661
0.2453224
0.7114114
0.2976576
0.3041245
-0.268263
0.1921544

Std Error

0.065044

0.040905

0.041687

0.041818

0.045332

0.046663

0.081116

0.07978
3 318.6599

Prob > F $<.0001$

F Ratio 0.7850

Prob > F 0.7808

Max RSq

0.9810

4

5 


\section{Residual by Predicted Plot}

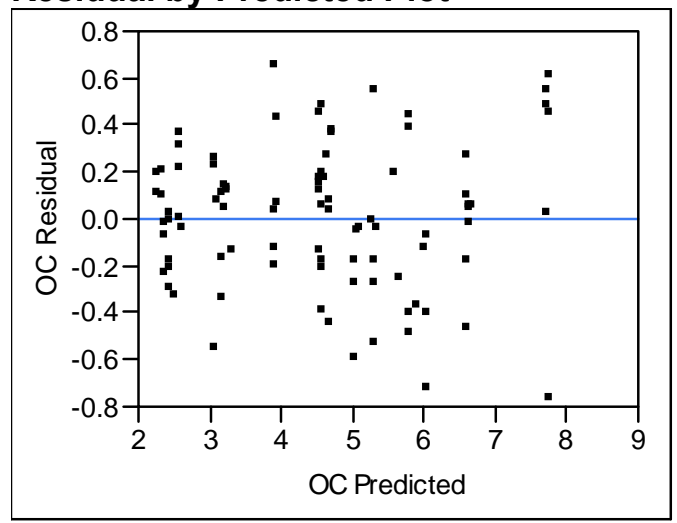

Speed(15,30)

Leverage Plot

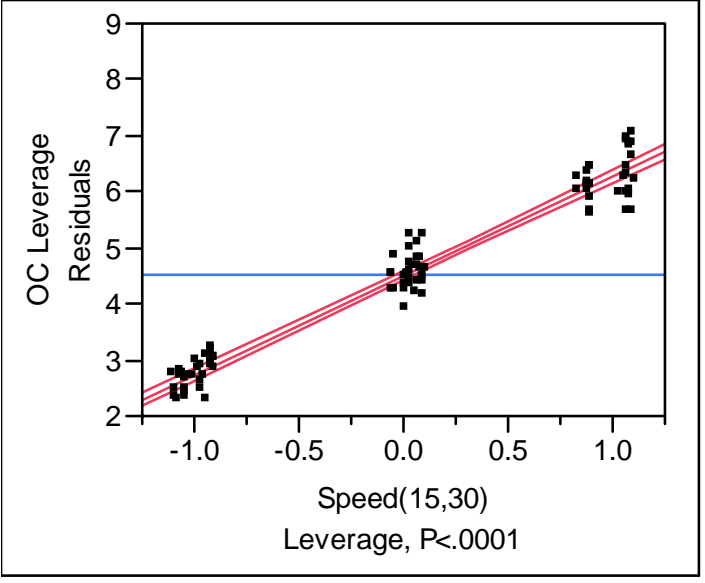

\section{6}

7

The numbers in the following text refer to the corresponding boxed numbers in Figure 4.5.

1) Scatter plot of whole model predicted values versus the actual experimental data.

2) The summary of the fit consists of the following.

- Rsquare: The number shows that the model accounts for or explains approximately $96 \%$ of the variation around the mean (for the example shown). It is the ratio of the Model Sum of Squares to the Total Sum of Squares from (3).

- Rsquare Adj: The adjusted Rsquare accounts for the number of parameters that define the model.

- Root Mean Square Error: Standard deviation of the residual error. It is the square root of the Mean Square of Error from (3).

- Mean of Response: The mean of all the observations.

- Observations: Number of data points. 
3) Analysis of Variance Table

- DF (Degrees of Freedom): The number of degrees of freedom for the model is the number of parameters excluding the intercept that define the model. The total degree of freedom is one less than the number of observations. The difference of the two gives the DF of error.

- Sum of Squares: The total sum of squares is the sum of squares of the residuals if all regression effects were removed except for the intercept. The Error Sum of Squares is sum of squares of residuals. The model sum of squares is the difference between the two or the sum of squares of residuals considering all the regression effects.

- Mean Square: The ratio of Sum of Squares to DF

- F Ratio: Ratio of Model Mean Square to Error Mean Square.

- Prob>F: Indicates whether the model fits better than simply fitting the mean if $\mathrm{p}<0.05$ (for $95 \%$ confidence). In the example $\mathrm{p}<0.0001$ indicates that the F Ratio is highly significant or that the model fits much better than just considering the mean. 


\section{4) Lack of Fit Table}

The Lack of Fit Total Error is same as the model error in (3). The total error is split into two : Lack of Fit Error and Pure Error.

- Pure Error is the error associated with the experiments as a result of random effects and can be determined for tests where replicates are performed.

- The Lack of Fit Error is obtained by subtracting the Pure Error from the total error.

- The number of degrees of freedom (DF) for the pure error depends on the number of exact replicates. For the currents study, 3 runs were performed at each of the 15 operating states for the two oils. Therefore, the DF of pure error should be, 30 * $(3-1)=60$. Since, the actual data for speed, phi, and boost were used for the analysis rather than the set points, the number of exact replicates will be less, and hence the DF of pure error is seen to be less than 60 in the example shown.

- The DF of Lack of Fit is, Total Error DF - Pure Error DF.

- The Sum of Squares (SS) of pure error is obtained from the replicate data points, and the Lack of Fit SS =Total SS - Pure Error SS.

- The Mean Square is the ratio of Sum of Squares to DF as in (3).

- F Ratio as in (3) is the ratio of Lack of Fit Mean Square to Pure Error Mean Square. In the example, the p-value denotes that the lack of fit is not significant, or which indicates that the model is adequate.

- Max RSq indicates the maximum Rsquare value that can be obtained by adding more parameters to the existing model.

5) The parameter estimates table lists the estimates of the model parameters, the standard error associated with the estimates, t-ratios, and the p-values.

- Parameter estimates are obtained such that their values minimize the residual Sum of Squares, and involve matrix computation for multiple regressions.

- Standard error is the estimate of the standard deviation of the parameter estimate.

- $\mathrm{t}$-Ratio is the ratio of the estimate to its standard error. Higher the t-Ratio, more the significance of the parameter. 
- Prob $>(t)$ : significance probability (p-value).

6) Plot of residuals versus the model predicted values. Residual plots help to visualize the adequacy of the models

7) Effects Leverage Plots: The Leverage plots illustrate how each effect contributes to the

fit. The leverage plots have the following included.

- The sloped line enclosed by the confidence curves (red lines). The distance from each point to the sloped line is the residual for the full model, the sum of squares of which is the SSE (Error Sum of Squares).

- The horizontal line (blue line) is the restricted model without the effect (the mean of the response). The distance from each point to this line is the residual for restricted model without the effect.

The effect is significant if the points support the sloped line significantly away from the horizontal line, that is, if the difference in sums of squares of the two residuals defined above is large, the effect is significant. Also, the confidence curves will not enclose the horizontal line, if the effect is significant.

\subsubsection{Normal Probability Plots}

Normal probability plots can be used for checking distributional normality for large samples of data, and also to point out suspect data values. The vertical axis scale is adjusted so that the probability versus data displayed is approximately a straight line for data from a normal distribution.

Normal Probability Plots are used in this study to compare the data from the two test oils so as to check the effect of oil type (in this case effect of volatility) on oil consumption. Normal probability plots can also give estimates of the mean and standard deviations of the data set. 


\subsubsection{Box Plots}

Box Plots provide a graphical summary of the data and is a common visual analysis tool to compare multiple data sets. Box Plots are used along with probability plots in the current study to compare data between the test oils. Figure 4-6 shows the box plot convention used in this study.

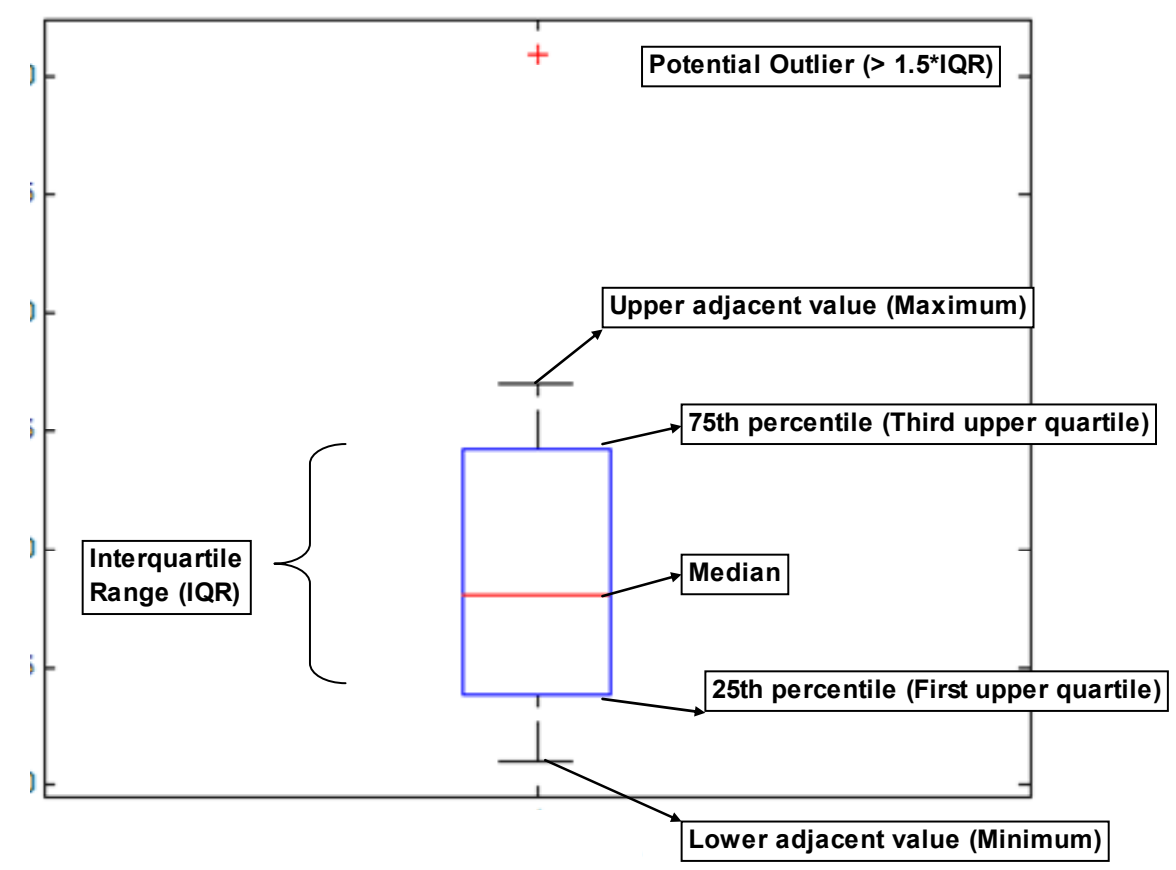

Figure 4-6 Typical Box Plot 


\section{RESULTS AND DISCUSSION}

The results discussed in this chapter are in the following order:

i. Oil consumption based on gaseous carbon emissions $\left(\mathrm{CO}_{2}, \mathrm{CO}, \mathrm{THC}\right)$

- Brake-specific (g/bhp-hr) oil consumption model as a function of speed, phi, and boost

- Absolute or time-specific ( $\mathrm{g} / \mathrm{hr}$ ) oil consumption model as a function of speed, phi, and boost

- The influence of combustion parameters, such as combustion duration, peak cylinder pressures, start of combustion, and exhaust temperatures on lubricant oil consumption and possible contribution of the different sources of oil consumption

ii. EC/OC, trace metals analyses results

- Oil consumption determined based on organic carbon in the exhaust

- Oil consumption determined based on $\mathrm{Ca}$ and $\mathrm{Zn}$ concentrations in the exhaust

- Comparison of the different methods for an understanding of total oil consumption

iii. Particle number, size, and surface area distributions

- Particle number concentration dependence on lubricant oil consumption, and engine operating conditions

- Particle size distributions during motoring (fuel shut-off) conditions

- Particle surface area and impact of lubricant derived PM on mutagenicity

iv. Effect of ageing on lubricant oil properties 


\subsection{Oil Consumption Analysis (Carbon Balance Method)}

The oil consumption was studied using the faced central composite design as shown in Figure 4-1. The fifteen operating conditions, shown in Table 5-1 were employed with the two oils, Valvoline (will be referred as "Mineral Oil" in the rest of the document), and Amsoil (will be referred as "Synthetic Oil" in the rest of the document). The values $-1,0$, and 1 denote the three levels of speed, phi, and boost already shown in Table 4-1. The operating conditions will be referred by their corresponding state numbers (given in Table 5-1) in the rest of the document.

Table 5-1 Steady-state Test Points Denoted by State Numbers

\begin{tabular}{|c|c|c|c|}
\hline State No. & Speed (rps)/Coded Speed & Phi/Coded Phi & Boost (kPa)/Coded Boost \\
\hline 1 & $15 /-1$ & $0.28 /-1$ & $20 /-1$ \\
\hline 2 & $15 /-1$ & $0.28 /-1$ & $60 /+1$ \\
\hline 3 & $15 /-1$ & $0.33 / 0$ & $40 / 0$ \\
\hline 4 & $15 /-1$ & $0.38 /+1$ & $20 /-1$ \\
\hline 5 & $15 /-1$ & $0.38 /+1$ & $60 /+1$ \\
\hline 6 & $22.5 / 0$ & $0.28 /-1$ & $40 / 0$ \\
\hline 7 & $22.5 / 0$ & $0.33 / 0$ & $20 /-1$ \\
\hline 8 & $22.5 / 0$ & $0.33 / 0$ & $40 / 0$ \\
\hline 9 & $22.5 / 0$ & $0.33 / 0$ & $60 /+1$ \\
\hline 10 & $22.5 / 0$ & $0.38 /+1$ & $40 / 0$ \\
\hline 11 & $30 /+1$ & $0.28 /-1$ & $20 /-1$ \\
\hline 12 & $30 /+1$ & $0.28 /-1$ & $60 /+1$ \\
\hline 13 & $30 /+1$ & $0.33 / 0$ & $40 / 0$ \\
\hline 14 & $30 /+1$ & $0.38 /+1$ & $20 /-1$ \\
\hline 15 & $30 /+1$ & $0.38 /+1$ & $60 /+1$ \\
\hline
\end{tabular}

The oil consumption model based on three factors, namely, speed, phi, and boost was determined by stepwise multiple linear regression analysis. The above tests were replicated twice for a total of three runs with each test oil. Tests were conducted in a random order. Table B1 in Appendix B shows the coded data matrix of factors and the response based on the actual data obtained in the order the tests were done. Table 5-2 shows the average oil consumption results for the two oils for the various operating states. 
Table 5-2 Brake-specific Oil Consumption (g/bhp-hr) Results for the Test Oils

\begin{tabular}{|c|c|c|c|c|c|c|}
\hline \multirow{2}{*}{ State No. } & \multicolumn{5}{|c|}{ Brake-specific Oil Consumption(g/bhp-hr) } \\
\cline { 2 - 7 } & \multicolumn{3}{|c|}{ Mineral Oil } & \multicolumn{3}{c|}{ Synthetic Oil } \\
\cline { 2 - 7 } & Avg & S.D. & COV & Avg & S.D. & COV \\
\hline 1 & 0.40 & 0.01 & 0.03 & 0.43 & 0.02 & 0.05 \\
\hline 2 & 0.36 & 0.00 & 0.01 & 0.36 & 0.01 & 0.04 \\
\hline 3 & 0.30 & 0.01 & 0.04 & 0.31 & 0.00 & 0.01 \\
\hline 4 & 0.28 & 0.02 & 0.07 & 0.31 & 0.01 & 0.03 \\
\hline 5 & 0.24 & 0.02 & 0.08 & 0.25 & 0.02 & 0.08 \\
\hline 6 & 0.43 & 0.03 & 0.06 & 0.42 & 0.01 & 0.02 \\
\hline 7 & 0.41 & 0.04 & 0.10 & 0.37 & 0.01 & 0.04 \\
\hline 8 & 0.34 & 0.02 & 0.06 & 0.35 & 0.01 & 0.03 \\
\hline 9 & 0.31 & 0.01 & 0.02 & 0.31 & 0.03 & 0.10 \\
\hline 10 & 0.31 & 0.02 & 0.06 & 0.31 & 0.01 & 0.02 \\
\hline 11 & 0.54 & 0.06 & 0.12 & 0.53 & 0.02 & 0.03 \\
\hline 12 & 0.41 & 0.01 & 0.03 & 0.39 & 0.02 & 0.04 \\
\hline 13 & 0.35 & 0.01 & 0.01 & 0.33 & 0.03 & 0.08 \\
\hline 14 & 0.42 & 0.01 & 0.03 & 0.37 & 0.01 & 0.02 \\
\hline 15 & 0.33 & 0.03 & 0.09 & 0.35 & 0.00 & 0.01 \\
\hline
\end{tabular}

Avg $=$ Average, S.D. $=$ Standard Deviation, $\mathrm{COV}=$ Coefficient of Variance

Stepwise regression was used to determine the significant factors, their quadratic effects, and two way interaction effects. The accuracy of the regression analysis was checked using ANOVA (analysis of variance), and the analysis of residuals. JMP ${ }^{\circledR}$ statistical analysis software was used for the regression analysis. The statistics toolbox of MATLAB ${ }^{\circledR}$ was also used for the analysis of results.

Quadratic models for both brake-specific (g/bhp-hr), and absolute (g/hr) oil consumption were developed using stepwise multiple linear regression. The absolute oil consumption model was found to fit better with experimental data; hence, it may be a better method to determine oil consumption as a function of engine operating conditions. Details for both analyses are provided in the following sections.

The gaseous emissions results of $\mathrm{CO}_{2}, \mathrm{CO}$, and $\mathrm{THC}$ which were used to calculate the oil consumption, and the NOx emissions results are given in Appendix $\mathrm{C} . \mathrm{CO}_{2}$ was the major contributor among the carbonaceous emissions. The NOx emissions were low as expected due to the low equivalence ratios. 


\subsubsection{Brake-specific Oil Consumption Analysis (Carbon Balance Method)}

A simple multiple linear regression showed no effect in the oil consumption as a result of the oil types used in the study. This was further reinforced by a normal probability plot and a box plot of the actual brake-specific oil consumption data obtained for the test oils. The normal probability plot and the box plots of brake-specific oil consumption for the mineral oil and synthetic oil are shown in Figures 5-1 and 5-2, respectively. The normal plot shows that the two data sets are part of similar normal distributions, and the box plot shows that the data have similar medians, as well. The normal plots and box plots are two of the most common techniques and basic analytical methods for this purpose.

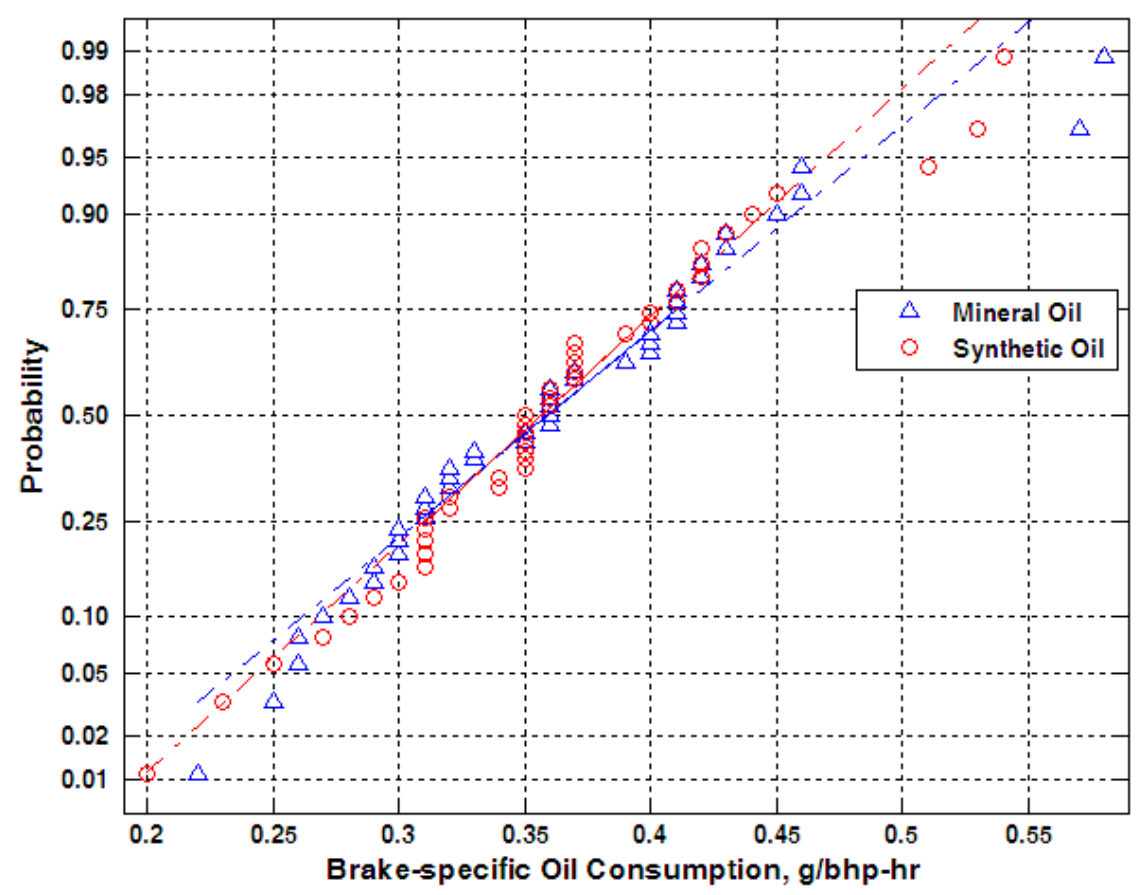

Figure 5-1 Normal Probability Plot of Brake-specific Oil Consumption Data for the Test Oils 


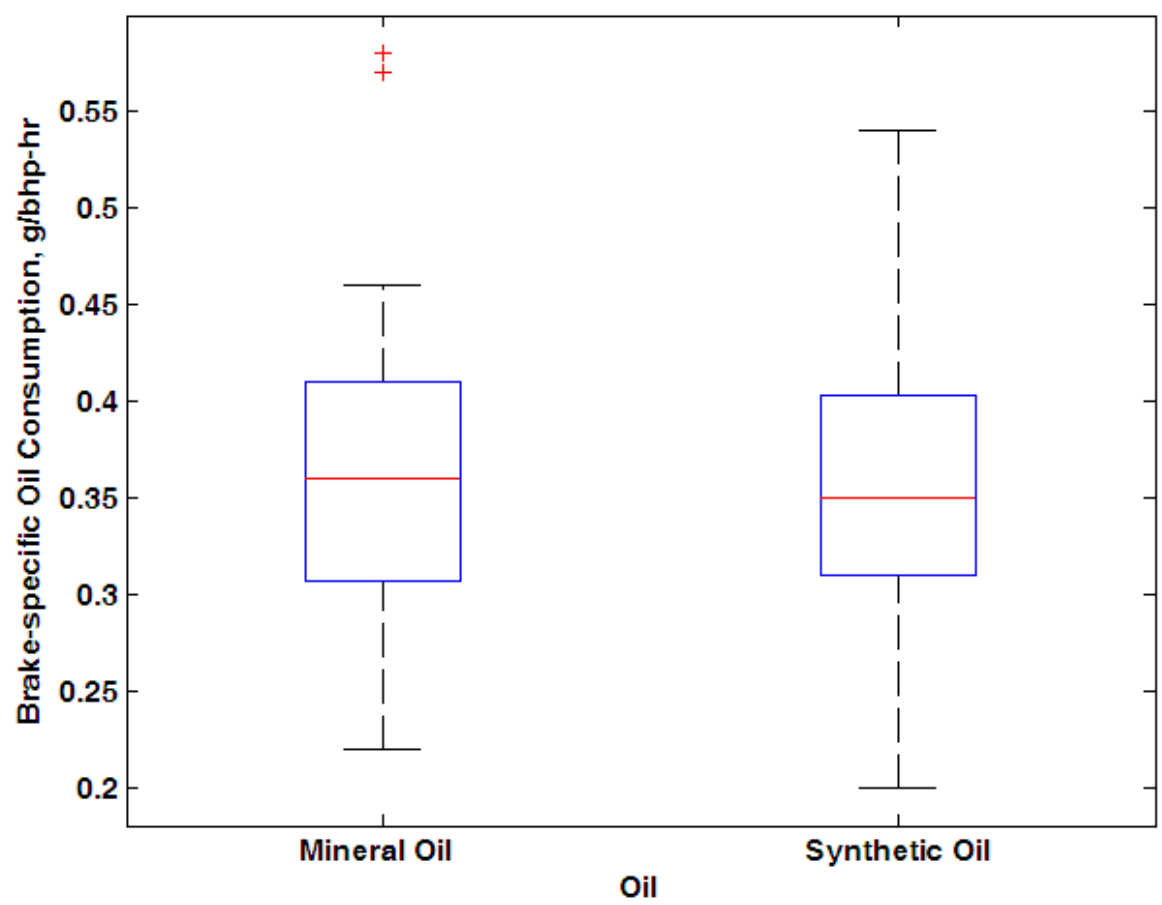

Figure 5-2 Box Plot of Brake-specific Oil Consumption Data for the Test Oils

Based on the finding that the two oil types had similar oil consumption behavior for the entire design, it was decided to analyze the data together. This also provided several more data points for the model determination. The model parameters, ANOVA table, and residual plots are shown in Report 5-1 below for the stepwise multiple linear regression analysis. Brake-specific oil consumption is denoted as "OC" in the statistical report. Speed data used for the analysis was in rps (revolutions per second). 


\section{Report 5-1 Statistical Analysis Report of the Stepwise Multiple Linear Regression of Brake-specific Oil Consumption Data}

Whole Model Actual by Predicted Plot

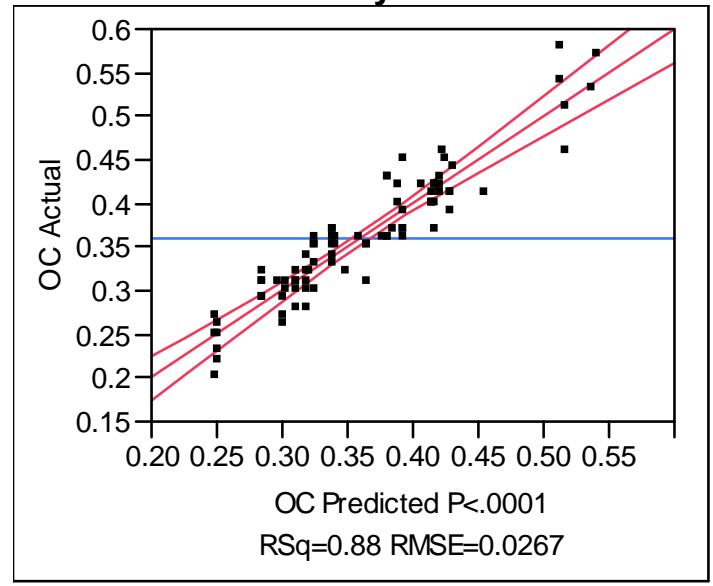

\section{Summary of Fit}

$\begin{array}{lr}\text { RSquare } & 0.876796 \\ \text { RSquare Adj } & 0.866279 \\ \text { Root Mean Square Error } & 0.026655 \\ \text { Mean of Response } & 0.361111 \\ \text { Observations (or Sum Wgts) } & 90\end{array}$

\section{Analysis of Variance}

Lack Of Fit
Source

Model

Error

C. Total

$\begin{array}{rr}\text { DF } & \text { Sum of Squares } \\ 7 & 0.41462710 \\ 82 & 0.05826179 \\ 89 & 0.47288889\end{array}$

\section{Lack Of Fit}

Source

Pure Error

Total Error

$\begin{array}{rr}\text { DF } & \text { Sum of Squares } \\ 43 & 0.03481179 \\ 39 & 0.02345000 \\ 82 & 0.05826179\end{array}$

$\begin{array}{rr}\text { Mean Square } & \text { F Ratio } \\ 0.059232 & 83.3661 \\ 0.000711 & \text { Prob > F } \\ & <.0001\end{array}$

$\begin{array}{rr}\text { Mean Square } & \text { F Ratio } \\ 0.000810 & 1.3464 \\ 0.000601 & \text { Prob }>\text { F } \\ & 0.1746 \\ & \text { Max RSq } \\ & 0.9504\end{array}$

\section{Parameter Estimates}

Term

Intercept

Speed $(15,30)$

Phi $(0.28,0.38)$

Boost $(14,54)$

Phi*Boost

Speed*Speed

Phi*Phi

Boost*Boost

Estimate
0.3388579
0.037392
-0.054989
-0.038662
0.0103953
-0.014358
0.0271126
0.0183959

t Ratio
57.29
10.88
-15.75
-11.02
2.62
-2.03
3.92
2.53

Prob $>|t|$
$<.0001$
$<.0001$
$<.0001$
$<.0001$
0.0105
0.0461
0.0002
0.0134 


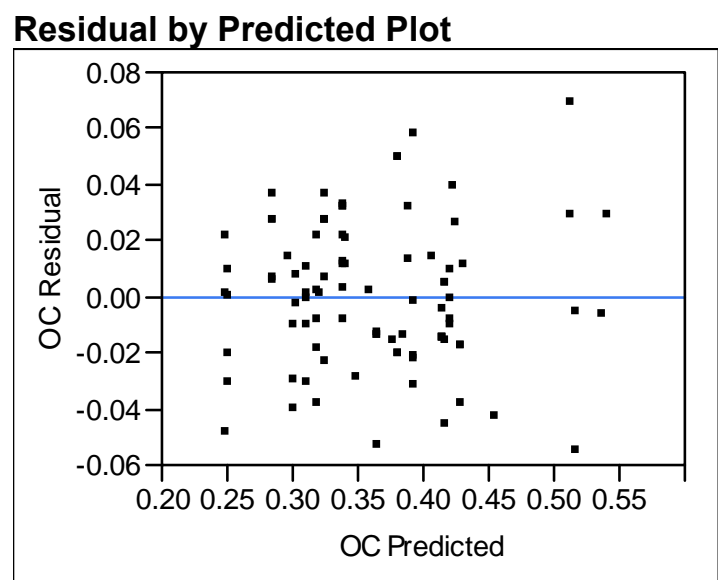

Speed(15,30)

Leverage Plot

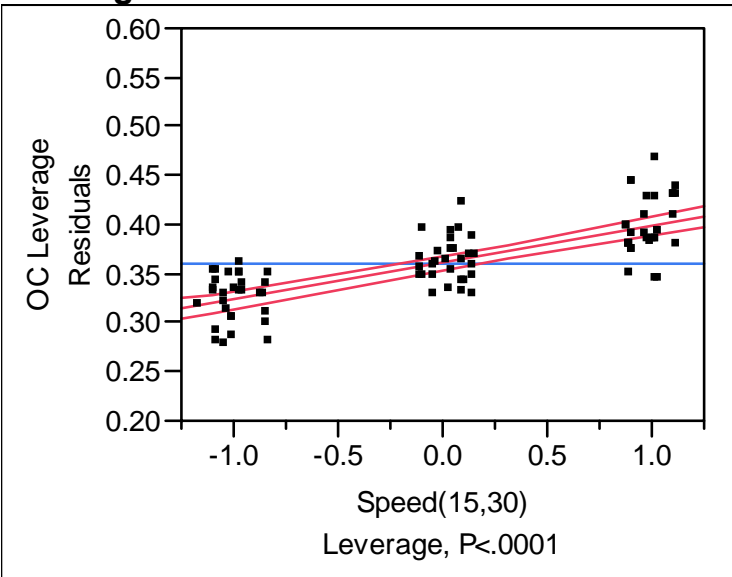

Boost(14,54)

Leverage Plot

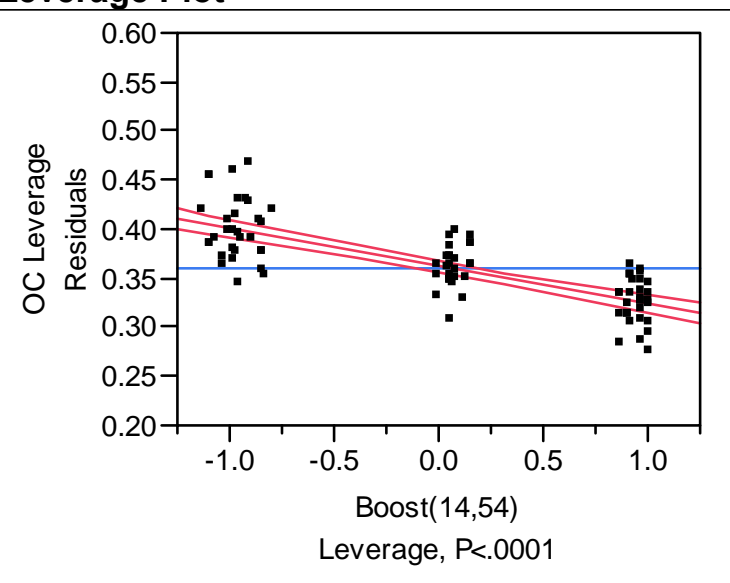

Phi(0.28,0.38)

Leverage Plot

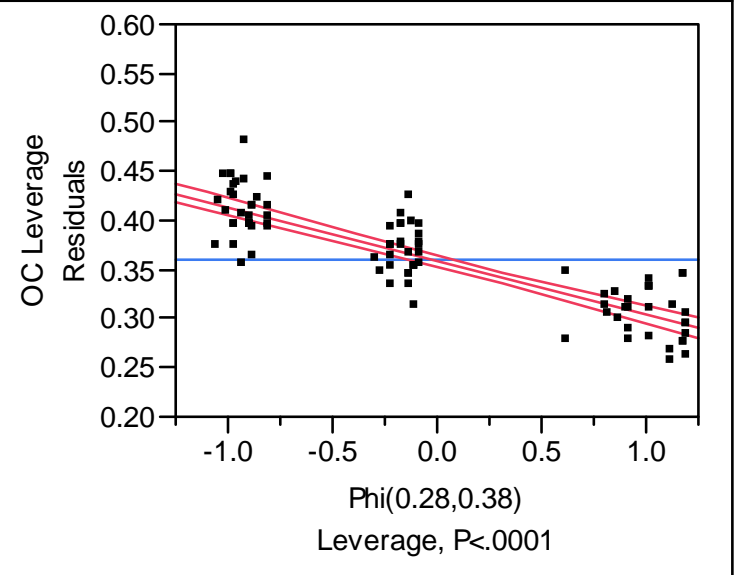

Phi*Boost

Leverage Plot

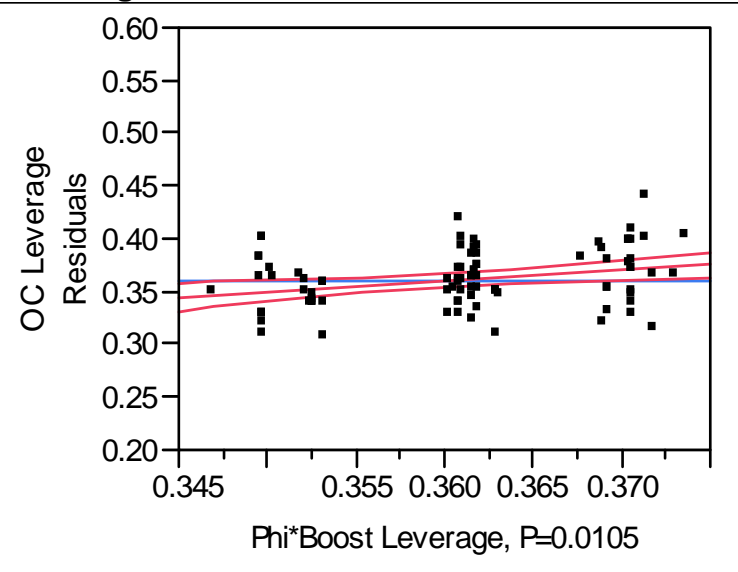




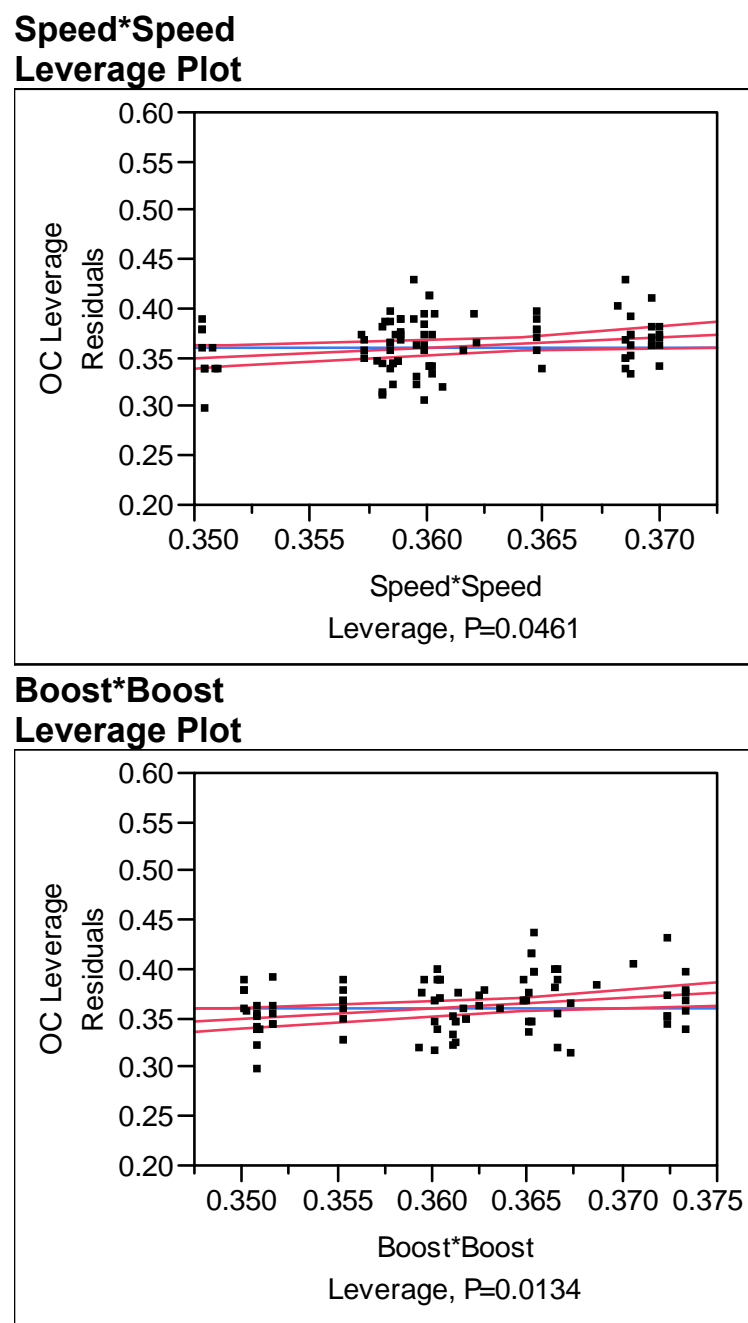

Phi*Phi

Leverage Plot

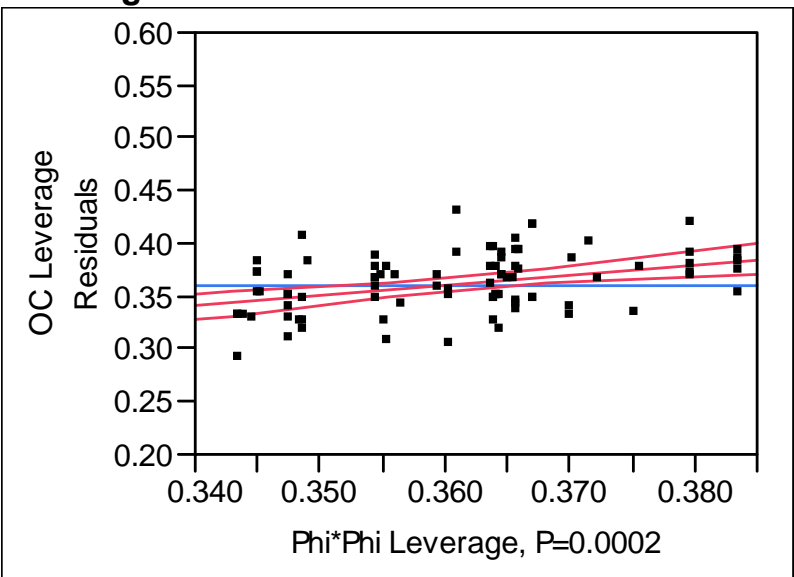

Boost*Boost

Leverage Plot

Speed, equivalence ratio, boost, and the quadratic effect of all three parameters were found to be significant at the $95 \%$ confidence level. The only interaction term found to be significant was the interaction effect of equivalence ratio and boost.

Robust regression allows removing any skewness in the model associated with outliers. A robust fit of the data was also performed using the coefficient estimates of the significant factors and factor interactions determined by the stepwise regression. The MATLAB ${ }^{\circledR}$ statistics toolbox was used for this purpose. The oil consumption predicted by robust regression analysis was similar to results from the stepwise regression analysis showing the absence of any potential outliers in the data set. Figure 5-3 shows parity plots of brake-specific oil consumption predicted by the stepwise regression model and robust regression model versus the actual data. The robust 
regression model provided a better fit for the model based on least squares and residual analysis. Figure 5-4 shows comparison of residuals based on step wise regression analysis model versus the robust regression analysis.

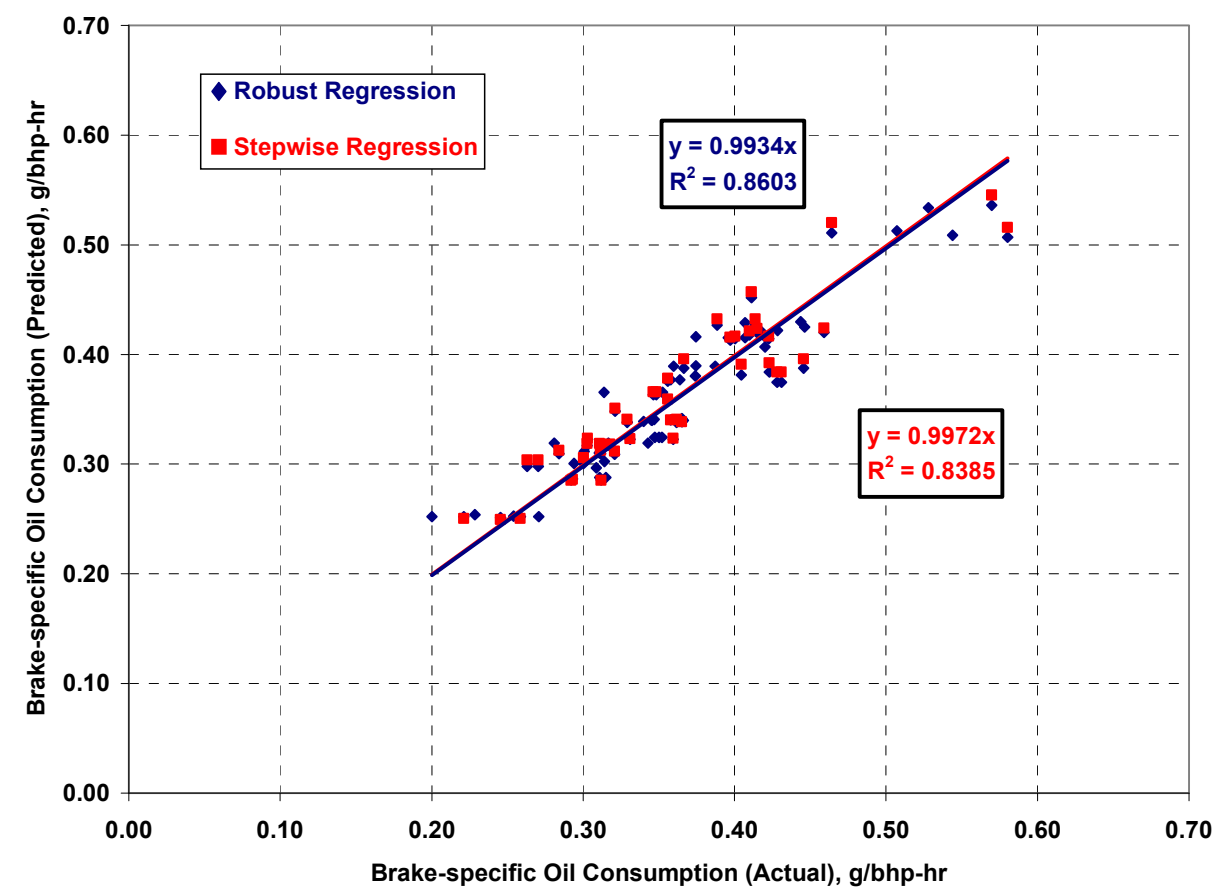

Figure 5-3 Comparison of Step-wise Regression Model vs. Robust Regression Model 


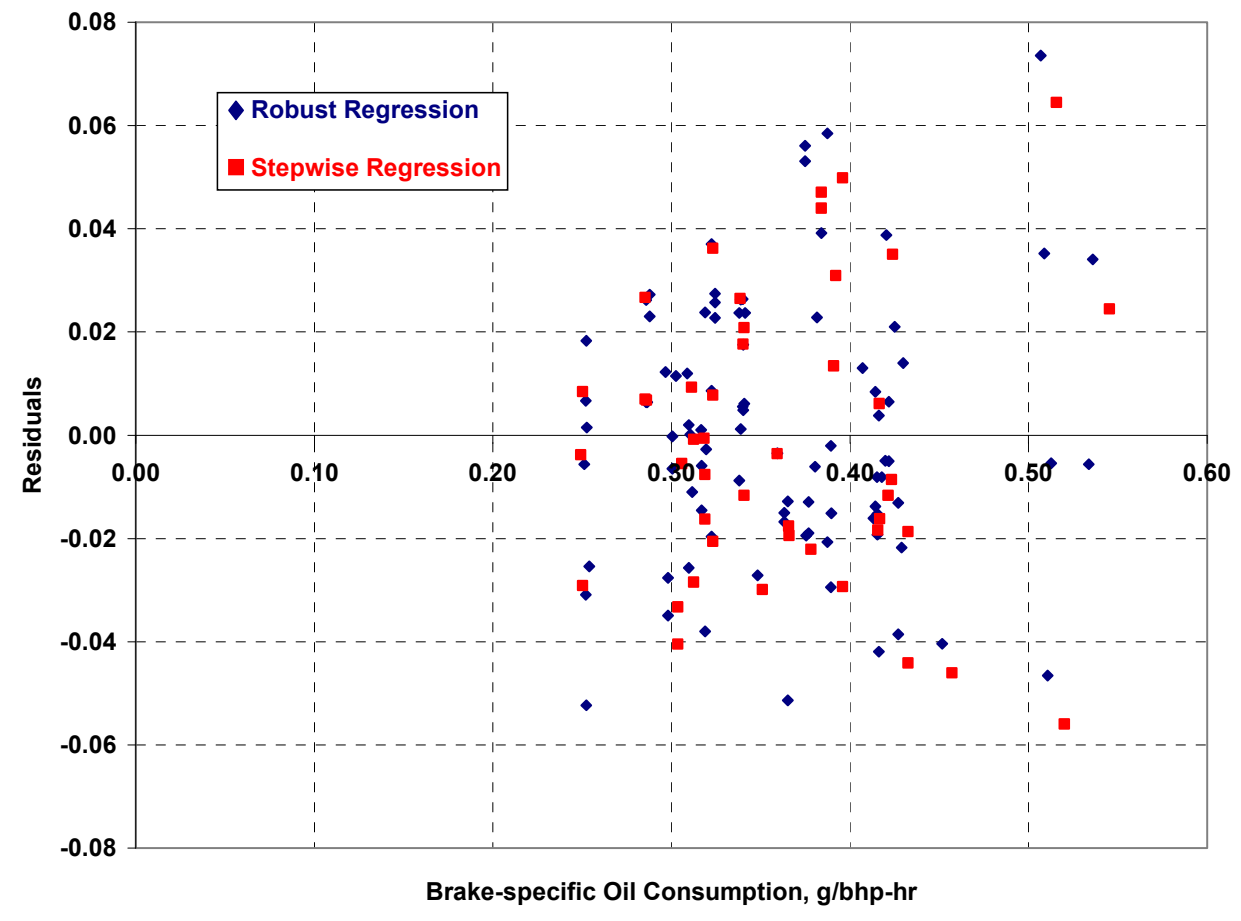

Figure 5-4 Residual Comparison

The robust linear fit was used to derive a quadratic response surface. The quadratic brakespecific oil consumption $\left(m_{\text {oil }}, \mathrm{g} / \mathrm{bhp}\right.$-hr) model based on the robust regression is given in Equation 5-1.

$$
\begin{aligned}
& m_{\text {oil }}=0.34+0.036 * \text { Speed }-0.055 * \text { Phi }-0.035 * \text { Boost }+0.011 *(\text { Phi } * \text { Boost }) \\
& -0.013 *(\text { Speed })^{2}+0.027 *(\text { Phi })^{2}+0.016 *(\text { Boost })^{2}
\end{aligned}
$$

Equation 5-1

The variables Speed, Phi, and Boost in the above equation are the coded speed, coded phi, and coded boost, respectively. The above equation was used to obtain brake-specific oil consumption behavior over the entire design envelope. The quadratic response surface is shown in Figure 5-5. The trend can be better visualized by analyzing slices of constant speed, phi, and boost as shown in Figures 5-6 through 5-8, respectively. 


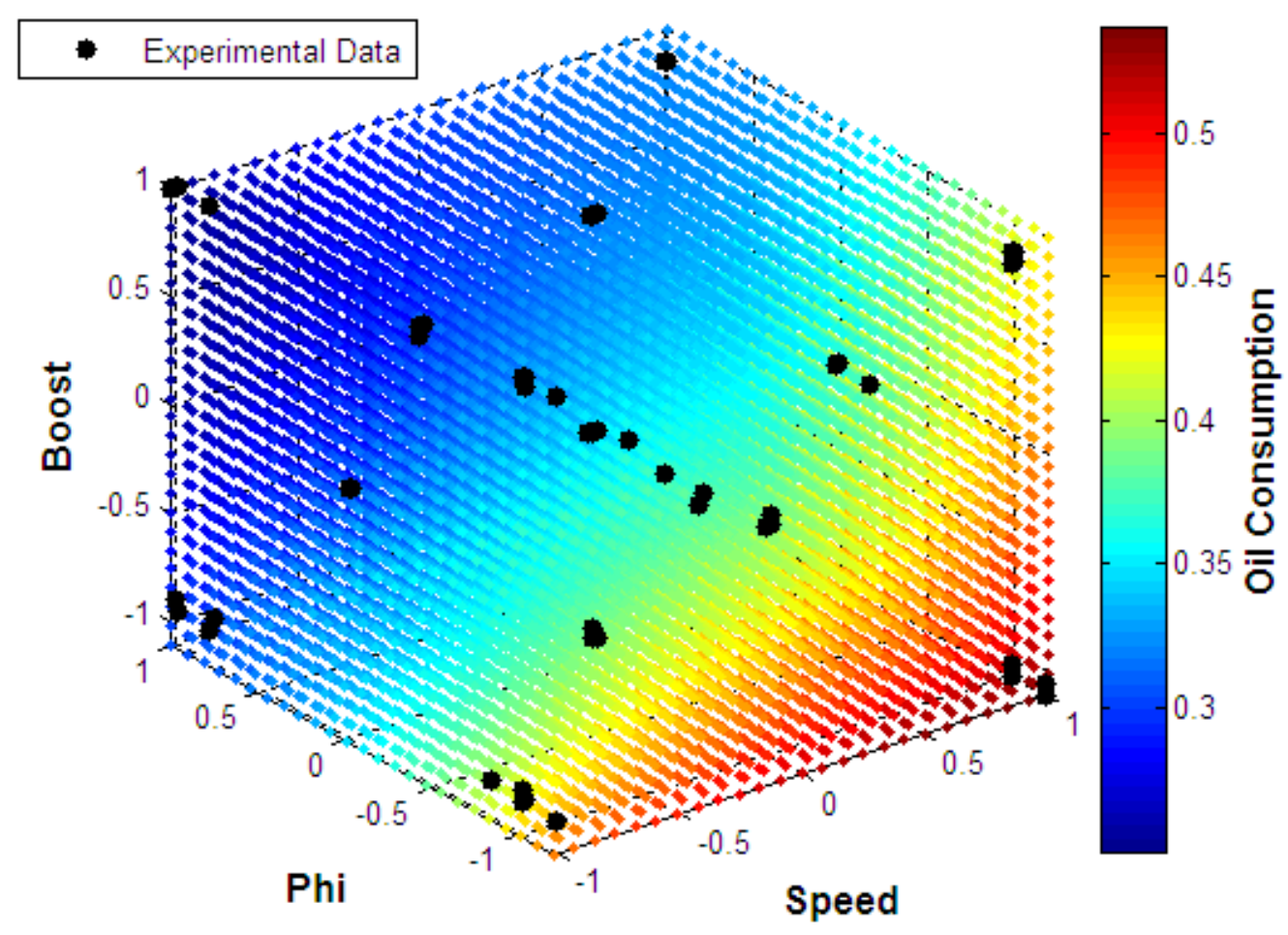

Figure 5-5 Quadratic Brake-specific Oil Consumption (g/bhp-hr) Model

The data clearly indicates increasing brake-specific oil consumption with increasing speed and decreasing equivalence ratio and boost. The diagonal joining the points represented by $[($ Speed, Phi, Boost $)=(-1,1,1)]$ and $[($ Speed, Phi, Boost $)=(1,-1,-1)]$ can be considered as the line of steepest ascent of brake-specific oil consumption for the model under consideration. The discussion of these results is presented in the next section following the absolute oil consumption analysis. 


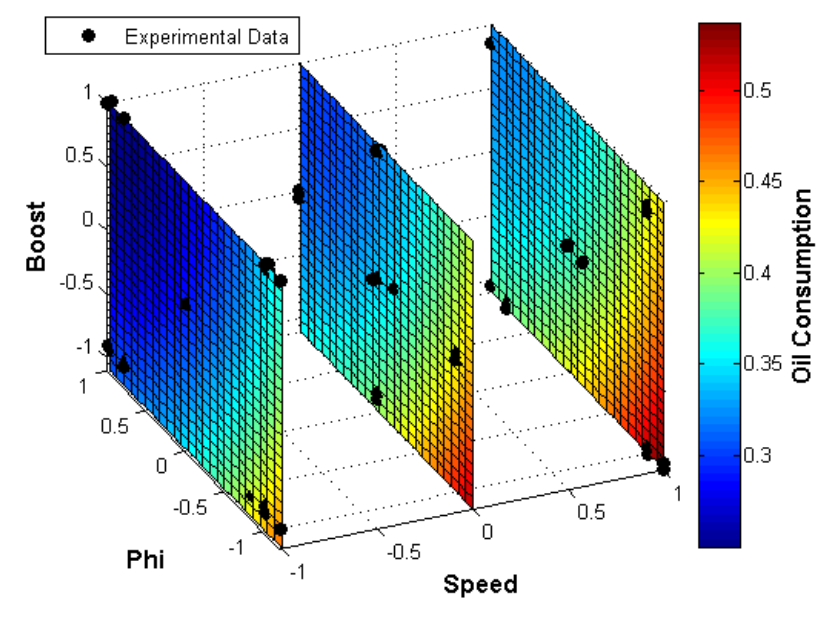

Figure 5-6 Quadratic Brake -specific Oil Consumption Model : Constant Speed Steps

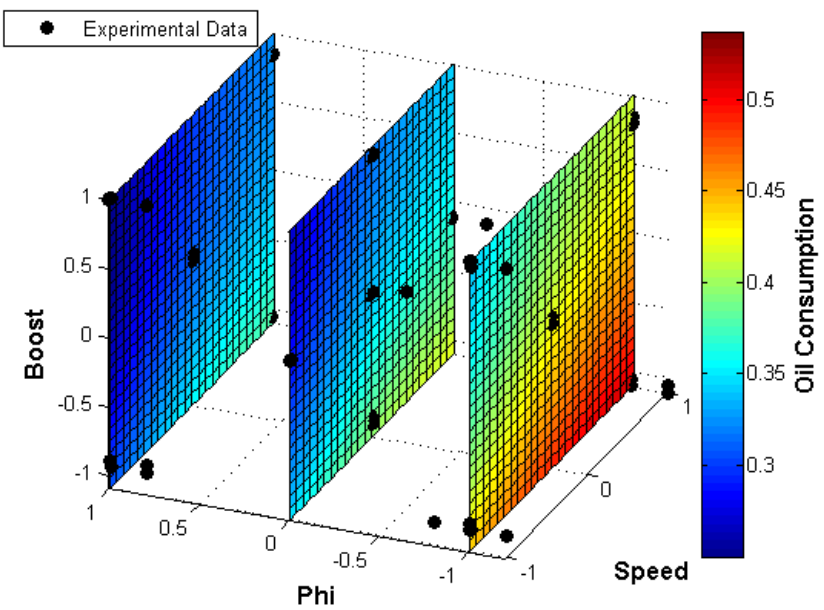

Figure 5-7 Quadratic Brake-specific Oil Consumption Model : Constant Phi Steps

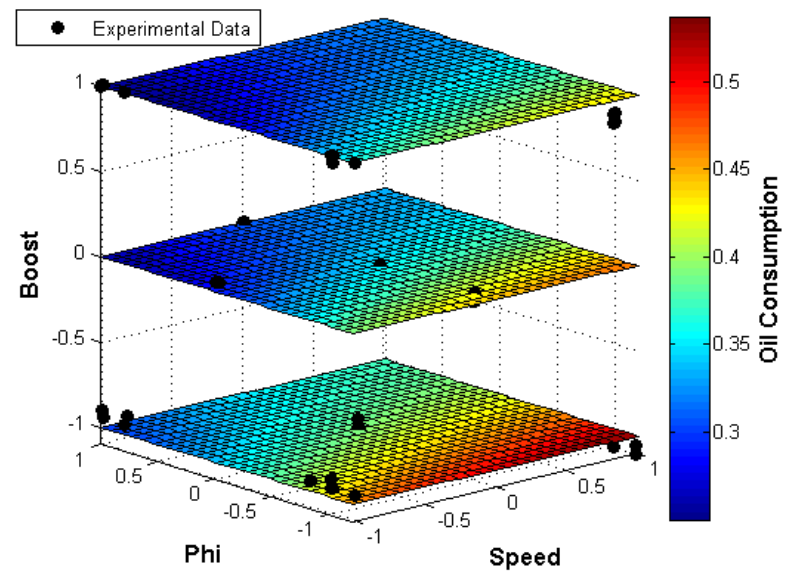

Figure 5-8 Quadratic Brake-specific Oil Consumption Model : Constant Boost Steps 


\subsubsection{Time-specific Oil Consumption Analysis (Carbon Balance Method)}

Absolute oil consumption (g/hr) or time-specific oil consumption was also analyzed as a function of speed, equivalence ratio, and boost as performed in the previous section. The analysis was done for the combined (mineral oil and synthetic oil) data as before.

The statistical analysis results are shown below in Report 5-2. Time-specific oil consumption is denoted as "OC" in the statistical report. Speed data used for the analysis was in rps (revolutions per second).

Report 5-2 Statistical Analysis Report of the Stepwise Multiple Linear Regression of Timespecific Oil Consumption Data

Whole Model Actual by Predicted Plot

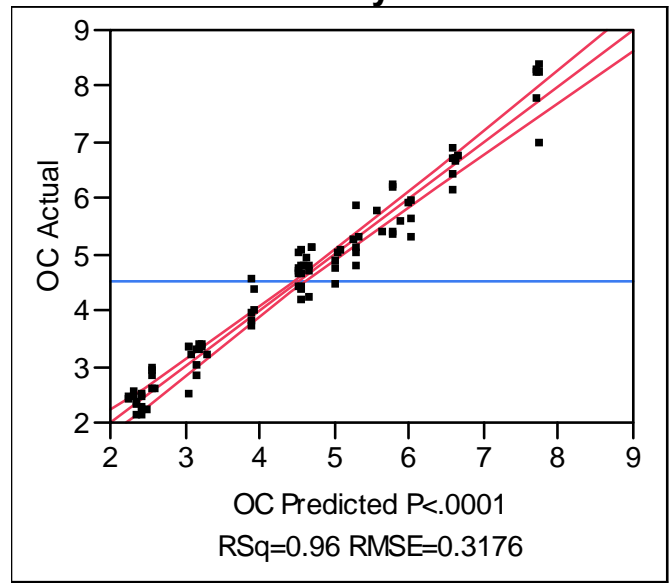

\section{Summary of Fit}

RSquare

RSquare Adj

Root Mean Square Error

Mean of Response

Observations (or Sum Wgts)
0.964542

0.961515

0.317621

4.531778

Analysis of Variance

Source

Model

Error

C. Total

7

82

89
Sum of Squares

225.03113

8.27239

233.30352

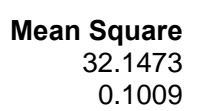

0.1009
F Ratio
318.6599
Prob > F $<.0001$

\section{Lack Of Fit}

Source

Lack Of Fit

Pure Error

Total Error

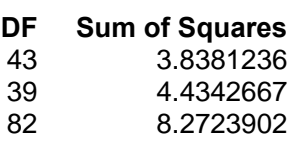

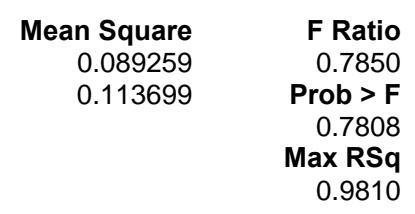

53 


\section{Parameter Estimates}

\section{Term}

Intercept

Speed $(15,30)$

Phi $(0.28,0.38)$

Boost $(14,54)$

Speed*Phi

Speed*Boost

Speed ${ }^{\star}$ Speed

Phi*Phi

$\begin{array}{rrrr}\text { Estimate } & \text { Std Error } & \text { t Ratio } & \text { Prob }>|t| \\ 4.568629 & 0.065044 & 70.24 & <.0001 \\ 1.7662661 & 0.040905 & 43.18 & <.0001 \\ 0.2453224 & 0.041687 & 5.88 & <.0001 \\ 0.7114114 & 0.041818 & 17.01 & <.0001 \\ 0.2976576 & 0.045332 & 6.57 & <.0001 \\ 0.3041245 & 0.046663 & 6.52 & <.0001 \\ -0.268263 & 0.081116 & -3.31 & 0.0014 \\ 0.1921544 & 0.07978 & 2.41 & 0.0183\end{array}$

\section{Residual by Predicted Plot}

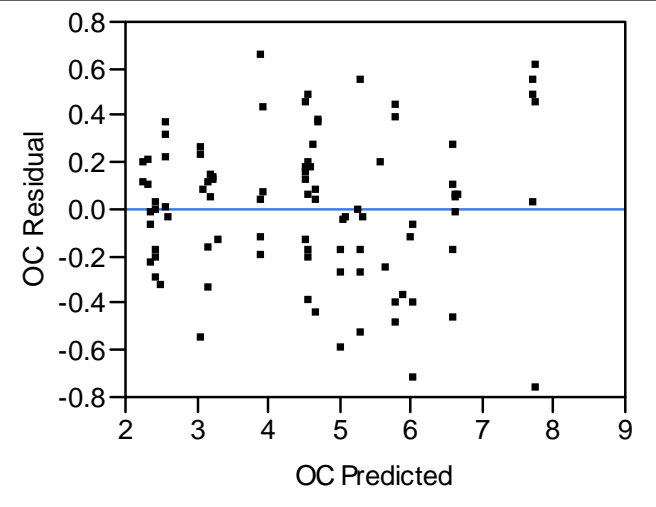

Speed(15,30)

Leverage Plot

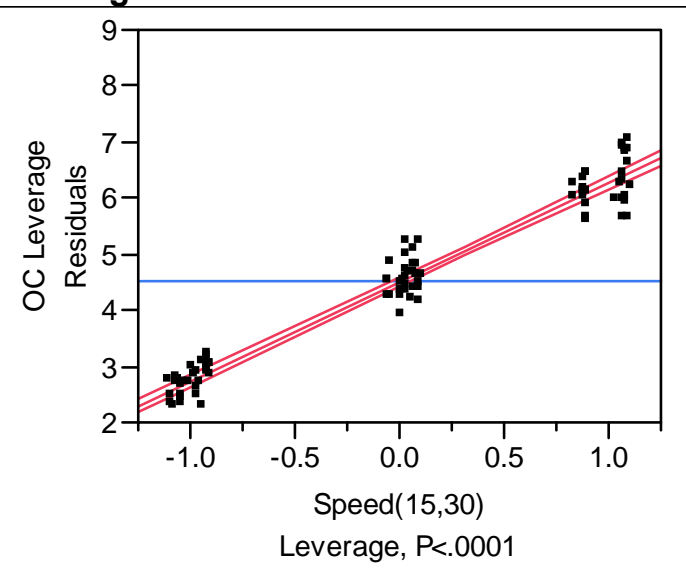

Phi(0.28,0.38)

Leverage Plot

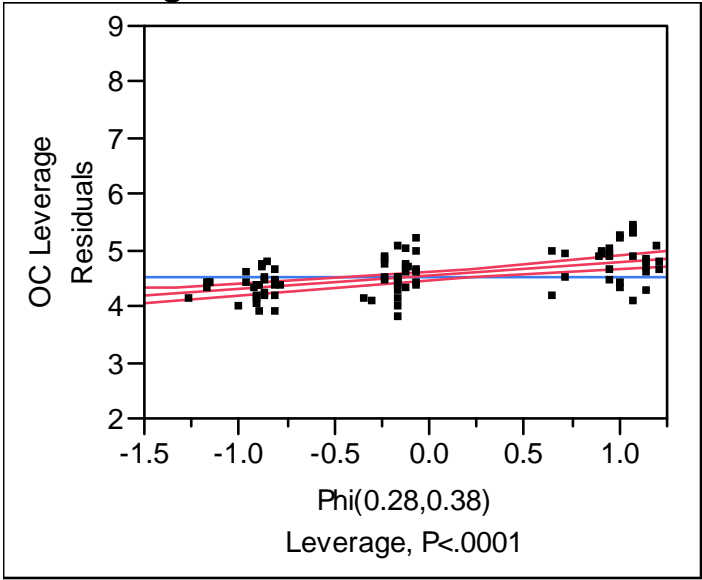


Boost(14,54)
Leverage Plo

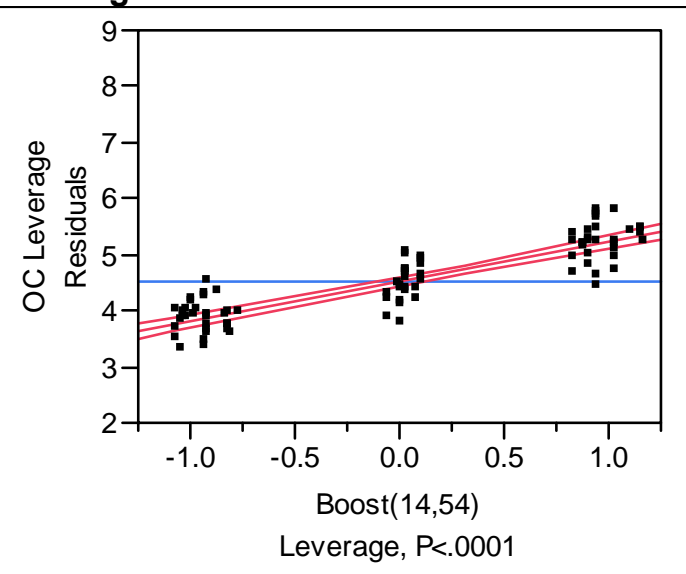

\section{Speed*Boost}

Leverage Plot

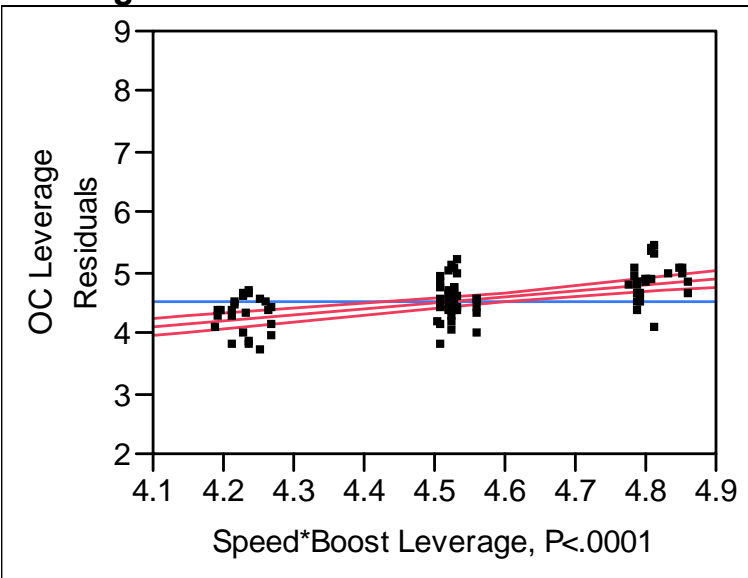

Speed*Phi

Leverage Plot

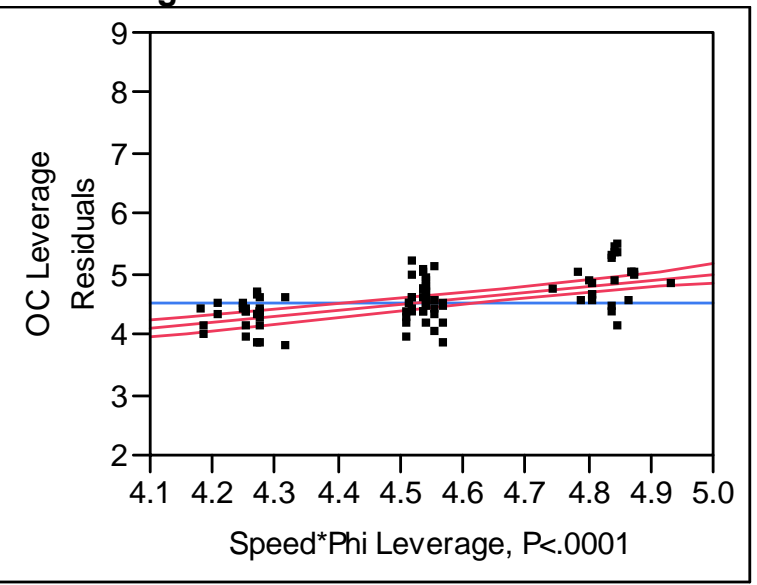

Speed*Speed

Leverage Plot

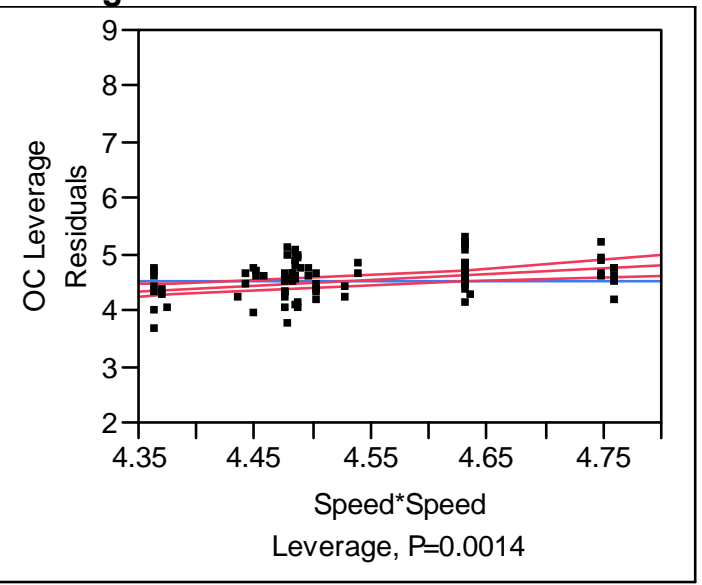

\section{Phi*Phi}

Leverage Plot

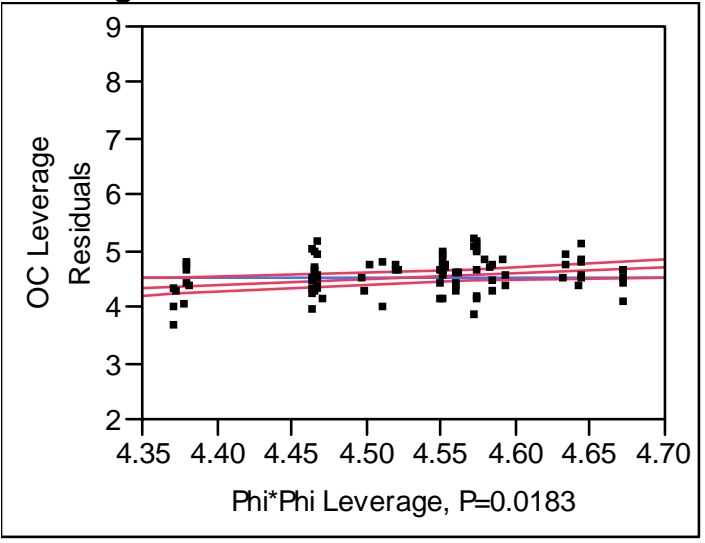

Speed was found to be the largest factor influencing the absolute oil consumption. This can be seen from the t-ratio of the parameter estimates table as well as the speed leverage plot. 
Equivalence ratio, boost, quadratic effects of speed, and equivalence ratio were also significant at the $95 \%$ confidence level. The quadratic time-specific oil consumption $\left(m_{\text {oil }}, \mathrm{g} / \mathrm{hr}\right)$ model based on the stepwise multiple linear regression analysis is given in Equation 5-2.

$$
\begin{aligned}
& m_{\text {oil }}=4.57+1.77 * \text { Speed }+0.245 * \text { Phi }+0.711 * \text { Boost }+0.298 *(\text { Speed } * \text { Phi }) \\
& +0.304 *(\text { Speed } * \text { Boost })-0.268 *(\text { Speed })^{2}+0.192 *(\text { Phi })^{2}
\end{aligned}
$$

Equation 5-2

The variables Speed, Phi, and Boost in the above equation are the coded speed, coded phi, and coded boost, respectively. The above equation was used to obtain time-specific oil consumption behavior over the entire design envelope. The quadratic response is shown in Figure 5-9 below, and the constant speed, phi, and boost slices are also shown in Figures 5-10 through 5-12.

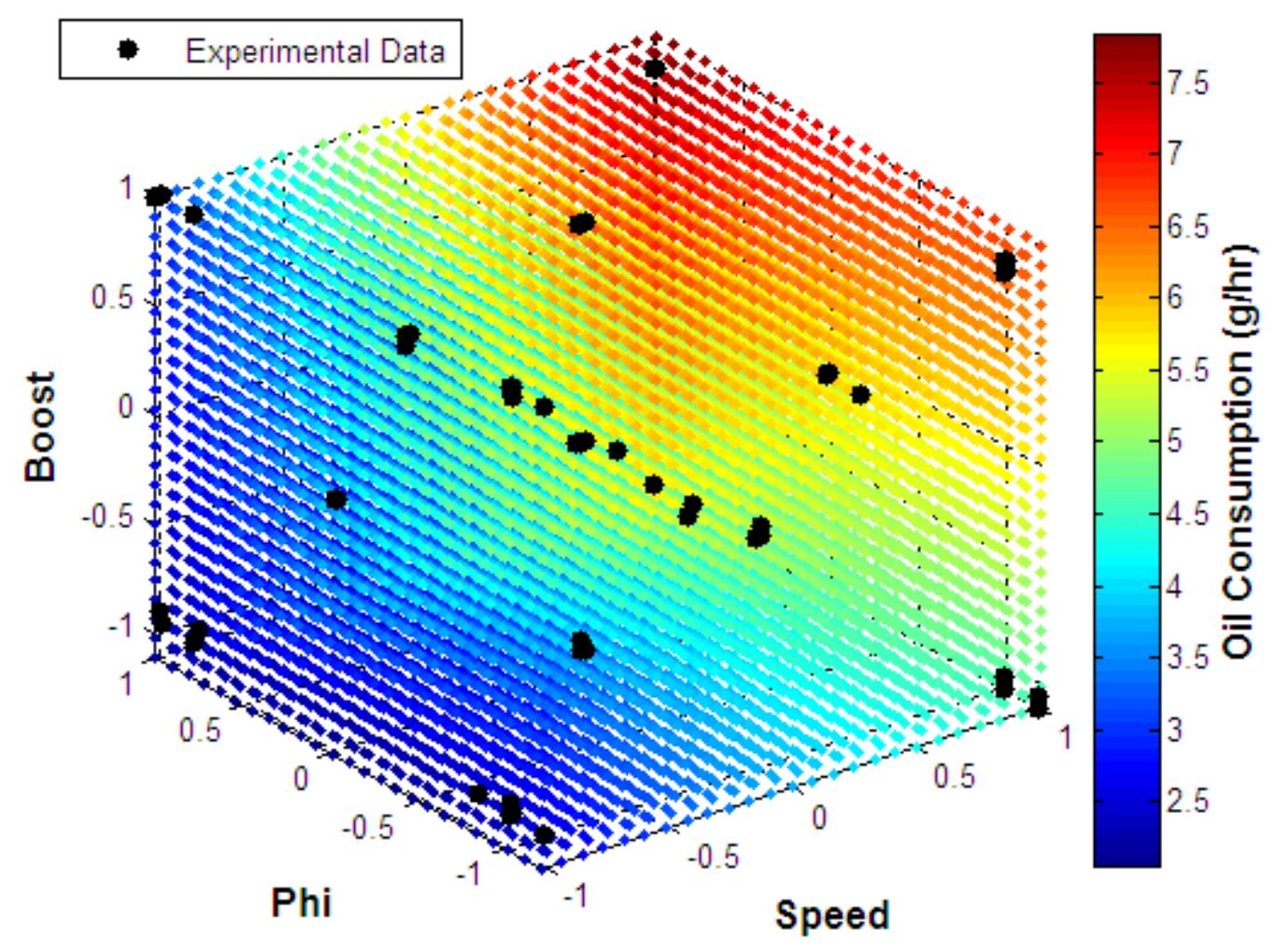

Figure 5-9 Quadratic Time-specific Oil Consumption (g/hr) Model 


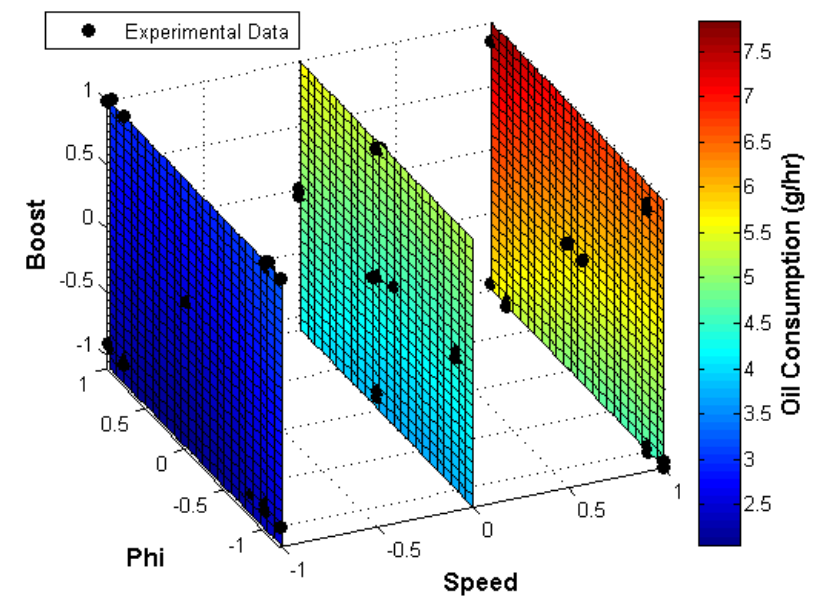

Figure 5-10 Quadratic Time -specific Oil Consumption (g/hr) Model: Constant Speed Steps

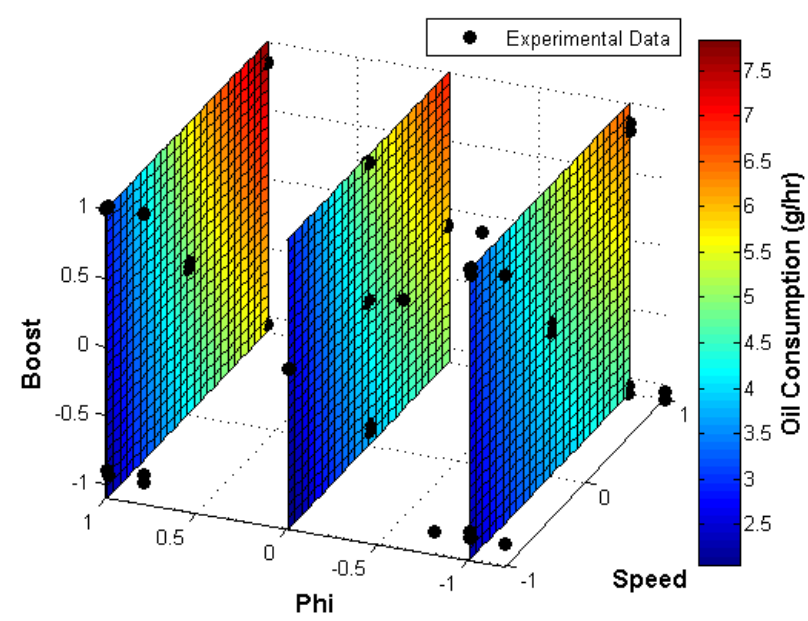

Figure 5-11 Quadratic Time -specific Oil Consumption (g/hr) Model: Constant Phi Steps

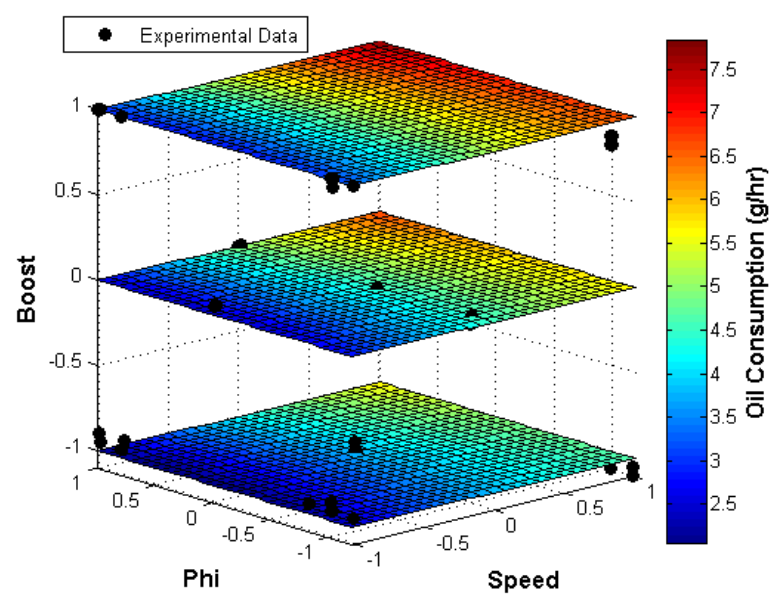

Figure 5-12 Quadratic Time -specific Oil Consumption (g/hr) Model: Constant Boost Steps 
The data clearly indicates increasing absolute oil consumption with increasing speed, equivalence ratio and boost. The diagonal joining the points represented by [(Speed, Phi, Boost) $=(-1,-1,-1)]$ and $[($ Speed, Phi, Boost $)=(1,1,1)]$ in Figure 5-9 can be considered as the line of steepest ascent of absolute oil consumption for the model under consideration. The trend can be better visualized by analyzing slices of constant speed, phi, and boost shown in Figures 5-10 through 5-12.

The results show that time-specific oil consumption determination provides a better fit compared to brake-specific oil consumption. The absolute oil consumption increases with increased speed, equivalence ratio, and boost.

The increase in speed results in increased revolutions and as a result an increase in the amount of oil transported to the combustion chamber may be expected. The effects of speed, phi, and boost can be better explained along with the combustion parameters data given in Table 5-3 and the statistical analysis that follows.

\subsubsection{Influence of Combustion Parameters on Oil Consumption}

The combustion parameters, namely, combustion duration, maximum cylinder pressure and start of combustion were also analyzed as a function of engine speed, phi, and boost using stepwise multiple linear regression. The combustion parameters data is shown in Table 5-3, and was used for the statistical analysis. The exhaust temperature was used as an indicator of the combustion temperature and was also analyzed as a function of engine operating conditions. The exhaust temperature data is shown in Table 5-4.

All of the four above mentioned parameters were found to be well correlated with the engine operating conditions. Reports 5-3 through 5-6 report the statistical analyses. 
Table 5-3 Combustion Parameters Data for the Operating States Tested for the Test Oils

\begin{tabular}{|c|c|c|c|c|c|c|c|c|c|c|c|c|c|c|c|c|c|c|}
\hline \multirow[t]{3}{*}{ State No. } & \multicolumn{6}{|c|}{ Combustion Duration ( ${ }^{\circ} \mathrm{Crank}$ Angle) } & \multicolumn{6}{|c|}{ Maximum Cyclinder Pressure (bar) } & \multicolumn{6}{|c|}{ Start of Combustion ( ${ }^{\circ}$ BTDC) } \\
\hline & \multicolumn{3}{|c|}{ Mineral Oil } & \multicolumn{3}{|c|}{ Synthetic Oil } & \multicolumn{3}{|c|}{ Mineral Oil } & \multicolumn{3}{|c|}{ Synthetic Oil } & \multicolumn{3}{|c|}{ Mineral Oil } & \multicolumn{3}{|c|}{ Synthetic Oil } \\
\hline & Avg & S.D. & COV & Avg & S.D. & COV & $\overline{\text { Avg }}$ & S.D. & COV & Avg & S.D. & COV & Avg & S.D. & COV & Avg & S.D. & COV \\
\hline 1 & 42.4 & 1.68 & 0.02 & 47.4 & 11.07 & 0.12 & 50.0 & 0.54 & 0.01 & 50.0 & 0.77 & 0.01 & -8.3 & 0.23 & 0.01 & -8.3 & 0.38 & 0.02 \\
\hline 2 & 32.8 & 4.20 & 0.064 & 33.4 & 2.414 & 0.04 & 64.1 & 2.54 & 0.02 & 64.4 & 1.24 & 0.01 & $\overline{-6.3}$ & 0.79 & 0.06 & -6.7 & 0.05 & 0.00 \\
\hline 3 & 38.4 & 2.03 & 0.026 & 38.4 & 4.721 & 0.06 & 60.7 & 3.70 & 0.03 & 60.0 & 0.88 & 0.01 & -5.3 & 2.26 & 0.21 & -5.0 & 0.38 & 0.04 \\
\hline 4 & 42.8 & 4.04 & 0.047 & 44.8 & 6.761 & 08 & 55.2 & 2.75 & 0.02 & 54.7 & 4.60 & $\overline{0.04}$ & -2.9 & 1.19 & .20 & -3.0 & 1.29 & 0.21 \\
\hline 5 & 30.7 & 1.73 & 0.028 & 30.8 & 7.732 & 0.13 & 68.3 & 0.62 & 0.00 & 68.2 & 5.11 & 0.04 & -0.8 & 0.25 & 0.16 & -0.8 & 0.82 & 0.50 \\
\hline 6 & 35.7 & 5.07 & 0.071 & 34.7 & 1.724 & 0.02 & 59.3 & 1.23 & 0.01 & 59.3 & 1.38 & 0.01 & -7.5 & 0.77 & 0.05 & -8.0 & 0.27 & 0.02 \\
\hline 7 & 44.7 & 1.42 & 0.016 & 48.4 & 6.483 & 0.07 & 54.5 & 1.97 & 0.02 & 54.0 & 0.52 & 0.00 & -5.7 & 0.64 & 0.06 & -5.5 & 1.22 & 0.11 \\
\hline 8 & 37.9 & 2.39 & 0.032 & 42.7 & 2.97 & 0.03 & 60.7 & 1.32 & 0.01 & 61.8 & 1.52 & 0.01 & -4.7 & 0.65 & 0.07 & -4.9 & 0.83 & 0.08 \\
\hline 9 & 32.8 & 1.09 & 0.017 & 35.6 & 4.647 & 0.07 & 68.2 & 1.72 & 0.01 & 68.1 & 1.76 & 0.01 & -4.1 & 0.78 & .09 & -4.0 & 0.54 & 0.07 \\
\hline 10 & 35.3 & 2.56 & 0.036 & 36.7 & 0.266 & 0.00 & 61.8 & 0.99 & 0.01 & 62.8 & 0.70 & $\overline{0.01}$ & -1.7 & 0.37 & 0.11 & -2.1 & 0.43 & 0.10 \\
\hline 11 & 44.0 & 6.03 & 0.068 & 45.0 & 4.422 & 0.05 & 50.1 & 1.24 & 0.01 & 51.4 & 5.74 & $\overline{0.06}$ & -9.2 & 0.60 & 0.03 & -8.8 & 1.06 & 0.06 \\
\hline 12 & 33.1 & 2.17 & 0.033 & 31.9 & 3.565 & 0.06 & 65.0 & 2.20 & 0.02 & 64.4 & 0.61 & 0.00 & -6.9 & 0.41 & 0.03 & -6.9 & 0.45 & 0.03 \\
\hline 13 & 38.0 & 5.10 & 0.067 & 37.3 & 1.143 & 0.02 & 59.5 & 1.97 & 0.02 & 59.6 & 0.14 & 0.00 & -5.1 & 0.25 & 0.02 & -5.1 & 0.47 & 0.05 \\
\hline 14 & 41.7 & 4.46 & 0.054 & 43.7 & 2.032 & 0.02 & $\overline{52.4}$ & 1.57 & 0.02 & 51.6 & 3.05 & 0.03 & -2.5 & 0.42 & .08 & -2.3 & 1.08 & 0.23 \\
\hline 15 & 29.8 & 1.57 & 0.026 & 29.4 & 0.389 & 0.01 & 61.7 & $\overline{1.18}$ & 0.01 & 62.5 & 0.31 & $\overline{0.00}$ & $\overline{0.7}$ & 0.37 & 0.26 & 0.5 & 0.54 & 0.58 \\
\hline
\end{tabular}


Table 5-4 Exhaust Temperature Data for the Operating States Tested for the Test Oils

\begin{tabular}{|c|c|c|c|c|c|c|}
\hline \multirow{3}{*}{ State No. } & \multicolumn{4}{|c|}{ Exhaust Temperature $\left({ }^{\circ} \mathrm{C}\right)$} \\
\cline { 2 - 7 } & \multicolumn{3}{|c|}{ Mineral Oil } & \multicolumn{3}{c|}{ Synthetic Oil } \\
\cline { 2 - 7 } & Avg & S.D. & COV & Avg & S.D. & COV \\
\hline 1 & 232.9 & 2.8 & 0.01 & 234.8 & 6.8 & 0.01 \\
\hline 2 & 234.1 & 7.6 & 0.02 & 236.1 & 4.5 & 0.01 \\
\hline 3 & 269.3 & 5.0 & 0.01 & 270.1 & 2.5 & 0.00 \\
\hline 4 & 300.1 & 3.2 & 0.01 & 298.4 & 9.2 & 0.02 \\
\hline 5 & 305.4 & 0.2 & 0.00 & 304.4 & 13.0 & 0.02 \\
\hline 6 & 254.6 & 2.8 & 0.01 & 256.6 & 1.3 & 0.00 \\
\hline 7 & 300.3 & 2.0 & 0.00 & 300.9 & 5.6 & 0.01 \\
\hline 8 & 293.7 & 4.3 & 0.01 & 299.6 & 7.8 & 0.01 \\
\hline 9 & 297 & 0.6 & 0.00 & 298.7 & 6.1 & 0.01 \\
\hline 10 & 332.8 & 1.4 & 0.00 & 334.6 & 1.0 & 0.00 \\
\hline 11 & 274.1 & 2.2 & 0.00 & 275.4 & 7.4 & 0.01 \\
\hline 12 & 268.3 & 5.3 & 0.01 & 270.1 & 3.0 & 0.01 \\
\hline 13 & 316.1 & 12.4 & 0.02 & 320 & 3.7 & 0.01 \\
\hline 14 & 358.3 & 4.2 & 0.01 & 357.7 & 4.8 & 0.01 \\
\hline 15 & 359 & 2.6 & 0.00 & 365.4 & 12.6 & 0.02 \\
\hline
\end{tabular}

Report 5-3 Statistical Analysis Report of the Stepwise Multiple Linear Regression of Combustion Duration (CD) Data

Whole Model Actual by Predicted Plot

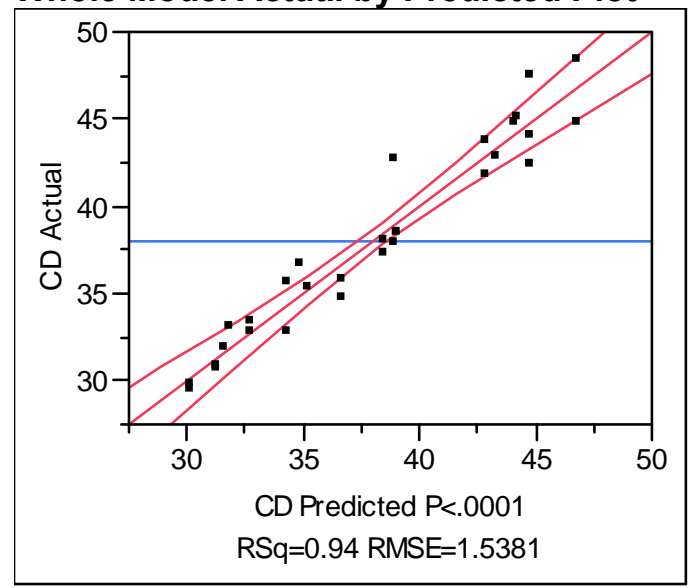

Summary of Fit

RSquare

RSquare Adj

0.923584

Root Mean Square Error

Mean of Response

1.538134

Observations (or Sum Wgts)

38.01
30 


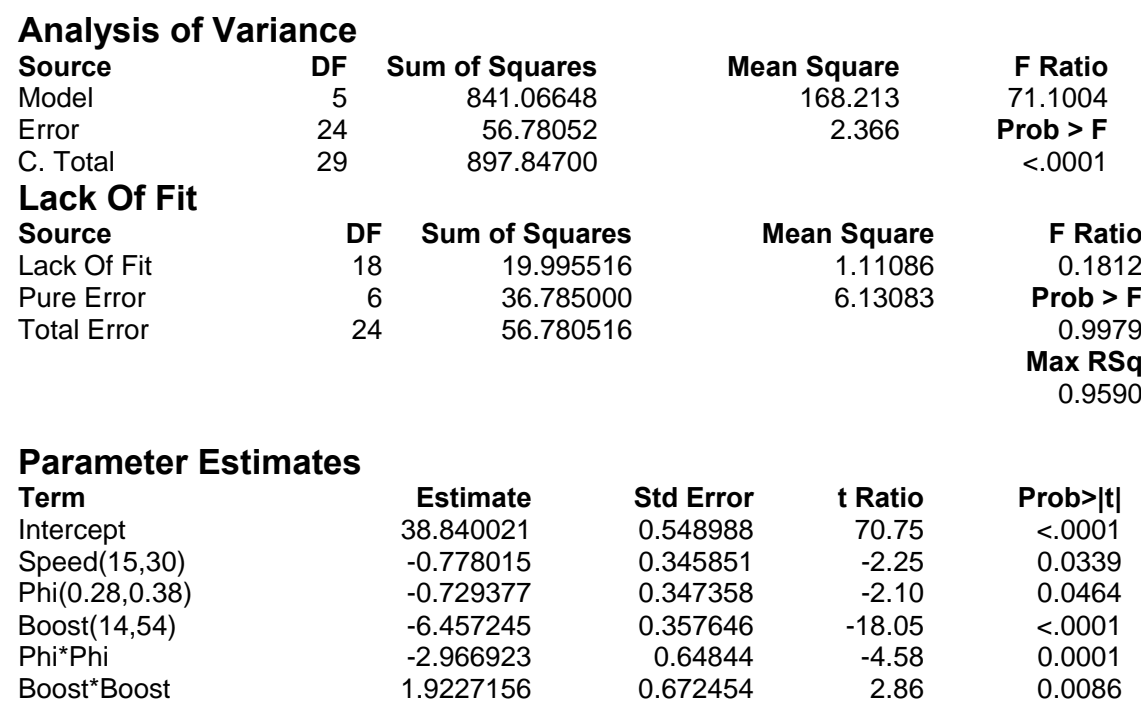

\section{Residual by Predicted Plot}

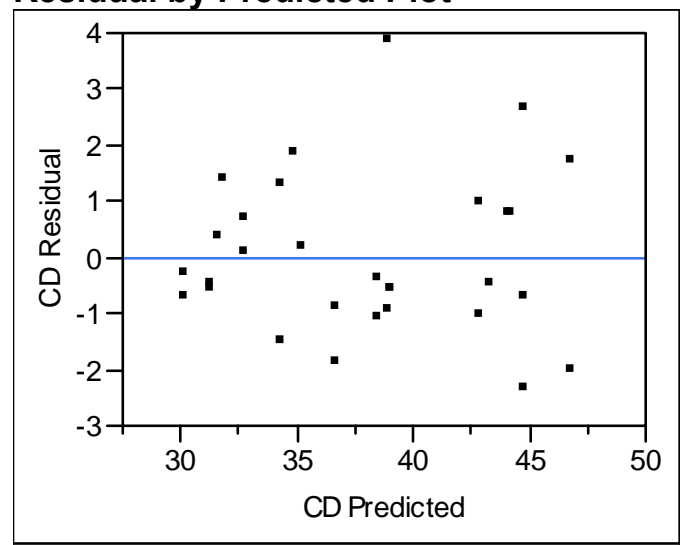

Speed(15,30)

Phi(0.28,0.38)

Leverage Plot

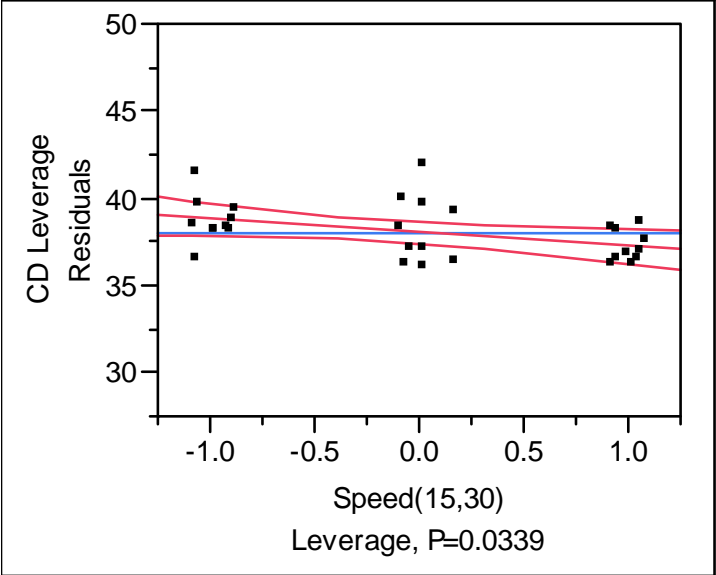

Leverage Plot

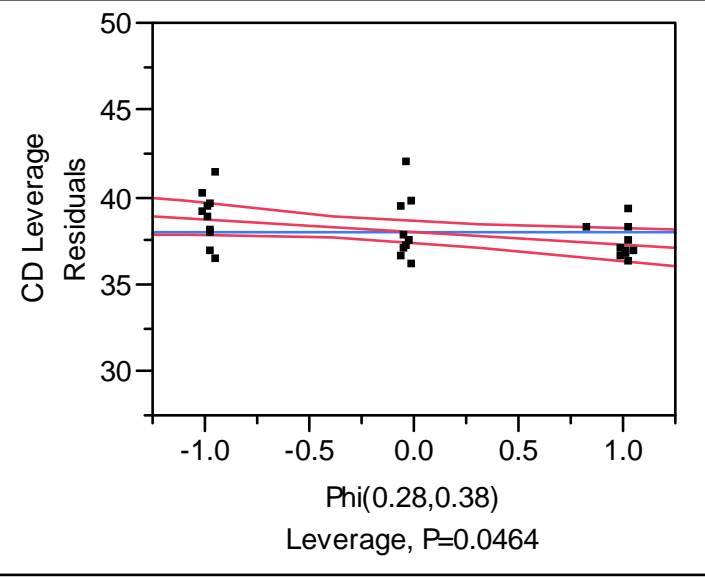


Boost $(14,54)$

Leverage Plot

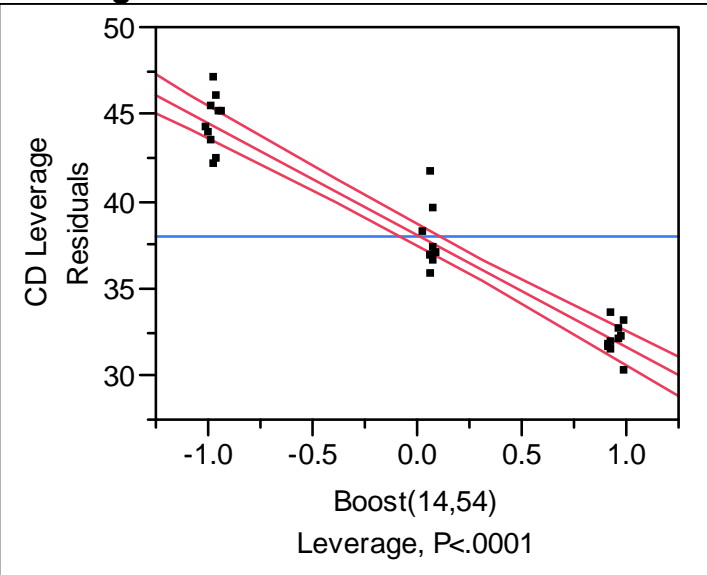

Boost*Boost

Leverage Plot

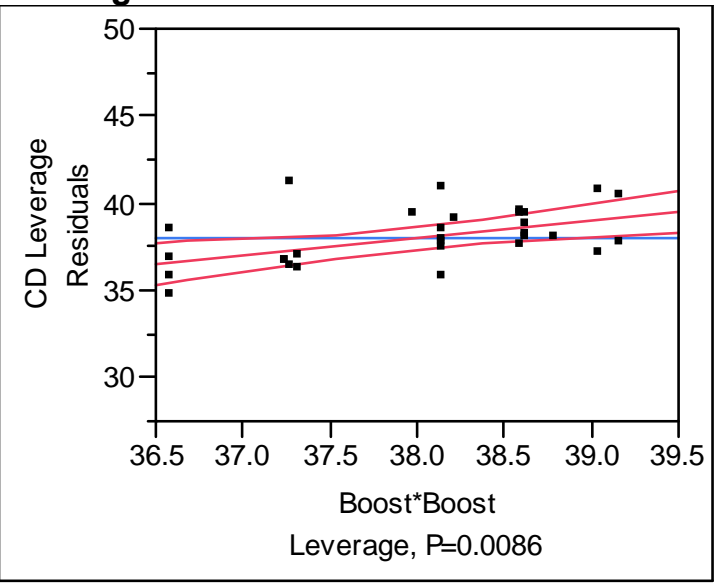

Phi*Phi

Leverage Plot

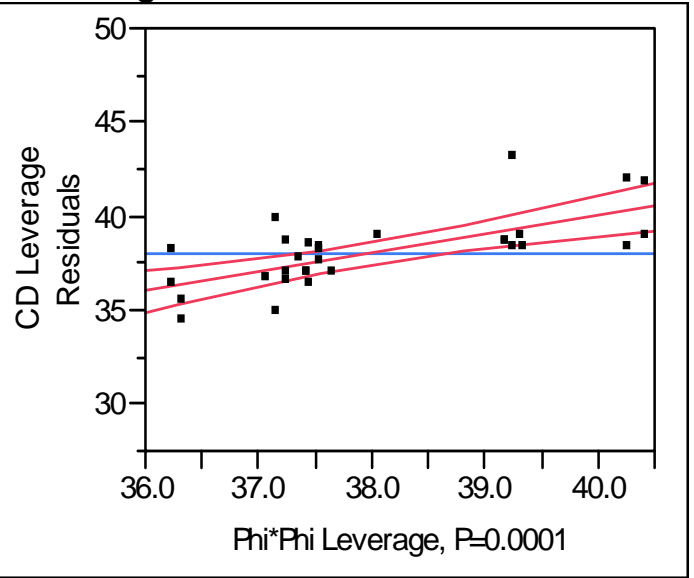




\section{Report 5-4 Statistical Analysis Report of the Stepwise Multiple Linear Regression of Maximum Cylinder Pressure (Pmax) Data}

\section{Whole Model Actual by Predicted Plot}

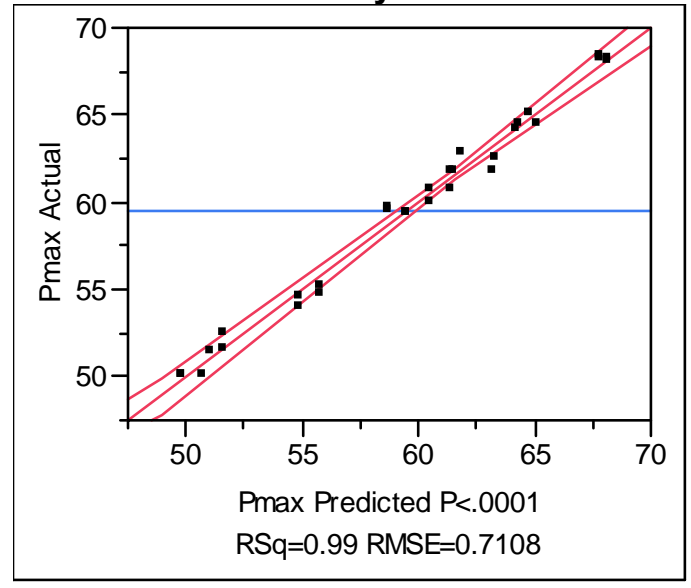

\section{Summary of Fit}

RSquare

RSquare Adj

Root Mean Square Error

Mean of Response

Observations (or Sum Wgts)
0.988715

0.985124

0.710756

59.47667

30

Analysis of Variance

Source

Model

Error

C. Total

Lack Of Fit

Source

Lack Of Fit

Pure Error

Total Error

$\begin{array}{rr}\text { DF } & \text { Sum of Squares } \\ 7 & 973.67982 \\ 22 & 11.11384 \\ 29 & 984.79367\end{array}$

DF

16

6

22
Sum of Squares

9.813843

1.300000

11.113843

\section{Mean Square \\ 139.097 \\ 0.505}

Mean Square

0.613365

0.216667

\section{Parameter Estimates}

\section{Term}

Intercept

Speed $(15,30)$

Phi $(0.28,0.38)$

Boost $(14,54)$

Speed*Phi

Phi*Boost

Speed*Speed

Phi*Phi

$\begin{array}{rr}\text { Estimate } & \text { Std Error } \\ 61.323131 & 0.254974 \\ -0.381407 & 0.159716 \\ 1.0242259 & 0.160666 \\ 6.7962999 & 0.165179 \\ -1.381211 & 0.180932 \\ -0.623102 & 0.187447 \\ -1.978252 & 0.299328 \\ -0.912087 & 0.302097\end{array}$

t Ratio

240.51

$-2.39$

6.37

41.15

$-7.63$

$-3.32$

$-6.61$

$-3.02$

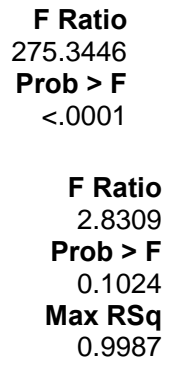

F Ratio 275.3446

Prob > F $<.0001$

$$
\begin{array}{r}
\text { F Ratio } \\
2.8309 \\
\text { Prob }>\text { F } \\
0.1024 \\
\text { Max RSq } \\
0.9987
\end{array}
$$

Prob $>|t|$

$<.0001$

0.0260

$<.0001$

$<.0001$

$<.0001$

0.0031

$<.0001$

0.0063 


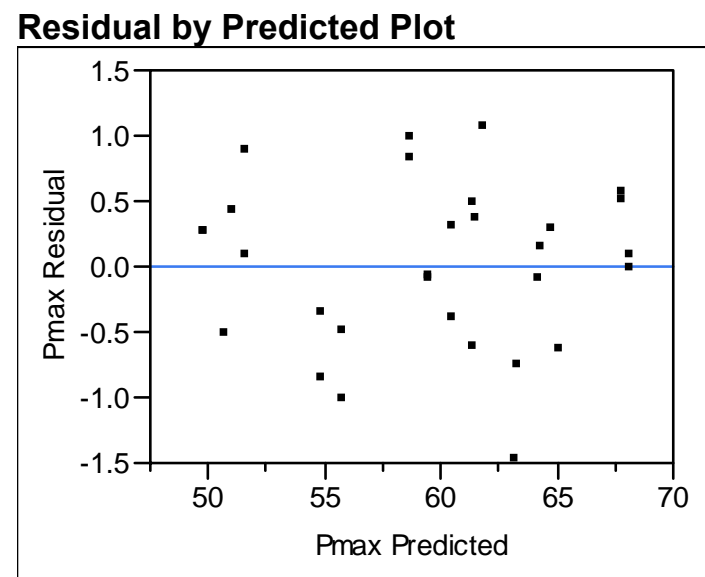

Speed(15,30)

Leverage Plot

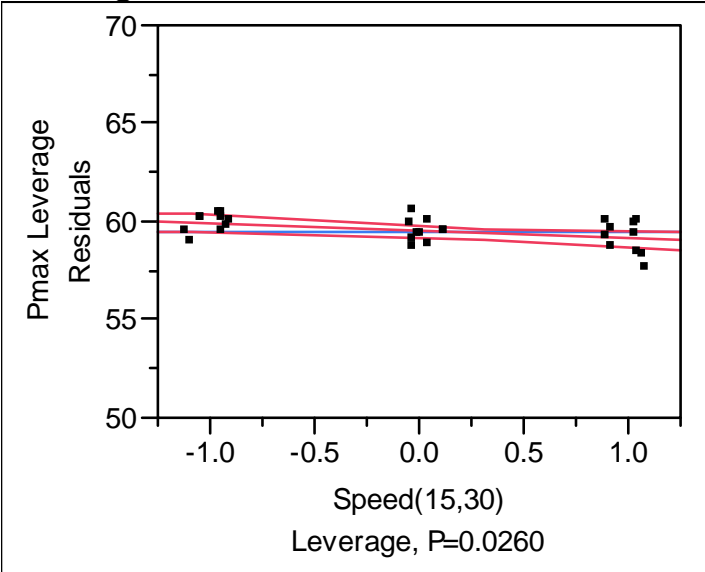

Boost(14,54)

Leverage Plot

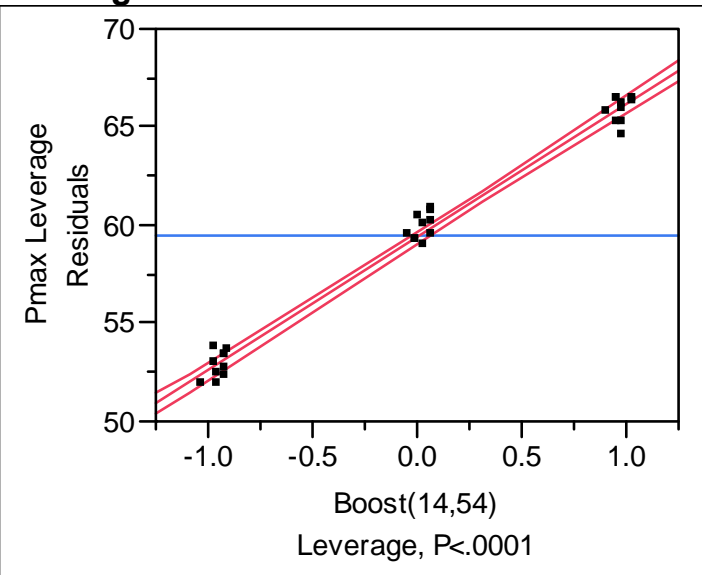

Phi(0.28,0.38)

Leverage Plot

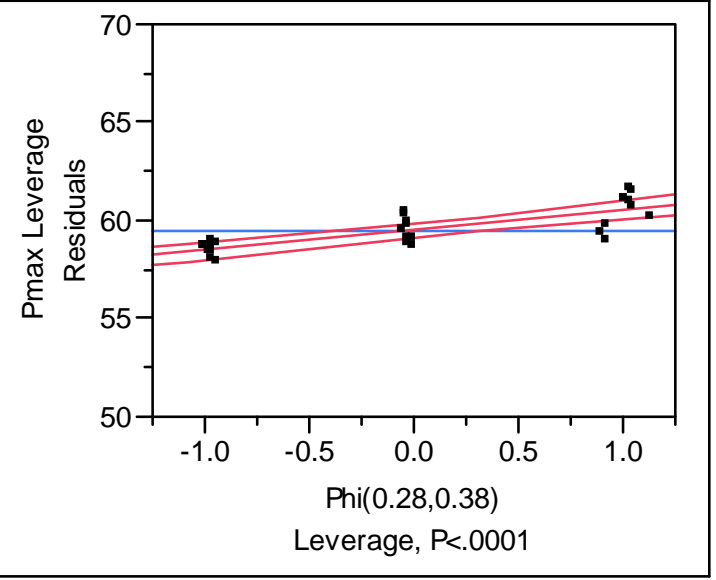

Speed*Phi

Leverage Plot

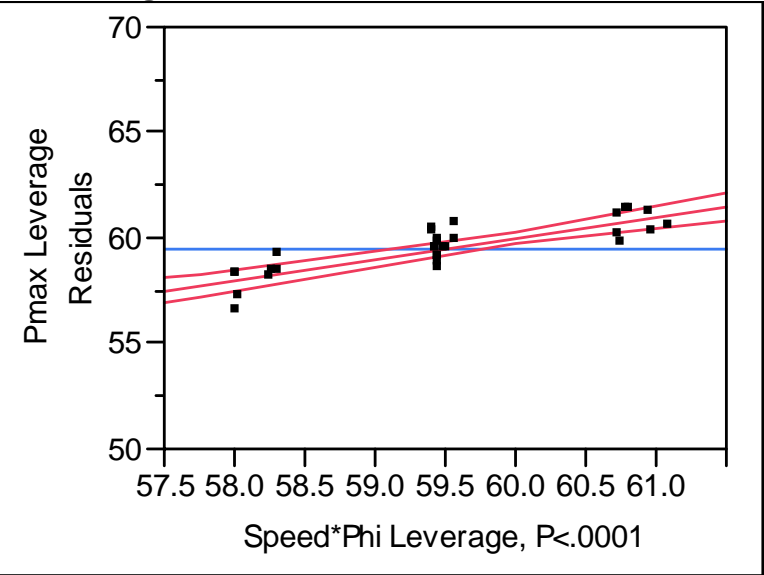




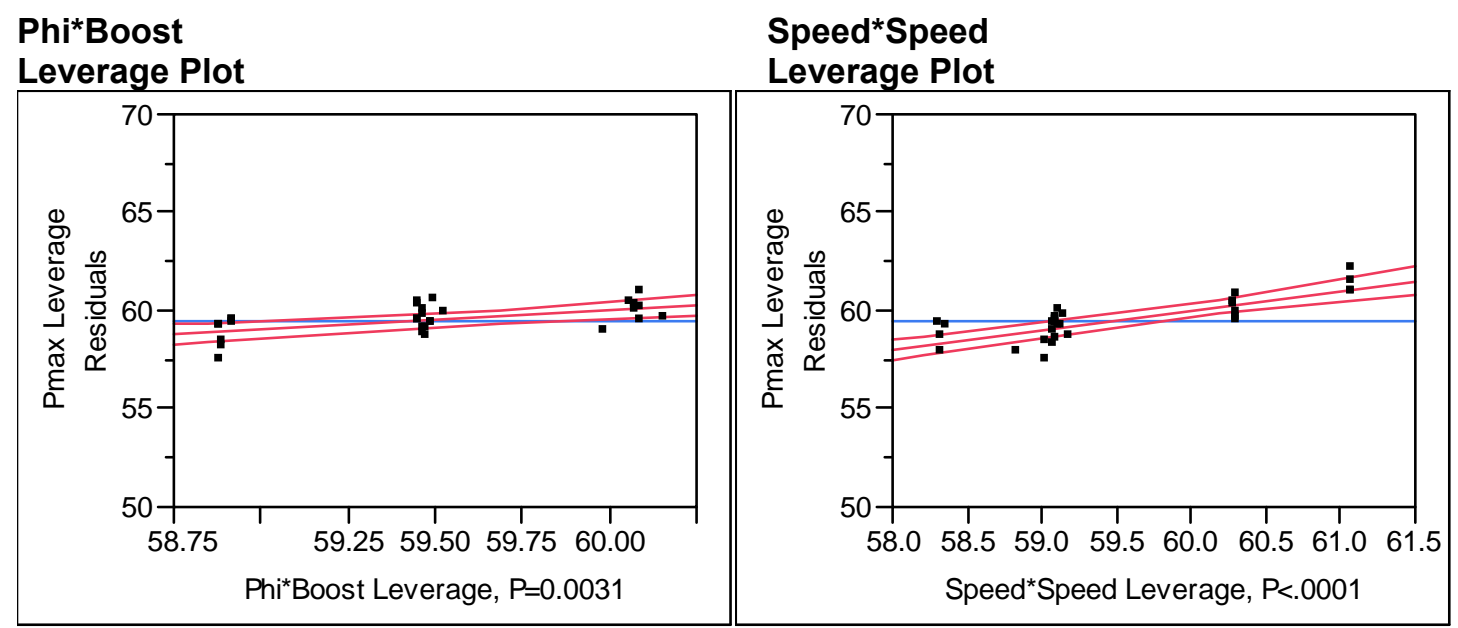

\section{PhiPhi}

Leverage Plot

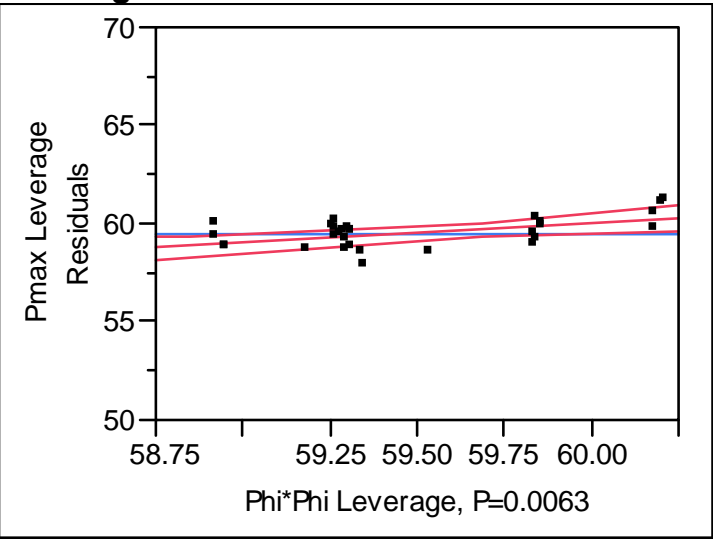

Report 5-5 Statistical Analysis Report of the Stepwise Multiple Linear Regression of Start of Combustion (SOC) Data

Whole Model Actual by Predicted Plot

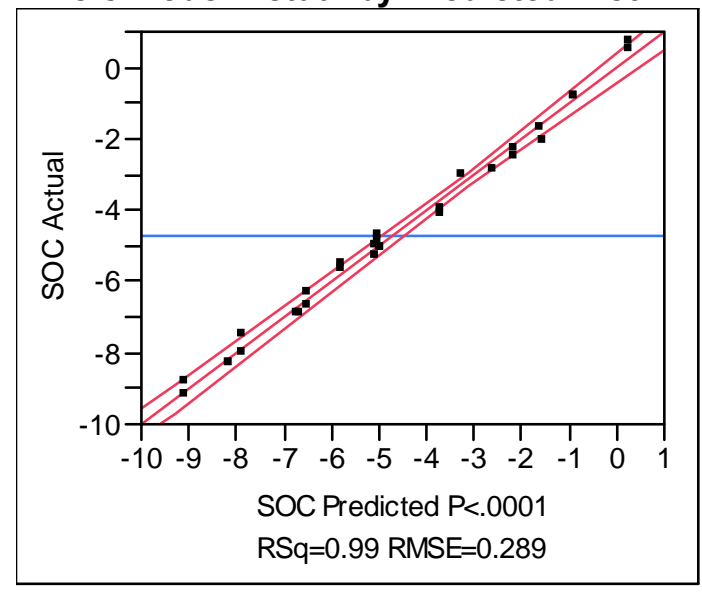




\section{Summary of Fit}

$\begin{array}{lr}\text { RSquare } & 0.991664 \\ \text { RSquare Adj } & 0.989012 \\ \text { Root Mean Square Error } & 0.288954 \\ \text { Mean of Response } & -4.70667 \\ \text { Observations (or Sum Wgts) } & 30\end{array}$

\section{Analysis of Variance}

$\begin{array}{lrr}\text { Source } & \text { DF } & \text { Sum of Squares } \\ \text { Model } & 7 & 218.52179 \\ \text { Error } & 22 & 1.83688 \\ \text { C. Total } & 29 & 220.35867\end{array}$

Mean Square F Ratio

$31.2174 \quad 373.8854$

0.0835 Prob $>$ F

$<.0001$

\section{Lack Of Fit}

Source

Lack Of Fit

Pure Error

Total Error

$\begin{array}{rr}\text { DF } & \text { Sum of Squares } \\ 16 & 1.7268806 \\ 6 & 0.1100000 \\ 22 & 1.8368806\end{array}$

$\begin{array}{rr}\text { Mean Square } & \text { F Ratio } \\ 0.107930 & 5.8871 \\ 0.018333 & \text { Prob }>\text { F } \\ & 0.0187 \\ & \text { Max RSq } \\ & 0.9995\end{array}$

Parameter Estimates

Term

Intercept

Speed $(15,30)$

Phi $(0.28,0.38)$

Boost $(14,54)$

Speed*Phi

Speed*Boost

Phi*Phi

Boost*Boost

Estimate
-5.055055
0.1361531
3.1192207
1.0592752
0.3371114
0.2437026
0.280601
0.2899599

Std Error

0.103876

0.064981

$\begin{array}{rr}\text { t Ratio } & \text { Prob }>|\mathbf{t}| \\ -48.66 & <.0001 \\ 2.10 & 0.0479\end{array}$

0.065282

0.067191

0.073235

0.077627

0.121998

0.130053

47.78

15.77

4.60

3.14

2.30

2.23

$<.0001$

$<.0001$

0.0001

0.0048

0.0313

0.0363

\section{Residual by Predicted Plot}

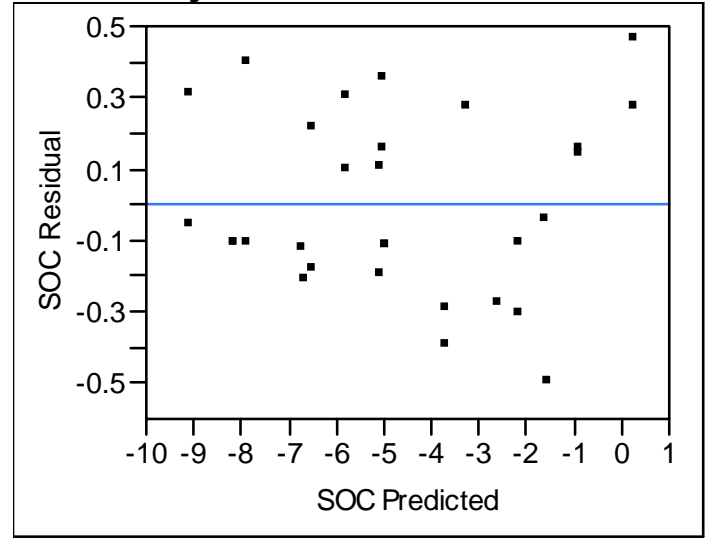




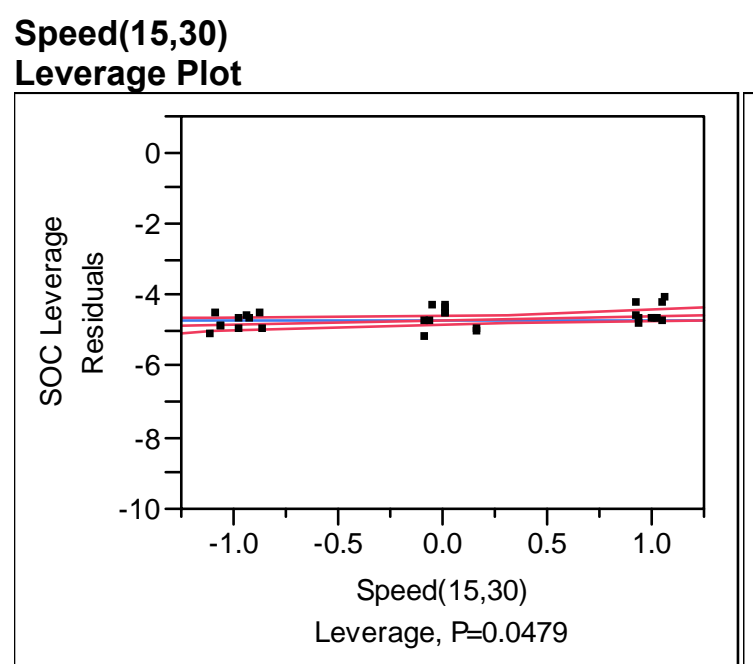

Boost(14,54)

Leverage Plot

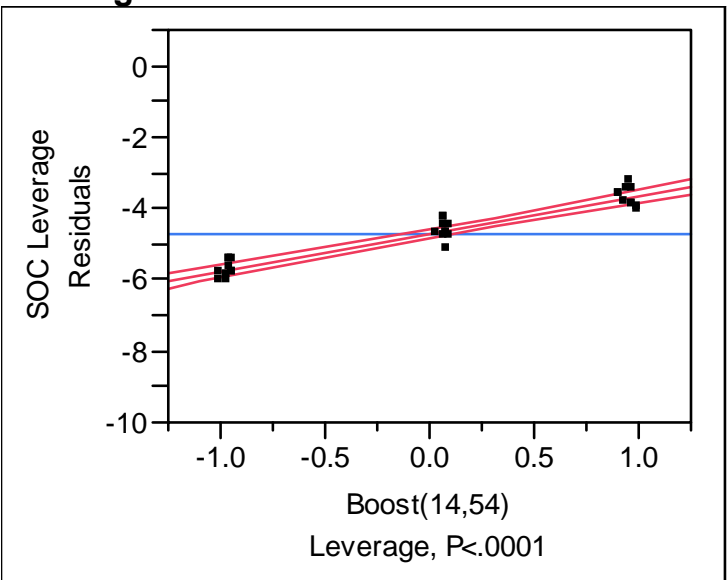

Speed*Boost

Leverage Plot

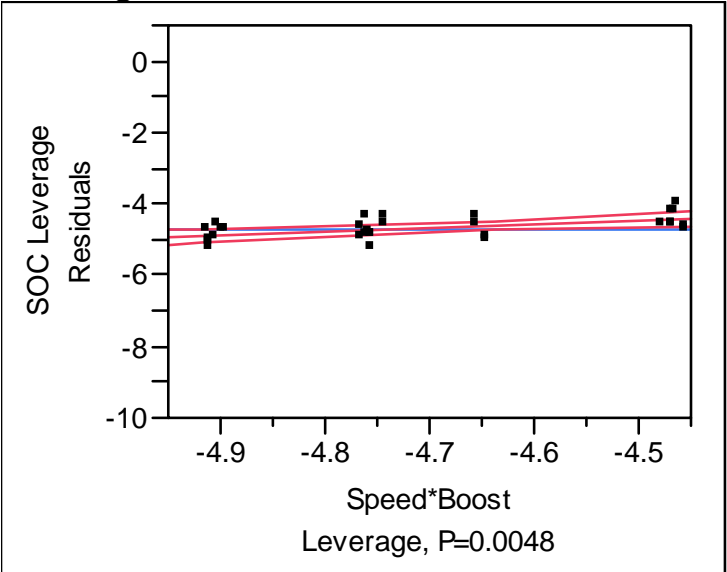

Phi(0.28,0.38)

Leverage Plot

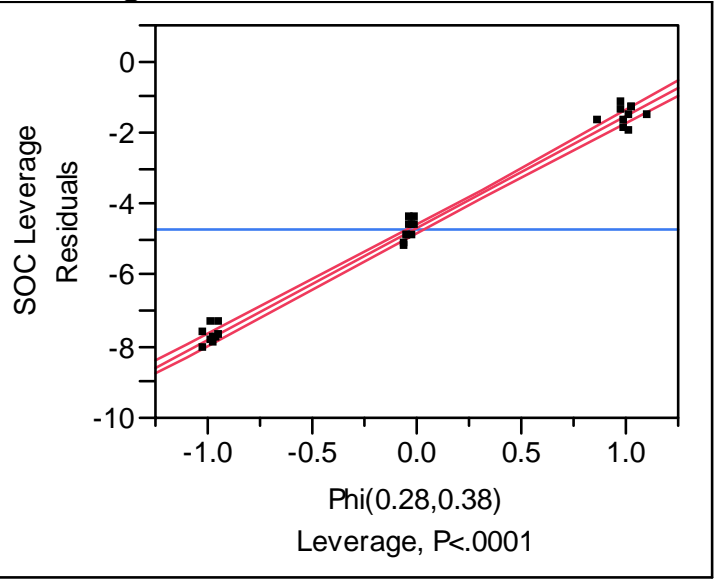

Speed*Phi

Leverage Plot

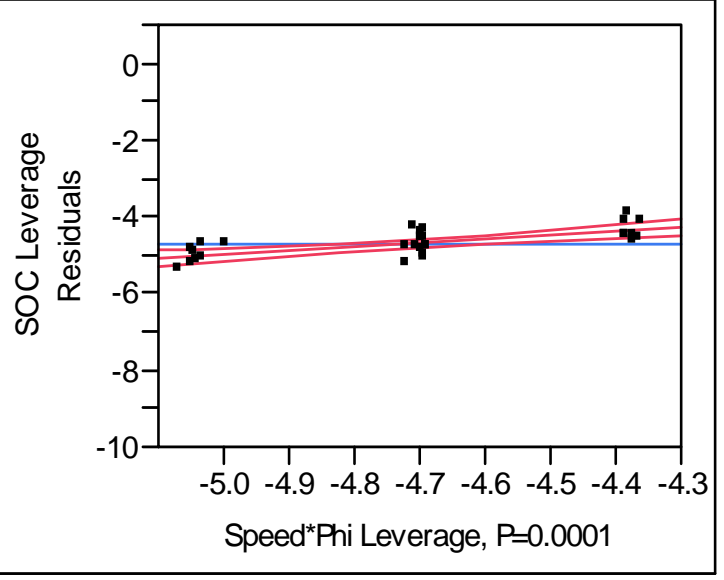

\section{Phi*Phi}

Leverage Plot

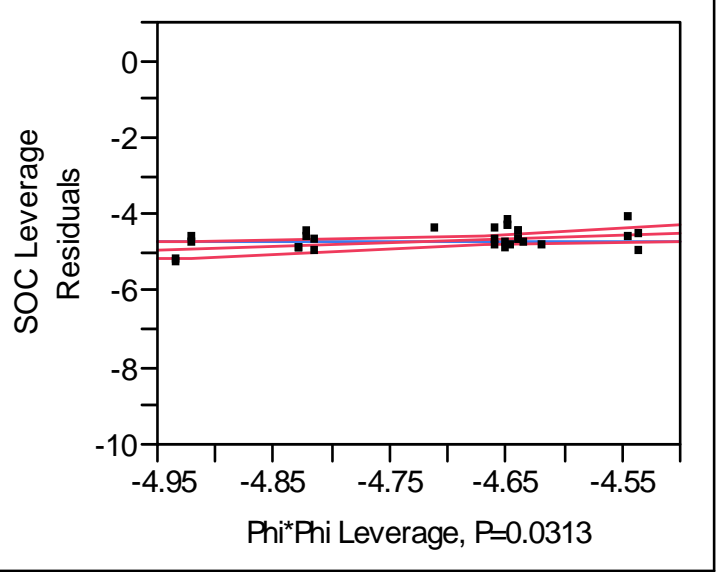




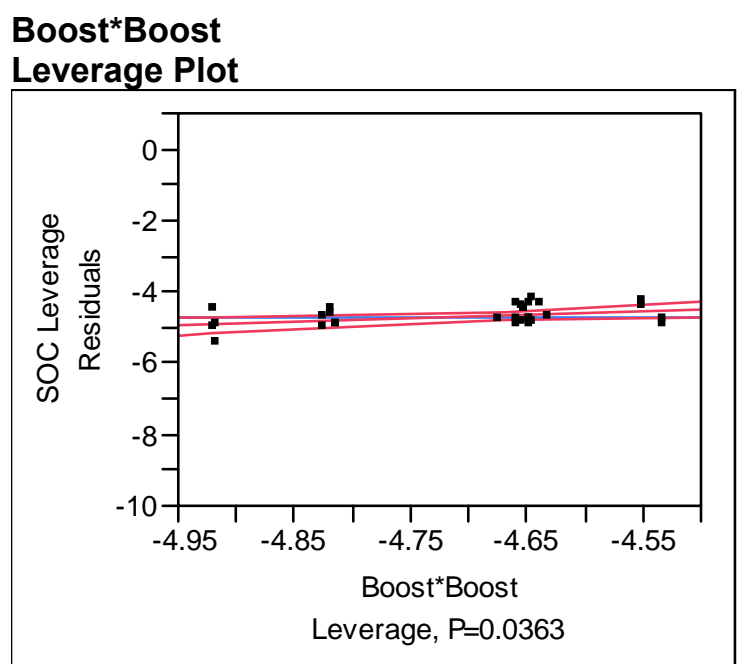

Report 5-6 Statistical Analysis Report of the Stepwise Multiple Linear Regression of Exhaust Temperature (Exhaust T) Data

Whole Model Actual by Predicted Plot

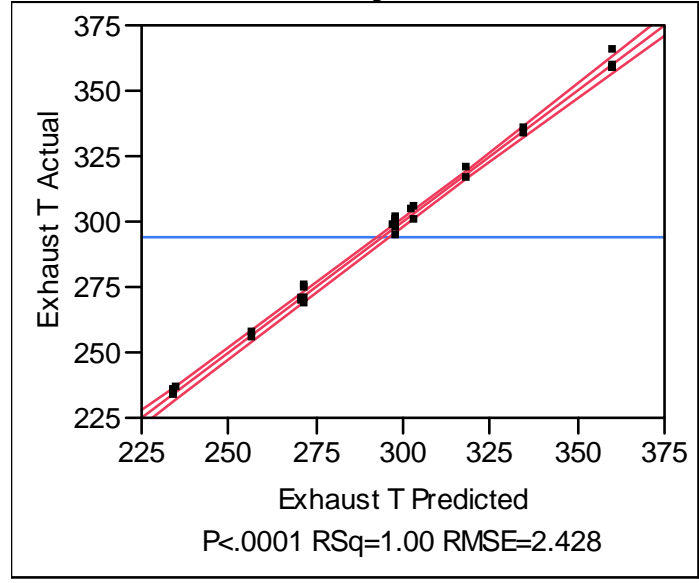

Summary of Fit

RSquare

RSquare Adj

Root Mean Square Error

Mean of Response

Observations (or Sum Wgts)
0.996672

0.995979

2.427951

293.9333

Analysis of Variance

Source

Model

Error

C. Total

5

24

29
Sum of Squares

42376.388

141.479

42517.867

$\begin{array}{rr}\text { Mean Square } & \text { F Ratio } \\ 8475.28 & 1437.719 \\ 5.89 & \text { Prob > F } \\ & <.0001\end{array}$




\section{Lack Of Fit}

Source

Lack Of Fit

Pure Error

Total Error

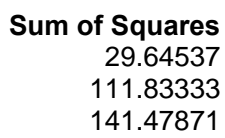

\section{Mean Square \\ 2.96454 \\ 7.98810 \\ F Ratio \\ 0.3711 \\ Prob > F \\ 0.9398 \\ Max RSq \\ 0.9974}

\section{Parameter Estimates}

Term

Intercept

Speed $(15,30)$

Phi $(0.28,0.38)$

Speed*Phi

Speed ${ }^{\star}$ Speed

Phi*Phi

$\begin{array}{rr}\text { Estimate } & \text { Std Error } \\ 298.07553 & 0.870835 \\ 23.704624 & 0.544038 \\ 39.159636 & 0.548382 \\ 4.9243973 & 0.615128 \\ -3.511783 & 1.022442 \\ -2.492186 & 1.030644\end{array}$

Prob $>|t|$

$<.0001$

$<.0001$

$<.0001$

$<.0001$

0.0022

\section{Residual by Predicted Plot}

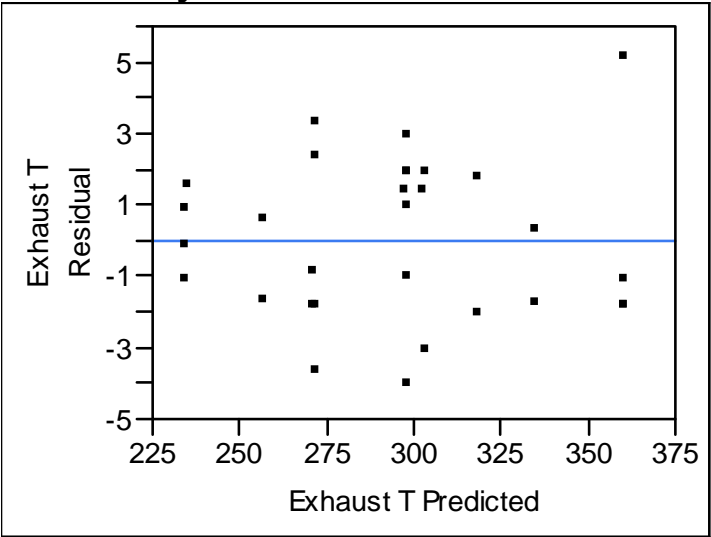

Speed(15,30)

Leverage Plot

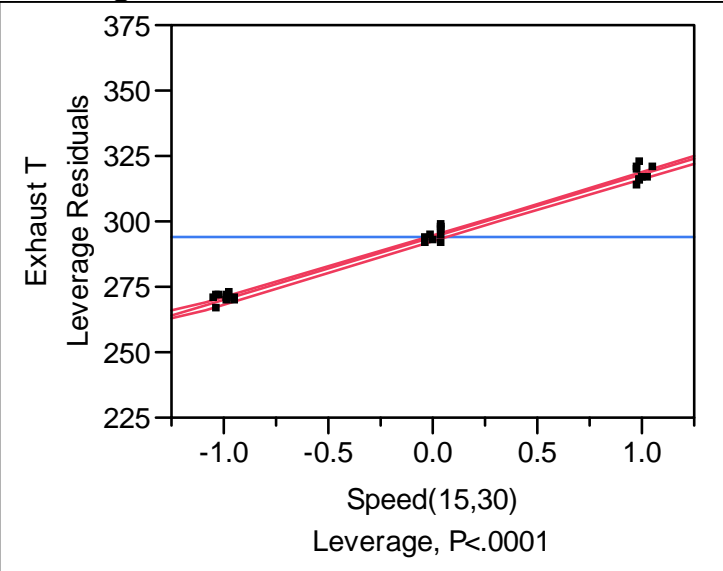

Phi(0.28,0.38)

Leverage Plot

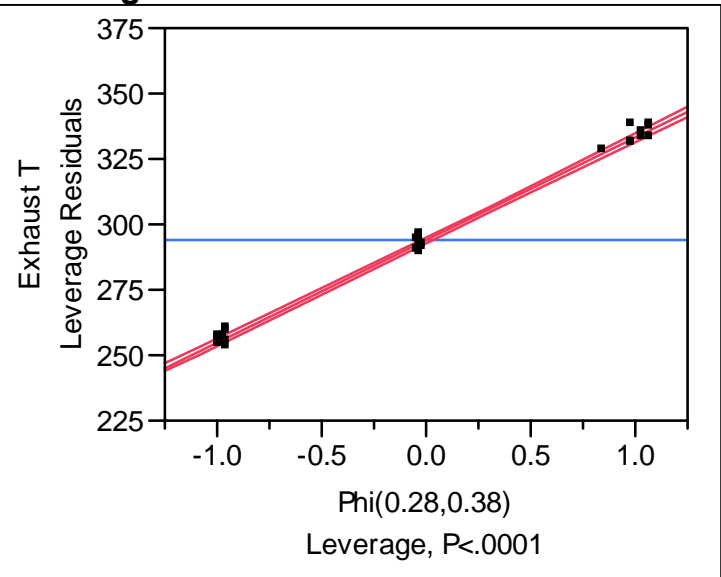



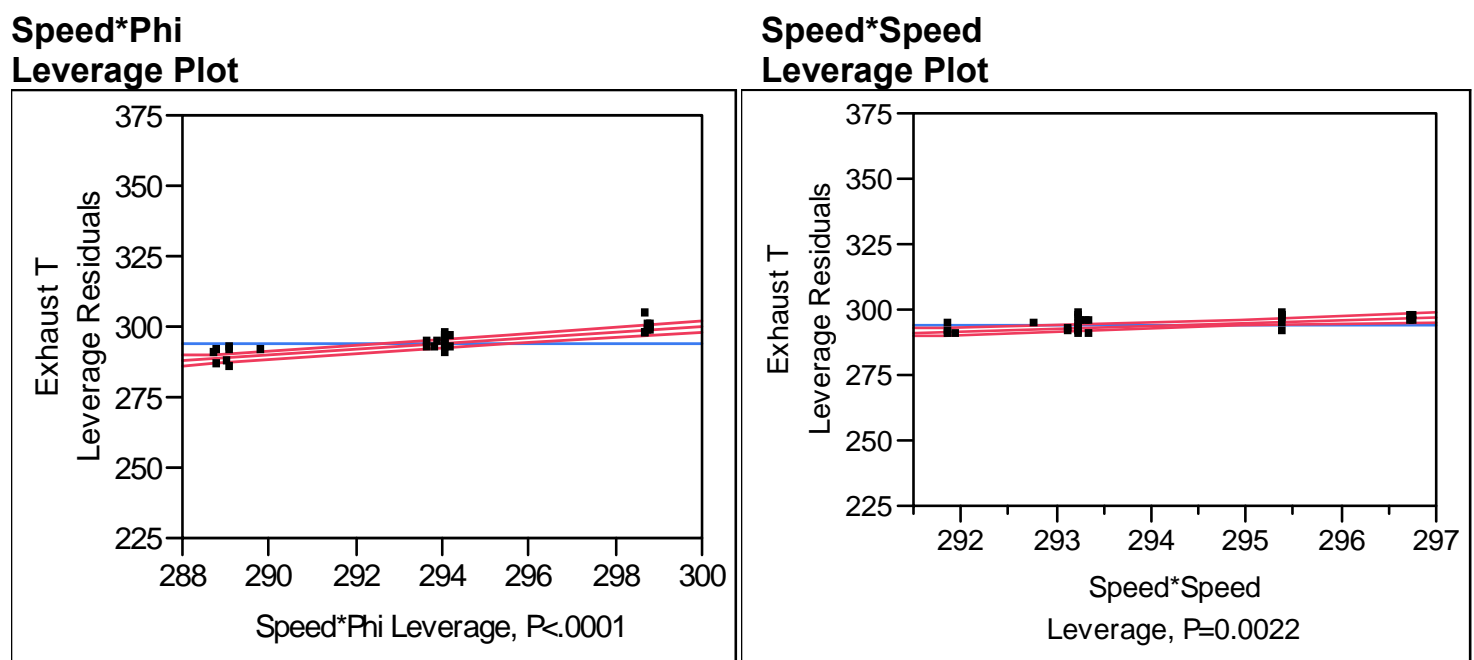

Phi*Phi

Leverage Plot

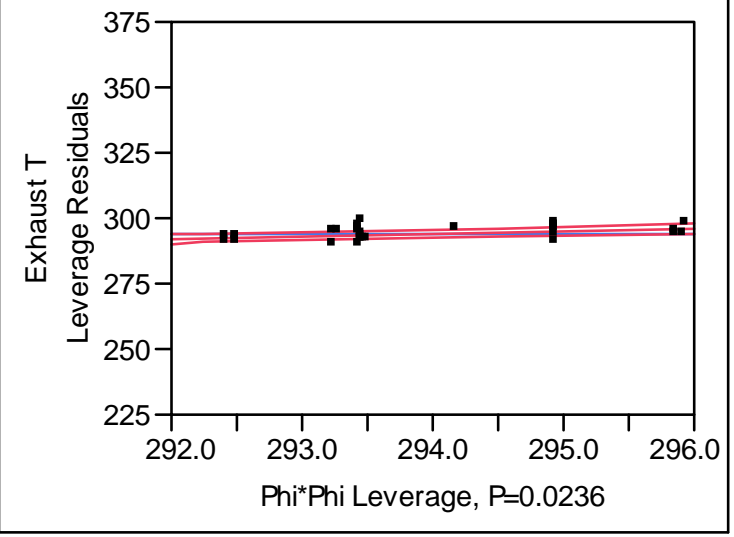

The combustion parameters, namely, combustion duration (CD, crank angle degrees), maximum cylinder pressure (Pmax, bar), start of combustion (SOC, ${ }^{\circ}$ BTDC), and exhaust temperature (Exhaust $\mathrm{T},{ }^{\circ} \mathrm{C}$ ) models based on the stepwise multiple linear regression analyses are given in Equations 5-3 through 5-6.

$$
C D=38.8-0.778 * \text { Speed }-0.729 * \text { Phi }-6.46 * \text { Boost }-2.97 *(\text { Phi })^{2}+1.92 *(\text { Boost })^{2}
$$

Equation 5-3

$$
\begin{aligned}
& P \max =61.3-0.381 * \text { Speed }+1.02 * \text { Phi }+6.80 * \text { Boost }-1.38 *\left(\text { Speed }^{*} \text { Phi }\right) \\
& -0.623 *(\text { Phi } * \text { Boost })-1.98 *(\text { Speed })^{2}-0.912 *(\text { Phi })^{2}
\end{aligned}
$$

Equation 5-4 


$$
\begin{aligned}
& \text { SOC }=-5.1+0.14 * \text { Speed }+3.1 * \text { Phi }+1.1 * \text { Boost }+0.34 *(\text { Speed } * \text { Phi }) \\
& +0.24 *(\text { Speed } * \text { Boost })+0.28 *(\text { Phi })^{2}+0.29 *(\text { Boost })^{2}
\end{aligned}
$$

\section{Equation 5-5}

$$
\begin{aligned}
& \text { Exhaust } T=298+23.7 * \text { Speed }+39.2 * \text { Phi }+4.92 *(\text { Speed } * \text { Phi }) \\
& -3.51 *(\text { Speed })^{2}-2.49 *(\text { Phi })^{2}
\end{aligned}
$$

Equation 5-6

The variables Speed, Phi, and Boost in the above equations are the coded speed, coded phi, and coded boost, respectively. The influence of the engine operating conditions on the combustion parameters, namely, combustion duration (CD), maximum cylinder pressure (Pmax), start of combustion (SOC) and the exhaust temperature (Exhaust T), and the resulting influence on oil consumption is summarized in Table 5-5. The influences of only the main effects, namely, speed, equivalence ratio (phi), and boost are shown in Table 5-5. Some of the interaction effects and quadratic effects were also significant as can be seen in Reports 5-3 through 5-6.

The significance of the corresponding factors (high to low) based on the parameter estimates are denoted by "+++", “++", and "+" in Table 5-5. The increase and decrease in the effect is denoted by “ $\uparrow$ " and " $\downarrow$ ”, respectively. The effects are shown for increase in speed, phi, and boost. The exhaust temperature was found to depend only on speed and phi.

Table 5-5 Effects of Combustion Parameters and Oil Consumption as a Result of Increasing Speed, Phi, and Boost

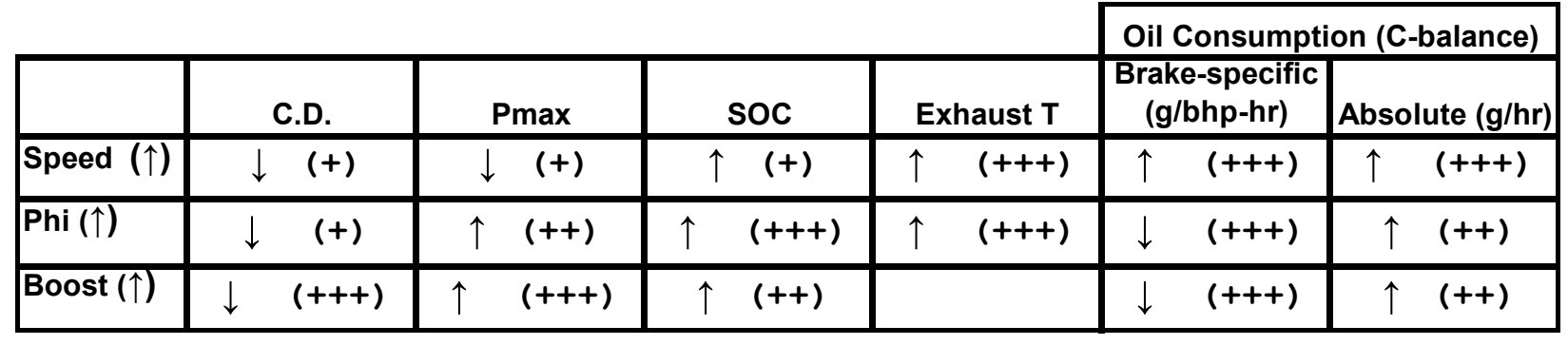

Based on parameter estimates in Report 5-2 (Section 5.1.2), boost was more significant than phi with respect to oil consumption. Boost was found to have a good correlation with combustion duration and is shown in Figure 5-13. The effect of boost on combustion duration was also seen in the statistical analysis, the results of which are summarized in Table 5-5. 
Combustion duration is inversely related to flame speed or flame propagation rate in the case of spark ignition engines [4]. As a result, shorter combustion duration (higher flame propagation) results in a higher consumption of oil from the combustion chamber walls. Figure 5-13 shows that boost is inversely related to combustion duration, and as a result increased boost results in increased absolute oil consumption. Li et al. [4] found a good correlation between phi and combustion duration, but this was not the case in this study. However, they had a wider range for phi at a lower compression ratio and had only a single level of boost.

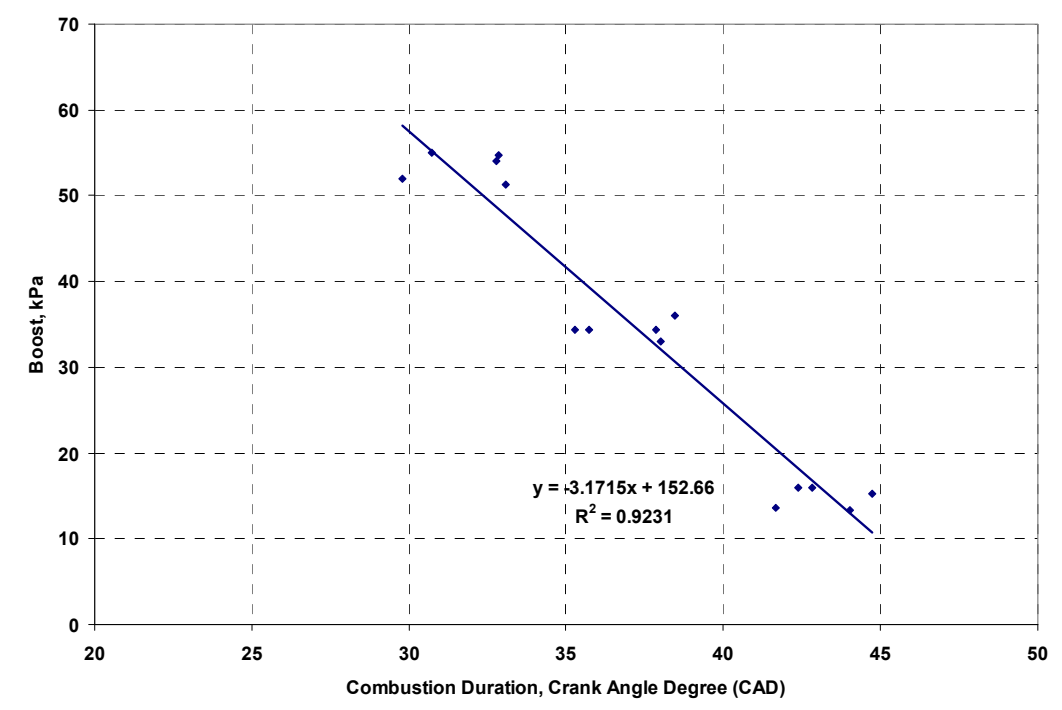

Figure 5-13 Correlation between Combustion Duration and Boost

The effect of phi can be explained by the relation between quenching distance and equivalence ratio. Shrestha and Karim [74] showed an inverse relation between phi and quenching distance. As can be seen from Table 5-5, increase in phi was found to decrease the combustion duration (though not as significant as the effect of boost), increase the maximum cylinder pressure, and increase combustion temperature, all of which influence the quenching distance; more specifically, decrease the quenching distance. Quenching distance is a characteristic length scale which is defined by the smallest crevice width that the flame can enter without being quenched. Increased phi results in smaller quenching distance and as a result the total oil consumed increases.

Speed was also not found to influence combustion duration as much as boost. Rather, speed can be considered to contribute to increased transport of oil into the combustion chamber, and it was the effect of phi and boost that impacted the consumption of oil entering the 
combustion chamber. This can be attributed to the significance of speed-phi, speed-boost interaction in Report 5-2.

The increase in phi at constant speed and boost results in increased work done. This leads to reduced brake-specific oil consumption even though the absolute consumption increases.

Li et al. [4] employed a similar oil consumption measurement approach. However, contrary to their results, this study found that the $\mathrm{HC}$ emissions were more significant for oil consumption determination than $\mathrm{CO}$ emissions. They had neglected HC emissions and were not reported. In the current study, the gaseous products of oil consumption were primarily $\mathrm{CO}_{2}$. $\mathrm{HC}$ was found to contribute around $10-25 \%$ of oil consumption depending on engine operating point consistent with studies of Furuhama and Hiruma [6], whereas CO emissions were almost zero for most test points. Szwabowski et al. [75] also reported HC emissions less than $1 \%$ of carbon oxide emissions for their test results.

It should also be noted that the previous studies $[4,6,7,75]$ mentioned here had limited operating points tested, where oil consumption was calculated for varying levels of only a single factor.

The oil consumption trend as a function of equivalence ratio was similar to the study of Li et al. [4]. The backfire limiting equivalence ratio in the case of Li et al. [4] was also similar to the current study for a compression ratio of 8.5. The compression ratio for the test engine in this study was 13.3:1.

\subsubsection{Influence of Engine Operating Conditions, and Combustion Parameters on Oil Consumption Sources}

The major contributing sources to oil consumption in this study can be classified as follows:

1) Oil evaporation from liner (O.E.)

2) Oil transported into combustion chamber from piston-ring-liner system (O.T.)

3) Oil transported past the valve guides (O.V.)

Based on results summarized in Table 5-5, a similar table was summarized for the effects of engine operating conditions on each of the oil consumption sources, and is shown in Table 56. It should be noted that the oil consumption sources(O.E., O.T., O.V.) were not measured, but 
the behavior of the sources are hypothized based on the changes of combustion parameters with engine operating conditions.

\section{Table 5-6 Effects of Engine Operating Conditions, and Combustion Parameters on Sources of Oil Consumption}

\begin{tabular}{|c|c|c|c|c|c|c|c|c|c|}
\hline & \multicolumn{3}{|c|}{ Oil Contribution Source } & \multicolumn{2}{|c|}{ Oil Consumption (C-balance) } \\
\hline & C.D. & Pmax & soc & Exhaust T & O.E. & O.T. & o.v. & $\begin{array}{c}\text { Brake-specific } \\
\text { (g/bhp-hr) }\end{array}$ & Absolute (g/hr) \\
\hline Speed $\uparrow$ & $\downarrow$ & $\downarrow$ & $\uparrow$ & $\uparrow$ & $\uparrow$ & $\uparrow$ & $\uparrow$ & $\uparrow \quad(+++)$ & $\uparrow \quad(+++)$ \\
\hline Phiा $\uparrow$ & $\downarrow$ & $\uparrow$ & $\uparrow$ & $\uparrow$ & $\uparrow$ & $\downarrow$ & $\downarrow$ & $\downarrow(+++)$ & $\uparrow(++)$ \\
\hline Boost $\uparrow$ & $\downarrow$ & $\uparrow$ & $\uparrow$ & & $\uparrow$ & $\downarrow$ & $\downarrow$ & $\downarrow \quad(+++)$ & $\uparrow \quad(++)$ \\
\hline
\end{tabular}

The increase in speed results in an increase in the combustion temperature, and hence results in increased O.E. contribution. The O.T. and O.V. sources are assumed to increase with speed as a result of the increased revolutions. Hence, increase in speed can be considered to result in an increase in all the contribution sources, and this explains the high significance of speed towards the increase in both the brake-specific and absolute oil consumption.

The increase in phi and boost results in decreased combustion duration, which as discussed in Section 5.1.3 would increase the O.E. contribution. The increased cylinder pressures with increasing phi, and boost is attributed to the decreased O.T. and O.V. contributions at these conditions. The increase in phi and boost results in increase in work done; hence, decreased brake-specific oil consumption even though the absolute oil consumption increases as O.E. contribution can be considered dominant compared to O.T and O.V. for these conditions.

\subsection{Elemental Carbon/ Organic Carbon (EC/OC), Trace Metals Analysis}

The oil consumption discussed thus far was calculated from a carbon-balance utilizing gaseous emissions; $\mathrm{CO}_{2}$ being the major contributor. The $\mathrm{CO}$ amounts were negligible, whereas the $\mathrm{HC}$ contributed to $10 \%-25 \%$ of the total oil consumption measured depending on the engine operating point. The oil consumed ending up in the gas phase can be considered as lubricant oil that is completely consumed. The partially burned and unburned lubricant oil gets converted to the particulate phase. Even though some of the gas phase hydrocarbons may also end up in the particulate phase and result in double counting, for the current study, it was assumed that the gas 
phase hydrocarbons did not end up in the particulate phase.

Oil consumption studies in published literature present or define oil consumption in different ways. A few of them are cited in this section.

Li et al. [4] has defined the oil consumption in their hydrogen fueled engine study as what ends up in the exhaust as carbon oxide emission (neglecting hydrocarbons). Min et al. [5] determined oil consumption in their hydrogen engine study from $\mathrm{CO}_{2}$ measurements alone. Furuhama and Hiruma [6,7] in their study using hydrogen engine employed an oxidation catalyst upstream of the $\mathrm{CO}_{2}$ analyzer so as to convert $\mathrm{HC}$ and $\mathrm{CO}$ emissions to $\mathrm{CO}_{2}$, and calculated oil consumption from the $\mathrm{CO}_{2}$ emissions.

Ariga et al. [25] and Froelund et al. [30,31] used $\mathrm{SO}_{2}$ tracer technique for oil consumption measurement. In both studies, there was a furnace upstream of the $\mathrm{SO}_{2}$ analyzer and the oil consumption calculated was represented as total oil consumption.

In studies [33-36] employing trace-metals or radio-tracer techniques, the oil consumption calculated from the tracer balance was assumed as total oil consumption.

The study by Puffel et al. [76] at the BMW liquid hydrogen test bed is of interest as they defined total oil consumption based on $\mathrm{HC}$ emissions. They defined measurements of single aromatic hydrocarbons made by a laser mass spectrometer as representative of unburned oil constituents, and HC measurements made by a Flame Ionization Detector (FID) and GC-FID as burned oil constituents. They assumed oil ending up as $\mathrm{CO}_{2}$ as negligible. This was in contrast to what was observed in the current study.

Based on the discussion above, it is obvious that the selection of measurement and analysis methodologies are critical and the nature of oil consumption measured (burned, unburned, or total) needs to be clearly stated. The oil consumption calculated using Equation 4-1 is the gas phase derived oil consumption, and is representative of oil that is completely consumed.

This section involves determination of oil consumption based on the organic fraction, and trace metals contained in the particulate matter sampled from the partial flow dilution tunnel. The oil consumption determined from the organic carbon in the exhaust can be considered as representative of partially burned and unburned oil and is denoted as $\mathrm{BSOC}_{\text {org }}(\mathrm{g} / \mathrm{bhp}-\mathrm{hr})$. 
The organic carbon based oil consumption was calculated for each steady-state test condition as follows,

BSOC $_{\mathrm{org}}=\frac{1}{m_{c} * W} *$ [Organic Carbon in the exhaust $] * \frac{1}{10^{6}}$

\section{Equation 5-7}

where, [Organic Carbon in the exhaust] $=\mathrm{OC} * \mathrm{SR}$,

where, $\mathrm{OC}=$ Background corrected Organic Carbon per test, $\mu \mathrm{g} /$ filter, and

$\mathrm{SR}=$ Split Ratio,

$\mathrm{W}=$ Power output (bhp) as defined in Section 4.7.

The Split Ratio, SR, is given by,

$$
\mathrm{SR}=\frac{\dot{m}_{a}+\dot{m}_{f}}{\dot{m}_{t u n}-\dot{m}_{d i l}}
$$

\section{Equation 5-8}

where, $\dot{m}_{a}=$ Intake air mass flow rate, $\mathrm{g} / \mathrm{s}$

$\dot{m}_{f}=$ Fuel (hydrogen) mass flow rate, $\mathrm{g} / \mathrm{s}$

$\dot{m}_{\text {tun }}=$ Diluted exhaust mass flow rate through the dilution tunnel, $\mathrm{g} / \mathrm{s}$

$\dot{m}_{d i l}=$ Dilution air mass flow rate into the tunnel, $\mathrm{g} / \mathrm{s}$

The EC/OC analysis performed showed that the EC fraction was negligible and the particulate matter collected was almost all organic carbon. The analysis report from Desert Research Institute (DRI) is given in Table D1 in Appendix D.

$\mathrm{Ca}$ and $\mathrm{Zn}$ were the only two trace metal components found in the exhaust with concentrations greater than the uncertainty levels associated with their measurement. $\mathrm{Mg}$ is also usually found in significant levels in the case of diesel engine particulate emissions, but was not the case for either of the two oils in this study for the test conditions considered. 
The brake-specific $\mathrm{Ca}$ and $\mathrm{Zn}$ balance based oil consumption (g/bhp-hr) were calculated as follows:

$\operatorname{BSOC}_{\mathrm{Ca}}=\frac{1}{m_{C a} * W} *[\mathrm{Ca}$ in the exhaust $] * \frac{1}{10^{6}}$

\section{Equation 5-9}

where, $[\mathrm{Ca}$ in the exhaust $]=[\mathrm{Ca}] * \mathrm{SR}$,

where, $[\mathrm{Ca}]=\mathrm{Ca}$ per test, $\mu \mathrm{g} /$ filter, and

$\mathrm{SR}=$ Split Ratio

$\mathrm{W}=$ Power output (bhp) as defined in Section 4.7.

$\mathrm{m}_{\mathrm{Ca}}=$ Mass fraction of $\mathrm{Ca}$ in the lubricant oil

Similarly,

$\mathrm{BSOC}_{\mathrm{Zn}}=\frac{1}{m_{Z n} * W} *[\mathrm{Zn}$ in the exhaust $] * \frac{1}{10^{6}}$

Equation 5-10

where, $[\mathrm{Zn}$ in the exhaust $]=[\mathrm{Zn}] * \mathrm{SR}$,

where, $[\mathrm{Zn}]=\mathrm{Zn}$ per test, $\mu \mathrm{g} /$ filter, and

$\mathrm{SR}=$ Split Ratio

$\mathrm{m}_{\mathrm{Zn}}=$ Mass fraction of $\mathrm{Zn}$ in the lubricant oil

Table 5-7 shows the oil consumption calculated based on the various calculations. Cbalance is the oil consumption based on gas phase emissions (completely burned oil). Organic C-balance, Ca-balance, Zn-balance, are based on the calculations in Equations 5-7 through 5-10, using the organic carbon, and trace metal concentrations contained in the PM sampled from a partial flow dilution tunnel. The \% C-balance in Table 5-7 denotes the ratio of the corresponding oil consumption calculated to C-balance in percentage. 
Table 5-7 Comparison of Oil Consumption (C-balance, Organic Fraction, Ca-balance, Znbalance)

\begin{tabular}{|l|c|c|c|c|c|c|c|}
\hline (Speed, Phi, Boost) & C-balance & \multicolumn{2}{c|}{ Organic C-balance } & \multicolumn{2}{c|}{ Ca-balance } & \multicolumn{2}{c|}{ Zn-balance } \\
\cline { 3 - 8 } Coded & g/bhp-hr & g/bhp-hr & \% C-balance & g/bhp-hr & \% C-balance & g/bhp-hr & $\%$ C-balance \\
\hline Valvoline & & & & & & & \\
$(-1,-1,-1)$ & 0.40 & 0.18 & 44 & 0.10 & 24 & 0.03 & 8 \\
$(-1,-1,1)$ & 0.36 & 0.15 & 43 & 0.09 & 25 & 0.10 & 27 \\
$(-1,1,-1)$ & 0.28 & 0.21 & 74 & 0.14 & 50 & 0.16 & 58 \\
$(-1,1,1)$ & 0.24 & 0.11 & 46 & 0.09 & 36 & 0.07 & 29 \\
$(0,0,0)$ & 0.34 & 0.10 & 29 & 0.10 & 31 & 0.06 & 18 \\
$(1,-1,-1)$ & 0.54 & 0.11 & 21 & 0.08 & 14 & 0.07 & 13 \\
$(1,-1,1)$ & 0.41 & 0.04 & 11 & 0.05 & 11 & 0.03 & 7 \\
$(1,1,-1)$ & 0.42 & 0.07 & 17 & 0.06 & 13 & 0.02 & 4 \\
$(1,1,1)$ & 0.33 & 0.03 & 10 & 0.07 & 21 & 0.05 & 15 \\
\hline Amsoil & & & & & & & \\
$(-1,-1,-1)$ & 0.43 & 0.15 & 35 & 0.04 & 10 & 0.03 & 7 \\
$(-1,-1,1)$ & 0.36 & 0.11 & 31 & 0.05 & 15 & 0.03 & 9 \\
$(-1,1,-1)$ & 0.31 & 0.15 & 51 & 0.04 & 12 & 0.03 & 9 \\
$(-1,1,1)$ & 0.25 & 0.09 & 34 & 0.06 & 23 & 0.04 & 14 \\
$(0,0,0)$ & 0.35 & 0.10 & 29 & 0.06 & 18 & 0.05 & 14 \\
$(1,-1,-1)$ & 0.53 & 0.06 & 11 & 0.02 & 3 & 0.04 & 8 \\
$(1,-1,1)$ & 0.39 & 0.03 & 9 & 0.02 & 4 & 0.03 & 7 \\
$(1,1,-1)$ & 0.37 & 0.04 & 10 & 0.05 & 13 & 0.01 \\
$(1,1,1)$ & 0.35 & 0.06 & 17 & 0.01 & 3 & 0.03 & 3 \\
\end{tabular}

The $\mathrm{Ca}$ and $\mathrm{Zn}$ based oil consumption may also be considered as representative of partially burned and unburned lubricant oil as it is obtained in the particulate matter.

In the previous section, it was seen that the carbon-balance derived oil consumption was similar for the two oils in spite of the synthetic oil being more volatile as indicated by the Noack volatility index. This shows that for conditions tested, the volatility does not have an impact on the completely consumed oil fraction. Figure 5-14 shows the normal probability plot and Figure 5-15 shows the box plot for the brake-specific organic fraction ( $\mathrm{mg} / \mathrm{bhp}-\mathrm{hr}$ ) for the two oils. Results indicate that the organic carbon in the exhaust is different for the two oils even though the carbon-balance derived oil consumption values calculated were the same for the given test conditions. This can be seen from results for organic fraction, and the $\mathrm{Ca}$ and $\mathrm{Zn}$ emissions results as well. 


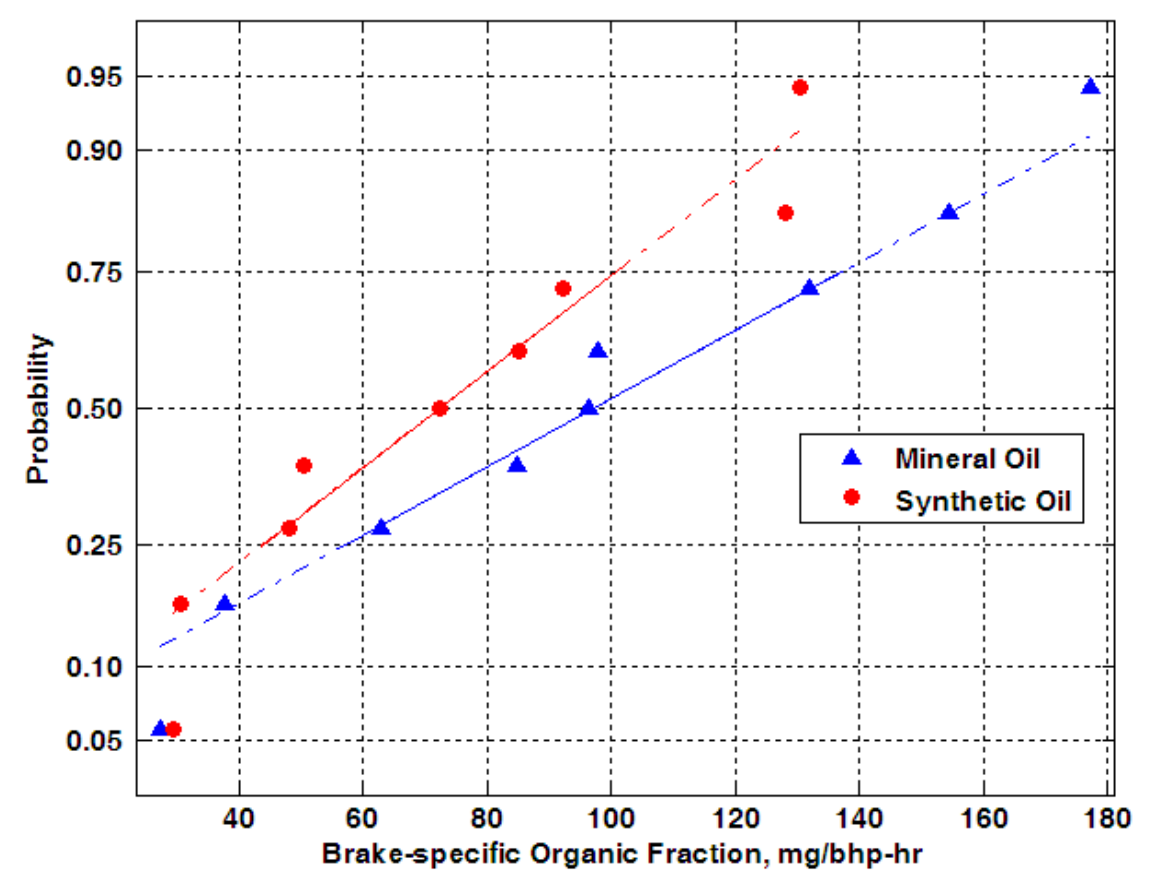

Figure 5-14 Normal Probability Plot (Organic Fraction Data for Mineral Oil and Synthetic Oil)

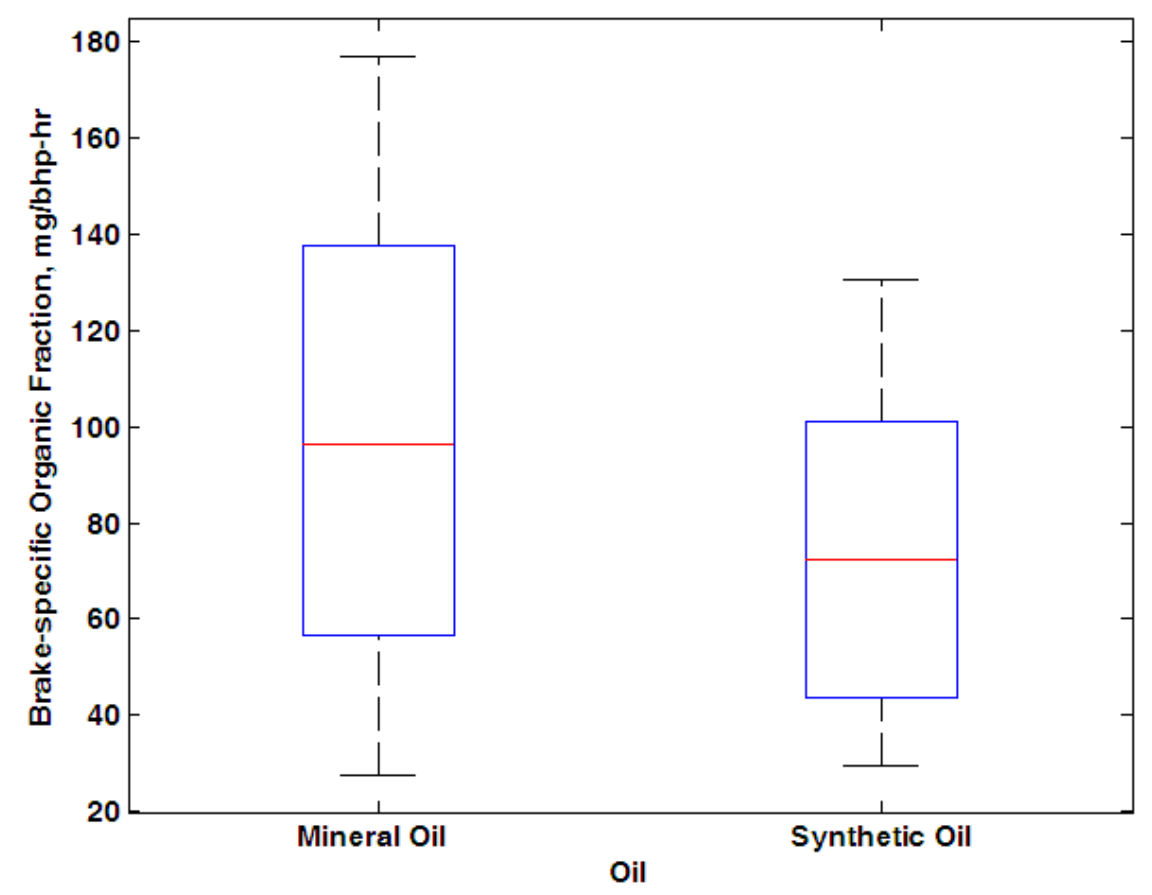

Figure 5-15 Box Plot (Organic Fraction Data for Mineral Oil and Synthetic Oil) 
The results in Table 5-3 shows that the oil consumption calculated from a Ca-balance and Zn-balance have a significant difference (5-50\% depending on operating state) compared to Cbalance. This is similar to the findings in previous studies $[36,62,77-80]$ where the $\mathrm{Ca}$ and $\mathrm{Zn}$ estimated from oil consumption estimates were higher than what was actually measured in the exhaust. The difference was attributed to the selective evaporation of the base-stocks compared to the additives. The two fractions evaporate at different temperatures; hence, result in the difference in calculated versus measured oil consumption. In this study, results of oil consumption based on C-balance were similar for the two oils, and the $\mathrm{Ca}$ and $\mathrm{Zn}$ mass fractions were also similar for the two oils, but the $\mathrm{Ca}$ and $\mathrm{Zn}$ that was detected in the PM samples were different. This was similar for the organic fraction as well. Figures 5-16 through 5-19 show the normal probability plots and box plots for brake-specific $\mathrm{Ca}$ and $\mathrm{Zn}$ emissions measured. The normal plots indicate that the data are normally distributed, but are different for the two oils, and the box plot also confirms the normal plot results.

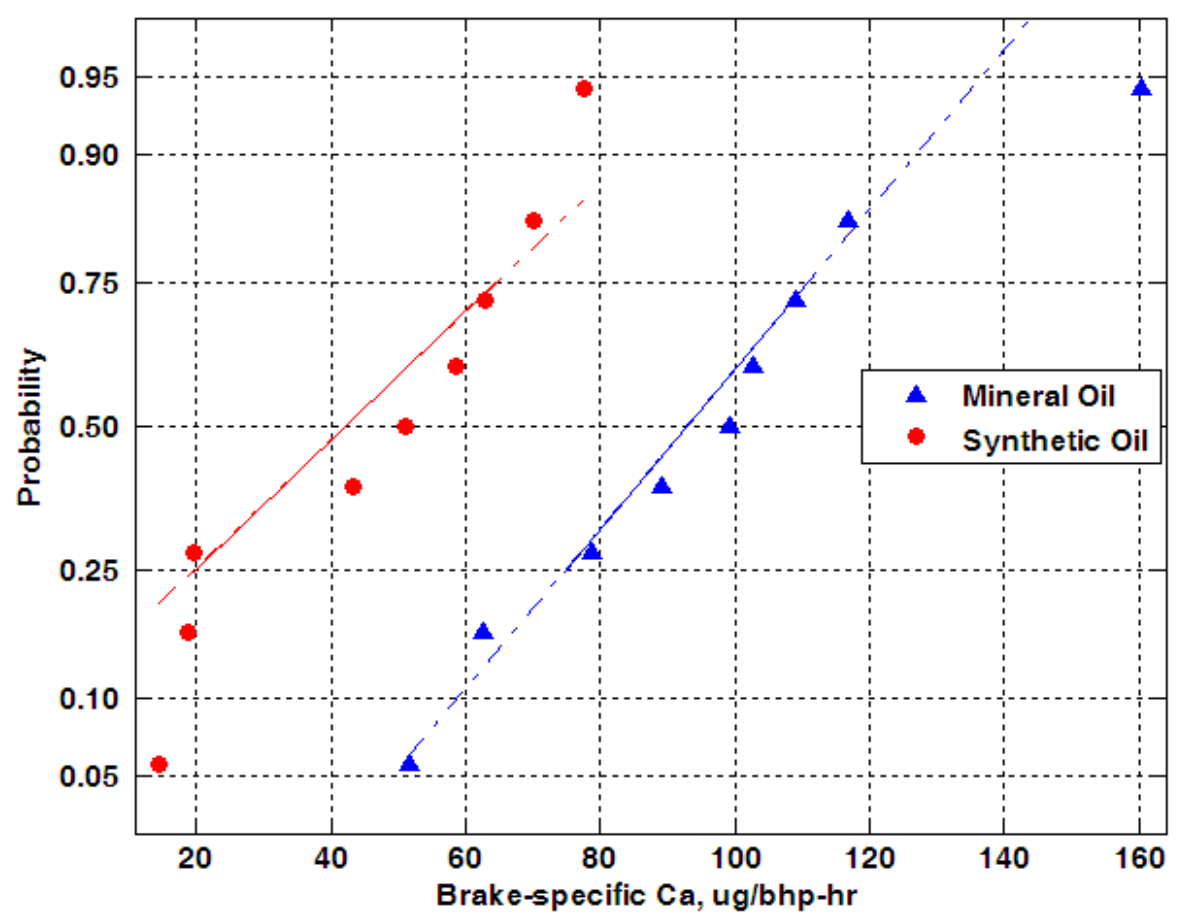

Figure 5-16 Normal Probability Plot (Brake-specific Ca: Mineral Oil and Synthetic Oil) 


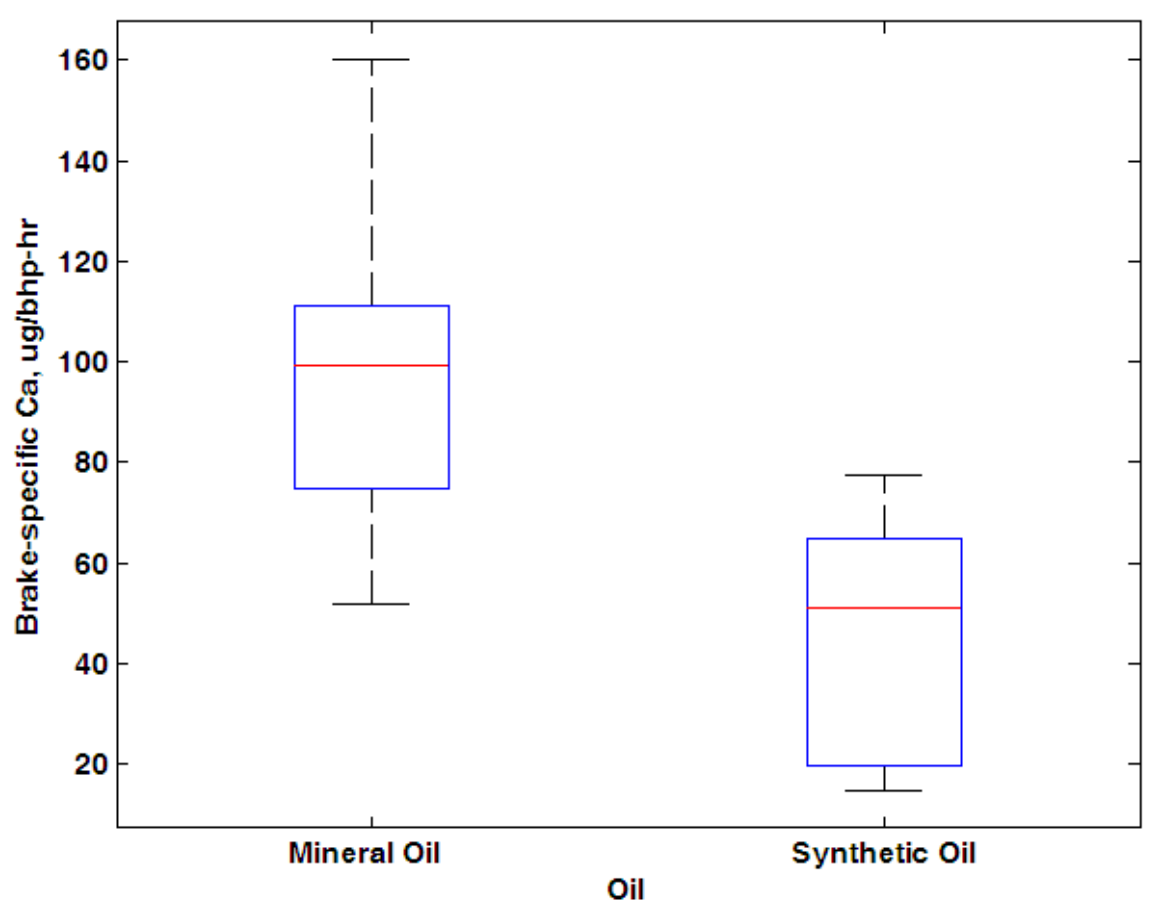

Figure 5-17 Box Plot (Brake-specific Ca: Mineral Oil and Synthetic Oil)

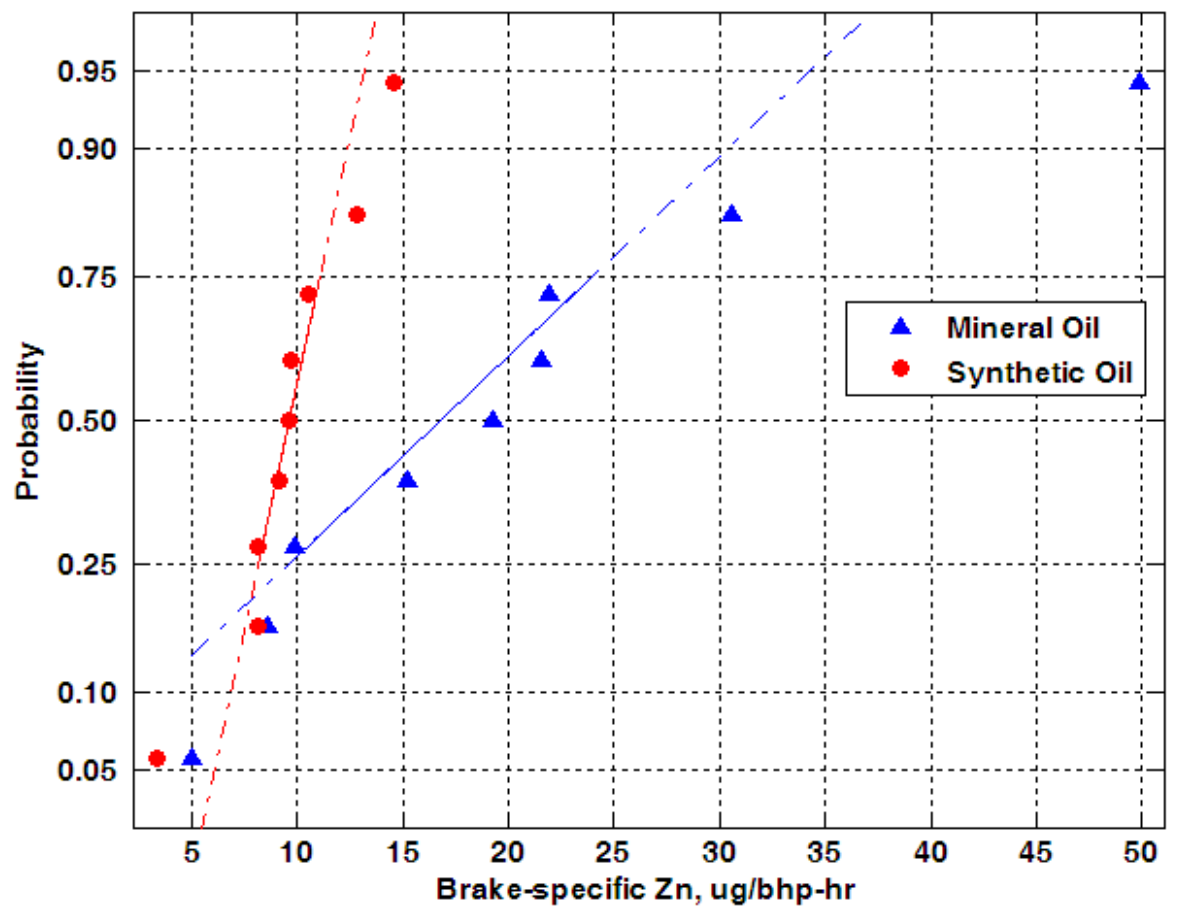

Figure 5-18 Normal Probability Plot (Brake-specific Zn: Mineral Oil and Synthetic Oil) 


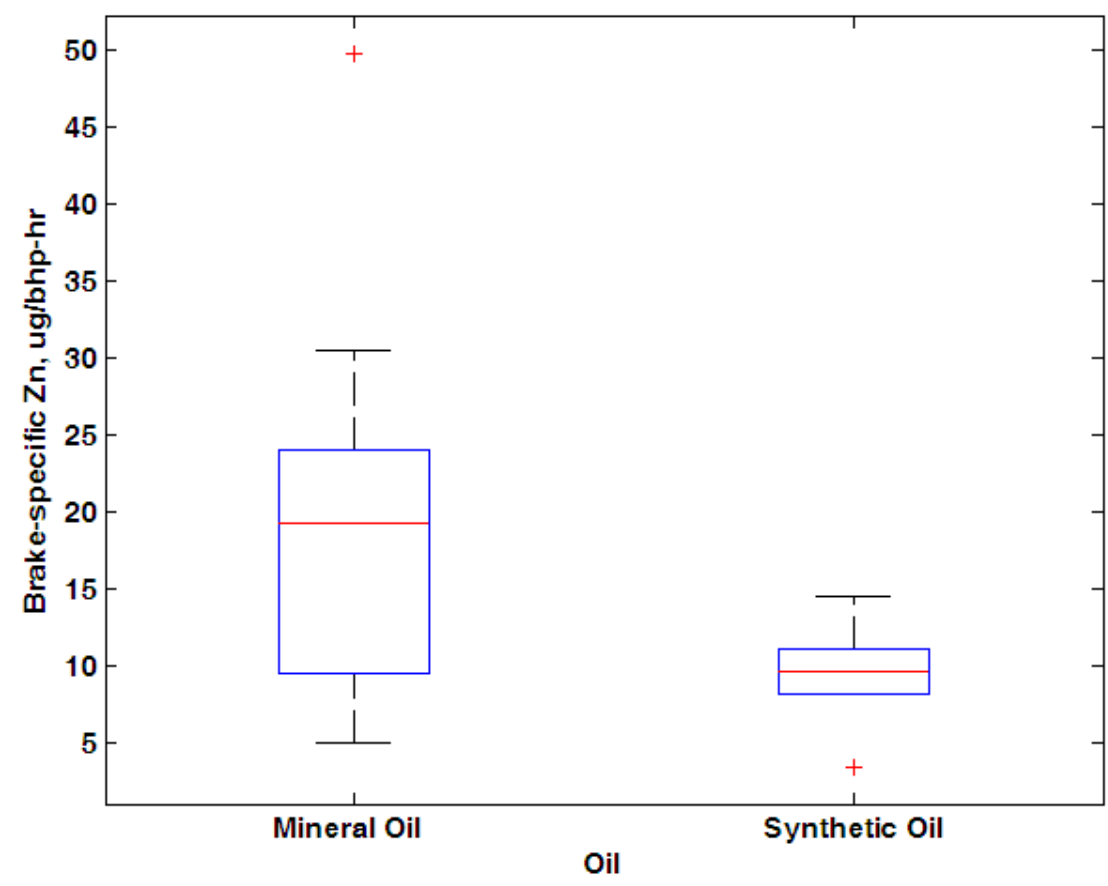

Figure 5-19 Box Plot (Brake-specific Zn: Mineral Oil and Synthetic Oil)

It is generally considered that higher volatility results in higher oil consumption. However, results presented above show evidence to the contrary, that is, the consumption of partially burned oil calculated from the organic carbon fraction is higher for the mineral oil in spite of its lower volatility. The same is true for $\mathrm{Ca}$ and $\mathrm{Zn}$ emissions, as well. This maybe attributed to differences in the base-stocks between the mineral oil and synthetic oil and the slightly lower C-mass fraction for the synthetic oil (approximately, 0.84-0.85) compared to the mineral oil (approximately, 0.85-0.86). In the case of synthetic oil base stocks, molecules are uniform in size and shape, and devoid of contaminants, which are attributed to the chemical processes adopted to produce the oils; hence, a more complete combustion of the oil that is consumed. Whereas, mineral oil base stocks are comprised of molecules of different chemical properties, shapes and sizes, which make some of its components evaporate more readily. It is very likely that mineral oils have contaminants resulting from inadequacies in the extraction and refining processes involved. This would explain the higher partially burned and unburned fraction for the mineral oil inspite of its lower volatility.

Figure 5-20 shows the comparison between C-balance, organic fraction based, and $\mathrm{Ca} / \mathrm{Zn}$ based oil consumption results. 


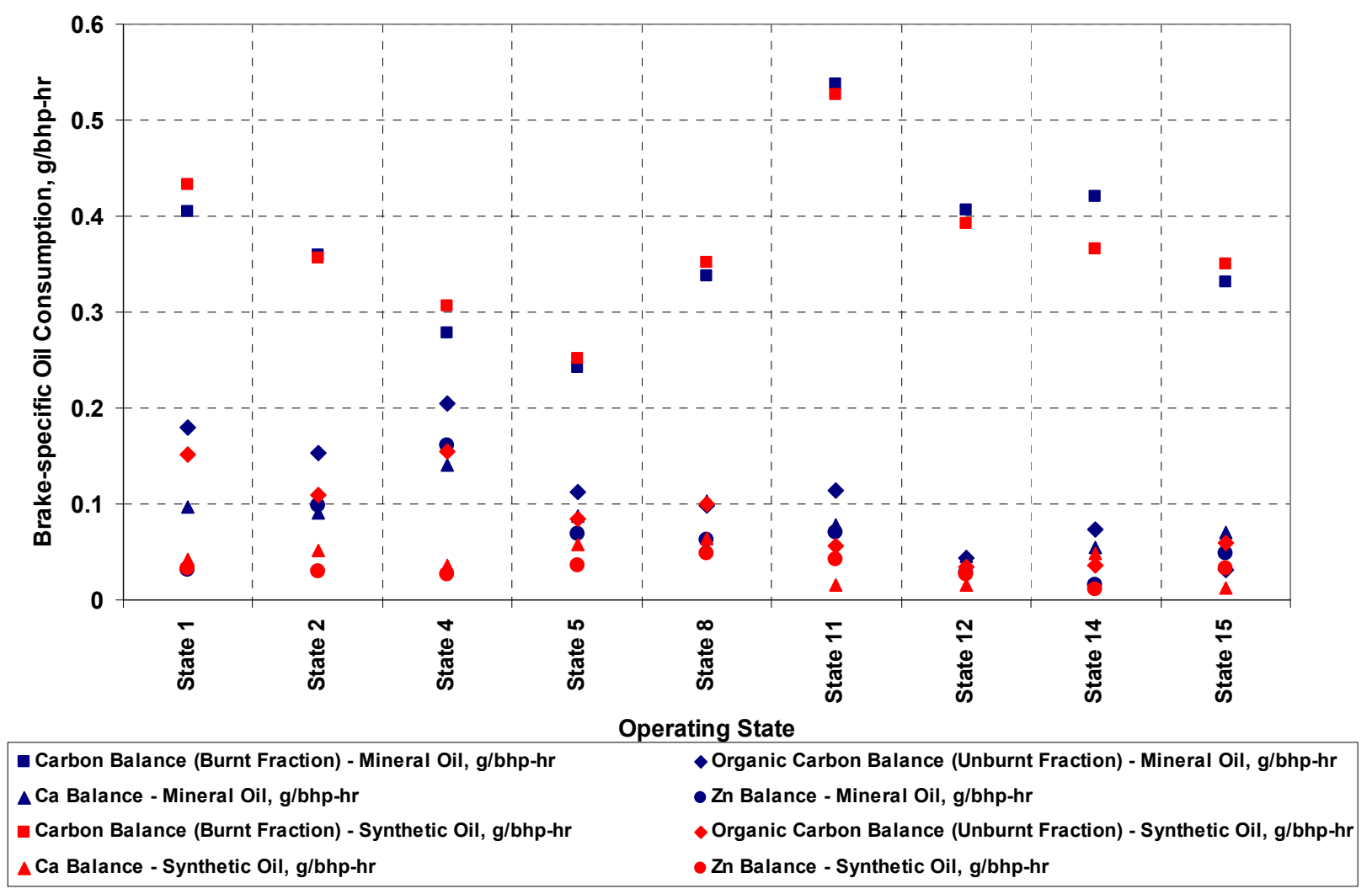

Figure 5-20 Comparison of Calculated Oil Consumption Values (Mineral Oil and Synthetic Oil)

Results clearly indicate that the trace-metal balance is not a suitable method for oil consumption determination because additives have a different rate of consumption compared to the base-stock. Also, it is seen from this study that the trace-metal concentrations measured in the exhaust are different for the two oils even though the oil consumption levels and the tracemetal concentrations in the oils are similar. Results presented in this section also indicate the importance of differentiating between the definition of oil consumption based on various methods employed for oil consumption determination.

\subsection{PM Concentrations and Size Distribution Analysis}

\subsubsection{Brake-specific Particle Size Distribution Results}

Particle size distributions were recorded using an SMPS for all the fifteen operating states for both the test oils. The SMPS recorded five samples for each test. The normalized particle size distribution data is shown in Appendix E, with error bars denoting two standard deviations 
$( \pm 2 \sigma)$. The particle number data was more repeatable for the high speed and high equivalence ratio operating states. Brake-specific particle number distributions were calculated using the following equation,

$\mathrm{BSPN}=\frac{P N^{*} D R^{*} V_{e x h} * t * 10^{6}}{W}$

Equation 5-11

$P N=$ Particle number concentration, $\# / \mathrm{cm}^{3}$

$V_{e x h}=$ Volumetric exhaust flowrate (Equation 4-2), $\mathrm{m}^{3} / \mathrm{s}$

$\mathrm{t}=$ Test time for the operating point under consideration

$\mathrm{W}=$ Work done during the operating state, bhp-hr

$D R=$ Dilution Ratio, and is given by,

$\mathrm{DR}=\frac{\dot{m}_{t u n}}{\dot{m}_{t u n}-\dot{m}_{d i l}}$

Equation 5-12

$\dot{m}_{\text {tun }}=$ Diluted exhaust mass flow rate through the dilution tunnel, $\mathrm{g} / \mathrm{s}$

$\dot{m}_{d i l}=$ Dilution air mass flow rate into the tunnel, g/s

Figure 5-21 shows the lognormal probability plot for the average particle number data in the case of the two test oils for all the operating states. It is seen that the PM has lognormal size distributions, and that there is no significant difference with respect to the total particle numbers between the mineral oil and synthetic oil. The data for the two oils are in the same order of magnitude for corresponding operating states. 


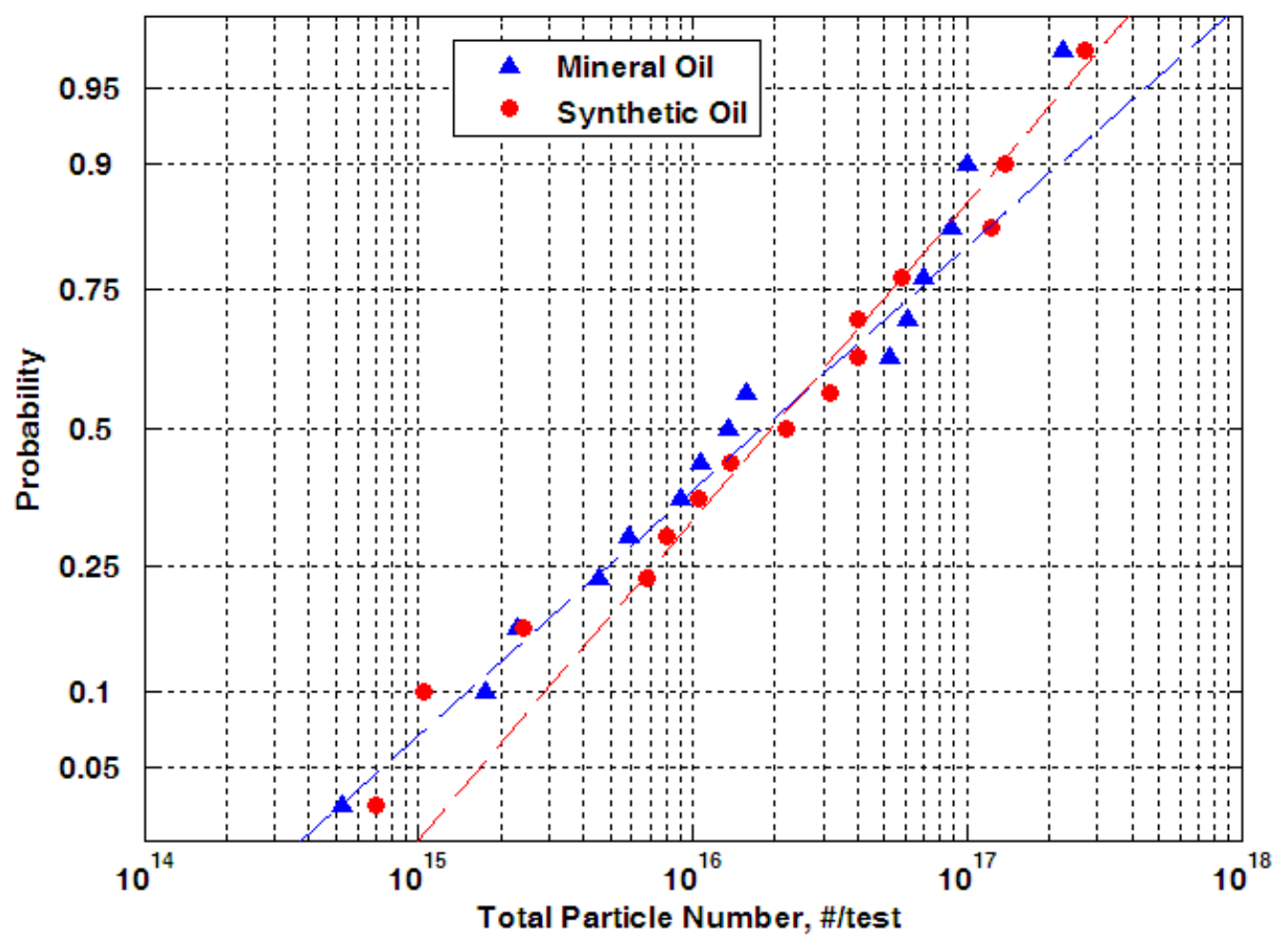

Figure 5-21 Lognormal Probability Plot of Particle Number Data

Figures 5-22 through 5-36 show the brake-specific particle number distribution, and the integrated particle number results. The integrated brake-specific number results are shown for each operating state alongside the brake-specific oil consumption (carbon-balance) and brakespecific organic fraction (from EC/OC results) data to illustrate the effects of lubricant oil consumption and organic fraction variation on particle formation. The error bars denote two standard deviations $( \pm 2 \sigma)$. The brake-specific organic fraction results do not have error bars since the results are based on one sample at each of the nine operating states for which PM was collected. 


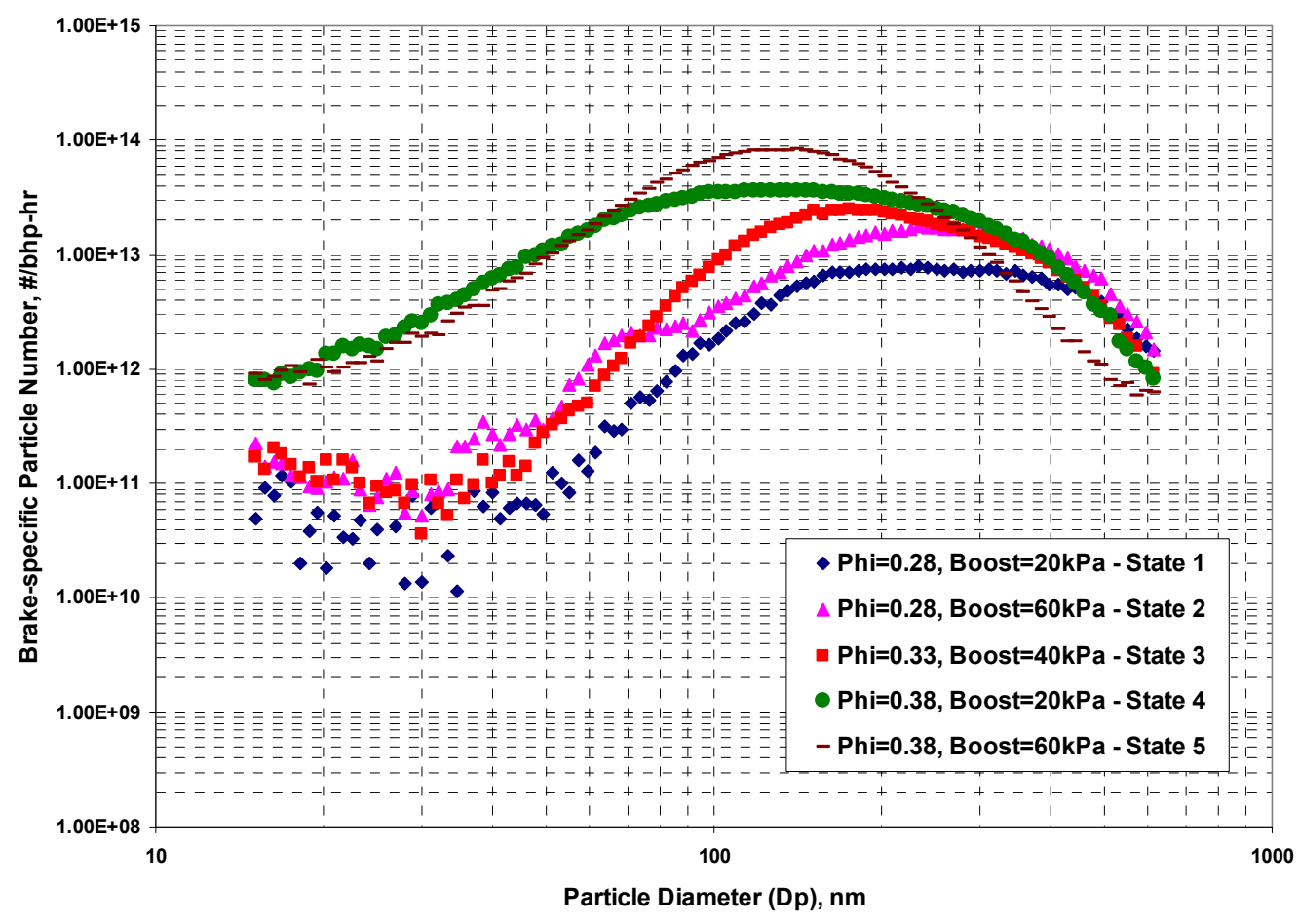

Figure 5-22 Brake-specific Particle Number Distribution (Mineral Oil): Speed = 15 rps

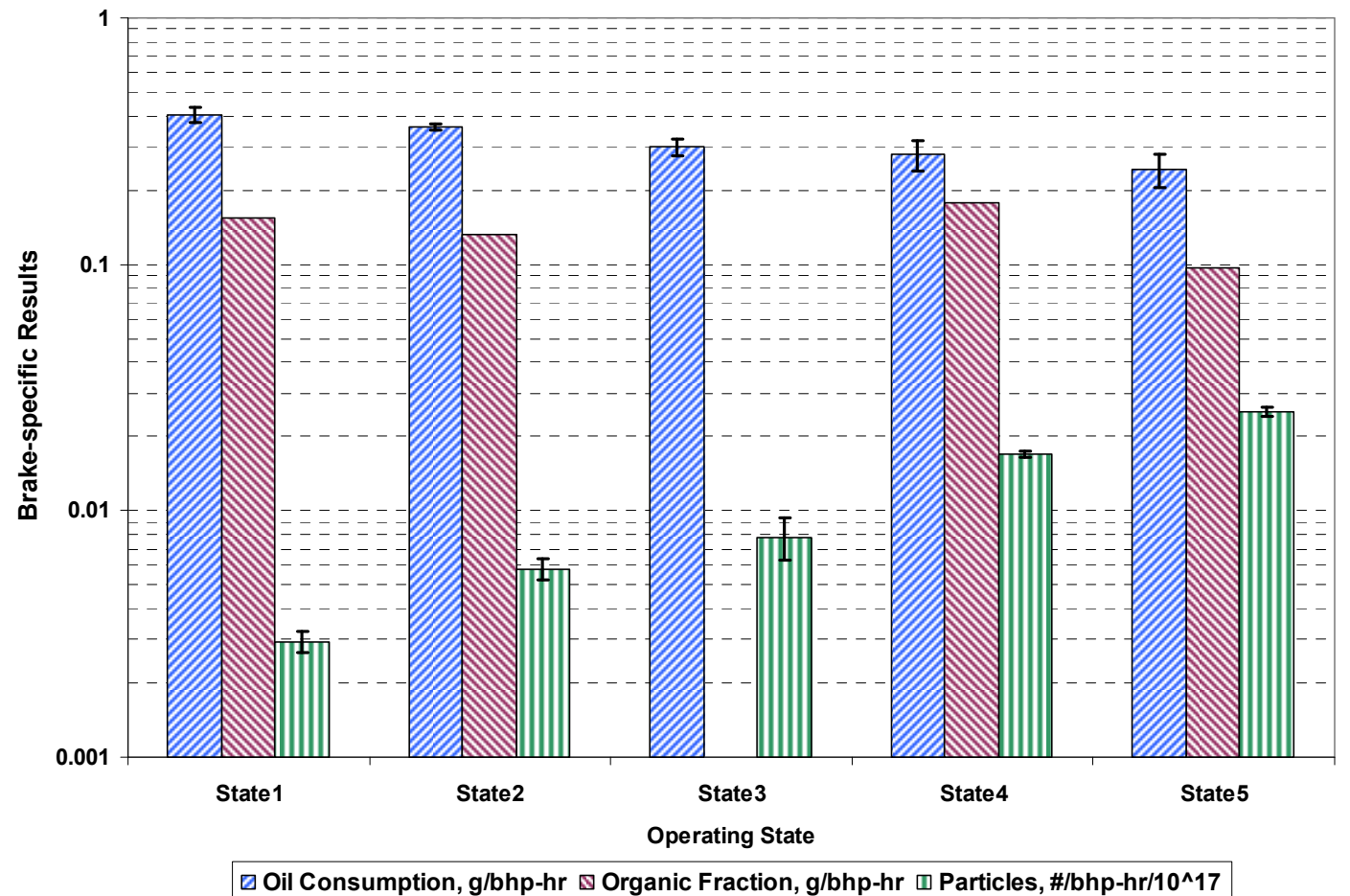

Figure 5-23 Brake-specific Oil Consumption, OC Fraction, Particle \# (Mineral Oil): Speed $=15$ rps 


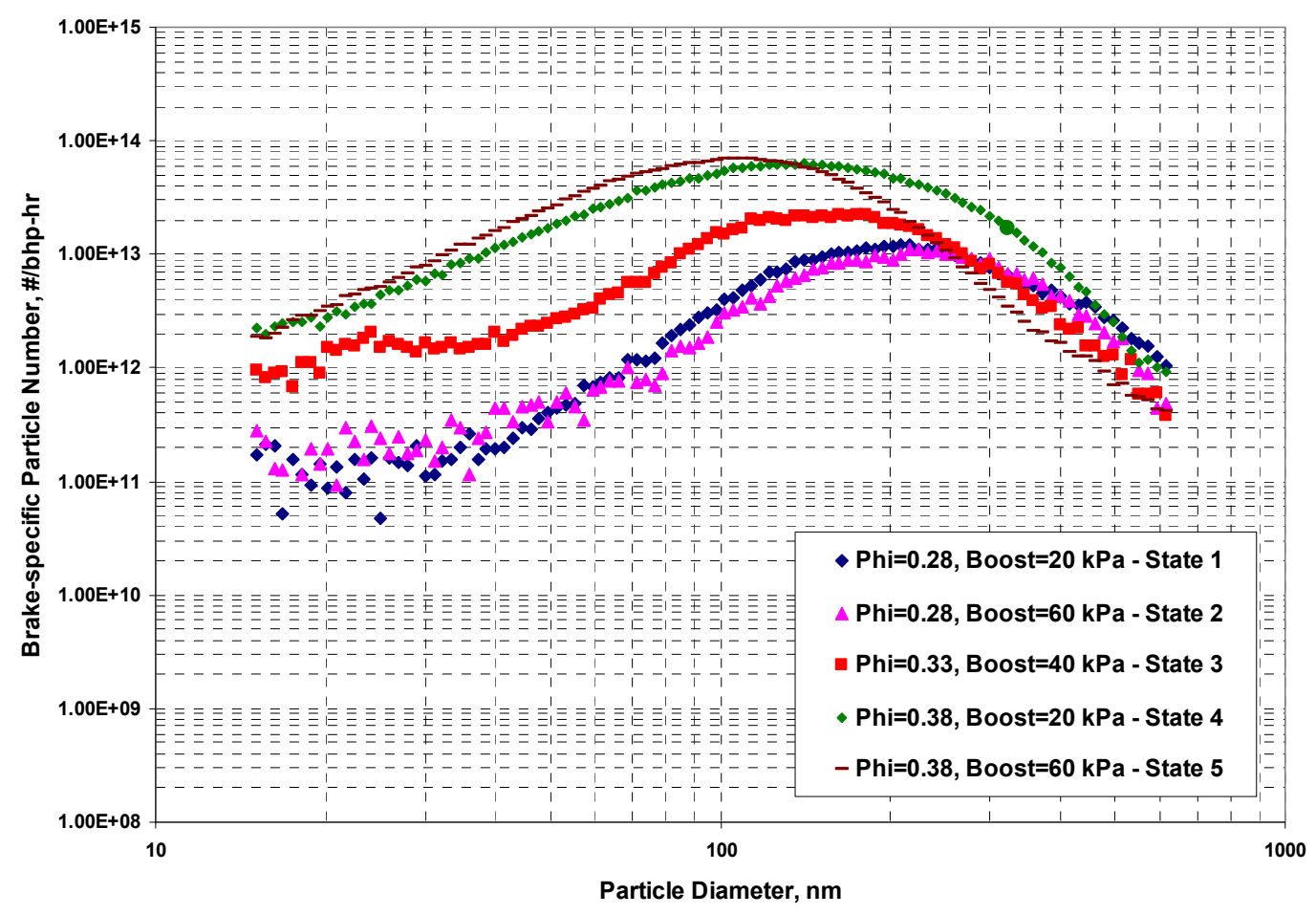

Figure 5-24 Brake-specific Particle Number Distribution (Synthetic Oil): Speed = 15 rps

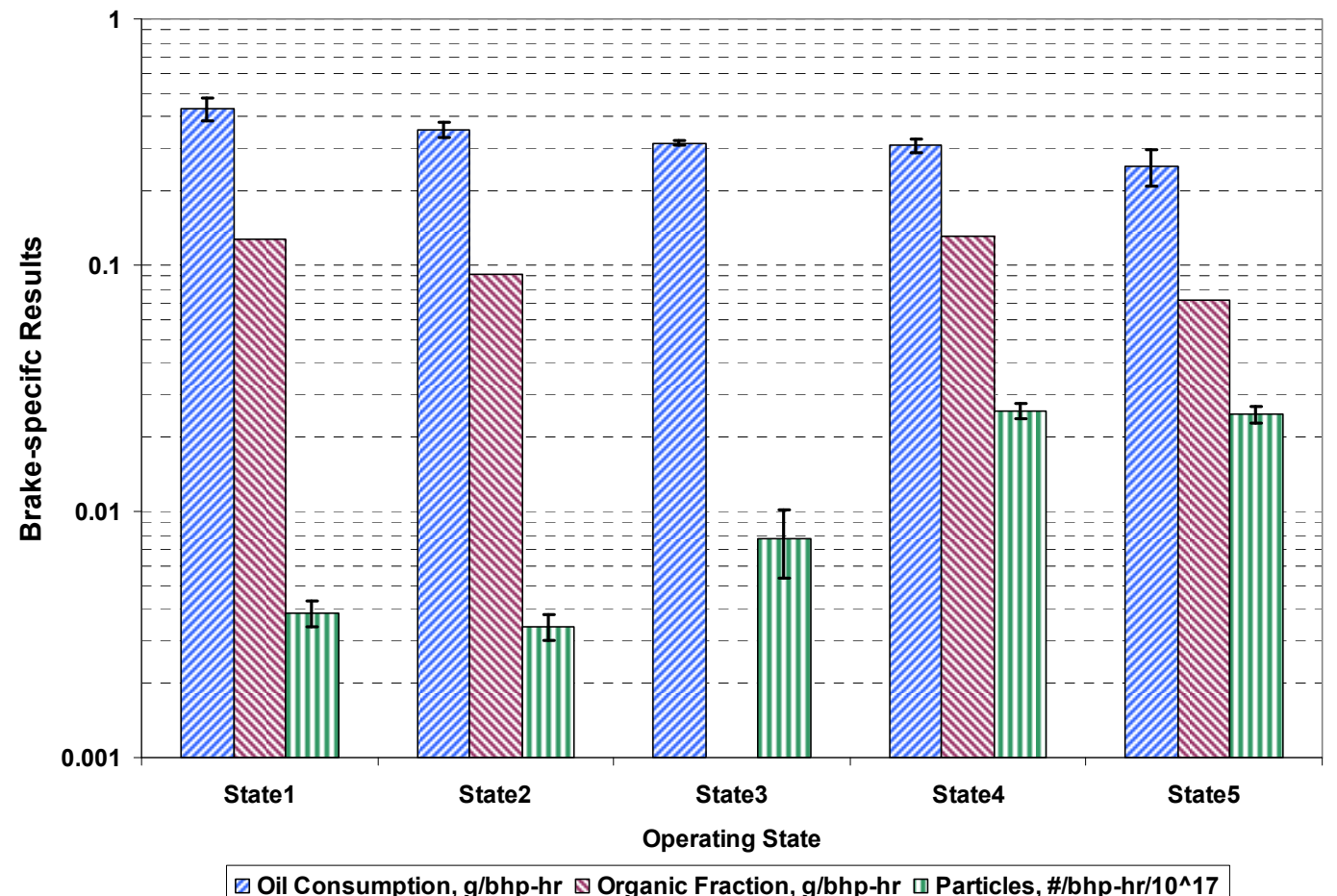

Figure 5-25 Brake-specific Oil Consumption, OC Fraction, Particle \# (Synthetic Oil): Speed $=15$ rps 


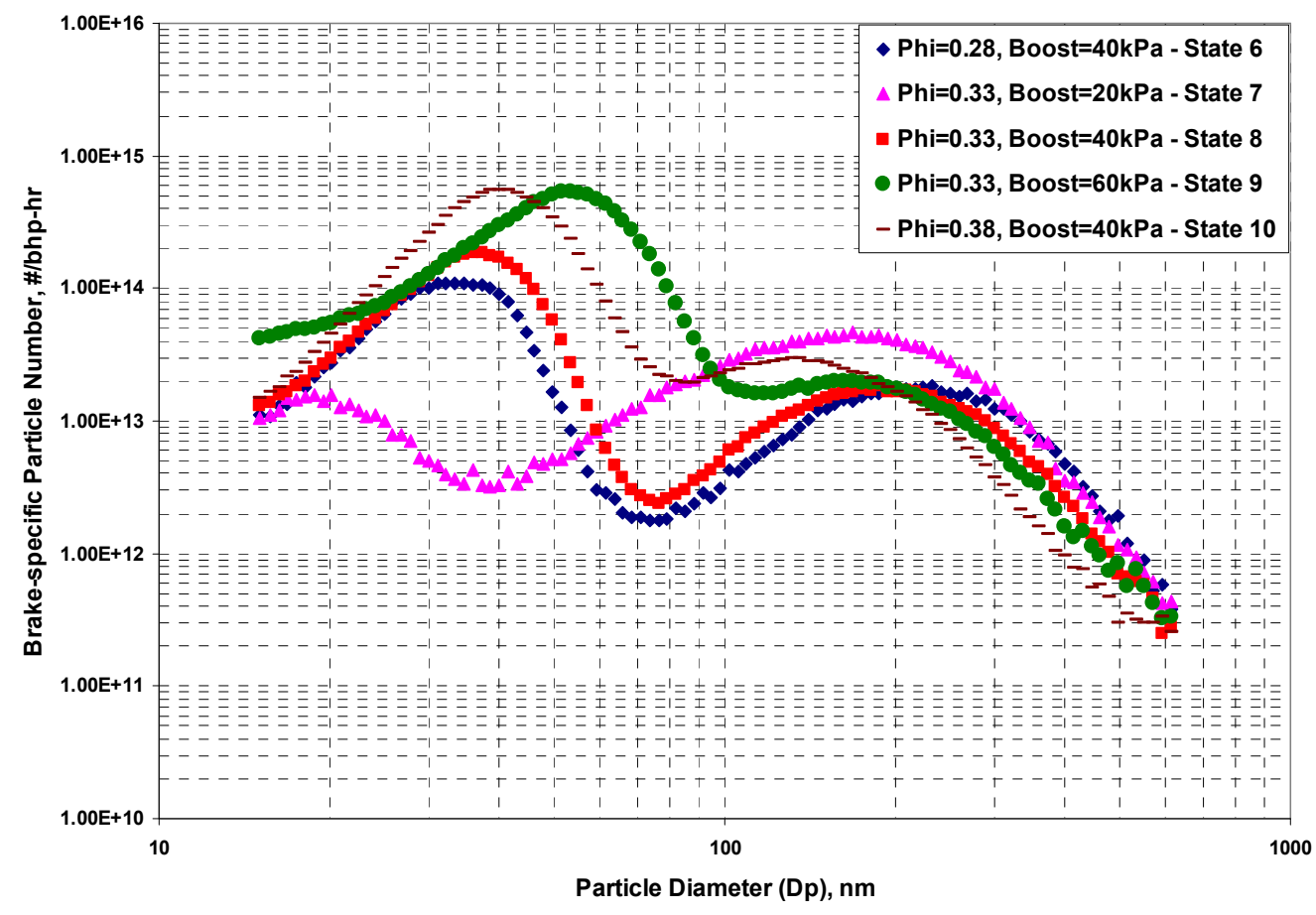

Figure 5-26 Brake-specific Particle Number Distribution (Mineral Oil): Speed = 22.5 rps

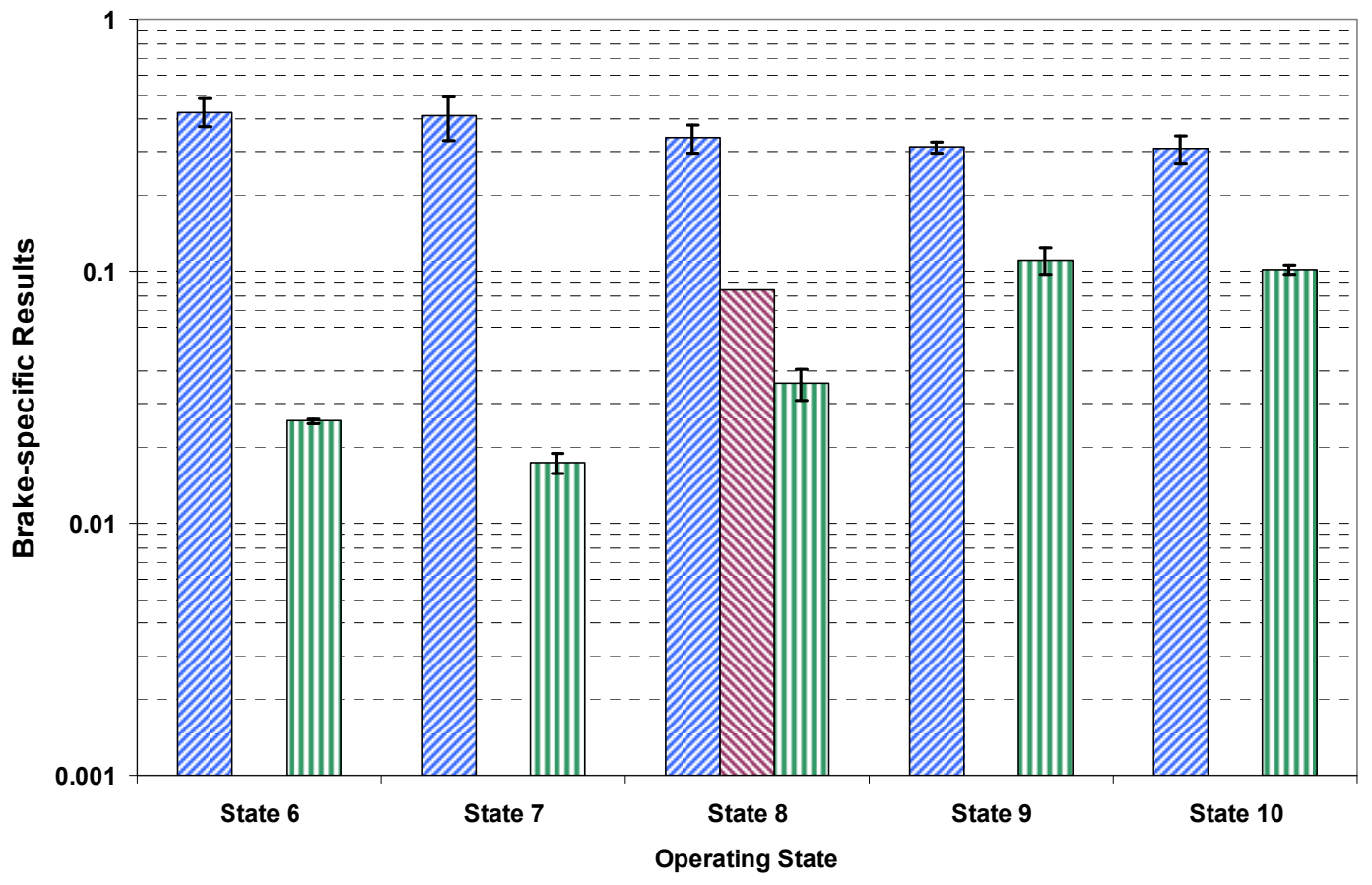

ఐ Oil Consumption, g/bhp-hr $₫$ Organic Fraction, g/bhp-hr \ Particles, \#/bhp-hr/10^17

Figure 5-27 Brake-specific Oil Consumption, OC Fraction, Particle \# (Mineral Oil): Speed $=22.5 \mathrm{rps}$ 


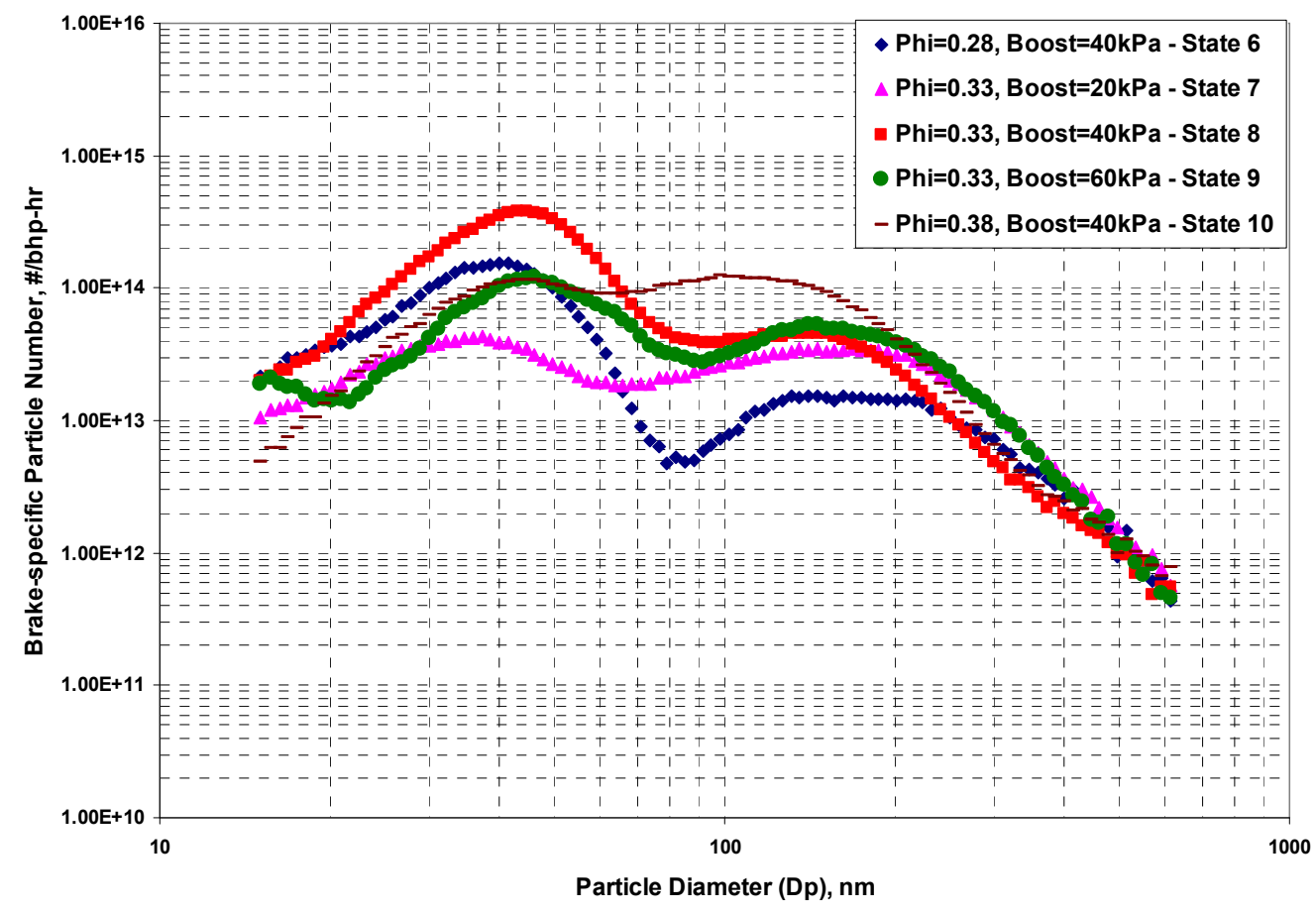

Figure 5-28 Brake-specific Particle Number Distribution (Synthetic Oil): Speed = 22.5 rps

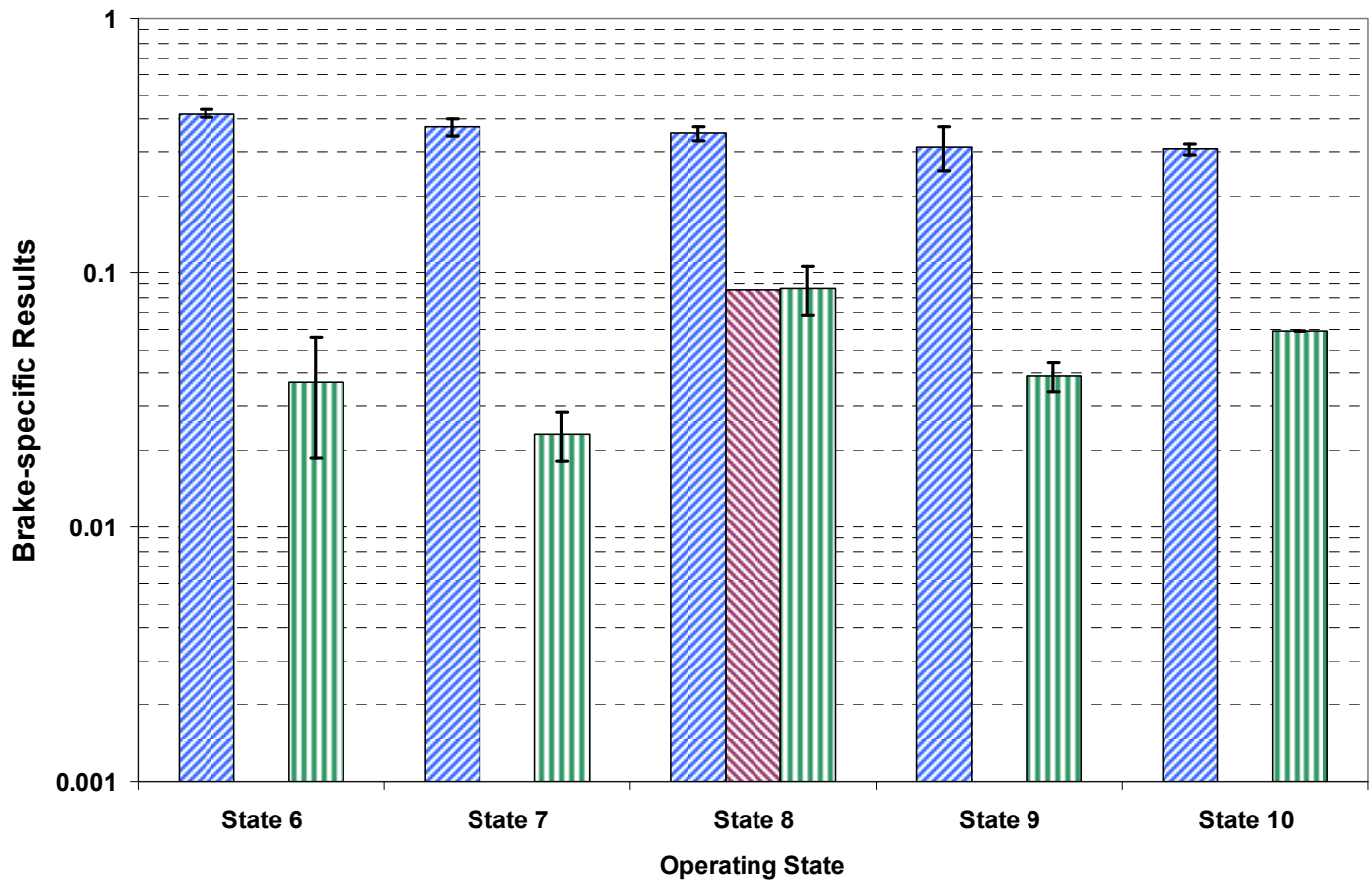

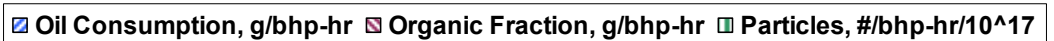

Figure 5-29 Brake-specific Oil Consumption, OC Fraction, Particle \# (Synthetic Oil):

$$
\text { Speed }=22.5 \mathrm{rps}
$$




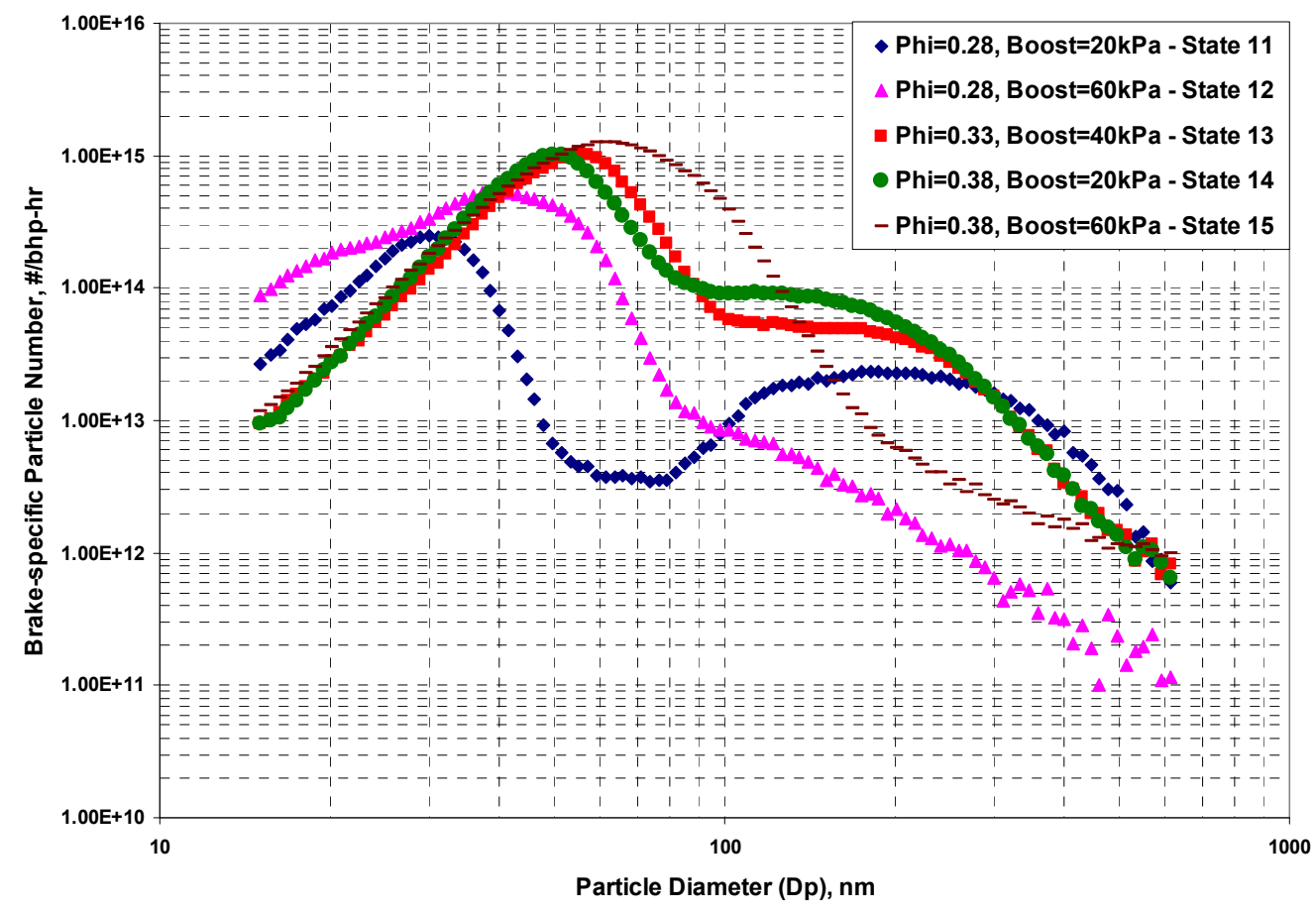

Figure 5-30 Brake-specific Particle Number Distribution (Mineral Oil): Speed = 30 rps

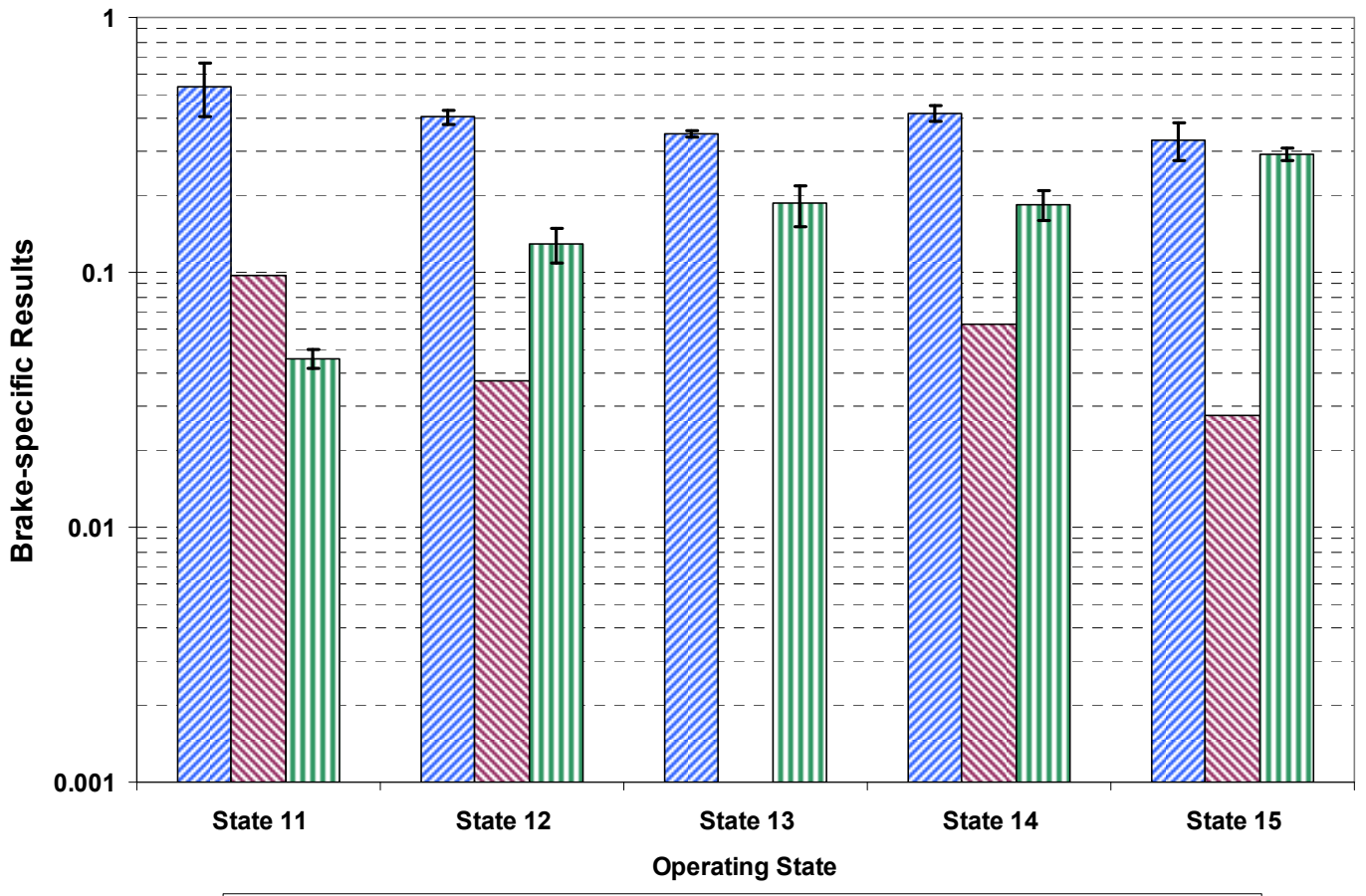

ఐ Oil Consumption, g/bhp-hr $₫$ Organic Fraction, g/bhp-hr $\square$ Particles, \#/bhp-hr/10^17

Figure 5-31 Brake-specific Oil Consumption, OC Fraction, Particle \# (Mineral Oil): Speed $=30$ rps 


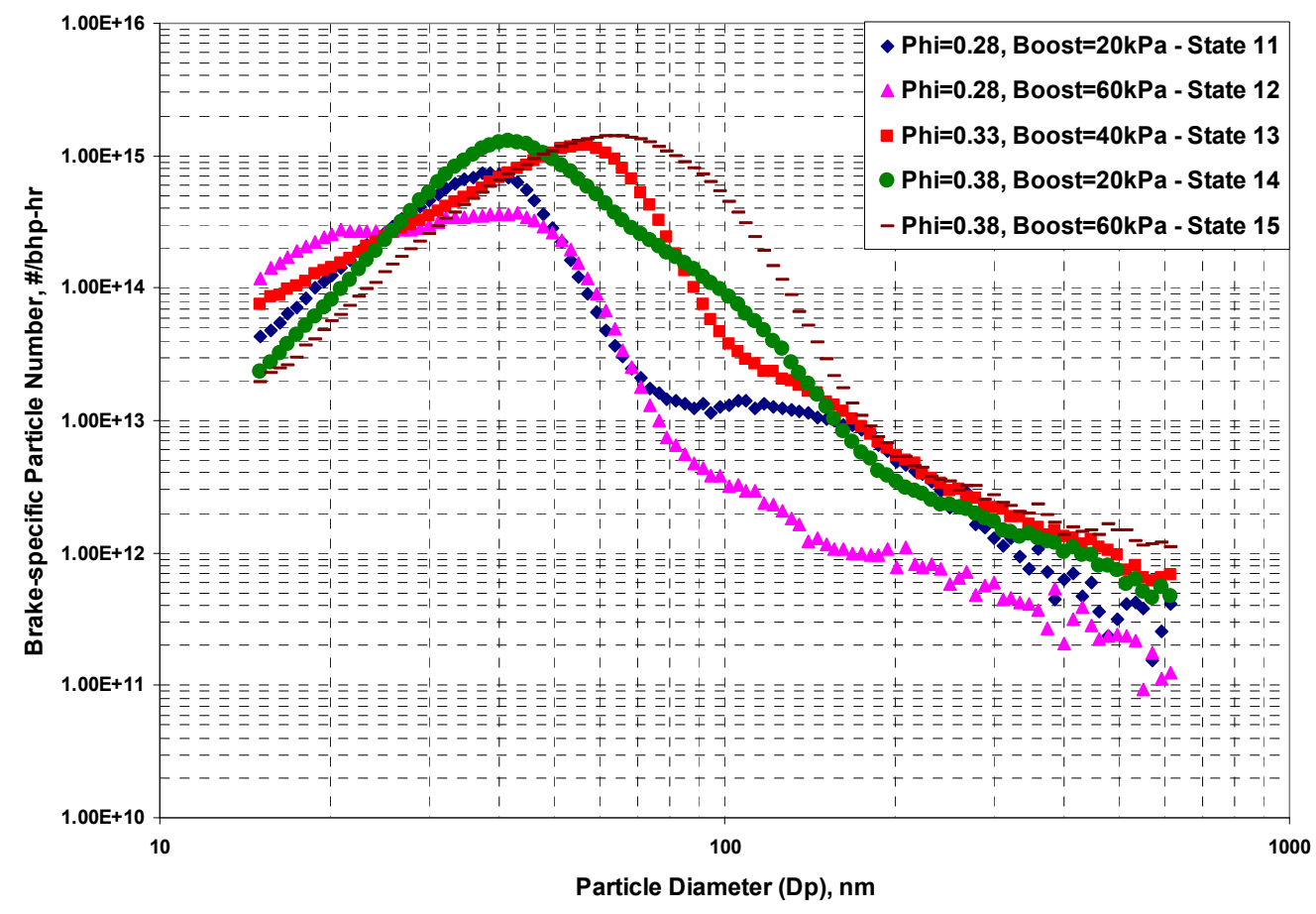

Figure 5-32 Brake-specific Particle Number Distribution (Synthetic Oil): Speed = 30 rps

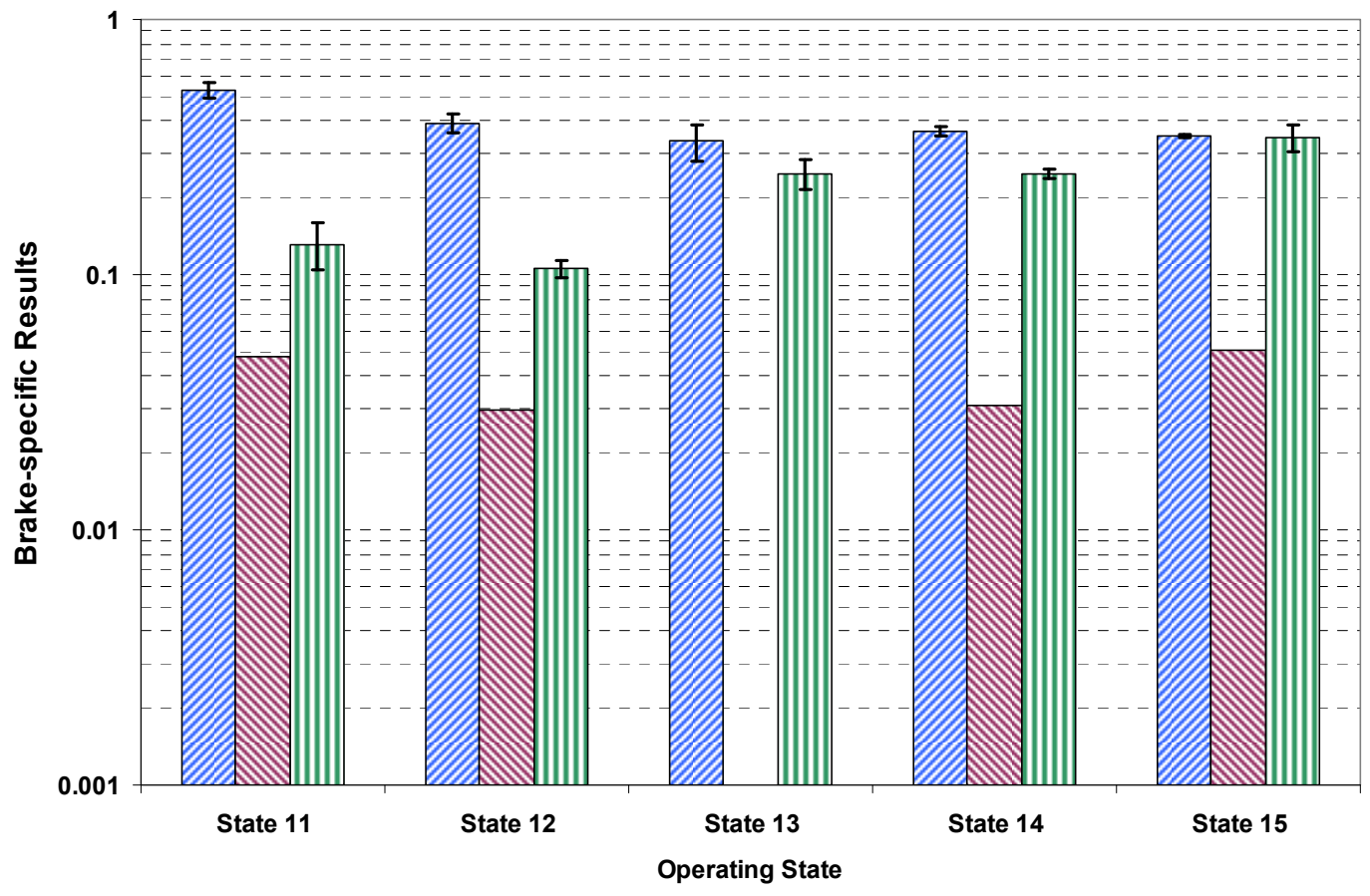

ఐ Oil Consumption, g/bhp-hr $₫$ Organic Fraction, g/bhp-hr \ Particles, \#/bhp-hr/10^17

Figure 5-33 Brake-specific Oil Consumption, OC Fraction, Particle \# (Synthetic Oil): Speed $=30 \mathrm{rps}$ 
The total brake-specific particle number increases for decreasing brake-specific oil consumption. Table 5-8 shows the integrated particle number data for each of the test points with the associated standard deviation and coefficient of variance (COV). The geometric mean diameter (or count median diameter, $\mathrm{CMD}$, for lognormal distribution) is also listed for the operating states tested. Some of the test points have multiple CMDs because of the bimodal distributions; hence, CMD was calculated for each mode. The CMD and geometric standard deviations (GSD) were calculated using the following equations,

$$
C M D=\exp \left[\frac{\sum n_{i} \ln d_{p}}{N}\right]
$$

\section{Equation 5-13}

where, $n_{i}=$ Number of particles in $\mathrm{i}^{\text {th }}$ bin,

$$
\begin{aligned}
& d_{p}=\text { Mean diameter of } i^{\text {th }} \text { bin, } \\
& N=\text { Total number of particles }
\end{aligned}
$$

$$
G S D=\exp \left[\frac{\sum n_{i}\left(\ln d_{p}-\ln C M D\right)^{2}}{N-1}\right]^{1 / 2}
$$

\begin{tabular}{|c|c|c|c|c|c|c|c|c|c|c|}
\hline \multirow[b]{3}{*}{ State No. } & \multicolumn{5}{|c|}{ Mineral Oil } & \multicolumn{5}{|c|}{ Synthetic Oil } \\
\hline & \multicolumn{3}{|c|}{ Integrated Particle Number } & \multirow[b]{2}{*}{ CMD } & \multirow[b]{2}{*}{ GSD } & \multicolumn{3}{|c|}{ Integrated Particle Number } & \multirow[b]{2}{*}{ CMD } & \multirow[b]{2}{*}{ GSD } \\
\hline & Avg (\#/cm3) & S.D. & COV & & & Avg (\#/cm3) & S.D. & COV & & \\
\hline 1 & $3.44 \mathrm{E}+07$ & $1.69 \mathrm{E}+06$ & 0.05 & 233 & 1.65 & $4.74 \mathrm{E}+07$ & $2.88 \mathrm{E}+06$ & 0.06 & 196 & 1.69 \\
\hline 2 & $8.32 \mathrm{E}+07$ & $4.09 \mathrm{E}+06$ & 0.05 & 225 & 1.68 & $5.66 \mathrm{E}+07$ & $6.64 \mathrm{E}+06$ & 0.12 & 200 & 1.72 \\
\hline 3 & $1.28 \mathrm{E}+08$ & $1.24 \mathrm{E}+07$ & 0.10 & 192 & 1.66 & $1.38 \mathrm{E}+08$ & $2.14 \mathrm{E}+07$ & 0.16 & 137 & 2.03 \\
\hline 4 & $3.10 \mathrm{E}+08$ & $4.59 \mathrm{E}+06$ & 0.01 & 130 & 2.35 & $4.79 \mathrm{E}+08$ & $1.64 \mathrm{E}+07$ & 0.03 & 121 & 2.20 \\
\hline 5 & $5.24 \mathrm{E}+08$ & $1.11 \mathrm{E}+07$ & 0.02 & 125 & 2.19 & $5.31 \mathrm{E}+08$ & $2.00 \mathrm{E}+07$ & 0.04 & 95 & 2.49 \\
\hline 6 & $1.33 \mathrm{E}+08$ & $3.66 \mathrm{E}+06$ & 0.03 & $(31,209)$ & $(1.31,1.49)$ & $5.14 \mathrm{E}+08$ & $1.28 \mathrm{E}+08$ & 0.25 & $(35,172)$ & $(1.39,1.55)$ \\
\hline 7 & $2.75 \mathrm{E}+08$ & $2.44 \mathrm{E}+07$ & 0.09 & 112 & 3.41 & $3.44 \mathrm{E}+08$ & $1.15 \mathrm{E}+07$ & 0.03 & $(32,145)$ & $(1.42,1.65)$ \\
\hline 8 & $5.90 \mathrm{E}+08$ & $4.20 \mathrm{E}+07$ & 0.07 & $(34,186)$ & $(1.33,1.51)$ & $1.54 \mathrm{E}+09$ & $1.68 \mathrm{E}+08$ & 0.11 & 48 & 1.73 \\
\hline 9 & $1.97 \mathrm{E}+09$ & $1.13 \mathrm{E}+08$ & 0.06 & 49 & 1.59 & $7.32 \mathrm{E}+08$ & $5.04 \mathrm{E}+07$ & 0.07 & $(43,163)$ & $(1.54,1.43)$ \\
\hline 10 & $2.00 \mathrm{E}+09$ & $4.46 \mathrm{E}+07$ & 0.02 & 42 & 1.57 & $1.17 \mathrm{E}+09$ & $5.87 \mathrm{E}+07$ & 0.05 & 74 & 2.28 \\
\hline 11 & $4.35 \mathrm{E}+08$ & $5.03 \mathrm{E}+07$ & 0.12 & $(28,189)$ & $(1.27,1.58)$ & $1.42 \mathrm{E}+09$ & $1.46 \mathrm{E}+08$ & 0.10 & 36 & 1.43 \\
\hline 12 & $1.51 \mathrm{E}+09$ & $3.36 \mathrm{E}+08$ & 0.22 & 36 & 1.48 & $1.46 \mathrm{E}+09$ & $1.03 \mathrm{E}+08$ & 0.07 & 32 & 1.50 \\
\hline 13 & $2.94 \mathrm{E}+09$ & $2.66 \mathrm{E}+08$ & 0.09 & 56 & 1.75 & $4.15 \mathrm{E}+09$ & $2.91 \mathrm{E}+08$ & 0.07 & 46 & 1.61 \\
\hline 14 & $3.14 \mathrm{E}+09$ & $2.18 \mathrm{E}+08$ & 0.07 & 55 & 1.79 & $4.46 \mathrm{E}+09$ & $9.19 \mathrm{E}+07$ & 0.02 & 43 & 1.51 \\
\hline 15 & $5.84 \mathrm{E}+09$ & $1.66 \mathrm{E}+08$ & 0.03 & 60 & 1.77 & $7.18 \mathrm{E}+09$ & $4.11 \mathrm{E}+08$ & 0.06 & 59 & 1.88 \\
\hline
\end{tabular}

\section{Equation 5-14}

Table 5-8 Particle Number Statistics for the Operating States 
It was observed that the CMD shifted to the smaller diameters as speed increased. The lower CMDs also correspond to operating states for which the ratio of organic fraction based oil consumption to gaseous emissions based oil consumption is lower (Refer Table 5-3). This signifies that as the organic fraction (which represents unburned and partially burned oil) increases, there is a corresponding rise in the accumulation mode particles. The shift in distribution to lower particle diameters at the higher speeds may also be attributed to the lesser time for agglomeration at high speeds.

PM distributions become bimodal with increasing speed (that is, the nuclei mode appears) in the case of some of the operating states. The increase in phi was found to increase the total particle number, and also shifted the CMDs to the lower diameters, whereas increase in boost resulted in increase in particle numbers without making any significant change in the size distribution pattern.

The results show no significant effects of volatility on particle formation. It is evident that the PM concentrations and size distributions depend more on the amount of oil consumed and the combustion conditions. Figures 5-34 through 5-36 show the oil-specific particle number (\#/g of oil) for the two oils for the operating conditions tested. The particle size distributions, the total particle numbers, and the mean diameters are very similar for the two oils tested, showing no significant advantage for either lubricant oil in terms of number of particles formed. The mean diameters were slightly lower for the synthetic oil compared to the mineral oil for the low speed operating states.

The lower organic fraction and trace-metal concentrations for the synthetic oil compared to mineral oil did not result in a corresponding decrease in particles formed for the synthetic oil (even though the mean diameters were slightly lower) leading to a possible explanation that most of the particles were formed from homogenous nucleation of the gas phase hydrocarbons. The nanoparticle formation is also driven by an absence of carbonaceous soot particles, which usually act as a "sponge" for the volatile particle forming precursors [81]. 


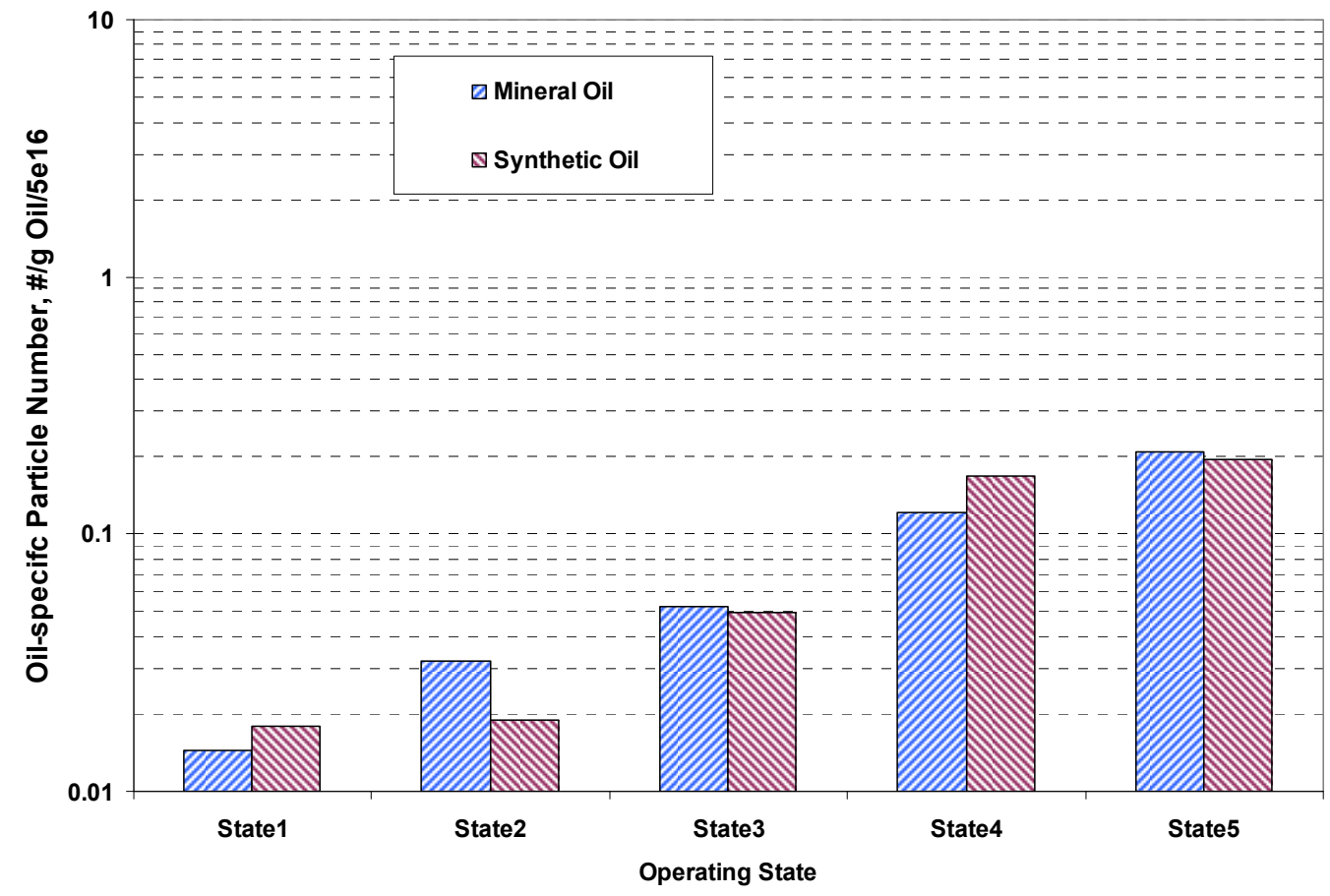

Figure 5-34 Comparison of Oil-specific Particle Number : Speed = 15 rps

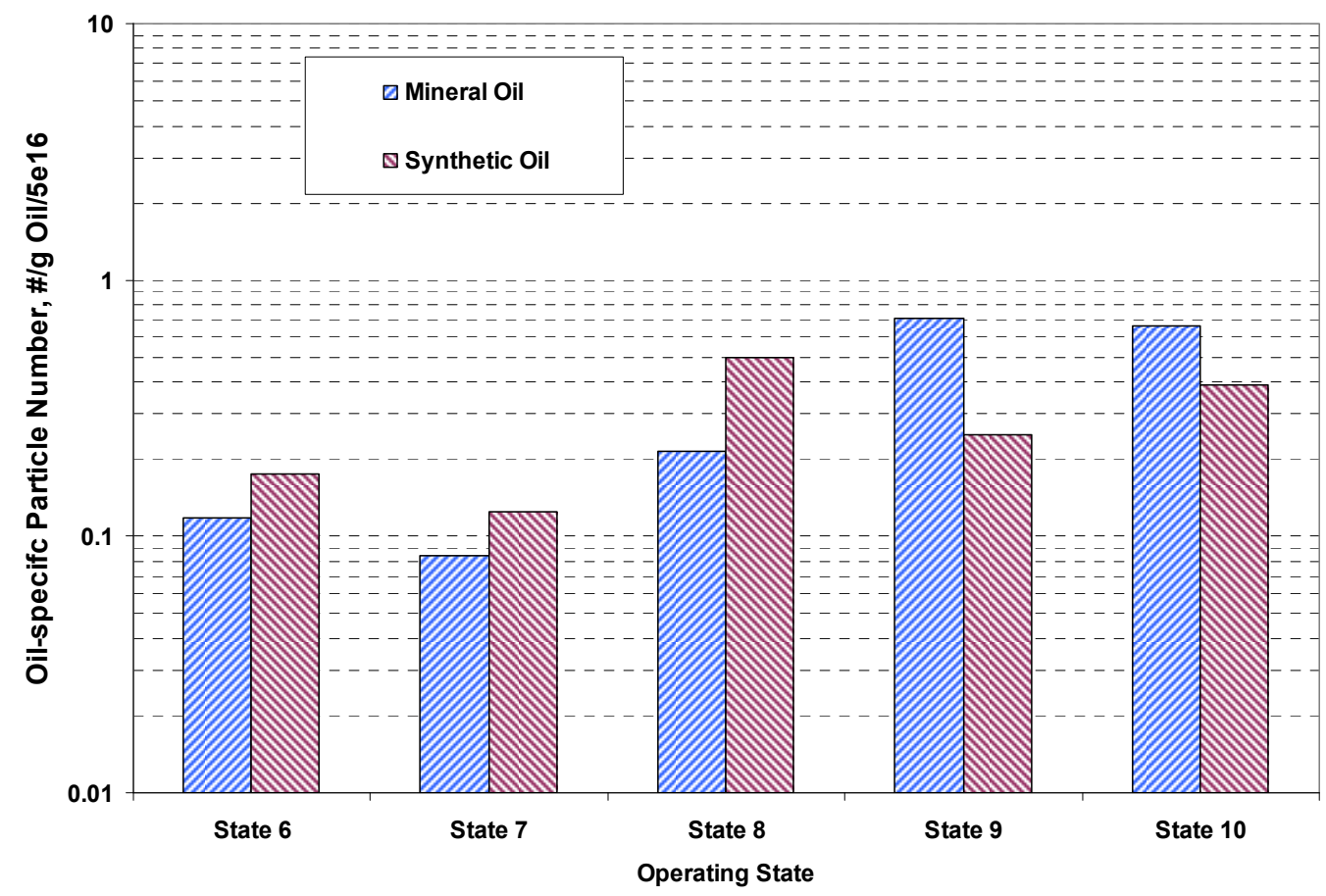

Figure 5-35 Comparison of Oil-specific Particle Number : Speed $=22.5$ rps 


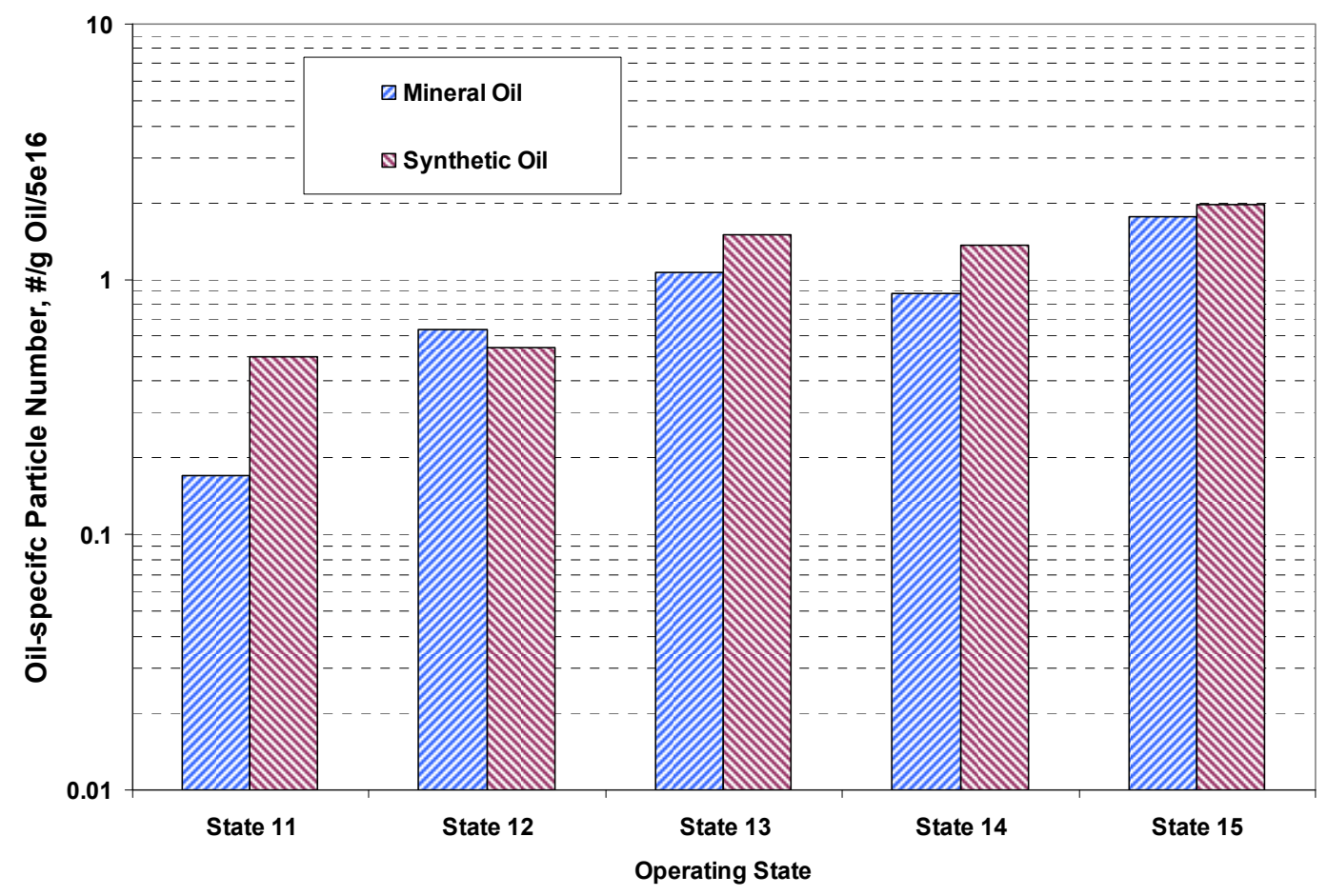

Figure 5-36 Comparison of Oil-specific Particle Number: Speed = 30 rps

The brake-specific particle number increases with speed, equivalence ratio, and boost and the increase is seen primarily in the number of nanoparticles formed. Even though the brakespecific oil consumed decreases, the increase in number is a result of the increase in the amount of oil (g/hr) consumed. In summary, as more oil consumed, higher the particles formed, and higher the combustion temperature, higher the number of nanoparticles formed.

\subsubsection{Particle Size Distribution (Motoring versus Combustion)}

Particle size distributions were measured at motoring (no-fuel operation) conditions for five different steady-state modes. It was assumed that the motoring operation results would shed light on how the oil is transported into the combustion chamber, and eventually gets consumed or partially consumed when combustion occurs.

Figures 5-37 and 5-39 illustrate the particle size distribution results for motoring conditions at a constant boost (40 kPa) operation (at the three levels of speed), and for constant speed (22.5 rps) operation (at the three levels of boost), respectively.

Figures 5-38 and 5-40 show the results for corresponding operating states (that is, same boost and speed) with combustion at a phi of 0.33 . 


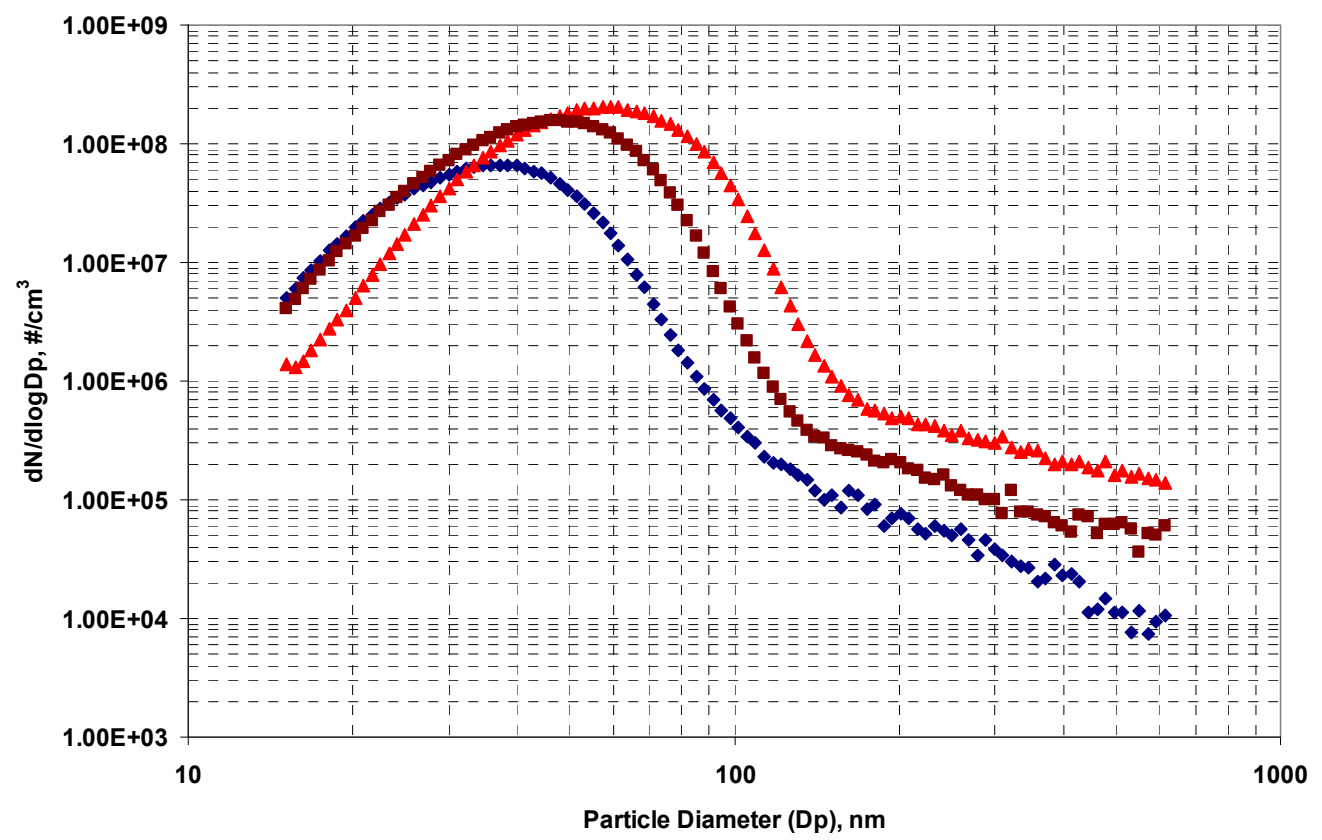

$\bullet$ Speed $=15 \mathrm{rps}$ (Motoring) $\Delta$ Speed $=22.5 \mathrm{rps}$ (Motoring) $\backsim$ Speed $=30 \mathrm{rps}$ (Motoring)

Figure 5-37 Particle Size Distribution (Motoring): Constant Boost $=40 \mathrm{kPa}$

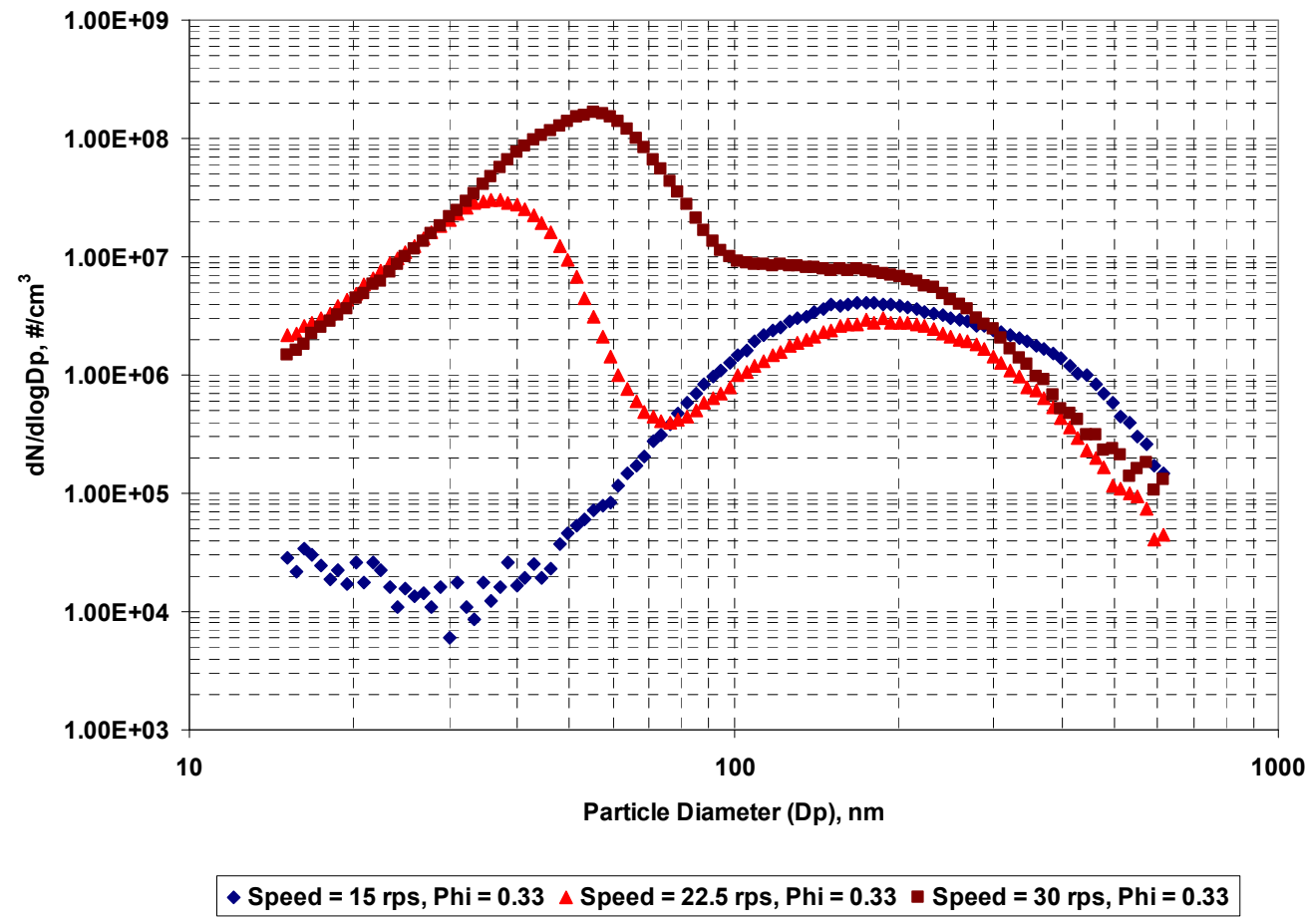

Figure 5-38 Particle Size Distribution: Constant Boost $=40 \mathrm{kPa}, \mathrm{Phi}=\mathbf{0 . 3 3}$ 


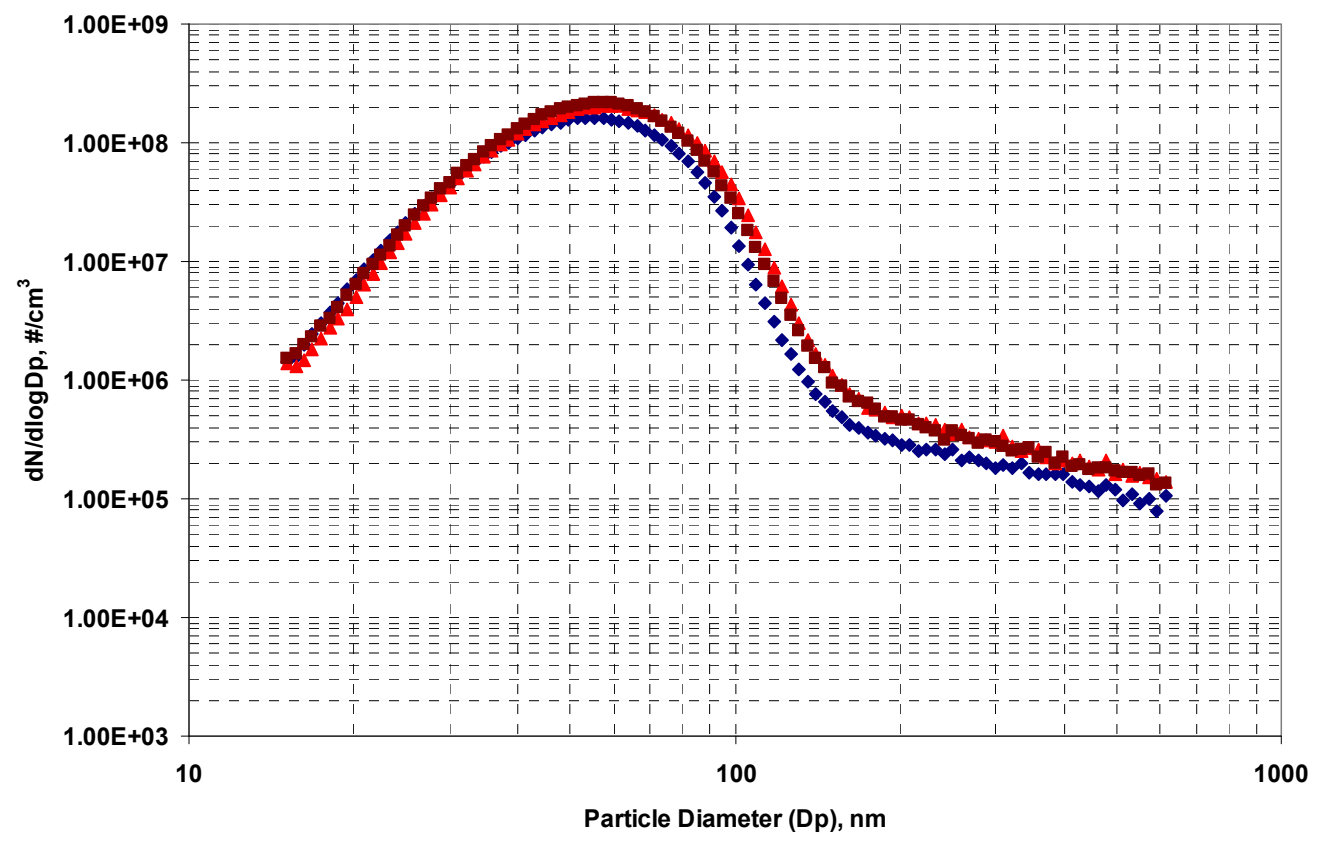

$\bullet$ Boost $=20 \mathrm{kPa}$ (Motoring) $\triangle$ Boost $=40 \mathrm{kPa}$ (Motoring) $\backsim$ Boost $=60 \mathrm{kPa}$ (Motoring)

Figure 5-39 Particle Size Distribution (Motoring): Constant Speed = 22.5 rps

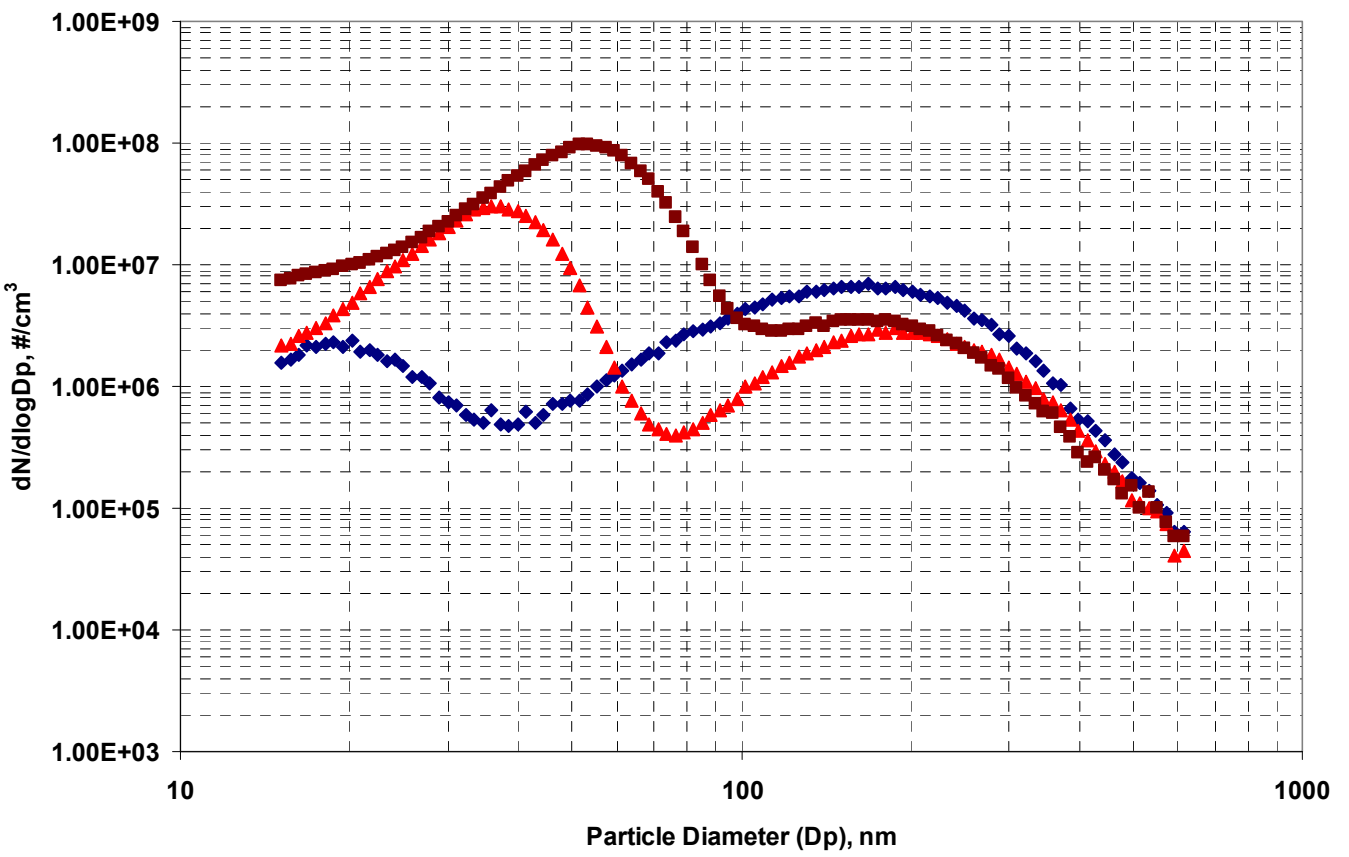

$\bullet$ Boost $=20 \mathrm{kPa}, \mathrm{Phi}=0.33 \triangle$ Boost $=40 \mathrm{kPa}, \mathrm{Phi}=0.33 \backsim$ Boost $=60 \mathrm{kPa}, \mathrm{Phi}=0.33$

Figure 5-40 Particle Size Distribution: Constant Speed $=22.5$ rps, $\mathbf{P h i}=0.33$ 
Table 5-5 shows integrated results, exhaust temperatures and maximum cylinder pressures obtained for the different states.

The difference between the combustion mode and the motoring mode in all the cases is an increase in the accumulation mode particles as a result of combustion. The amount of oil entering the combustion chamber and hence number of particles formed will be different in the two modes because of the difference in the cylinder pressures and the combustion conditions. Nevertheless, results provide evidence of lubricant oil derived nanoparticle formation at motoring conditions. This would be observed in on-road vehicles during coasting or downhill drives.

At lower speeds, the accumulation mode was dominant. This could be attributed to the higher ratio of particulate phase to gas phase hydrocarbons as can be seen from Table 5-2 presented in Section 5-2. 
Table 5-9 Comparison of Integrated Particle Number, Exhaust Temperatures, and Maximum Cylinder Pressures (Combustion vs Motoring)

\begin{tabular}{|c|c|c|c|}
\hline \multicolumn{2}{|c|}{ Motoring (Constant Boost = 40 kPa) } & \multicolumn{3}{|c|}{} \\
\hline Speed (rps) & Total (\#/cm3) & Exhaust Temp (oC) & Pmax (bar) \\
\hline 15 & $1.54 \mathrm{E}+09$ & 38 & 40 \\
22.5 & $4.82 \mathrm{E}+09$ & 43 & 40 \\
30 & $3.65 \mathrm{E}+09$ & 60 & 40 \\
\hline
\end{tabular}

\begin{tabular}{|c|c|c|c|c|}
\hline Combustion & \multicolumn{5}{|l|}{} \\
\hline Speed (rps) & Phi & Total (\#/cm3) & Exhaust Temp (oC) & Pmax (bar) \\
\hline 15 & 0.33 & $1.28 \mathrm{E}+08$ & 270 & 60 \\
22.5 & 0.33 & $5.90 \mathrm{E}+08$ & 294 & 60 \\
30 & 0.33 & $2.94 \mathrm{E}+09$ & 316 & 60 \\
\hline
\end{tabular}

\begin{tabular}{|c|c|c|c|}
\hline \multicolumn{2}{|c|}{ Motoring (Constant Speed = 22.5 rps) } & \\
\hline Boost (kPa) & Total (\#/cm3) & Exhaust Temp (oC) & Pmax (bar) \\
\hline 20 & $3.82 E+09$ & 51 & 35 \\
40 & $4.82 E+09$ & 43 & 41 \\
60 & $4.97 \mathrm{E}+09$ & 35 & 47 \\
\hline
\end{tabular}

\begin{tabular}{|c|cc|c|c|}
\hline Combustion & \multicolumn{4}{|c|}{} \\
\hline Boost (kPa) & Phi & Total (\#/cm3) & Exhaust Temp (oC) & Pmax (bar) \\
\hline 20 & 0.33 & $2.59 \mathrm{E}+08$ & 300 & 55 \\
40 & 0.33 & $5.90 \mathrm{E}+08$ & 294 & 61 \\
60 & 0.33 & $1.97 \mathrm{E}+09$ & 297 & 68 \\
\hline
\end{tabular}

\subsubsection{Particle Surface Area Distribution Analysis}

In recent years the relation between nanoparticles to health effects has been of concern [82-84]. The increased concentrations of nanoparticles result in a greater surface area which in turn results in higher exposure of PM-bound toxic compounds. Figures 5-41 through 5-49 show the surface area distributions for the different operating states for the two oils and also the integrated surface areas. The total geometric surface area was calculated from the particle number data based on electrical mobility diameter assuming the particles to be spherical. The surface area results trend in much the same way as the particle number results: higher the number, higher the surface area. The increase in number is always due to an increase in the concentration of nanoparticles; hence, increased surface area. 


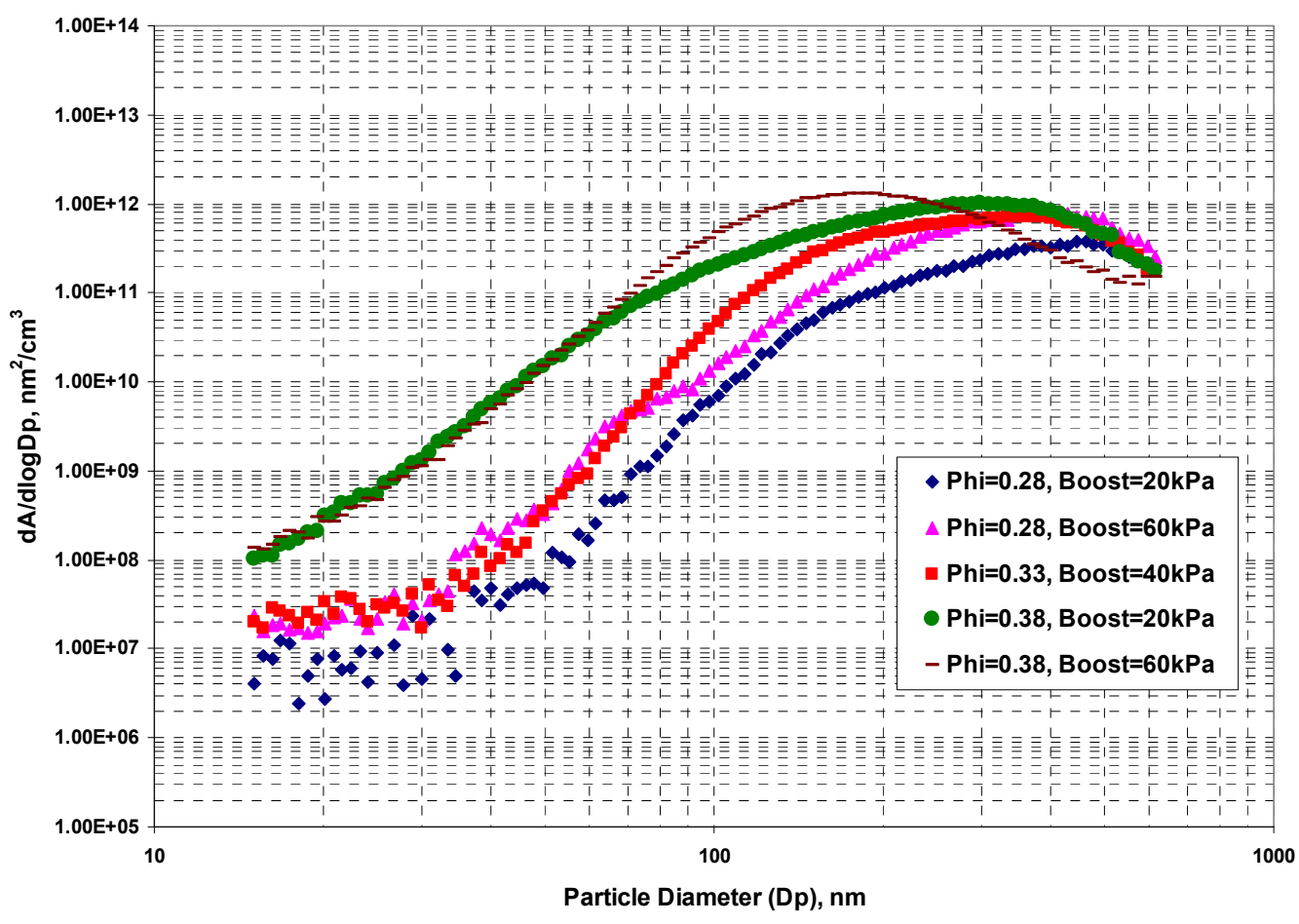

Figure 5-41 Particle Surface Area Distribution (Mineral Oil): Speed = 15 rps

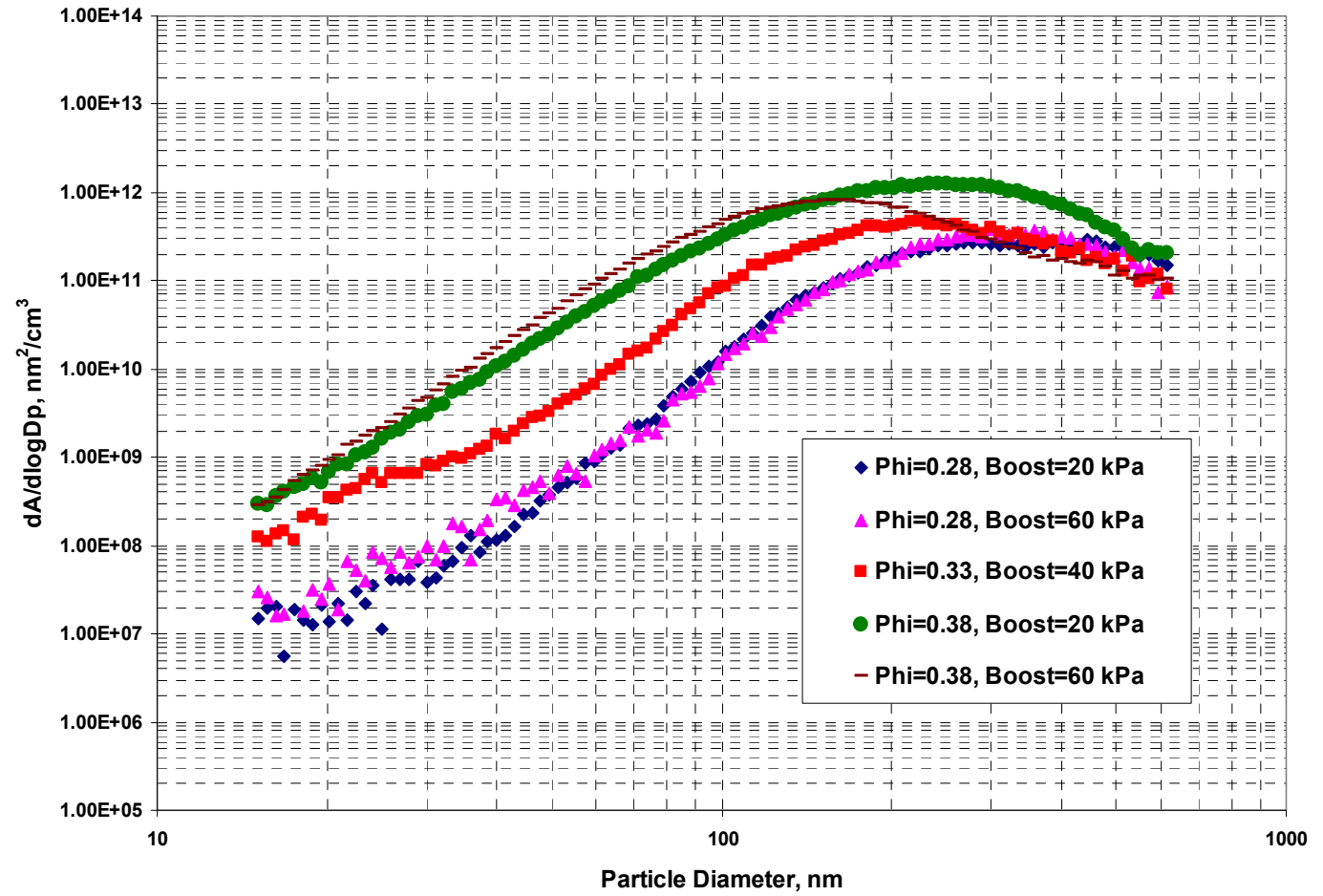

Figure 5-42 Particle Surface Area Distribution (Synthetic Oil): Speed = 15 rps 


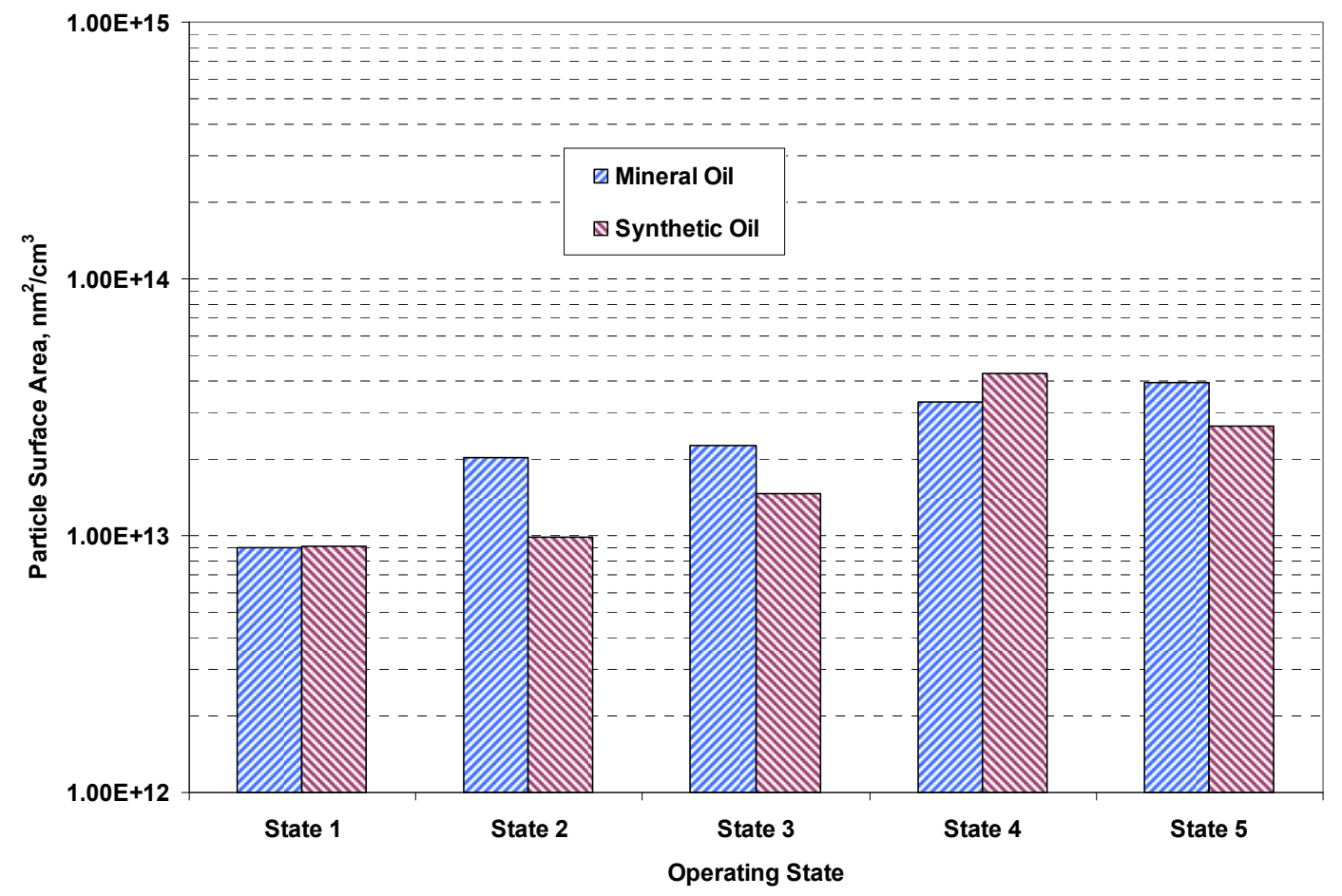

Figure 5-43 Comparison of Integrated Particle Surface Area (Mineral vs. Synthetic): Speed $=15$ rps

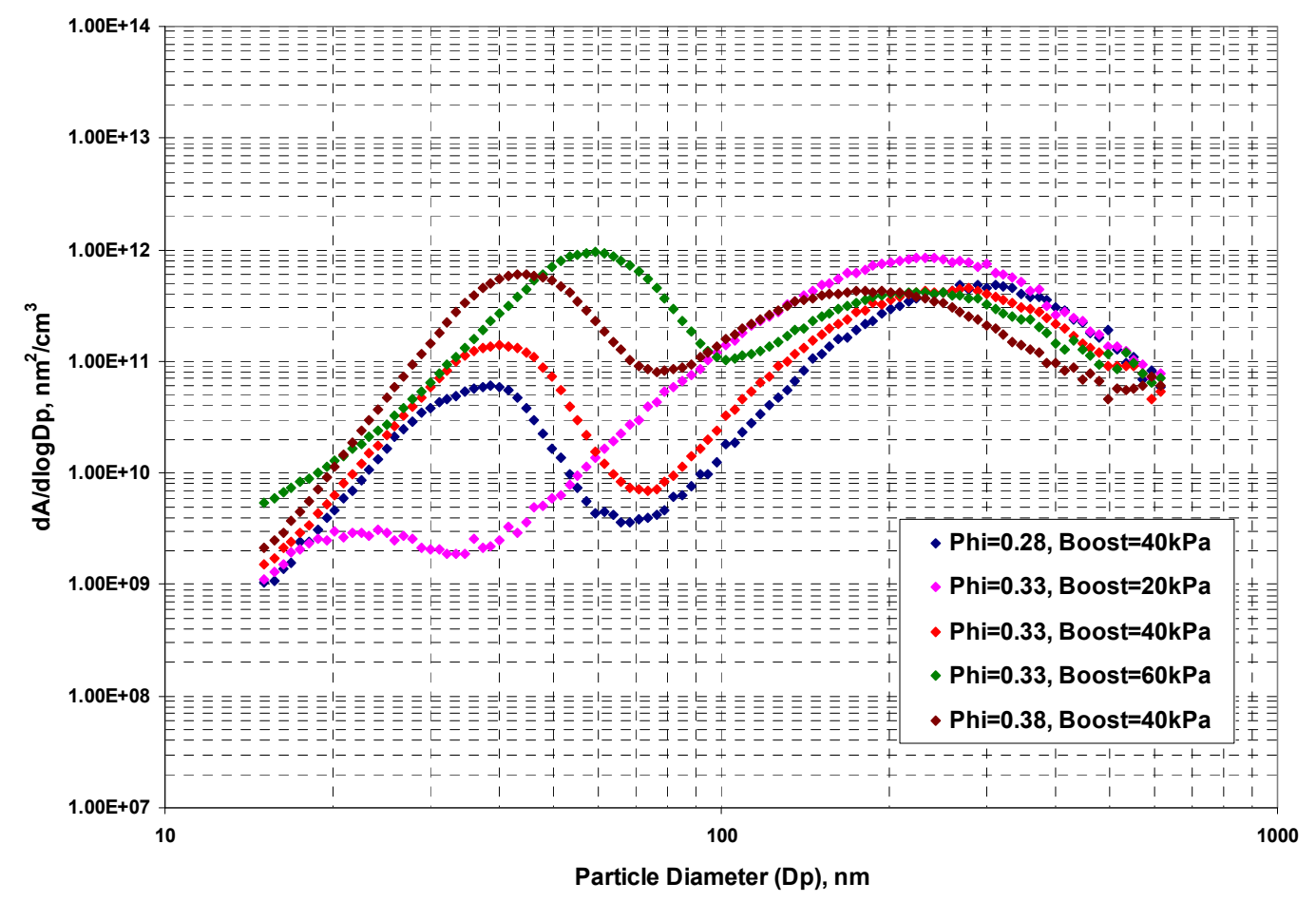

Figure 5-44 Particle Surface Area Distribution (Mineral Oil): Speed = 22.5 rps 


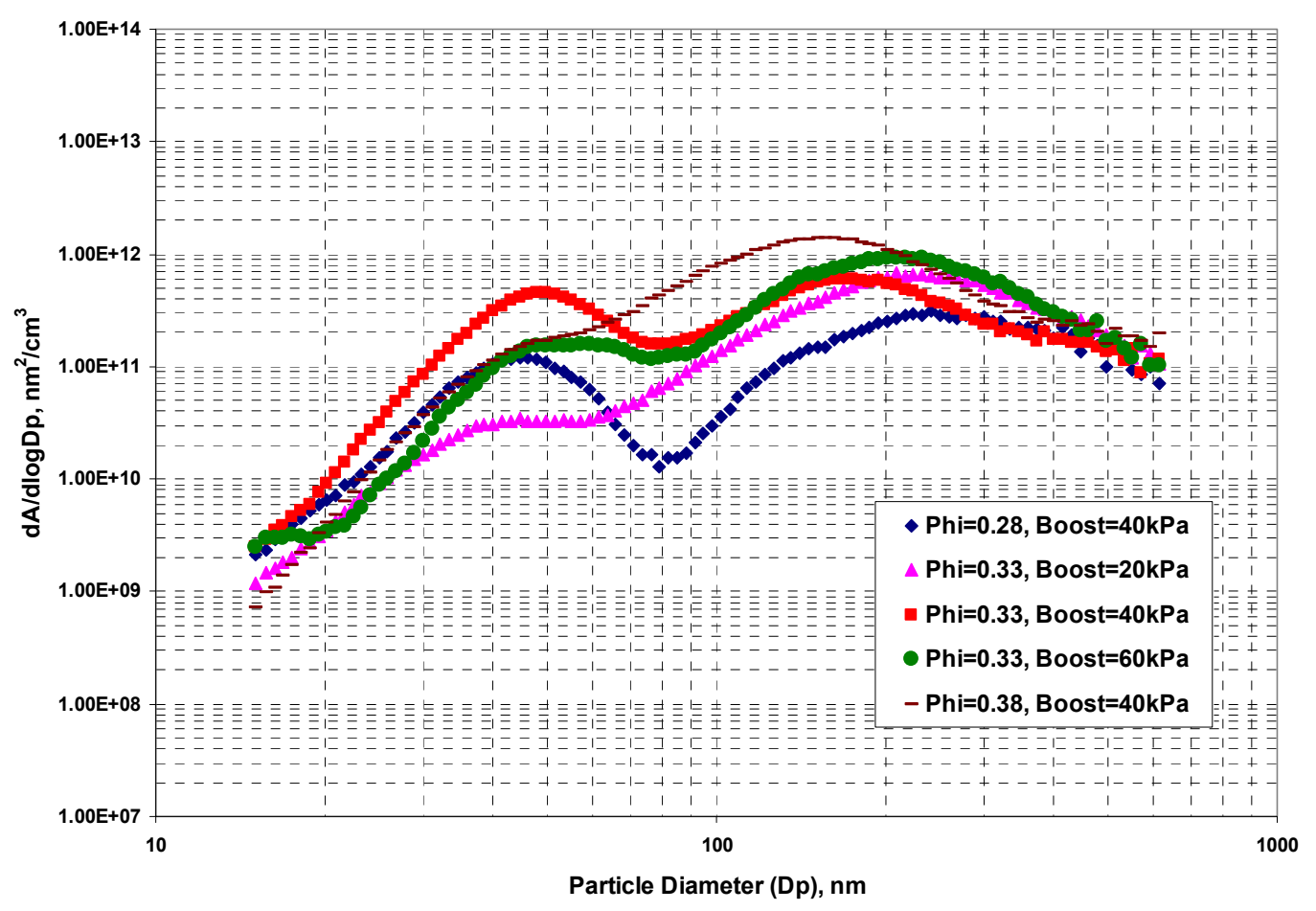

Figure 5-45 Particle Surface Area Distribution (Synthetic Oil): Speed = 15 rps

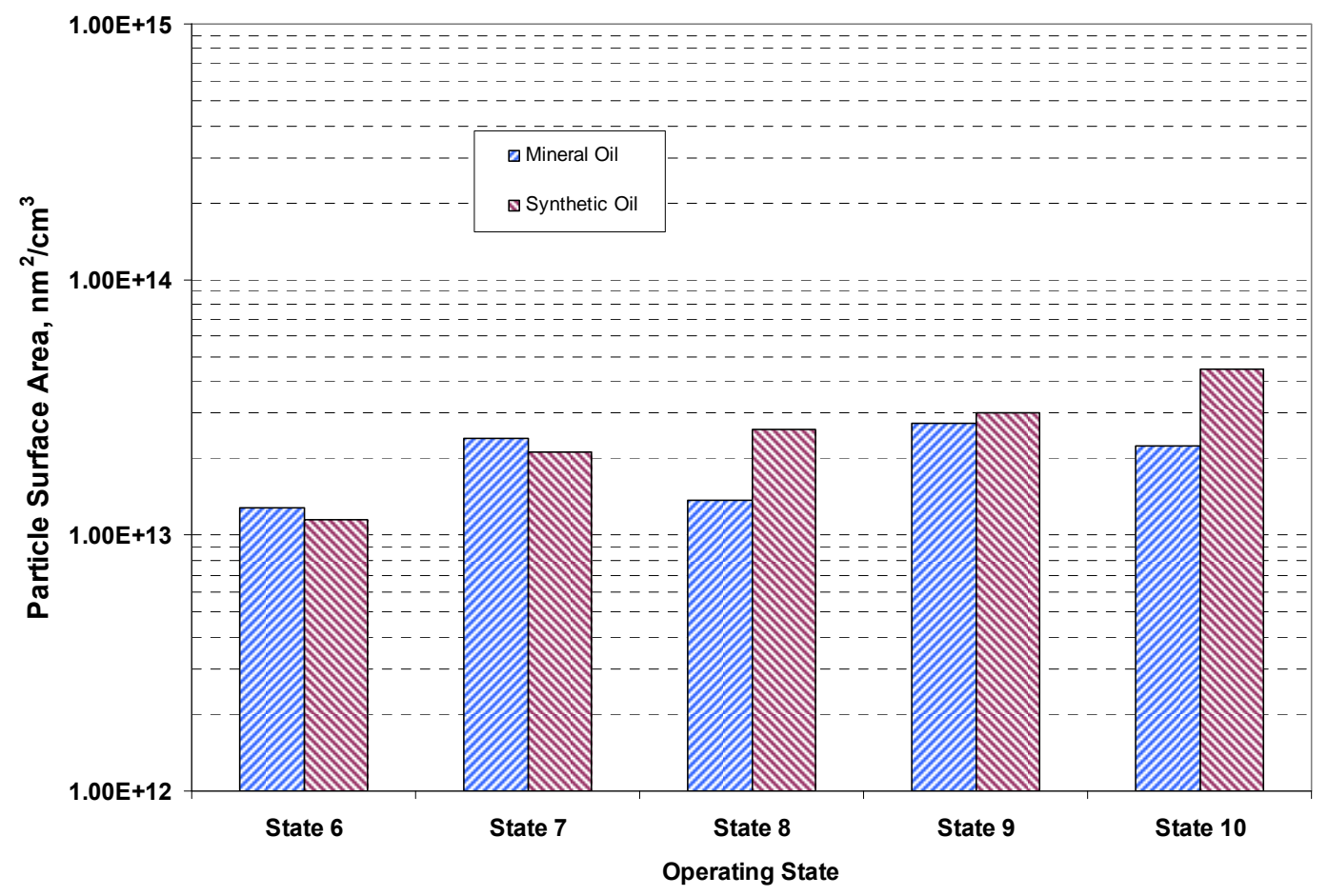

Figure 5-46 Comparison of Integrated Particle Surface Area (Mineral vs. Synthetic): Speed $=22.5 \mathrm{rps}$ 


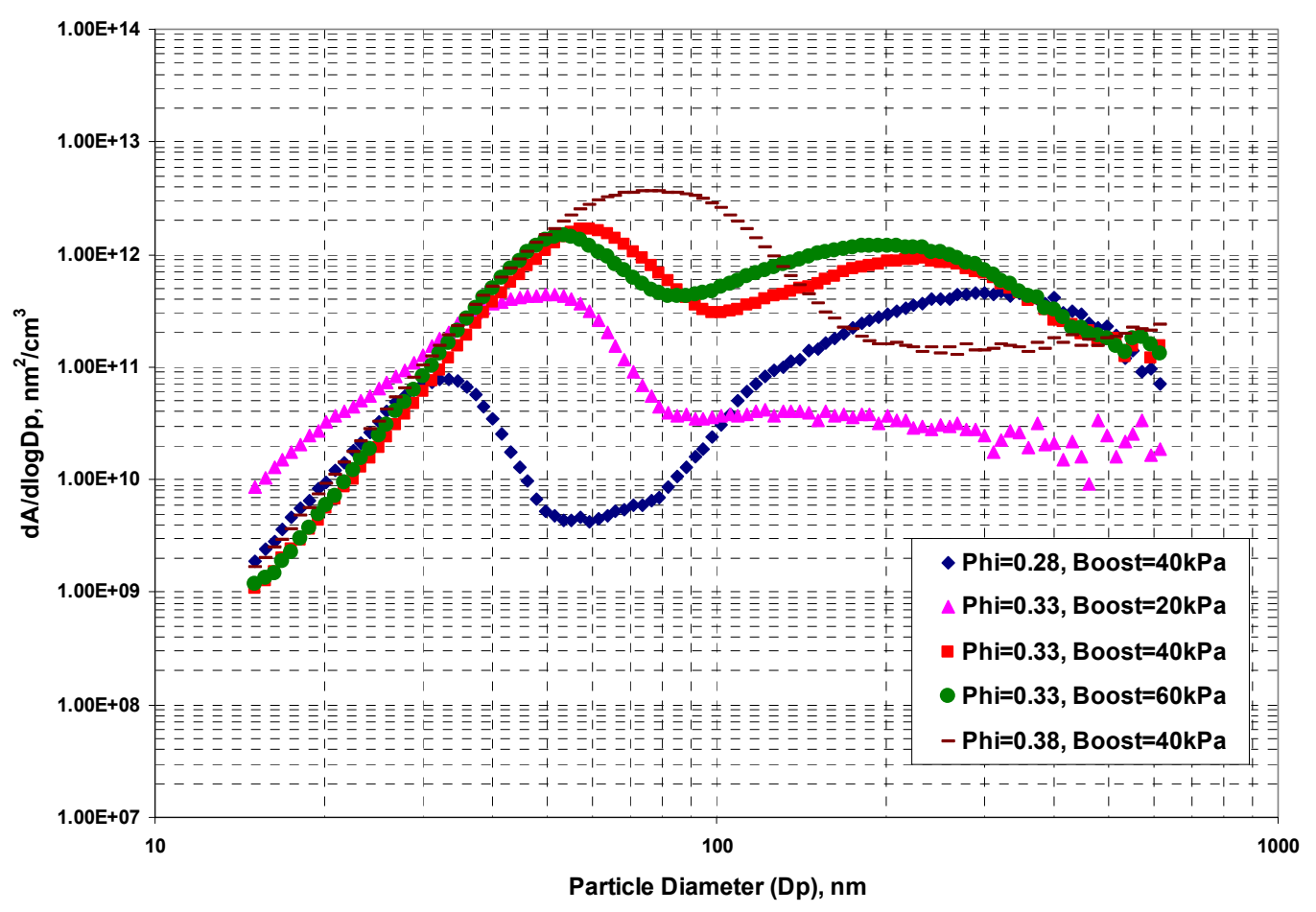

Figure 5-47 Particle Surface Area Distribution (Mineral Oil): Speed $=30$ rps

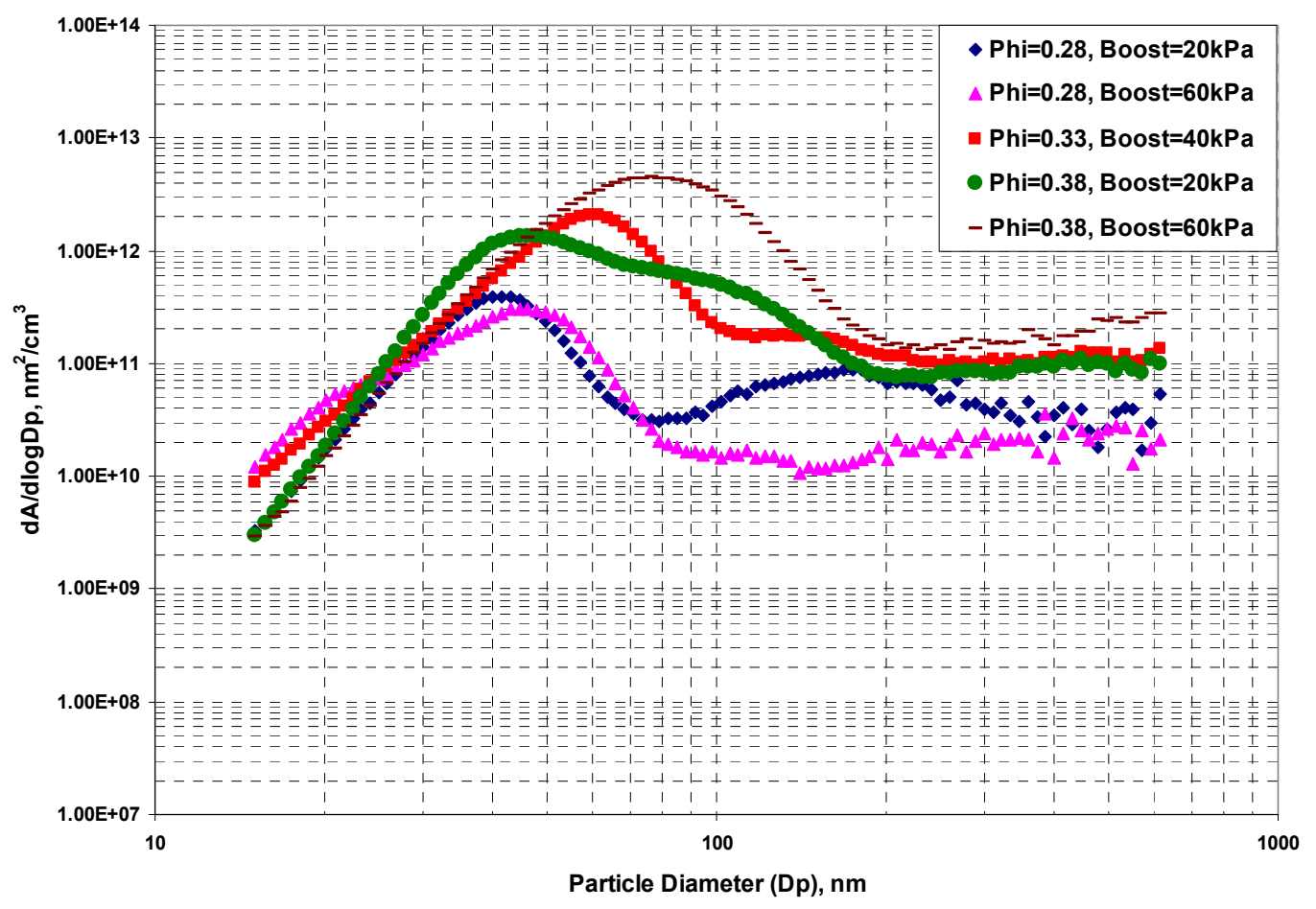

Figure 5-48 Particle Surface Area Distribution (Synthetic Oil): Speed = 30 rps 


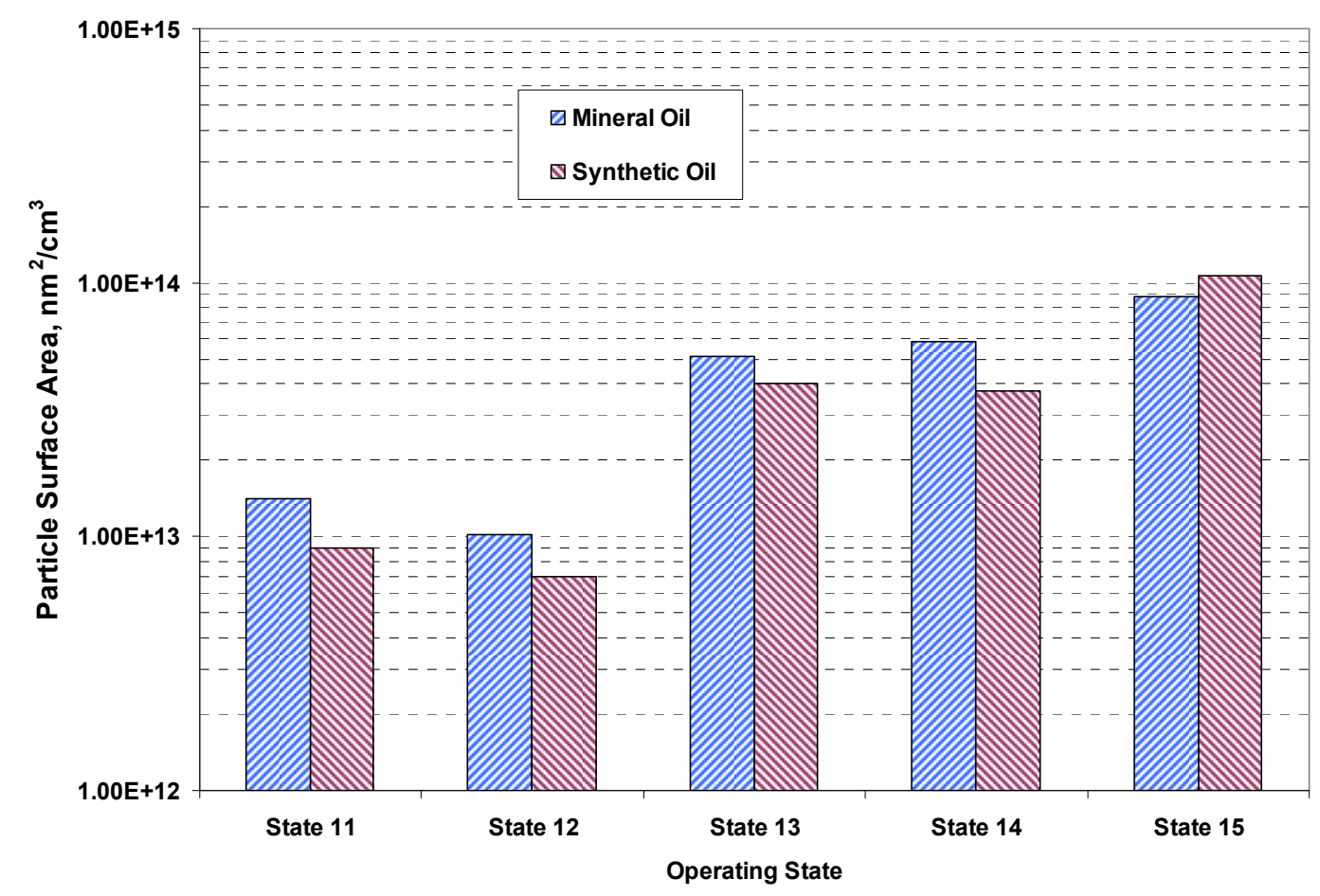

Figure 5-49 Comparison of Integrated Particle Surface Area (Mineral vs. Synthetic): Speed $=30 \mathrm{rps}$

As seen for the particle number behavior, the surface area is also found to increase with increasing speed, load and boost. Mutagenicity (a measure of the toxicity associated with a substance) of the particulate matter collected for selected operating states were simultaneously performed with this study by Solano [23]. Results showed increased mutagenic activity with increasing speed and load, which relates with the increased surface area found at these conditions. It was found that even though the surface area, and the particle numbers were similar for both oils, the mineral oil was found to be more mutagenic at most of the operating states. This could be due to multiple reasons. One, the organic fraction was more for the mineral oil which could be the driving factor for mutagenicity, and second, the chemical properties of the synthetic base stock. However, considerable more experiments are needed before arriving at any firm conclusions. 


\subsection{Lubricant Oil Aging: Effects on Lubricant Properties}

Lubricant samples were collected after the lubricant break-in and approximately at 15-20 hour intervals over the 50 hour test matrix for both test oils. A previous study [51] on a hydrogen fueled engine has reported a decrease in kinematic viscosity at $100^{\circ} \mathrm{C}$ and a breakdown in lubricating and wear-resisting additives after a limited but unspecified testing time. The study had also suggested crankcase ventilation as a possible remedy to avoid such a situation. The current study used a forced crankcase ventilation system which consisted of a continuous supply of site air so as to purge the crankcase of any blow-by gases into the exhaust stack. Table 5-6 shows the lubricant properties analyzed for samples collected at different intervals. The lubricant analysis was performed by the Valvoline Product Development Laboratory.

Viscosities and volatilities were fairly uniform over the entire testing period for both the test oils. The carbon, and hydrogen mass fractions, and the trace metal fractions were also the same for the different samples.

The Total Acid Number (TAN) and Total Base Number (TBN) are good indicators of oil quality. TAN is a measure of the acidity level of the lubricant oil. Increase in TAN indicates lubricant oxidation or contamination of the oil with acidic products. TBN on the other hand is a measure of the alkalinity or the alkaline additives of the lubricant oil. The alkaline additives are required to neutralize the acidic products (for example, nitric acid or sulfuric acid formed by reaction of $\mathrm{NOx}$ or $\mathrm{SO}_{2}$ with water vapor). The TAN usually increases and TBN usually decreases over period of time for in-service lubricant oil. The time of cross over of TAN and TBN is an indicator of loss of lubricant properties. In this study, both the TAN and TBN were about the same level for all the samples. In fact, the TAN and TBN were found to decrease slightly over the test duration. The same can be said for the oxidation and nitration levels also.

The water content was also found to decrease with time. The water is usually evaporated as a result of the hot operating conditions during engine operation. In the case of a hydrogenfueled engine, the by-product of combustion is water; hence, the water content would be of concern, as water would deteriorate the lubricant properties.

Results presented in Table 5-6 show no significant variation in properties over the 50 hour testing time for both oils. The short test duration, and forced crankcase ventilation could be offered as reasons for the lack of variations in oil properties. 
Table 5-10 Lubricant Oil Properties at Various Testing Intervals

\begin{tabular}{|c|c|c|c|c|c|c|c|c|c|c|}
\hline Oil Type & & Mine & Oil (Valvo & & & & Synt & tic Oil (Ams & & \\
\hline Sample Age & Fresh & $\sim 3 \mathrm{hr}$ & $\sim 18 \mathrm{hr}$ & $\sim 33 \mathrm{hr}$ & $\sim 48 \mathrm{hr}$ & Fresh & $\sim 3 \mathrm{hr}$ & $\sim 18 \mathrm{hr}$ & $\sim 33 \mathrm{hr}$ & $\sim 48 \mathrm{hr}$ \\
\hline Properties & & & & & & & & & & \\
\hline Carbon (wt. \%) & 85.56 & 85.62 & 86.55 & 86 & 85.75 & 85.41 & 85.03 & 84.04 & 84.16 & 83.72 \\
\hline Hydrogen (wt. \%) & 13.86 & 13.85 & 14.25 & 13.74 & 13.68 & 14.22 & 14.14 & 13.95 & 14.05 & 14 \\
\hline Viscosity@ 100 C & 15.01 & 14.997 & 14.94 & 14.95 & 14.96 & 13.97 & 13.99 & 14.02 & 14.03 & 14.06 \\
\hline Viscosity @ 40 C & 140.76 & 141.36 & 141.21 & 140.97 & 140.64 & 103 & 103.13 & 103.76 & 103.61 & 103.61 \\
\hline Pour Point (oC) & -27 & -27 & -27 & -27 & -27 & -48 & -48 & -48 & -45 & -45 \\
\hline Noack (\% wt. loss) & $2.68 \%$ & $2.89 \%$ & $2.97 \%$ & $2.98 \%$ & $2.91 \%$ & $4.17 \%$ & $4.43 \%$ & $4.57 \%$ & $4.38 \%$ & $4.42 \%$ \\
\hline X-Ray Metals & & & & & & & & & & \\
\hline $\mathrm{Ca}$ (wt. \%) & 0.112 & 0.111 & 0.115 & 0.114 & 0.113 & 0.118 & 0.121 & 0.12 & 0.117 & 0.118 \\
\hline$Z n$ (wt. \%) & 0.03 & 0.031 & 0.031 & 0.031 & 0.031 & 0.03 & 0.03 & 0.03 & 0.03 & 0.03 \\
\hline$P$ (wt. \%) & 0.022 & 0.02 & 0.02 & 0.022 & 0.021 & 0.019 & 0.019 & 0.018 & 0.021 & 0.019 \\
\hline$S$ (wt. \%) & 0.079 & 0.075 & 0.077 & 0.079 & 0.081 & 0.075 & 0.075 & 0.074 & 0.075 & 0.076 \\
\hline Water \% & 0.075 & 0.051 & 0.057 & 0.045 & 0.049 & 0.054 & 0.054 & 0.047 & 0.05 & 0.039 \\
\hline Sulfated Ash \% & 0.371 & 0.427 & 0.39 & 0.347 & 0.438 & 0.43 & 0.366 & 0.45 & 0.442 & 0.421 \\
\hline TAN & 1.04 & 0.89 & 1.01 & 0.9 & 0.78 & 1.23 & 1.22 & 1.1 & 1.09 & 1.16 \\
\hline TBN & 6.18 & 5.22 & 5.25 & 4.88 & 5.21 & 4.26 & 5.68 & 4.49 & 4.74 & 4.46 \\
\hline Fuel \% & 0.5 & 0.5 & 0.5 & 0.5 & 1.3 & 0.5 & 0.5 & 0.5 & 0.5 & 0.5 \\
\hline Soot \% & 0 & 0 & 0 & 0 & 0 & 0 & 0 & 0 & 0 & 0 \\
\hline Oxidation & 6 & 6 & 7 & 6 & 6 & 6 & 9 & 9 & 6 & 6 \\
\hline Nitration & 8 & 8 & 11 & 8 & 8 & 8 & 9 & 10 & 8 & 8 \\
\hline
\end{tabular}




\section{CONCLUSIONS AND RECOMMENDATIONS}

The objective of the study was to determine lubricant oil consumption as a function of engine operating conditions, and also provide an understanding of the lubricant oil consumed that ends up in the gaseous and particulate phases.

\subsection{Conclusions}

The relevant conclusions from this study are summarized below:

1. Lubricant oil consumption was found to be well correlated to engine operating conditions, such as engine speed, equivalence ratio, and intake air boost pressure. The brake-specific oil consumption ( $\mathrm{g} / \mathrm{bhp}-\mathrm{hr}$ ) was found to increase with increase in speed, decrease with increase in equivalence ratio, and decrease with increase in boost. The time-specific or absolute oil consumption ( $\mathrm{g} / \mathrm{hr})$ was found to increase with increase in speed, increase in equivalence ratio, and increase in boost. (Section 5.1.1 and Section 5.1.2)

2. The oil consumption measurements based upon the carbon-balance method were found to be very repeatable at the steady-state modes tested in this study. This was in contrast to previous studies on diesel-fueled engines, where the repeatability of data based upon the sulfur-balance method was poor, and was attributed to the nature of oil consumption. (Section 5.1)

3. The oil consumption based on carbon balance was found to be similar for the two oils (mineral and synthetic). The organic fraction and trace metals which are representative of partially and unburned lubricant oil were higher for the mineral oil operation in spite of its lower volatility. (Section 5.1)

4. The combustion parameters, namely combustion duration, peak cylinder pressure, start of combustion, and exhaust temperature were well correlated to the engine operating conditions; hence, influenced the variation in oil consumption, and oil consumption sources at the various operating states. (Section 5.1.3 and Section 5.1.4)

5. Absolute or time-specific oil consumption $(\mathrm{g} / \mathrm{hr})$ was found to be better predicted compared to brake-specific oil consumption. Hence, absolute oil consumption 
( $\mathrm{g} / \mathrm{hr}$ ) would be a better metric to represent oil consumption. (Section 5.1)

6. The need for distinguishing between the completely consumed oil fraction (gas based or gas phase measurements), and partially and unburned fraction (based on particulate phase measurement) was deemed important because of the significant differences between the two and the large variations in the ratios of the two measurements at different engine operating states. A review of published literature revealed the use of several different methods for oil consumption measurement, but in most cases the measured parameter was defined as total oil consumed, irrespective of the method employed. (Section 5.2)

7. $\mathrm{Ca}$ and $\mathrm{Zn}$ were the only elements found in detectable quantities in the particulate phase. The low levels of other elements are attributed to the low equivalence ratios used in this study, and the extremely low ash composition of the two oils $(<0.45$ wt.\%). (Section 5.2)

8. It was found that the trace metal marker balance for oil consumption measurement was not a feasible method of oil consumption determination as a result of the variation in base stock versus additive consumption. The selective evaporation of base stock versus additives was also found to be vary with the operating conditions. (Section 5.2)

9. Carbon balance method can be considered reliable to a certain extent, since carbon is the most abundant element in lubricant oil. Other methods, such as sulfur balance, trace metal balance, or radio-tracer method require extremely accurate measurements owing to the extremely low $(<1 \%)$ mass fractions of these elements compared to carbon $(>80 \%)$. However, the carbon balance method would not be applicable in the case of diesel or CNG fueled engines (carbon based fueled engines). Therefore, care must be taken in interpreting results of lubricant consumption from such engines when the method is based on sulfur balance, and trace metal balance methods. (Section 5.2)

10. The particle size distributions and total particle number were found to be a function of mass of oil consumed. Lower CMDs were associated with higher speed, and loads, and lower ratios of organic fraction to oil consumed. The 
particle size distributions also tended to be bimodal distributions (that is, nanoparticles appear) at certain operating conditions of higher speeds for both oils. (Section 5.3.1)

11. The PM concentrations for both oils were of the same order of magnitude, and the size distributions were also similar even though the CMD were slightly lower for the synthetic oil compared to mineral oil for the low speed operating points. This showed there were no significant effects of volatility, or synthetic versus mineral base stock on particle formation. It was evident that the particle number concentrations and size distributions depended more on the amount of oil consumed and the combustion conditions. (Section 5.3.1)

12. The particle size distributions for the motoring (no-fuel) test conditions were found to have higher concentrations, particularly in the nuclei mode, compared to the corresponding "fueled" modes. This highlights the presence of nanoparticle emissions during coasting or downhill driving conditions in the case of on-road vehicles. (Section 5.3.2)

13. The particle surface area distributions were found to have trends similar to the particle size distributions. A simultaneous study conducted to determine the mutagenicity of lubricant derived PM, found higher mutagenic activities for higher speed, and load conditions especially in the case of the mineral oil operation. This was found to correlate with the higher particle surface areas found at these conditions, and the higher organic fractions for the mineral oil compared to the synthetic oil. (Section 5.3.3)

14. Lubricant oil ageing (50 hours) showed no significant impact on oil properties. This could be attributed to the forced crankcase ventilation system used in this study which prevented blow-by gases from getting trapped in the crankcase, whereas in normal engines blow-by gases are either vented out into the exhaust or introduced back into the intake air system (positive crankcase ventilation). (Section 5.4) 


\subsection{Recommendations}

Based on the findings from this study, the following recommendations for further improvement are suggested for future studies:

1. The operating envelope for the current study was limited by the premixed hydrogen-air fueling and the resulting backfire limiting equivalence ratios. It would help in a more complete understanding of oil consumption over the entire operating curve if a direct injection system employed engine is made available for a similar study.

2. Wider operating ranges could also help in using a circumscribed or inscribed central composite designs for the test matrix which employ five levels for each factor; hence, a better coverage of the operating envelop.

3. It is recommended to use several more oil formulations of lubricant oils with varying additive compositions, and varying lubricant properties (viscosity and volatility) so as to understand the components contributing to organic fraction and particle formation.

4. The oil temperature in this study was controlled at approximately $80^{\circ} \mathrm{C}$ for all the steady state operating states. It is recommended to study the effects of varying oil temperature on lubricant oil consumption and lubricant properties.

5. The lubricant oil is also recommended to be tested for 150-200 hours of operation to study variations in properties as a result of extended use, because 50 hours at the operating conditions tested in the current study found no significant effect on the oils tested. 


\section{REFERENCES}

1. International Agency for Research on Cancer, "Evaluation of Carcinogenic Risks to Humans: Diesel and Gasoline Engine Exhausts and Some Nitroarenes," IARC Monographs, 46, 41-185, 1989.

2. http://www.epa.gov/otaq/highway-diesel/regs/f00057.pdf

3. Gautam, M., Kappanna, H., Wayne, S., John, B., Carder, D., "Control of Toxics and Nanoparticle Emission from CNG-Fueled, Heavy-duty Transit Buses," $15^{\text {th }}$ CRC On-Road Vehicle Emissions Workshop, April 4-6, San Diego, 2005.

4. Li, H., Karim, G.A., Sohrabi, A., "Examination of the Oil Combustion in a S.I. Hydrogen Engine,” SAE 2004-01-2916, Warrendale, PA, 2004.

5. Min, B., Kim, J., Oh, D., Choi, J., Jin, J., "Dynamic Characteristics of Oil Consumption - Relationship between the Instantaneous Oil Consumption and the Location of Piston Ring Gap,” SAE 982442, Warrendale, PA, 1998.

6. Furuhama, S., Hiruma, M., "Some Characteristics of Oil Consumption Measured by Hydrogen Fueled Engine," Journal of American Society of Lubrication Engineers, 34 (12), 665-675, 1978.

7. Furuhama, S., Hiruma, M., Yoshida, H., "An Increase of Engine Oil Consumption at High Temeperature of Piston and Cylinder," SAE 810976, Warrendale, PA, 1981.

8. Lapin, C.A., Gautam, M., Zielinska, B., Wagner, V.O., McClellan, R.O., "Mutagenicity of Emissions from a Natural Gas Fueled Truck," Mutation Research, 519, 205-209, 2002.

9. Seagrave, J., Gigliotti, A., McDonald, J.D., Seilkop, S.K., Whitney, K.A., Zielinska, B., Mauderly, J.L., "Composition, Toxicity, and Mutagenicity of Particulate and Semivolatile Emissions from Heavy-Duty Compressed Natural Gas-Powered Vehicles,” Toxicological Sciences, 87(1), 232-241, 2005.

10. Kado, N.Y., Okamoto, R.A., Kuzmicky, P.A., Kobayashi, R., Ayala, A., Gebel, M.E., Rieger, P.L., Maddox, C., Zafonte, L., "Emissions of Toxic Pollutants from Compressed Natural Gas and Low Sulfur Diesel-Fueled Heavy-Duty Transit 
Buses Tested over Multiple Driving Cycles," Environmental Science and Technology, 39, 7638-7649, 2005.

11. Okamoto, R.A., Kado, N.Y., Kuzmicky, P.A., Ayala, A., Kobayashi, R., "Unregulated Emissions from Compressed Natural Gas (CNG) Transit Buses Configured with and without Oxidation Catalyst," Environmental Science and Technology, 40, 332-341, 2006.

12. Braun, A.G., Pakzaban, P., Toqan, M.A., Beer, J.M., "Genration of Biologically Active Substances in a Natural Gas Flame," Environmental Health Perspectives, 72, 297-303, 1987.

13. Kado, N.Y., Kuzmicky, P.A., "Bioassay Analyses of Particulate Matter from a Diesel Bus Engine Using Various Biodiesel Feedstock Fuels," Final Report, Report 3 of 6 submitted to National Renewable Energy Laboratory (NREL), February 2003.

14. Bunger, J., Krahl, J., Franke, H-U, Munack, A., Hallier, E., "Mutagenic and Cytotoxic Effects of Exhaust Particulate Matter of Biodiesel Compared to Fossil Diesel Fuel," Mutation Research, 415, 13-23, 1998.

15. Bagley, S.T., Gratz, L.D., Johnson, J.H., McDonald, J.F., "Effects of an Oxidation Catalytic Converter and a Biodiesel Fuel on the Chemical, Mutagenic, and Particle Size Characteristics of Emissions from a Diesel Engine," Environmental Science and Technology, 32, 1183-1191, 1998.

16. McMillian, M.H., "Combustion Analysis and Particulate Mutagenicity Characterization for a Single-Cylinder Diesel Engine Fueled by Fischer-Tropsch Derived Liquids," Ph.D. Dissertation, Department of Mechanical and Aerospace Engineering, West Virginia University, Morgantown, WV, 2003.

17. Gragg, K., "Chemical Characterization and Biological Testing of Exhaust from a Truck Fueled with EC1 and EPEFE Reference Fuel," ASB Motor Test Center, Report no. MTC 9510, 1995.

18. Crebelli, R., Fuselli, S., Conti, G., Conti, L., Carere, A., "Mutagenicity Spectra in Bacterial Strains of Airborne and Engine Exhaust Particulate Extracts," Mutation 
Research, 261(4), 237-248, December 1991.

19. Demarini, D.M., Brooks, L.R., Warren, S.H., Kobayashi, T., Gilmour, M.I., Singh, P., "Bioassay-Directed Fractionation and Salmonella Mutagenicity of Automobile and Forklift Diesel Exhaust Particles," Environmental Health Perspectives, 112(8), 814-819, June 2004.

20. Seagrave, J., McDonald, J.D., Gigliotti, A.P., Nikula, K.J., Seilkop, S.K., Gurevich, M., Mauderly, J.L., "Mutagenicity and in Vivo Toxicity of Combined Particulate and Semivolatile Organic Fractions of Gasoline and Diesel Engine Emissions," Toxicological Sciences, 70, 212-226, 2002.

21. California Air Resources Board, "Report to the Air Resources Board on the Proposed Identification of Diesel Exhaust as a Toxic Air Contaminant," Sacramento, California, 1998.

22. "Diesel Fumes Under Study as Possible Cancer Cause," New York Times, p.41, New York, 13 November, 1977.

23. Solano, J.L., "Mutageni Potential of Particulate Matter Emissions from a Single Cylinder Hydrogen-Fueled Engine: Lubricating Oil Effects," Ph.D. Dissertation, Department of Mechanical and Aerospace Engineering, West Virginia University, Morgantown, WV, 2008.

24. Froelund, K., Yilmaz, E., "Impact of Engine Oil Consumption on Particulate Emissions," International Conference on Automotive Technology, Istanbul, November, 2004.

25. Yilmaz, E., "Sources and Characteristics of Oil Consumption in a Spark-Ignition Engine," Ph.D. Dissertation, Department of Mechanical Engineering, Massachusetts Institute of Technology, Cambridge, MA, 2003.

26. Ariga, S., Sui, P.C., Shahed, S.M., "Instantaneous Unburned Oil Consumption Measurement in a Diesel Engine Using $\mathrm{SO}_{2}$ Tracer Technique," SAE 922196, Warrendale, PA, 1992.

27. Miller, T.C., "Characterization of Lubricant Oil Derived Diesel Engine Particulate Emission Rate vs. Lubricant Oil Consumption,” M.S. Thesis, Departments of 
Ocean Engineering and Mechanical Engineering, Massachusetts Institute of Technology, Cambridge, MA, 1996.

28. Jackson, M.A., "Assessment of a Sulfur Dioxide Based Diagnostic System in Characterizing Real Time Oil Consumption in a Diesel Engine," M.S. Thesis, Departments of Ocean Engineering and Mechanical Engineering, Massachusetts Institute of Technology, Cambridge, MA, 1996.

29. Schofield, D.M., "Diesel Engine Instantaneous Oil Consumption Measurements Using the Sulfur Dioxide Tracer Technique," M.S. Thesis, Departments of Ocean Engineering and Mechanical Engineering, Massachusetts Institute of Technology, 1995.

30. Froelund, K., Menezes, L.A., Johnson, H.R., Rein, W.O., "Real-Time Transient and Steady-State Measurement of Oil Consumption for Several Production SIEngines,” SAE 2001-01-1902, Warrendale, PA, 2001.

31. Froelund, K., Fritz, S., Smith, B., "Lubricating Oil Consumption Measurements on an EMD 16-645E Locomotive Diesel Engine," ICE 2003-549, Proceedings of ICES03, 2003 Spring Technical Conference of the American Society of Mechanical Engineers Internal Combustion Engines Division, Salzburg, Austria, 2003.

32. Li, H., Karim, G.A., Sohrabi, A., "Examination of the Oil Combustion in a S.I. Hydrogen Engine,” SAE 2004-01-2916, Warrendale, PA, 2004.

33. Andrews, G.E., Elamir, I.E., Abdelhalim, S., Ahamed, F.M., Shen, Y., "The Measurement of Lubricating Oil Combustion Efficiency Using Particulate Analysis," SAE 980523, Warrendale, PA, 1998.

34. Cooke, V.B., "Lubrication of Low Emission Diesel Engines," SAE 900814, SAE Transactions, Volume 93, Warrendale, PA, 1990.

35. Elamir, I.E., Andrews, G.E., Williams, P.T., "Determination of Diesel Engine Lubricating Oil Consumption Through Analysis of the Calcium in Diesel Particulates," Second IMechE Seminar on Experimental Methods in Engine Research and Development, Mechanical Engineering Publications Limited 
(MEP), pp. 171-180, 1991.

36. Stetter, J., Forster, N., Ghandhi, J., Foster, D., "The Impact of Oil Consumption Mechanisms on Diesel Exhaust Particle Size Distributions and Detailed Exhaust Chemical Composition,” DEER Conference, Newport, Rhode Island, 2003.

37. Karim, G., Li, H., "Knock in Gas Fueled S.I. Engines," Mechanical and Manufacturing Engineering, University of Calgary.

38. Tang, X., Kabat, D.M., Natkin, R.J., Stockhausen, W.F., Heffel, J., “Ford P2000 Hydrogen Engine Dynamometer Development," SAE 2002-01-0242, Warrendale, PA, 2002.

39. MacCarley, C.A., "A Study of Factors Influencing Thermally Induced Backfiring in Hydrogen Fueled Engines, and Methods for Backfire Control," SAE 819632, Warrendale, PA, 1981.

40. Kondo, T., Iio, S., and Hiruma, M., "A Study on the Mechanism of Backfire in External Mixture Formation Hydrogen Engines - About Backfire Occurred by Cause of the Spark Plug," SAE 971704, Warrendale, PA, 1997.

41. Furuhama, S., "Problems of Forecasting the Future of Advanced Engines and Engine Characteristics of the Hydrogen Injection with $\mathrm{LH}_{2}$ Tank and Pump," 1995 Calvin Rice Lecture, ASME, 23/4/95, 1995.

42. Lynch, F.E., "Backfire Control Techniques for Hydrogen Fueled Internal Combustion Engines," Billings Energy Research Corporation, Provo, Utah.

43. Sierens, R., Rosseel, E., “A Study of Backfire in Hydrogen Engines,” University of Gent, Gent, Belgium.

44. Koyanagi, K., Hiruma, M., Furuhama, S., "Study on Mechanism of Backfire in Hydrogen Engines," SAE 942035, Warrendale, PA, 1994.

45. Lee, J.T., Kim, Y.Y., Lee, C.W., and Canton, J.A., "An Investigation of a Cause of Backfire and its Control Due to Crevice Volumes in a Hydrogen Fueled Engine," American Society of Mechanical Engineers Journal of Engineering for Gas Turbines and Power, 123, 204-210, 2001.

46. Jingding, L., Yingqing, L., Tianshen, D., "Backfire in Hydrogen Fueled Engine 
and its Control," Department of Thermal Physics Engineering, Zhejiang University, China, 1986.

47. King, R.O., Durand, I.J., Wood, B.D., and Allan, A.B., "The Oxidation, Ignition, and Detonation of Fuel Vapors and Gases," Canadian Journal of Research, Volume 28, Section F, 1950.

48. Obert, E.F., INTERNAL COMBUSTION ENGINES, $3^{\text {rd }}$ Ed., International Textbook Co., Scranton, PA., 314-316, 1968.

49. Adt, R.A., Swain, M.R., "Hydrogen Engine Performance Analysis Project," Quarterly Report, University of Miami, Coral Gables, FL, March 1977.

50. Lee, S.T., Yi, H.S., Kim, E.S., "Combustion Characteristics of Intake Port Injection Type Hydrogen Fueled Engine," International Journal of Hydrogen Energy, 20, 317-322, 1995.

51. Verhelst, S., Sierens, R., “Aspects Concerning the Optimization of a Hydrogen Fueled Engine,” International Journal of Hydrogen Energy, 26, 987-990, 2001.

52. Miller, A.L., Stipe, C.B., Habjan, M.C., and Ahlstrand, G.G., "Role of Lubrication Oil in Particulate Emissions from a Hydrogen-Powered Internal Combustion Engine," Environmental Science and Technology, 41, 6828-6835, 2007.

53. Dowling, M., "Impact of Oil Formulation on Emissions from Diesel Engines," SAE 922198, Warrendale, PA, 1992.

54. Andrews, G.E., Abdelhalim, S., Williams, P.T., “The Influence of Lubricating Oil Age on Emissions from an IDI Diesel," SAE 931003, Warrendale, PA,1993.

55. Laurence, R.B., Wong, V.W., Brown, A.J., "Effects of Lubrication System Parameters on Diesel Particulate Emission Characteristics," SAE 960318, Warrendale, PA, 1996.

56. Froelund, K., Owens, E.C., Frame, E., Buckingham, J.P., Garbak, J., Tseregounis, S., Jackson, A., "Impact of Lubricant Oil on Regulated Emissions of a Light-Duty Mercedes-Benz OM611 CIDI-Engine," SAE 2001-01-1901, Warrendale, PA, 2001. 
57. Orrin, D.S., Coles, B.W., "Effects of Engine Oil Composition on Oil Consumption," SAE 710141, Warrendale, PA, 1971.

58. Kiovsky, T.E., Yates, N.C., Bales, J.R., "Fuel Efficient Lubricants and the Effect of Special Base Oils," Journal of the Society of Tribologists and Lubrication Engineers, $48^{\text {th }}$ Annual Meeting, Calgary, Canada, May 1993.

59. Hartman, R.M., "Tritium Method Oil Consumption and its Relation to Oil Film Thickness in a Production Diesel Engine," Masters Thesis, Department of Mechanical Engineering, Massachusetts Institute of Technology, Cambridge, MA, 1990.

60. Andersson, J., Preston, H., Warrens, C., Brett, P., "Fuel and Lubricant Effects on Nucleation Mode Particle Emissions from a Euro III Light Duty Diesel Vehicle," SAE 2004-01-1989, Warrendale, PA, 2004.

61. Andersson, J.D., Preston, H., Warrens, C., Brett, P., Payne, M., "Lubricant Composition Impact on the Emissions from a European Heavy Duty Diesel Engine Equipped with a Diesel Particulate Filter," SAE 2004-01-3012, Warrendale, PA, 2004.

62. "Advanced Petroleum-Based Fuels- Diesel Emissions Control (APBF-DEC)," Lubricants Project Phase 1, Final Report, U.S. Department of Energy.

63. Horiba Instruments Manual for FIA-236 HFID, March 1997.

64. Horiba Instruments Manual for VIA-510 General Purpose Gas Analyzer Unit, August 1997.

65. California Analytical Instruments, Inc., Model 601 NDIR Operator's Manual.

66. Thermo Environmental Instruments, Inc., Model 42C High Level Chemiluminescence NO-NO $2-\mathrm{NOx}$ Analyzer Instruction Manual.

67. TSI Model 3936 SMPS (Scanning Mobility Particle Sizer) Instruction Manual, September 2003.

68. http://www.nexumresearch.com/Ignition.pdf

69. www.mathworks.com/access/helpdesk/help/toolbox/stats/f56650.html 
70. Box, G.E.P., Hunter, J.S., Hunter, W.G., STATISTICS FOR EXPERIMENTERS - DESIGN, INNOVATION, AND DISCOVERY, Wiley Series in Probability and Statistics, Second Edition, 2005.

71. http://webbook.nist.gov/chemistry/mw-ser.html

72. http://ecfr.gpoaccess.gov, Code of Federal Regulations, Title 40, Part 86

73. Sall, J., Creighton, L., Lehman, A., JMP® START STATISTICS, SAS Institute Inc.

74. Shrestha, S.O.B., Karim, G.A., “An Experimental and Analytical Examination of the Combustion Period for Gas-Fueled Spark Ignition Engine Applications," Journal of Power and Energy, 215, Part A, 63-74.

75. Szwabowski, S.J., Hashemi, S., Stockhausen, F., Natkin, R.J., Reams, L., Kabat, D.M., Potts, C., “Ford Hydrogen Engine Powered P200 Vehicles,” SAE 2002-010243, Warrendale, PA, 2002.

76. Puffel, P.K., Thiel, W., Frey, R., Boesl, U., “A New Method for the Investigation of Unburned Oil Emissionsin the Raw Exhaust of SI Engines," SAE 982438, Warrendale, PA, 1998.

77. Tsuchihashi, K., Shirakawa, H., Saitoh, Y., "Experimental Analysis for Accumulated Ash in DPF Effect of High Quality Low Ash Oil," SAE 2003-080408, Warrendale, PA, 2003.

78. Givens, W.A., Buck, W.H., Jackson, A., Kaldor, A., Hertzberg, A., Moehrmann, W., Mueller-Lunz, S., Pelz, N., Wenninger, G., "Lubricant Formulation Effects on Transfer of Elements to Exhaust After-Treatment System Components," SAE 2003-01-3109, Warrendale, PA, 2003.

79. Takeuchi, Y., Hirano, S., Kanauchi, M., Ohkubo, H., Nakazato, M., Sutherland, M., Van Dam, W., "The Impact of Diesel Engine Lubricants on Deposit Formation in Diesel Particulate Filters," SAE 2003-01-1870, Warrendale, PA, 2003.

80. Barris, M.A., Reinhart, S.B., Wahlquist, F.H., "The Influence of Lubricating Oil and Diesel Fuel on Ash Accumulation in an Exhaust Particulate Trap," SAE 
910131, Warrendale, PA, 1991.

81. Kittleson, D., Abdul-Khalek, I., "Formation of Nanoparticles during Exhaust Dilution,” EFI Members Conference, Fuels, Lubricants, Engines, and Emissions, January 18-20, 1999.

82. Bagley, S.T., Baumgard, K.J., Gratz, L.D., Johnson, J.H., Leddy, D.G., "Characterization of Fuel and Aftertreatment Device Effects on Diesel Emissions," Health Effects Institute Research Report No. 76.

83. Ostiguy, C., Lapointe, G., Trottier, M., Menard, L., Clouher, Y., Boutin, M., Antoun, M., Normand, C., "Health Effects of Nanoparticles," IRSST Report R451, August 2006.

84. Sawyer, R., "Understanding the Potential Ultrafine Particle Pollution Problem and its Impact on California's Air Quality," SCAQMD Ultrafine Particle Conference, April 30-May 2, 2006.

85. http://vista.cira.colostate.edu/IMPROVE/Publications/SOPs/DRI_SOPs/2005/2216r1_IMPROVEA_20051115.pdf

86. http://www.epa.gov/ttnamti1/files/ambient/pm25/spec/xrfsop.pdf

87. http://omega.physics.uoi.gr/xrf/english/the_xrf technique.htm

88. http://www.nilu.no/projects/ccc/manual/documents/04-Chemical\%20analysis.htm 


\section{APPENDIX A : Uncertainty Analysis}

The uncertainty associated with the carbon balance oil consumption, dilution ratio, and split ratio calculations are calculated below, using the root-sum square equation.

For any given equation,

$F(x)=f\left(x_{1}, x_{2}, x_{3}, \ldots \ldots, x_{n}\right)$,

the uncertainty associated with the measurement of $\mathrm{F}$ is given by,

$\Delta \mathrm{F}=\sqrt{\left(\frac{\partial F}{\partial x_{1}} \Delta x_{1}\right)^{2}+\left(\frac{\partial F}{\partial x_{2}} \Delta x_{2}\right)^{2}+\ldots . .+\left(\frac{\partial F}{\partial x_{n}} \Delta x_{n}\right)^{2}}$

where $\Delta \mathrm{x}_{1}, \Delta \mathrm{x}_{2}, \ldots ., \Delta \mathrm{x}_{\mathrm{n}}$ are the errors associated with $\mathrm{x}_{1}, \mathrm{x}_{2}, \ldots, \mathrm{x}_{\mathrm{n}}$ respectively.

\section{A1 C-balance OilCconsumption Calculation : Uncertainty}

The carbon balance oil consumption $(\mathrm{g} / \mathrm{hr})$ was calculated as,

$$
\dot{m}_{\text {oil }}=\frac{3600}{m_{c}} *\left[K_{w}\left\{\left(\frac{\left[C O_{2}\right]}{10^{6}} V_{e x h} \rho_{C O_{2}} \frac{M W_{c}}{M W_{C O_{2}}}\right)+\left(\frac{[C O]}{10^{6}} V_{e x h} \rho_{C O} \frac{M W_{C}}{M W_{C O}}\right)\right\}+\left(\frac{[T H C]}{10^{6}} V_{e x h} \rho_{T H C} \frac{M W_{C}}{M W_{T H C}}\right)\right]
$$

The uncertainty associated with $\dot{m}_{\text {oil }}$ neglecting the uncertainties in the constants used, that is, $\rho_{\mathrm{CO}_{2}}, \rho_{\mathrm{CO}}, \rho_{T H C}, M W_{c}, M W_{C O 2}, M W_{C O}, M W_{T H C}, m_{c}$, is given as,

$$
\begin{aligned}
& \Delta \dot{m}_{\text {oil }}=\left[\left(\frac{\partial \dot{m}_{\text {oil }}}{\partial K_{W}} \Delta K_{W}\right)^{2}+\left(\frac{\partial \dot{m}_{\text {oil }}}{\partial C O_{2}} \Delta C O_{2}\right)^{2}+\left(\frac{\partial \dot{m}_{\text {oil }}}{\partial C O} \Delta C O\right)^{2}+\left(\frac{\partial \dot{m}_{\text {oil }}}{\partial T H C} \Delta T C\right)^{2}+\left(\frac{\partial \dot{m o i l}}{\partial V_{\text {exh }}} \Delta V_{\text {exh }}\right)^{2}\right]^{\frac{1}{2}} \\
& \frac{\partial \dot{m}_{\text {oil }}}{\partial K_{W}}=\frac{3600}{m_{c}}\left[\left(\frac{\left[C O_{2}\right]}{10^{6}} V_{e x h} \rho_{C O_{2}} \frac{M W_{C}}{M W_{C O}}\right)+\left(\frac{[C O]}{10^{6}} V_{e x h} \rho_{C O} \frac{M W_{C}}{M W_{C O}}\right)\right] \\
& K_{W}=1-M_{H_{2} O} \\
& \Delta K_{W}=\frac{\partial K_{W}}{\partial M_{H_{2} O}} \cdot \Delta M_{H_{2} O} \\
& =-\Delta M_{H_{2} O}
\end{aligned}
$$




$$
\begin{aligned}
& M_{\mathrm{H}_{2} \mathrm{O}}=\frac{2 \phi}{\phi+4.76} \\
& \Delta M_{\mathrm{H}_{2} O}=\frac{\partial M_{\mathrm{H}_{2} O}}{\partial \phi} \cdot \Delta \phi \\
& =\frac{9.52}{(\phi+4.76)^{2}} \cdot \Delta \phi \\
& \phi=34.2 * \frac{\dot{m}_{f}}{\dot{m}_{a}},
\end{aligned}
$$

where, 34.2 is the stoichiometric air-fuel ratio for hydrogen combustion in air.

$$
\begin{aligned}
& \Delta \phi=\left[\left(\frac{\partial \phi}{\partial \dot{m}_{f}} \Delta \dot{m}_{f}\right)^{2}+\left(\frac{\partial \phi}{\partial \dot{m}_{a}} \Delta \dot{m}_{a}\right)^{2}\right]^{\frac{1}{2}} \\
& \frac{\partial \phi}{\partial \dot{m}_{f}}=\frac{34.2}{\dot{m}_{a}} \\
& \frac{\partial \phi}{\partial \dot{m}_{a}}=\frac{-34.2 * \dot{m}_{f}}{\dot{m}_{a}{ }^{2}}
\end{aligned}
$$$$
\frac{\partial \dot{m}_{\text {oil }}}{\partial_{\mathrm{CO}_{2}}}=\frac{3600 * K_{W} * V_{e x h} * \rho_{\mathrm{CO}_{2}}}{m_{C} * 10^{6}} \cdot \frac{M W_{C}}{M W_{C O_{2}}}
$$$$
\frac{\partial \dot{m}_{o i l}}{\partial_{C O}}=\frac{3600 * K_{W} * V_{e x h} * \rho_{C O}}{m_{C} * 10^{6}} \cdot \frac{M W_{C}}{M W_{C O}}
$$$$
\frac{\partial \dot{m}_{o i l}}{\partial_{T C H}}=\frac{3600 * V_{e x h} * \rho_{T C H}}{m_{C} * 10^{6}} \cdot \frac{M W_{C}}{M W_{T H C}}
$$$$
\frac{\partial \dot{m}_{\text {oil }}}{\partial V_{\text {exh }}}=\frac{3600}{m_{c}} *\left[K_{w}\left\{\left(\frac{\left[C O_{2}\right]}{10^{6}} \rho_{\mathrm{CO}_{2}} \frac{M W_{c}}{M W_{C O_{2}}}\right)+\left(\frac{[C O]}{10^{6}} \rho_{C O} \frac{M W_{C}}{M W_{C O}}\right)+\left(\frac{[T H C]}{10^{6}} \rho_{T H C} \frac{M X_{C}}{M W_{T H C}}\right)\right\}\right]
$$ 


$$
\begin{aligned}
& V_{\text {exh }}=\frac{\dot{m}_{a}+\dot{m}_{f}}{\rho_{\text {air }}} \\
& \Delta V_{\text {exh }}=\left[\left(\frac{\partial V_{e x h}}{\partial \dot{m}_{a}} \Delta \dot{m a}\right)^{2}+\left(\frac{\partial V_{e x h}}{\partial \dot{m}_{f}} \Delta \dot{m}_{f}\right)^{2}\right]^{\frac{1}{2}} \\
& \frac{\partial V_{e x h}}{\partial \dot{m}_{a}}=\frac{1}{\rho_{\text {air }}} \\
& \frac{\partial V_{e x h}}{\partial \dot{m}_{f}}=\frac{1}{\rho_{\text {air }}}
\end{aligned}
$$

Substituting for the above values, the calculated uncertainty in oil consumption measured ranged between $9-12 \%$ for the ranges of operating states considered in the study.

\section{A2 Dilution Ratio Calculation : Uncertainty}

The dilution ratio is calculated as,

$$
D R=\frac{\dot{m_{t u n}}}{\dot{m}_{t u n}-\dot{m}_{d i l}}
$$

The uncertainty associated with DR is given by,

$$
\begin{aligned}
& \Delta D R=\left[\left(\frac{\partial D R}{\partial \dot{m}_{t u n}} \Delta \dot{m}_{t u n}\right)^{2}+\left(\frac{\partial D R}{\partial \dot{m}_{d i l}} \Delta \dot{m}_{d i l}\right)^{2}\right]^{\frac{1}{2}} \\
& \frac{\partial D R}{\partial \dot{m}_{t u n}}=-\frac{\dot{m}_{d i l}}{\left(\dot{m_{t u n}-\dot{m}_{d i l}}\right)^{2}} \\
& \frac{\partial D R}{\dot{m}_{d i l}}=\frac{\left(\dot{m}_{t u n}\right.}{\left(\dot{m}_{t u n}-\dot{m}_{d i l}\right)^{2}}
\end{aligned}
$$

The uncertainty in dilution ratio for a dilution ratio of 12 used in this study was 
approximately $9 \%$.

\section{A3 Split Ratio Calculation : Uncertainty}

The split ratio is calculated as,

$$
S R=\frac{\dot{m}_{a}+\dot{m}_{f}}{\dot{m}_{t u n}-\dot{m}_{d i l}}
$$

The uncertainty associated with SR is given by,

$\Delta S R=\left[\left(\frac{\partial S R}{\partial \dot{m}_{a}} \Delta \dot{m}_{a}\right)^{2}+\left(\frac{\partial S R}{\partial \dot{m}_{f}} \Delta \dot{m}_{f}\right)^{2}+\left(\frac{\partial S R}{\partial \dot{m}_{t u n}} \Delta \dot{m}_{t u n}\right)^{2}+\left(\frac{\partial S R}{\partial \dot{m}_{d i l}} \Delta \dot{m}_{d i l}\right)^{2}\right]^{\frac{1}{2}}$

$$
\frac{\partial S R}{\partial \dot{m}_{a}}=\frac{1}{\dot{m}_{t u n}-\dot{m}_{d i l}}
$$$$
\frac{\partial S R}{\partial \dot{m}_{f}}=\frac{1}{\dot{m}_{t u n}-\dot{m}_{\text {dil }}}
$$$$
\frac{\partial S R}{\partial \dot{m}_{t u n}}=-\frac{\dot{m}_{a}+\dot{m}_{f}}{\left(\dot{m}_{t u n}-\dot{m}_{d i l}\right)^{2}}
$$$$
\frac{\partial S R}{\partial \dot{m}_{d i l}}=\frac{\dot{m}_{a}+\dot{m}_{f}}{\left(\dot{m}_{t u n}-\dot{m}_{d i l}\right)^{2}}
$$

The uncertainty in the split ratio ranged from approximately $3 \%$ to $13 \%$ in this study depending on the tunnel flow rate and exhaust flow rate at the various operating states. 
APPENDIX B : Lubricant Oil Consumption Analysis - Experiment Matrix and Data

\begin{tabular}{|c|c|c|c|c|c|c|}
\hline Test & Pattern & Speed & Phi & Boost & Oil & Coded \\
\hline & & rps & & $\mathrm{kPa}$ & & Speed \\
\hline 1 & +++ & 30.1 & 0.38 & 52 & $\bar{M}$ & 1.01 \\
\hline 2 & 000 & 22.5 & 0.33 & 34 & M & 0.00 \\
\hline 3 & --- & 15.0 & 0.28 & 16 & M & -1.00 \\
\hline 4 & $\mathrm{a} 00$ & 15.1 & 0.33 & 36 & M & -0.99 \\
\hline 5 & $\mathrm{~A} 00$ & 29.9 & 0.32 & 33 & M & 0.99 \\
\hline 6 & +-+ & 30.1 & 0.28 & 51 & M & 1.01 \\
\hline 7 & --+ & 15.0 & 0.28 & 55 & M & -1.00 \\
\hline 8 & ++- & 30.0 & 0.38 & 14 & M & 1.00 \\
\hline 9 & $00 \mathrm{~A}$ & 22.4 & 0.33 & 54 & M & -0.01 \\
\hline 10 & OAO & 22.6 & 0.38 & 35 & M & 0.01 \\
\hline 11 & $0 \mathrm{aO}$ & 22.6 & 0.28 & 34 & M & 0.01 \\
\hline 12 & $00 a$ & 22.5 & 0.33 & 16 & M & 0.00 \\
\hline 13 & +-- & 30.0 & 0.28 & 13 & M & 1.00 \\
\hline 14 & -++ & 15.1 & 0.38 & 55 & M & -0.99 \\
\hline 15 & -+- & 15.1 & 0.38 & 16 & M & -0.99 \\
\hline 16 & $00 a$ & 22.5 & 0.33 & 15 & M & 0.00 \\
\hline 17 & --+ & 15.0 & 0.27 & 55 & M & -1.00 \\
\hline 18 & +-+ & 30.0 & 0.28 & 52 & M & 1.00 \\
\hline 19 & OAO & 22.5 & 0.38 & 34 & M & 0.00 \\
\hline 20 & --- & 15.0 & 0.28 & 16 & M & -1.00 \\
\hline 21 & +++ & 30.0 & 0.38 & 52 & M & 1.00 \\
\hline 22 & +-- & 30.0 & 0.28 & 14 & M & 1.00 \\
\hline 23 & -++ & 15.1 & 0.38 & 55 & M & -0.99 \\
\hline 24 & $0 \mathrm{aO}$ & 22.6 & 0.28 & 35 & M & 0.01 \\
\hline 25 & -+- & 15.0 & 0.37 & 16 & M & -1.00 \\
\hline 26 & $\mathrm{a} 00$ & 15.0 & 0.33 & 36 & M & -1.00 \\
\hline 27 & A00 & 29.9 & 0.33 & 33 & M & 0.99 \\
\hline 28 & OOA & 22.5 & 0.33 & 54 & M & 0.00 \\
\hline 29 & 000 & 22.5 & 0.33 & 34 & M & 0.00 \\
\hline 30 & ++- & 30.0 & 0.38 & 14 & M & 1.00 \\
\hline 31 & $00 a$ & 22.5 & 0.33 & 15 & M & 0.00 \\
\hline 32 & -++ & 15.0 & 0.38 & 55 & M & -1.00 \\
\hline 33 & $\mathrm{a} 00$ & 15.0 & 0.33 & 36 & M & -1.00 \\
\hline 34 & $\mathrm{~A} 00$ & 30.0 & 0.33 & 33 & M & 1.00 \\
\hline 35 & +++ & 30.1 & 0.38 & 52 & M & 1.01 \\
\hline 36 & +-+ & 30.0 & 0.28 & 51 & M & 1.00 \\
\hline 37 & OAO & 22.5 & 0.38 & 34 & M & 0.00 \\
\hline 38 & 000 & 22.5 & 0.32 & 35 & M & 0.00 \\
\hline 39 & $0 \mathrm{aO}$ & 22.5 & 0.28 & 34 & M & 0.00 \\
\hline 40 & -- & 15.0 & 0.27 & 16 & M & -1.00 \\
\hline 41 & +-- & 30.0 & 0.27 & 13 & M & 1.00 \\
\hline 42 & --+ & 15.1 & 0.28 & 54 & M & -0.99 \\
\hline 43 & ++- & 30.0 & 0.37 & 13 & M & 1.00 \\
\hline 44 & $00 \mathrm{~A}$ & 22.5 & 0.33 & 54 & M & 0.00 \\
\hline 45 & -+- & 15.1 & 0.38 & 16 & M & -0.99 \\
\hline 46 & -++ & 15.1 & 0.38 & 55 & s & -0.99 \\
\hline 47 & $\mathrm{~A} 00$ & 30.0 & 0.33 & 33 & S & 1.00 \\
\hline 48 & --- & 15.0 & 0.28 & 17 & $\mathrm{~s}$ & -1.00 \\
\hline 49 & +-- & 30.0 & 0.28 & 13 & $\mathrm{~S}$ & 1.00 \\
\hline 50 & --+ & 15.1 & 0.28 & 55 & $\mathrm{~S}$ & -0.99 \\
\hline 51 & OAO & 22.5 & 0.38 & 34 & $\mathrm{~S}$ & 0.00 \\
\hline 52 & +++ & 30.0 & 0.38 & 52 & $\mathrm{~s}$ & 1.00 \\
\hline 53 & $\mathrm{a} 00$ & 15.0 & 0.33 & 36 & $\mathrm{~s}$ & -1.00 \\
\hline 54 & $00 \mathrm{~A}$ & 22.5 & 0.33 & 54 & $\mathrm{~s}$ & 0.00 \\
\hline 55 & 000 & 22.5 & 0.33 & 15 & $\mathrm{~s}$ & 0.00 \\
\hline 56 & ++- & 30.0 & 0.38 & 14 & S & 1.00 \\
\hline 57 & 000 & 22.5 & 0.33 & 34 & S & 0.00 \\
\hline 58 & +-+ & 30.1 & 0.28 & 52 & $\mathrm{~S}$ & 1.01 \\
\hline 59 & -+- & 15.0 & 0.38 & 17 & $\mathrm{~S}$ & -1.00 \\
\hline 60 & $0 \mathrm{a} 0$ & 22.5 & 0.28 & 34 & $\mathrm{~S}$ & 0.00 \\
\hline 61 & $\mathrm{~A} 00$ & 30.0 & 0.33 & 33 & $\mathrm{~s}$ & 1.00 \\
\hline 62 & --- & 15.0 & 0.28 & 16 & S & -1.00 \\
\hline 63 & 000 & 22.5 & 0.33 & 15 & $\mathrm{~s}$ & 0.00 \\
\hline 64 & +- & 30.0 & 0.27 & 14 & $\mathrm{~s}$ & 1.00 \\
\hline 65 & -+- & 15.0 & 0.37 & 16 & $\mathrm{~s}$ & -1.00 \\
\hline 66 & -++ & 15.0 & 0.37 & 55 & S & -1.00 \\
\hline 67 & +++ & 30.0 & 0.38 & 52 & $\mathrm{~S}$ & 1.00 \\
\hline 68 & 000 & 22.5 & 0.33 & 34 & $\mathrm{~s}$ & 0.00 \\
\hline 69 & ++- & 30.0 & 0.38 & 14 & $\mathrm{~s}$ & 1.00 \\
\hline 70 & OOA & 22.6 & 0.33 & 54 & $\mathrm{~s}$ & 0.01 \\
\hline 71 & $\mathrm{a} 00$ & 15.0 & 0.33 & 36 & S & -1.00 \\
\hline 72 & OAO & 22.5 & 0.38 & 35 & $\mathrm{~s}$ & 0.00 \\
\hline 73 & $0 \mathrm{aO}$ & 22.5 & 0.28 & 34 & $\mathrm{~s}$ & 0.00 \\
\hline 74 & +-+ & 30.1 & 0.28 & 51 & $\mathrm{~s}$ & 1.01 \\
\hline 75 & --+ & 15.0 & 0.28 & 55 & S & -1.00 \\
\hline 76 & -+- & 15.1 & 0.37 & 17 & S & -0.99 \\
\hline 77 & $00 \mathrm{~A}$ & 22.5 & 0.33 & 54 & $\mathrm{~s}$ & 0.00 \\
\hline 78 & -++ & 14.9 & 0.38 & 55 & $\mathrm{~s}$ & -1.01 \\
\hline 79 & ++- & 30.1 & 0.37 & 14 & $\mathrm{~S}$ & 1.01 \\
\hline 80 & +-+ & 30.0 & 0.28 & 52 & $\mathrm{~s}$ & 1.00 \\
\hline 81 & $00 \mathrm{a}$ & 22.6 & 0.33 & 15 & S & 0.01 \\
\hline 82 & +++ & 30.1 & 0.38 & 52 & $\mathrm{~s}$ & 1.01 \\
\hline 83 & 000 & 22.6 & 0.33 & 34 & $\mathrm{~s}$ & 0.01 \\
\hline 84 & --. & 15.1 & 0.28 & 16 & $\mathrm{~s}$ & -0.99 \\
\hline 85 & -++ & 15.0 & 0.37 & 55 & $\mathrm{~s}$ & -1.00 \\
\hline 86 & +-+ & 30.0 & 0.28 & 52 & $\mathrm{~s}$ & 1.00 \\
\hline 87 & 000 & 22.3 & 0.33 & 34 & $\mathrm{~s}$ & -0.03 \\
\hline 88 & --. & 15.1 & 0.29 & 16 & $\mathrm{~S}$ & -0.99 \\
\hline 89 & +-+ & 30.0 & 0.28 & 51 & $\mathrm{~s}$ & 1.00 \\
\hline 90 & +-- & 30.0 & 0.28 & 14 & $\mathrm{~s}$ & 1.00 \\
\hline
\end{tabular}

M : Mineral Oil, S: Synthetic Oil 
APPENDIX C : Brake-specific Gaseous Emissions $\left(\mathrm{CO}_{2}, \mathrm{CO}, \mathrm{THC}\right.$, and NOx) Data

\begin{tabular}{|c|c|c|c|c|c|c|c|c|c|c|c|c|c|c|c|c|c|c|c|c|c|c|c|c|}
\hline \multirow[t]{3}{*}{ State No. } & \multicolumn{6}{|c|}{$\mathrm{CO}_{2}$ (g/bhp-hr) } & \multicolumn{6}{|c|}{ CO (g/bhp-hr) } & \multicolumn{6}{|c|}{ THC (g/bhp-hr) } & \multicolumn{6}{|c|}{ NOx (g/bhp-hr) } \\
\hline & \multicolumn{3}{|c|}{ Mineral Oil } & \multicolumn{3}{|c|}{ Synthetic Oil } & \multicolumn{3}{|c|}{ Mineral Oil } & \multicolumn{3}{|c|}{ Synthetic Oil } & \multicolumn{3}{|c|}{ Mineral Oil } & \multicolumn{3}{|c|}{ Synthetic Oil } & \multicolumn{3}{|c|}{ Mineral Oil } & \multicolumn{3}{|c|}{ Synthetic Oil } \\
\hline & Avg & S.D. & COV & Avg & S.D. & COV & $\overline{\text { Avg }}$ & S.D. & COV & Avg & S.D. & COV & Avg & S.D. & $\mathrm{COV}$ & Avg & S.D. & COV & Avg & S.D. & COV & Avg & S.D. & COV \\
\hline 1 & 1.08 & $\overline{0.04}$ & 0.03 & 1.15 & $\overline{0.06}$ & 0.05 & 0.00 & 0.00 & - & 0.00 & 0.00 & - & 0.07 & 0.00 & 0.05 & 0.06 & 0.01 & 0.13 & 0.01 & 0.01 & 0.57 & 0.01 & 0.00 & 0.53 \\
\hline 2 & 0.93 & 0.05 & 0.06 & 0.97 & 0.08 & 0.08 & 0.00 & 0.00 & 0.55 & 0.00 & 0.00 & 1.41 & 0.07 & 0.01 & 0.19 & 0.04 & 0.01 & 0.33 & 0.01 & 0.01 & 0.59 & 0.01 & 0.00 & 0.04 \\
\hline 3 & 0.77 & 0.05 & 0.06 & 0.78 & 0.02 & 0.02 & 0.00 & 0.00 & - & 0.00 & 0.00 & 1.41 & 0.06 & 0.00 & 0.06 & 0.06 & 0.01 & 0.16 & 0.04 & 0.00 & 0.12 & 0.03 & 0.01 & 0.19 \\
\hline 4 & 0.68 & 0.07 & 0.10 & 0.73 & 0.01 & 0.02 & 0.00 & 0.00 & - & 0.00 & 0.00 & - & 0.07 & 0.00 & 0.04 & 0.07 & 0.01 & 0.11 & 0.15 & 0.04 & 0.28 & 0.13 & 0.07 & 0.57 \\
\hline 5 & 0.59 & 0.05 & 0.09 & 0.59 & 0.06 & 0.11 & 0.00 & 0.00 & - & 0.00 & 0.00 & - & 0.06 & 0.01 & 0.12 & 0.06 & 0.00 & 0.05 & 0.14 & 0.01 & 0.08 & 0.14 & 0.05 & 0.38 \\
\hline 6 & 1.14 & 0.06 & 0.05 & 1.06 & 0.05 & 0.05 & 0.01 & 0.00 & 0.45 & 0.00 & 0.00 & 0.94 & 0.07 & 0.01 & 0.14 & 0.08 & 0.01 & 0.10 & 0.01 & 0.01 & 0.67 & 0.01 & 0.00 & 0.39 \\
\hline 7 & 1.04 & 0.14 & 0.14 & 0.94 & 0.03 & 0.03 & 0.00 & 0.00 & 0.57 & 0.00 & 0.00 & 1.73 & 0.07 & 0.01 & 0.10 & 0.08 & 0.02 & 0.25 & 0.04 & 0.01 & 0.17 & 0.03 & 0.00 & 0.16 \\
\hline 8 & 0.86 & 0.07 & 0.09 & 0.86 & 0.01 & 0.01 & 0.01 & 0.01 & 1.54 & 0.00 & 0.00 & 1.73 & 0.07 & 0.01 & 0.13 & 0.08 & 0.01 & 0.17 & 0.03 & 0.00 & 0.13 & 0.04 & 0.01 & 0.22 \\
\hline 9 & 0.77 & 0.02 & 0.02 & 0.79 & 0.06 & 0.08 & 0.00 & 0.00 & - & 0.00 & 0.00 & 1.73 & 0.07 & 0.01 & 0.09 & 0.06 & 0.02 & 0.28 & 0.04 & 0.00 & 0.05 & 0.03 & 0.00 & 0.07 \\
\hline 10 & 0.75 & 0.06 & 0.08 & 0.70 & 0.01 & 0.01 & 0.00 & 0.00 & 1.73 & 0.00 & 0.00 & - & 0.07 & 0.01 & 0.10 & 0.08 & 0.01 & 0.10 & 0.11 & 0.01 & 0.09 & 0.12 & 0.01 & 0.06 \\
\hline 11 & 1.42 & 0.16 & 0.12 & 1.38 & 0.04 & 0.03 & 0.01 & 0.01 & 0.52 & 0.00 & 0.01 & 1.73 & 0.09 & 0.01 & 0.11 & 0.09 & 0.02 & 0.20 & 0.01 & 0.00 & 0.29 & 0.01 & 0.01 & 0.84 \\
\hline 12 & 1.05 & 0.03 & 0.03 & 1.01 & 0.03 & 0.02 & 0.00 & 0.01 & 1.72 & 0.00 & 0.00 & 1.12 & 0.08 & 0.03 & 0.32 & 0.07 & 0.01 & 0.18 & 0.02 & 0.01 & 0.33 & 0.01 & 0.00 & 0.27 \\
\hline 13 & 0.90 & 0.00 & 0.00 & 0.83 & 0.08 & 0.10 & 0.00 & 0.00 & 1.12 & 0.00 & 0.00 & 1.00 & 0.07 & 0.01 & 0.08 & 0.07 & 0.00 & 0.02 & 0.03 & 0.00 & 0.03 & 0.04 & 0.00 & 0.07 \\
\hline 14 & 1.01 & 0.05 & 0.05 & 0.84 & 0.03 & 0.04 & 0.01 & 0.00 & 0.33 & 0.00 & 0.00 & - & 0.10 & 0.01 & 0.14 & 0.10 & 0.01 & 0.09 & 0.10 & 0.02 & 0.23 & 0.09 & 0.02 & 0.22 \\
\hline 15 & 0.81 & 0.01 & 0.01 & 0.81 & 0.03 & 0.04 & 0.00 & 0.00 & 0.15 & 0.01 & 0.01 & 1.39 & 0.08 & 0.03 & 0.35 & 0.09 & 0.01 & 0.15 & 0.08 & 0.01 & 0.07 & 0.07 & 0.02 & 0.24 \\
\hline
\end{tabular}

Avg $=$ Average, S.D. $=$ Standard Deviation, $\mathrm{COV}=$ Coefficient of Variance 


\section{APPENDIX D : Elemental Carbon (EC)/Organic Carbon (OC), Ions, Trace Metals Analysis: Procedure and Data from Desert Research Institute (DRI)}

\section{D1 Thermal/Optical Carbon Analysis Method (EC/OC Analysis)[85]}

The Elemental Carbon/Organic Carbon (EC/OC) analysis was done using a DRI Model 2001 Thermal/Optical Carbon Analyzer. The analyzer operates based on the preferential oxidation of EC and OC at different temperatures in an oxidizing and non-oxidizing environment respectively.

The particulate samples for analysis were collected on pre-fired quartz filters to ensure the absence of any residual carbon contamination. A small sample punch is taken from the exposed filter for the analysis.

The filter was first subjected to a non-oxidizing helium (He) atmosphere. In this stage, the organic carbon compounds are volatilized. The volatilized compounds are then oxidized in an oxidizer (heated manganese dioxide, $\mathrm{MnO}_{2}$ ). The oxidized products are then reduced to methane $\left(\mathrm{CH}_{4}\right)$ in a methanator (hydrogen enriched nickel catalyst), concentration of which is measured by a flame ionization detector (FID).

The above mentioned OC part of the analysis is done for four fractions (four temperature steps) as follows:-

1) $\mathrm{OC}_{1}$ : Organic fraction volatilized between ambient and $120^{\circ} \mathrm{C}$.

2) $\mathrm{OC}_{2}$ : Organic fraction volatilized between 120 and $250^{\circ} \mathrm{C}$.

3) $\mathrm{OC}_{3}$ : Organic fraction volatilized between 250 and $450^{\circ} \mathrm{C}$.

4) $\mathrm{OC}_{4}$ : Organic fraction volatilized between 450 and $550^{\circ} \mathrm{C}$.

The optical component of the analyzer is used for pyrolysis correction of OC reported. There are chances for some of the OC to be charred into EC as a result of pyrolysis, and the reported OC fraction may be underestimated. The correction is done by continuously monitoring the filter reflectance and for transmittance throughout the analysis. The optical component consists of a helium-neon laser and a photo detector. The reflectance and transmittance, which would depend upon the quantity of light absorbing EC, would decrease as pyrolysis take place and increase as EC is oxidized during the EC analysis stage. 
During the EC analysis stage, oxygen is added to the helium at temperatures greater than $550^{\circ} \mathrm{C}$. This oxidizes the EC into $\mathrm{CO}_{2}$, which is then reduced to $\mathrm{CH}_{4}$ and detected by the FID. The EC is reported as three fractions as follows:-

1) $\mathrm{EC} 1$ : $\mathrm{EC}$ fraction oxidized at temperature $550^{\circ} \mathrm{C}$.

2) $\mathrm{EC} 2$ : EC fraction oxidized at temperature between 550 and $700^{\circ} \mathrm{C}$.

3) EC1: EC fraction oxidized at temperature between 700 and $800^{\circ} \mathrm{C}$.

The complete EC/OC results are shown in Table D1 with the uncertainty associated with the measurements.

\section{D2 Trace Metal Analysis [86]}

$\mathrm{X}$-ray fluorescence (XRF) technique was used by DRI to determine the trace metal concentration in the particulate samples collected.

Figure D1 illustrates the XRF principle [87]. An inner shell electron of the metal atom is excited by an incident photon from the X-ray source. When an electron gets de-excited from a higher energy level to fill the void, the energy differences between the shells appear as an X-ray. The X-ray spectrum acquired by the detector will have several characteristic peaks, the energy of which helps to determine the elements present. The intensity of the peaks provides a measure of the concentration of the particular element. 


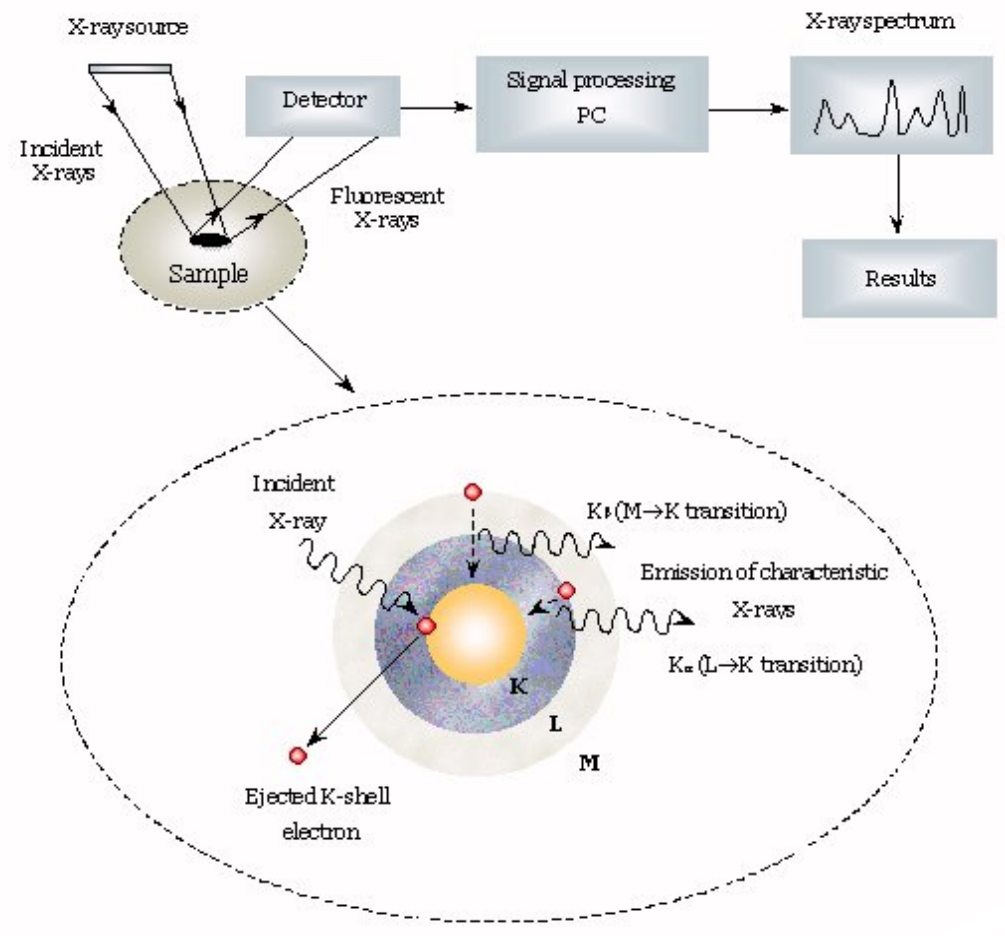

Figure D 1 The Principle of XRF and the typical XRF Detection Arrangement [87]

The instrument used by DRI was a Kevex EDX-771 energy dispersive X-ray spectrometer. It used a 200 watt Rhodium target tube as an excitation source. The detector was cryogenically cooled Lithium-drifted silicon with a $5 \mathrm{~mm}$ Be window and a resolution of $158 \mathrm{eV}$.

The samples for the analysis were collected on $90 \mathrm{~mm}$ Teflon-membrane filters. The complete results for the trace metals analysis is shown in Table D2. Ca and Zn were the only elements present in quantities significantly greater than the uncertainty levels involved. Magnesium (Mg) and phosphorus (P) are also generally present in the case of diesel engine lubricant derived PM in detectable quantities. This was not the case in this study. This could be attributed to the low levels of detergents, dispersants required in gaseous engine lubricants. The low levels of phosphorus also show less loss of the anti-wear component of the additives. The lower levels of $\mathrm{Zn}$ (which is also a major element of the anti-wear component, ZDDP or zinc dialkyl-dithio-phosphate) compared to $\mathrm{Ca}$ can also be attributed to the lower loss of anti-wear agents. 


\section{D3 Ions Analysis (Ion Chromatography) [88]}

Water-soluble nitrates, sulfates, nitrites, chloride and ammonium were measured using an ion chromatograph (IC), by DRI. The particulate was also checked for the presence of soluble sodium and potassium ions.

The tests were performed using the samples collected on the quartz filters for the EC/OC analysis. The water soluble ions were extracted using de-ionized distilled water. The analysis was done using a Dionex Model DX-500 ion chromatograph. The technique is based on separation of ions and polar molecules based on the change of properties of the molecules.

Table D3 shows the ion analysis results. Sulfates are usually found in detectable quantities in lubricant derived particulate along with nitrates. For the operating states tested in this study, none of the water soluble ions were found in notable amounts. Sulfates were almost zero or less than the uncertainty levels. The reason could be the very low concentration of sulfur for both test oils, which was less than $800 \mathrm{ppm}$, whereas the sulfur levels in typical diesel engine lubricants are around three to four times higher. Nitrate was the only water soluble ion found in detectable levels but was found in trace quantities in the order of 0.05 to $0.25 \mathrm{mg} / \mathrm{bhp}-\mathrm{hr}$ (Table D3). The nitrates were higher for the mineral oil compared to synthetic oil for all operating states, similar to the organic fraction, $\mathrm{Ca}$, and $\mathrm{Zn}$ results. The complete ions analysis results are shown in Table D4. 


\section{Table D1 EC/OC Results : Raw Data From DRI}

\begin{tabular}{|c|c|c|c|c|c|c|c|c|c|c|c|c|c|c|c|c|c|c|c|c|c|c|c|c|}
\hline QID & 01TC & 01TU & O2TC & 02TU & O3TC & O3TU & O4TC & 04TU & OPTRC & OPTRU & OPTTC & OPTTU & \begin{tabular}{|l|} 
OCTRC \\
\end{tabular} & OCTRU & E1TC & E1TU & E2TC & E2TU & IF-3TCI & E3TU & ECTRC & ECTRU & \begin{tabular}{|l|} 
TCTC \\
\end{tabular} & ТСTU \\
\hline WVU90Q020 & 279.898 & 86.123 & $\begin{array}{ll}717.914 \\
\end{array}$ & 157.045 & 540.602 & 49.648 & & 20.857 & 35.963 & 15.030 & \begin{tabular}{|l|}
74.055 \\
\end{tabular} & $\begin{array}{l}9.685 \\
\end{array}$ & & \begin{tabular}{|l|}
68.588 \\
\end{tabular} & 63.897 & 9.998 & 10.158 & 3.294 & & 0.902 & \begin{tabular}{|l|l|}
38.092 \\
\end{tabular} & & \begin{tabular}{|l|l}
1732.420 \\
\end{tabular} & \\
\hline WVU90Q021 & 630.080 & 193.844 & 2585.663 & 565.520 & 551.545 & 50.612 & \begin{tabular}{|l|}
121.023 \\
\end{tabular} & 21.037 & 45.847 & 19.025 & 74.380 & 9.723 & 3934.158 & 156.214 & 61.221 & 9.600 & 13.158 & 3.640 & \begin{tabular}{|l|l|}
0.000 \\
\end{tabular} & \begin{tabular}{ll|}
0.902 \\
\end{tabular} & 28.533 & 11.705 & \begin{tabular}{|l|l|}
3962.691 \\
\end{tabular} & 152.539 \\
\hline WVU90Q022 & 929.453 & 285.941 & 3579.392 & 782.857 & 480.575 & 44.377 & 111.390 & 19.424 & 67.203 & 27.715 & 105.452 & 13.477 & 5168.012 & 204.820 & 92.347 & 14.272 & 13.105 & 3.633 & 0.000 & 0.902 & 38.249 & 15.391 & 5206.261 & 199.899 \\
\hline WVU90Q023 & 415.409 & 127.806 & 739.486 & 161.763 & 333.474 & 31.640 & \begin{tabular}{|l|}
90.391 \\
\end{tabular} & 15.932 & 14.122 & 6.471 & 42.785 & 6.071 & & & 33.296 & 5.528 & 9.489 & & & .902 & & & & 64.268 \\
\hline /U90Q024 & 341.488 & 105.068 & 4314.000 & 943.523 & 510.197 & 46.974 & \begin{tabular}{|l|l|}
107.941 \\
\end{tabular} & 18.848 & 26.070 & 11.076 & & 7.643 & & 210.012 & 50.198 & 7.968 & 6.499 & 2.960 & & 0.902 & 30.627 & & & 204.6 \\
\hline WVU90Q025 & 744.954 & 229.183 & \begin{tabular}{|l|l|}
1374.242 \\
\end{tabular} & 300.577 & 780.557 & 70.909 & 140.538 & 24.316 & 84.523 & 34.789 & \begin{tabular}{|l|}
145.638 \\
\end{tabular} & 18.409 & \begin{tabular}{|l|}
3124.813 \\
\end{tabular} & 124.402 & 116.729 & 17.963 & 28.147 & 5.869 & \begin{tabular}{|l|}
0.762 \\
\end{tabular} & 0.902 & 61.114 & 24.217 & \begin{tabular}{|l|}
3185.928 \\
\end{tabular} & 123.044 \\
\hline \begin{tabular}{|l|} 
WVU90Q026 \\
\end{tabular} & 390.170 & 120.043 & \begin{tabular}{|l|l|}
1978.028 \\
\end{tabular} & 432.627 & 373.850 & 35.100 & 81.708 & \begin{tabular}{|l|}
14.501 \\
\end{tabular} & 43.963 & 18.262 & \begin{tabular}{|l|}
69.630 \\
\end{tabular} & $\begin{array}{l}.159 \\
9.159 \\
\end{array}$ & \begin{tabular}{|l|}
2867.719 \\
\end{tabular} & 114.318 & 59.924 & \begin{tabular}{|c|} 
\\
9.407 \\
\end{tabular} & 9.706 & 3.247 & \begin{tabular}{|l|}
0.000 \\
\end{tabular} & \begin{tabular}{|l|l|}
0.902 \\
\end{tabular} & 25.666 & 10.635 & \begin{tabular}{|l|}
2893.386 \\
\end{tabular} & \begin{tabular}{|l|}
111.966 \\
\end{tabular} \\
\hline & & & & & & & & & & & & & & & & & & & & & & & & \\
\hline WVU90Q028 & 1233.875 & 379.592 & \begin{tabular}{|l|}
5474.587 \\
\end{tabular} & 1197.355 & \begin{tabular}{|l|}
1842.905 \\
\end{tabular} & 166.018 & \begin{tabular}{|l|}
223.247 \\
\end{tabular} & 38.316 & 121.748 & 50.021 & 183.847 & 23.132 & \begin{tabular}{|l|l|}
8896.362 \\
\end{tabular} & 351.974 & 150.482 & 23.090 & 33.365 & 6.741 & 000 & 0.902 & 62.098 & 24.599 | & 958.460 & 343.165 \\
\hline WVU90Q029 & 371.831 & 114.401 & 2706.112 & 591.864 & 1079.401 & 97.581 & 110.511 & 19.278 & 23.256 & 9.966 & 69.693 & & \begin{tabular}{|l|l|}
4291.111 \\
\end{tabular} & 170.266 & 61.656 & 9.664 & 8.037 & 3.087 & & 0.902 & 46.437 & 18.536 & \begin{tabular}{|l|}
4337.548 \\
\end{tabular} & 166.802 \\
\hline WVU90Q030 & 917.527 & 282.272 & \begin{tabular}{|l|}
2752.078 \\
\end{tabular} & 601.917 & \begin{tabular}{|r|}
518.739 \\
\end{tabular} & 47.725 & \begin{tabular}{|l|l|}
61.869 \\
\end{tabular} & \begin{tabular}{|l|}
11.282 \\
\end{tabular} & 0.000 & 2.885 & 42.018 & & & 168.656 & 31.791 & 5.317 & 10.227 & & & & 42.018 & 16.835 & \begin{tabular}{|l|}
4292.231 \\
\end{tabular} & 165.077 \\
\hline VVU90Q031 & 221.323 & $\begin{array}{ll}68.107 \\
\end{array}$ & \begin{tabular}{|l|}
910.196 \\
\end{tabular} & 199.093 & 374.5 & 35.1 & & & & & 28.205 & & & & & & & & & & & & & 62.742 \\
\hline WVU90Q033 & 1157.933 & 356.229 & 1029.958 & 225.284 & 2.041 & $5 \varepsilon$ & 126.6 & & & & 67.7 & & & & 48.329 & 7.694 & 19.416 & & & & & & & 116.921 \\
\hline WVU90Q034 & 380.034 & 116.925 & \begin{tabular}{|l|}
515.856 \\
\end{tabular} & 112.865 & 631.107 & 57.639 & \begin{tabular}{|l|}
88.043 \\
\end{tabular} & 15.544 & 54.647 & 22.599 & 85.041 & 11.001 & \begin{tabular}{|l|}
1669.686 \\
\end{tabular} & 67.637 & 71.709 & 11.166 & 13.333 & 3.661 & \begin{tabular}{|l|}
0.000 \\
\end{tabular} & 0.902 & 30.395 & 12.406 & 700.080 & 67.173 \\
\hline & 347.371 & 106.877 & 2600.758 & 568.8 & 954.4 & .416 & 94.325 & 16.583 & 22.326 & & 52.1 & & & 59. & & & & & & & & & & \\
\hline & 292.341 & 89.950 & \begin{tabular}{|l|}
509.819 \\
\end{tabular} & 111.545 & 429.441 & & 69.843 & 565 & 0.6 & 2. & 32.481 & & 445 & 53.528 & 25.066 & 4.39 & & & & & & & & 53.7 \\
\hline WVU90Q037 & 604.664 & 186.02 & \begin{tabular}{|l|l|}
4711.333 \\
\end{tabular} & 1030.424 & 1471.215 & 132.674 & \begin{tabular}{|l|l|}
129.801 \\
\end{tabular} & 22.510 & 42.655 & 17.732 & 97.707 & 12.534 & 6959.669 & 275.505 & 84.524 & 13.092 & 13.182 & 3.643 & & & 55.051 & 21.865 & 7014.720 & 268.910 \\
\hline WVU90Q038 & 60.474 & 18.675 & 65.405 & 14.630 & 76.934 & 12.241 & 14.067 & \begin{tabular}{ll|}
4.637 \\
\end{tabular} & 1.160 & 2.924 & 1.160 & 2.889 & \begin{tabular}{|l|}
218.041 \\
\end{tabular} & 17.116 & 1.160 & 2.171 & 0.000 & 2.705 & 0.00 & 0.9 & 0.000 & 3.426 & \begin{tabular}{|l|}
218.041 \\
\end{tabular} & 18.731 \\
\hline WVU90Q039 & 45.472 & 14.083 & 48.932 & 11.132 & 65.902 & 11.709 & 7.579 & 4.173 & 0.000 & 2.885 & 0.000 & 2.885 & 167.885 & 16.208 & 0.000 & 2.164 & 0.000 & 2.705 & \begin{tabular}{|l|}
0.000 \\
\end{tabular} & \begin{tabular}{|l|l|} 
\\
\end{tabular} & 0.000 & 3.426 & \begin{tabular}{|l|}
167.885 \\
\end{tabular} & 17.959 \\
\hline
\end{tabular}

QID

O1TC

Quartz filter ID

Organic Carbon Fraction 2 concentration ( $\mu \mathrm{g} / \mathrm{filter})$

O2TU Organic Carbon Fraction 2 concentration ( $\mu \mathrm{g} / \mathrm{filter})$ uncertainty

O3TC Organic Carbon Fraction 3 concentration ( $\mu \mathrm{g} / \mathrm{fil}$ iter)

O3TU Organic Carbon Fraction 3 concentration $(\mu \mathrm{g} / \mathrm{filter})$ uncertainty

O4TC Organic Carbon Fraction 4 concentration ( $\mu \mathrm{g} / \mathrm{filter})$

O4TU Organic Carbon Fraction 4 concentration ( $\mu \mathrm{g} / \mathrm{filter})$ uncertainty

OPTTC Pyrolyzed organic carbon, thermal method, transmittance concentration ( $\mu \mathrm{g} / \mathrm{filter})$

OPTTU Pyrolyzed organic carbon, thermal method, transmittance concentration ( $\mu \mathrm{g} / \mathrm{filter})$ uncertainty

OPTRC Pyrolyzed organic carbon, thermal method, reflectance concentration ( $\mu \mathrm{g} / \mathrm{filter})$

OPTRU Pyrolyzed organic carbon, thermal method, reflectance concentration ( $\mu \mathrm{g} / \mathrm{filter})$ uncertainty

OCTRC Organic carbon,thermal method, reflectance concentration ( $\mu \mathrm{g} / \mathrm{filter})$

OCTRU Organic carbon,thermal method, reflectance concentration ( $\mu \mathrm{g} / \mathrm{filt}$ (ter) uncertainty

E1TC Elemental Carbon Fraction 1 concentration $(\mu \mathrm{g} / \mathrm{filter})$

E1TU Elemental Carbon Fraction 1 concentration $(\mu \mathrm{g} /$ filter) uncertainty

E2TC Elemental Carbon Fraction 2 concentration $(\mu \mathrm{g} / \mathrm{filter})$

E2TU Elemental Carbon Fraction 2 concentration $(\mu \mathrm{g} / \mathrm{filter})$ uncertainty

E3TC Elemental Carbon Fraction 3 concentration $(\mu \mathrm{g} / \mathrm{filter})$

E3TU Elemental Carbon Fraction 3 concentration $(\mu \mathrm{g} / \mathrm{filter})$ uncertainty

ECTRC Elemental carbon,thermal method, reflectance concentration $(\mu \mathrm{g} / \mathrm{filter})$

ECTRU Elemental carbon,thermal method, reflectance concentration ( $\mu \mathrm{g} / \mathrm{filter})$ uncertainty

TCTC Total Carbon concentration ( $\mu \mathrm{g} / \mathrm{filter})$

TCTU Total Carbon concentration $(\mu \mathrm{g} / \mathrm{filter})$ uncertainty 


\section{Table D2 Trace Metals Results : Raw Data From DRI}

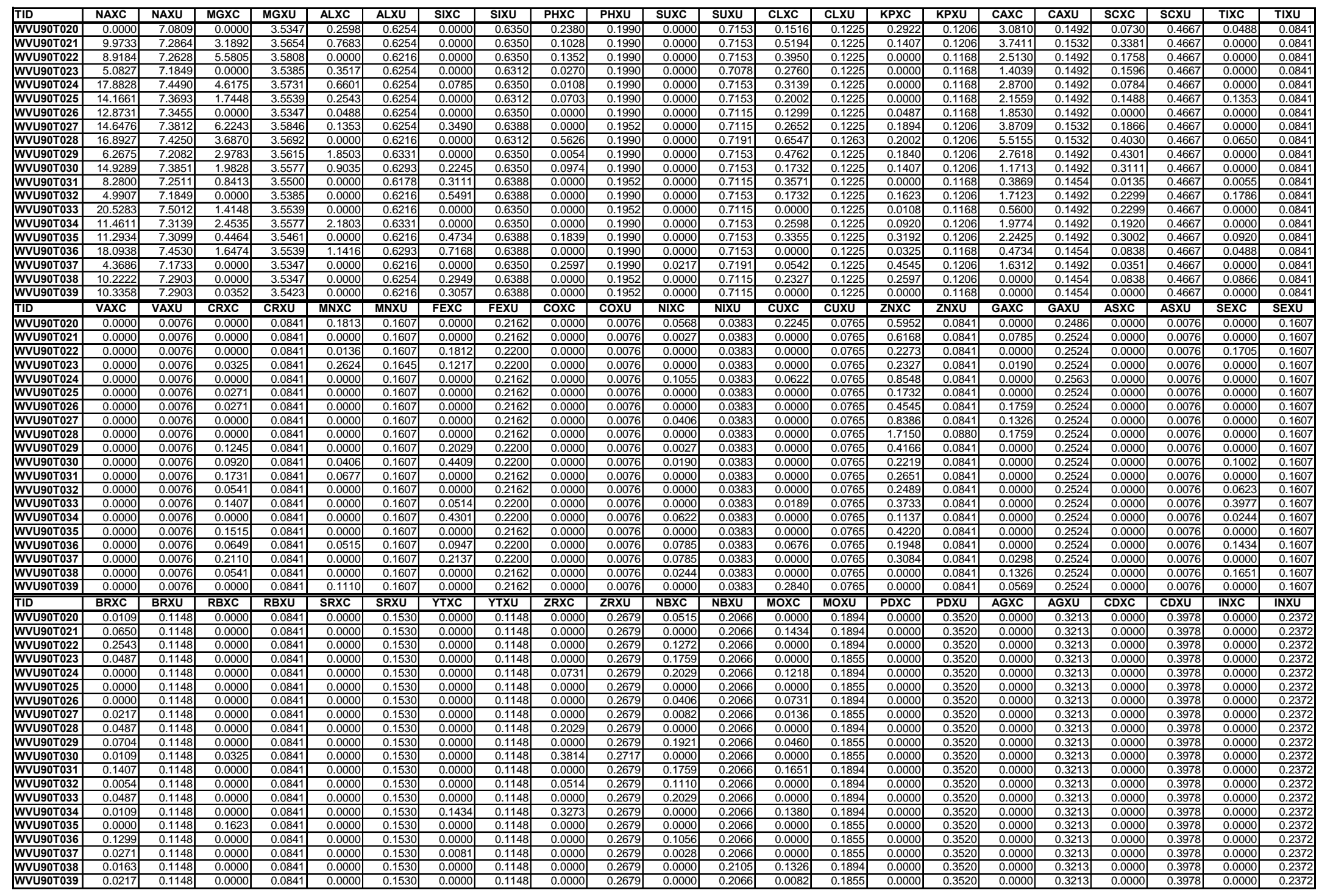




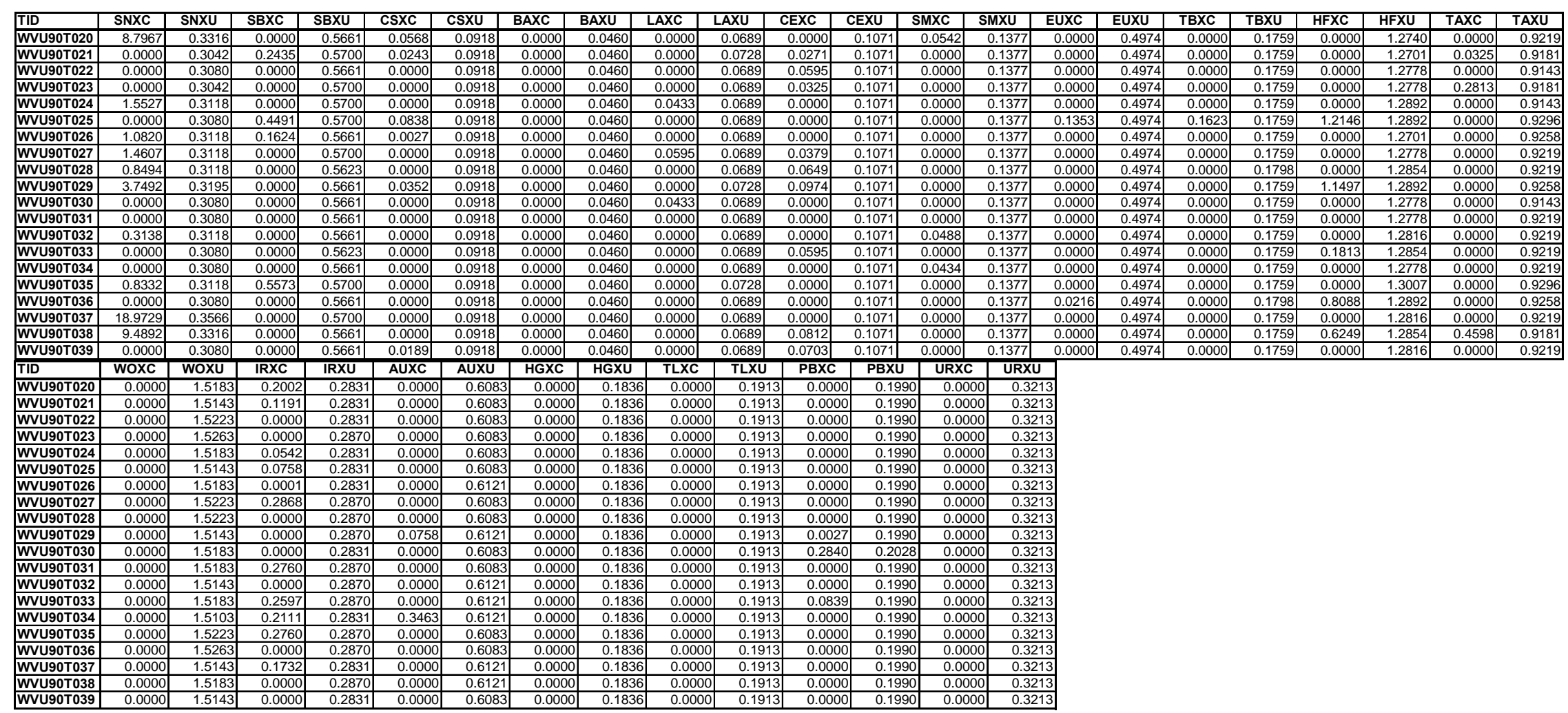

Note: The element concentrations and uncertainties in the above are denoted by four letters. The first two denote the element, the next two denote whether it represents concentration or the uncertainty, that is, XC denotes the concentration in $\mu \mathrm{g} /$ filter, and XU denotes the uncertainty in $\mu \mathrm{g} /$ filter.

The elements denoted by the symbols in the above table, and the state number corresponding to the filters are shown in Table D5, and D6 respectively. TID denotes Teflon filter ID, and QID denotes Quartz filter ID. 
Table D3 Brake-specific Nitrates

\begin{tabular}{|c|c|c|}
\hline \multirow{2}{*}{ State \# } & \multicolumn{2}{|c|}{ Brake-specifc Nitrates (mg/bhp-hr) } \\
\cline { 2 - 3 } & Mineral Oil & Synthetic Oil \\
\hline $\mathbf{1}$ & 0.15 & 0.09 \\
\hline $\mathbf{2}$ & 0.12 & 0.06 \\
\hline $\mathbf{4}$ & 0.25 & 0.14 \\
\hline $\mathbf{5}$ & 0.18 & 0.09 \\
\hline $\mathbf{8}$ & 0.19 & 0.12 \\
\hline $\mathbf{1 1}$ & 0.20 & 0.05 \\
\hline $\mathbf{1 2}$ & 0.11 & 0.05 \\
\hline $\mathbf{1 4}$ & 0.14 & 0.09 \\
\hline $\mathbf{1 5}$ & 0.16 & 0.05 \\
\hline
\end{tabular}

Table D4 Ions Analysis Results : Raw Data From DRI

\begin{tabular}{|c|c|c|c|c|c|c|c|c|c|c|c|c|}
\hline QID & CLIC & CLIU & N3IC & N3IU & S4IC & S4IU & N4CC & N4CU & NAAC & NAAU & KPAC & KPAU \\
\hline WVU90Q020 & 0.0000 & 1.5600 & 12.1961 & 1.5848 & 3.1356 & 1.5710 & 2.9390 & 1.5811 & 0.1404 & 0.1212 & 0.2153 & 0.1596 \\
\hline WVU90Q021 & 0.0000 & .5600 & 12.0650 & 1.5843 & 0.0000 & 1.5600 & 2.7144 & 1.5780 & 0.1872 & 0.1389 & .1217 & .1572 \\
\hline WVU90Q022 & 0.0000 & 1.5600 & 8.3866 & 1.5718 & 0.0000 & 1.5600 & 2.8735 & 1.5801 & 0.1217 & 0.1150 & 0.1498 & .1578 \\
\hline WVU90Q023 & 0.0000 & 1.5600 & 7.8062 & 1.5702 & 0.0000 & 1.5600 & 2.9016 & 1.5805 & 0.6833 & 0.3863 & 0.1030 & 0.1568 \\
\hline WVU90Q024 & 0.0000 & 1.5600 & 8.1900 & 1.5712 & 0.0000 & 1.5600 & 2.5553 & 1.5759 & 0.0374 & 0.0958 & 0.0936 & .1567 \\
\hline WVU90Q025 & 0.0000 & 1.5600 & 10.1275 & 1.5771 & 0.0000 & 1.5600 & 3.0046 & 1.5820 & 0.1404 & 1212 & 1030 & 1568 \\
\hline WVU90Q026 & 0.0000 & 1.5600 & 9.1447 & 1.5740 & 3.0794 & 1.5706 & 2.5459 & 1.5758 & 1.7316 & 0.9543 & 0.1685 & 0.1582 \\
\hline WVU90C & 0.0000 & 1.5600 & 13.6469 & 1.5910 & 0.0000 & 1.5600 & 2.8829 & 1.5803 & 0.0281 & 0.0949 & 1123 & 1570 \\
\hline WVU90Q028 & 0.0000 & 1.5600 & 16.1647 & 1.6033 & 2.9858 & 1.5699 & 3.1824 & 1.5847 & 0.1030 & 0.1093 & 0.1217 & 0.1572 \\
\hline WVU90Q029 & 0.0000 & 1.5600 & 8.5082 & 1.5721 & 0.0000 & 1.5600 & 2.7986 & 1.5791 & 0.0374 & 0.0958 & 0.0187 & .1560 \\
\hline WVU90Q030 & 0.0000 & 1.5600 & 6.3929 & 1.5669 & 0.0000 & 1.5600 & 3.4258 & 1.5885 & 0.0187 & 0.0942 & 1030 & 0.1568 \\
\hline WVU90Q031 & 0.0000 & 1.5600 & 5.0170 & 1.5642 & 3.7159 & 1.5754 & 3.2292 & 1.5854 & 0.4493 & 0.2636 & 0.2527 & 0.1610 \\
\hline WVU90Q032 & 0.0000 & 1.5600 & 6.1402 & 1.5663 & 3.5849 & 1.5743 & 2.5646 & 1.5761 & 0.1685 & 0.1315 & 0.1217 & 1572 \\
\hline WVU90Q033 & 0.0000 & 1.5600 & 6.5614 & 1.5672 & 3.0514 & 1.5704 & 3.9499 & 1.5978 & 0.1217 & 0.1150 & 0.2059 & 0.1593 \\
\hline WVU90Q034 & 0.0000 & 1.5600 & 8.0496 & 1.5709 & 0.0000 & 1.5600 & 3.0514 & 1.5827 & 0.0374 & 0.0958 & 0.1217 & 0.1572 \\
\hline WVU90Q035 & 0.0000 & 1.5600 & 8.9201 & 1.5733 & 0.0000 & 1.5600 & 2.8267 & 1.5795 & 0.2527 & 0.1672 & 0.2902 & 0.1626 \\
\hline WVU90Q036 & 0.0000 & 1.5600 & 5.3914 & 1.5649 & 0.0000 & 1.5600 & 2.7518 & 1.5785 & 0.0374 & 0.0958 & 0.1685 & 0.1582 \\
\hline WVU90Q037 & 0.0000 & 1.5600 & 11.0635 & 1.5804 & 0.0000 & 1.5600 & 3.0794 & 1.5831 & 0.0187 & 0.0942 & 0.1217 & 0.1572 \\
\hline WVU90Q038 & 0.0000 & 1.5600 & 3.6785 & 1.5623 & 0.0000 & 1.5600 & 2.4991 & 1.5753 & 0.2902 & 0.1846 & 0.1217 & 0.1572 \\
\hline WVU90Q039 & 0.0000 & 1.5600 & 3.6878 & 1.5623 & 0.0000 & 1.5600 & 2.3119 & 1.5731 & 0.1872 & 0.1389 & 0.1217 & 0.1572 \\
\hline
\end{tabular}


Table D5 Trace Metals Analysis : Elements and Corresponding Symbols

\begin{tabular}{|l|l|l|l|l|l|}
\hline NA & Sodium & CU & Copper & SB & Antimony \\
\hline MG & Magnesium & ZN & Zinc & CS & Cesium \\
\hline AL & Aluminum & GA & Gallium & BA & Barium \\
\hline SI & Silicon & AS & Arsenic & LA & Lanthanum \\
\hline PH & Phosphorous & SE & Selenium & CE & Cerium \\
\hline SU & Sulfur & BR & Bromine & SM & Samarium \\
\hline CL & Chlorine & RB & Rubidium & EU & Europium \\
\hline KP & Potassium & SR & Strontium & TB & Terbium \\
\hline CA & Calcium & YT & Yttrium & HF & Hafnium \\
\hline SC & Scandium & ZR & Zirconium & TA & Tantalum \\
\hline TI & Titanium & NB & Niobium & WO & Wolfram \\
\hline VA & Vanadium & MO & Molybdenum & IR & Iridium \\
\hline CR & Chromium & PD & Palladium & AU & Gold \\
\hline MN & Manganese & AG & Silver & HG & Mercury \\
\hline FE & Iron & CD & Cadmium & TL & Thallium \\
\hline CO & Cobalt & IN & Indium & PB & Lead \\
\hline NI & Nickel & SN & Tin & UR & Uranium \\
\hline
\end{tabular}

Table D6 Operating State Numbers and Corresponding Filter IDs

\begin{tabular}{|l|l|c|c|}
\hline QID & TID & State Number & Test Oil \\
\hline WVU90Q020 & WVU90T020 & 15 & Mineral Oil \\
\hline WVU90Q021 & WVU90T021 & 8 & Mineral Oil \\
\hline WVU90Q022 & WVU90T022 & 1 & Mineral Oil \\
\hline WVU90Q023 & WVU90T023 & 12 & Mineral Oil \\
\hline WVU90Q024 & WVU90T024 & 2 & Mineral Oil \\
\hline WVU90Q025 & WVU90T025 & 14 & Mineral Oil \\
\hline WVU90Q026 & WVU90T026 & 11 & Mineral Oil \\
\hline WVU90Q027 & WVU90T027 & 5 & Mineral Oil \\
\hline WVU90Q028 & WVU90T028 & 4 & Mineral Oil \\
\hline WVU90Q029 & WVU90T029 & 5 & Synthetic Oil \\
\hline WVU90Q030 & WVU90T030 & 1 & Synthetic Oil \\
\hline WVU90Q031 & WVU90T031 & 11 & Synthetic Oil \\
\hline WVU90Q032 & WVU90T032 & 2 & Synthetic Oil \\
\hline WVU90Q033 & WVU90T033 & 15 & Synthetic Oil \\
\hline WVU90Q034 & WVU90T034 & 14 & Synthetic Oil \\
\hline WVU90Q035 & WVU90T035 & 8 & Synthetic Oil \\
\hline WVU90Q036 & WVU90T036 & 12 & Synthetic Oil \\
\hline WVU90Q037 & WVU90T037 & 4 & Synthetic Oil \\
\hline WVU90Q038 & WVU90T038 & Background 1 & \\
\hline WVU90Q039 & WVU90T039 & Background 2 & \\
\hline
\end{tabular}




\section{APPENDIX E : Particle Size Distribution Data: Experimental Data with Error Bars}

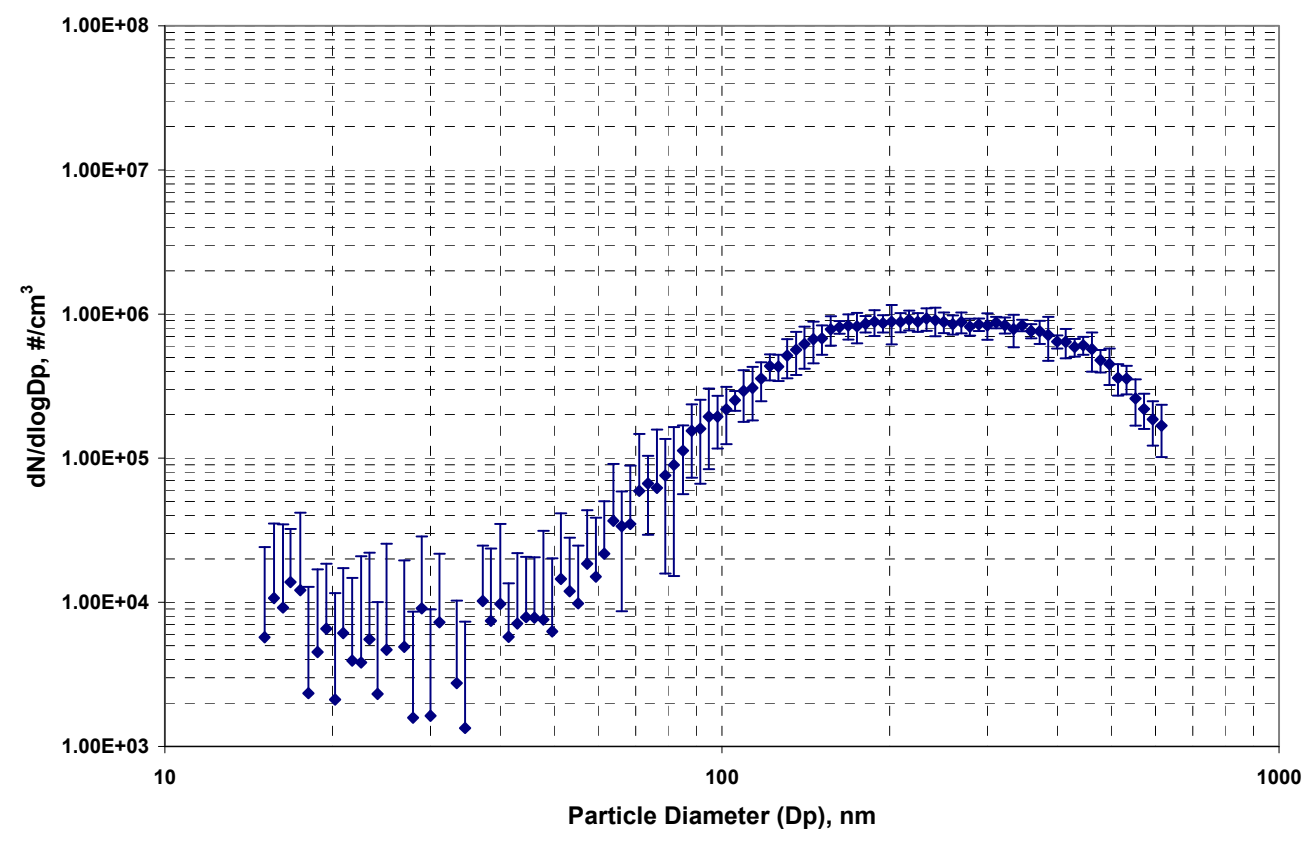

Figure E1 Particle Size Distribution: Mineral Oil (Speed=15 rps, Phi=0.28, Boost=20 kPa)

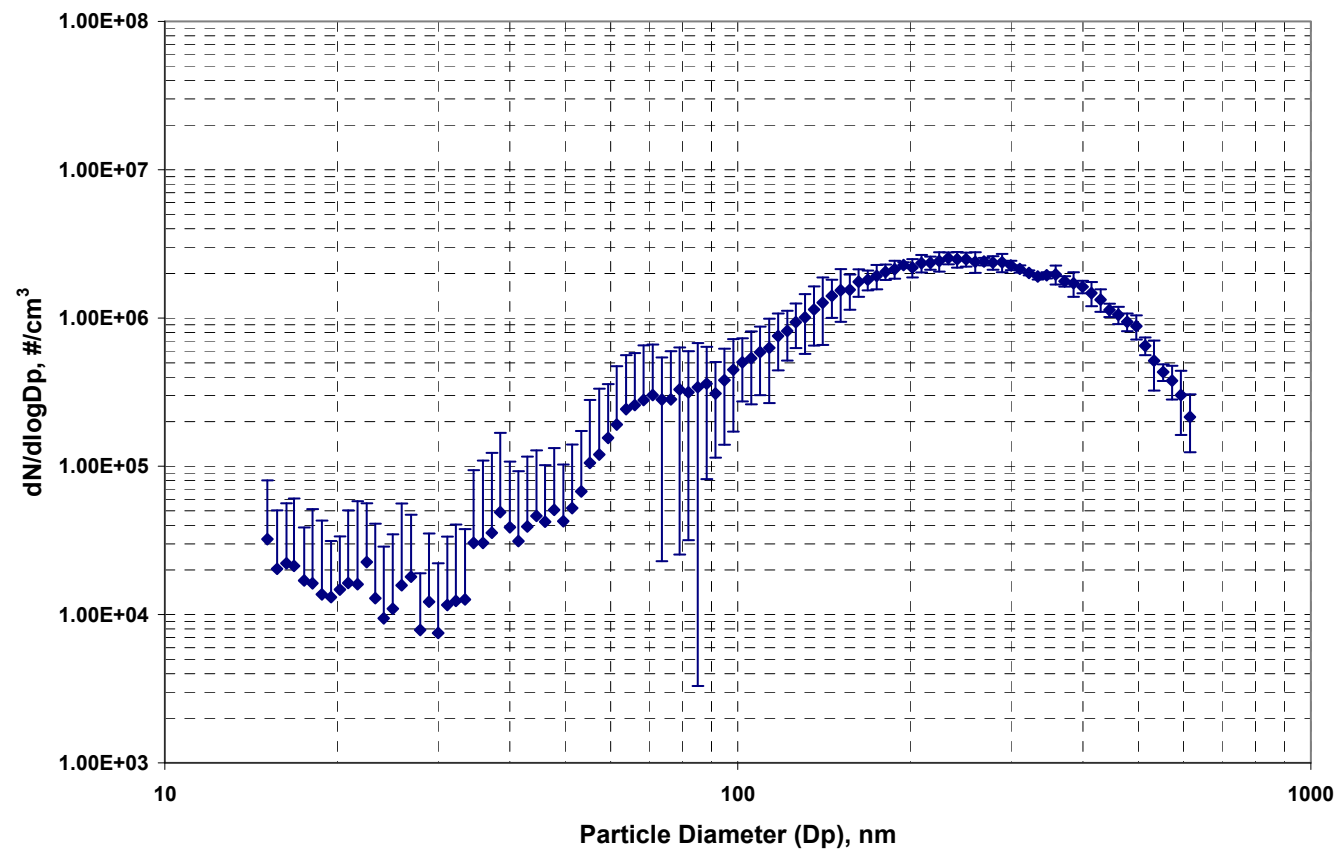

Figure E2 Particle Size Distribution: Mineral Oil (Speed=15 rps, Phi=0.28, Boost=60 kPa) 


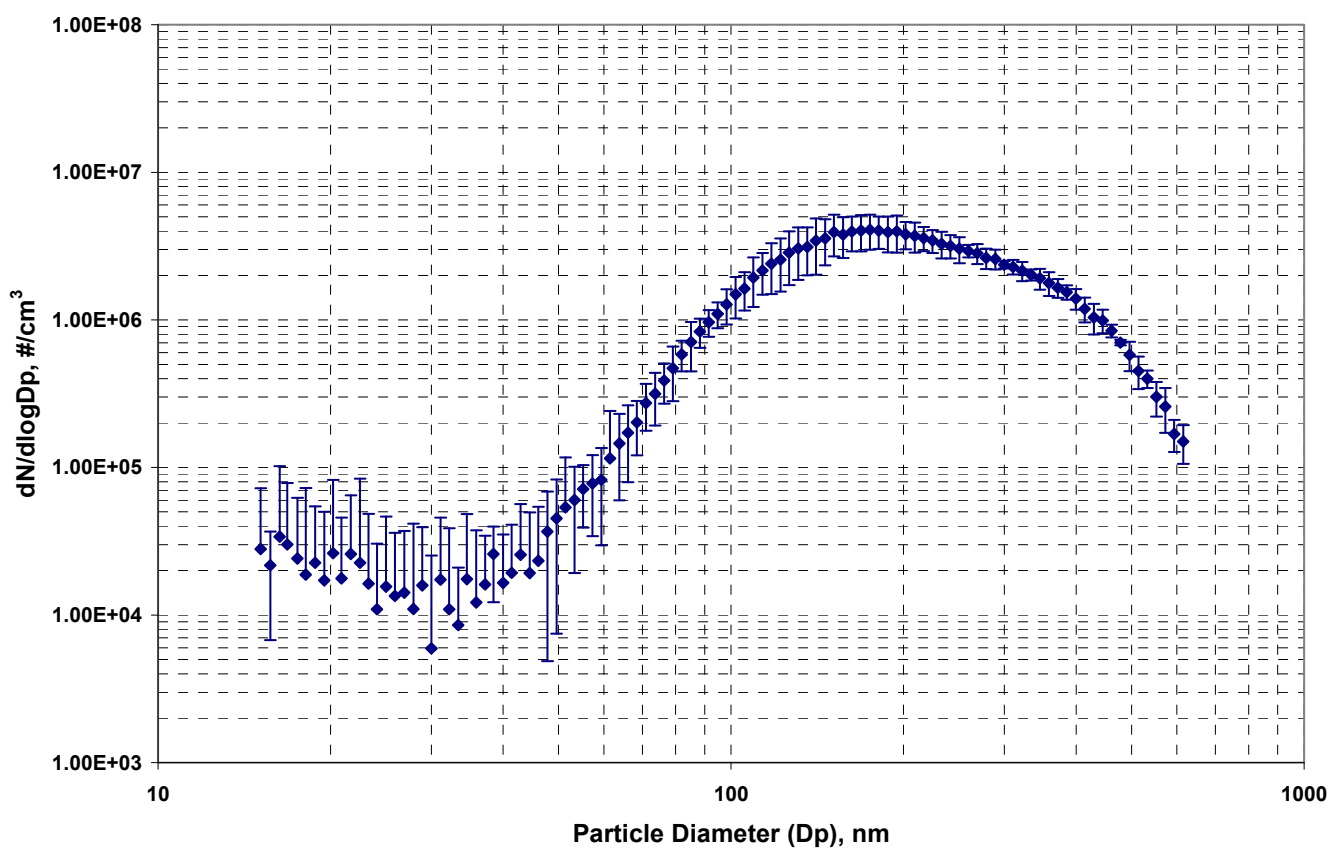

Figure E3 Particle Size Distribution: Mineral Oil (Speed=15 rps, Phi=0.33, Boost=40 kPa)

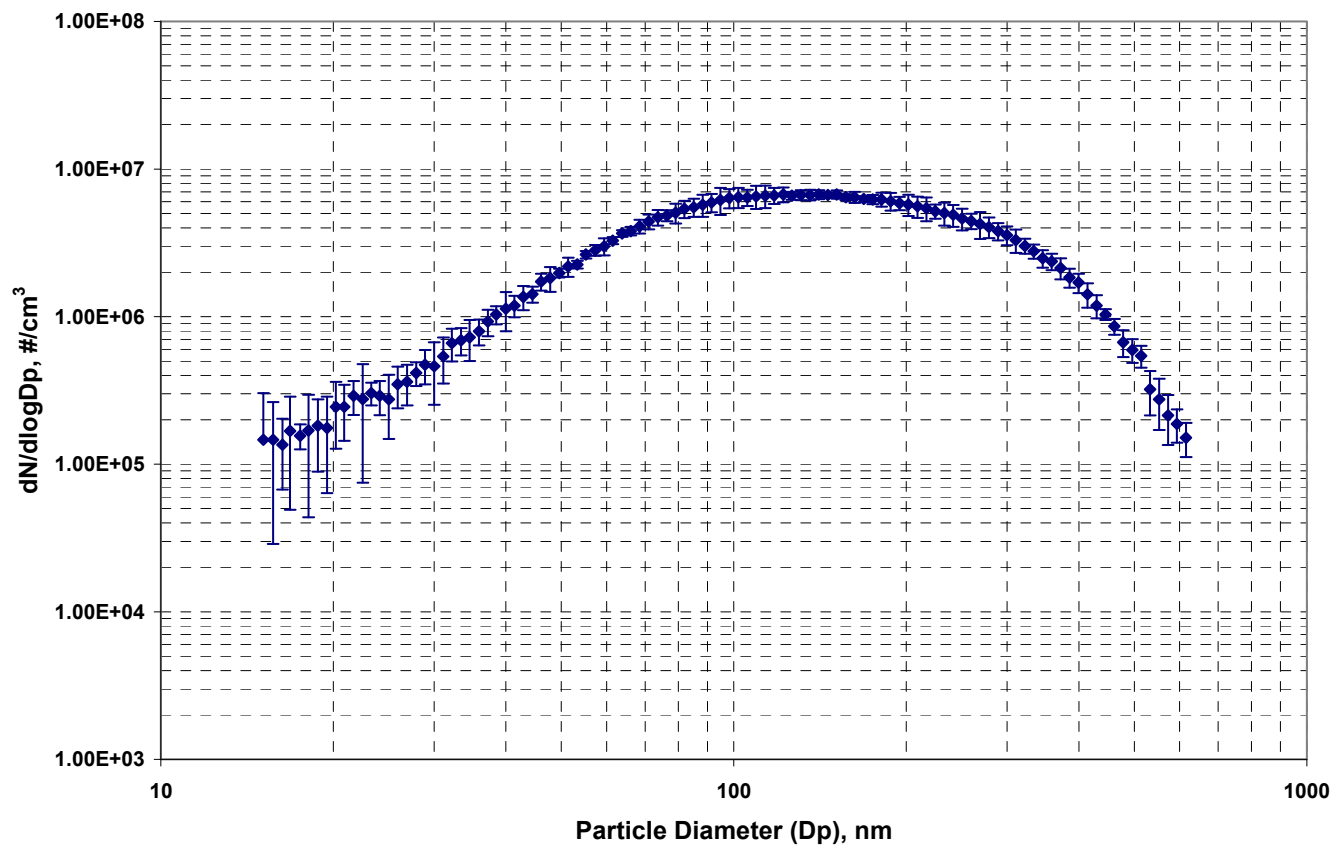

Figure E4 Particle Size Distribution: Mineral Oil (Speed=15 rps, Phi=0.38, Boost=20 kPa) 


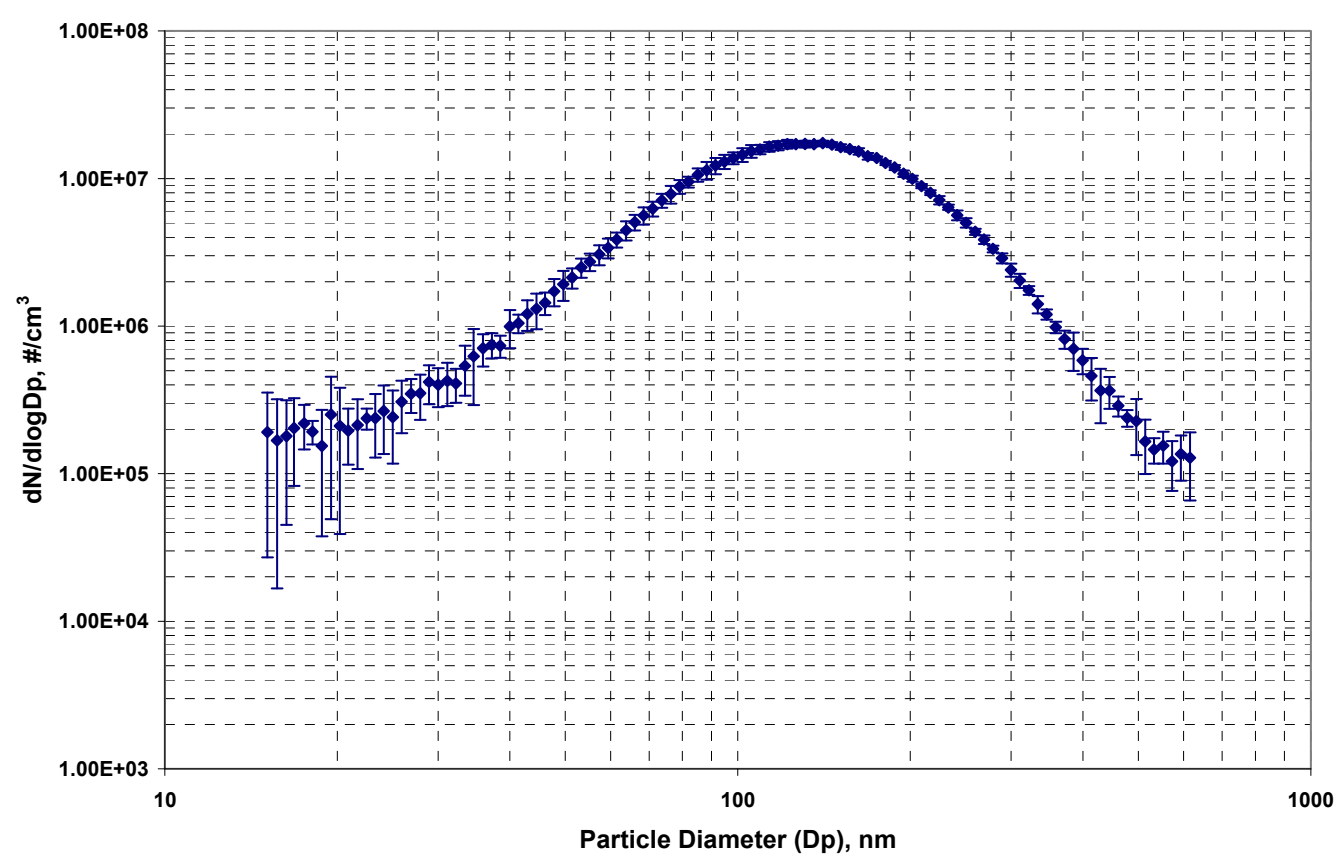

Figure E5 Particle Size Distribution: Mineral Oil (Speed=15 rps, Phi=0.38, Boost=60 kPa)

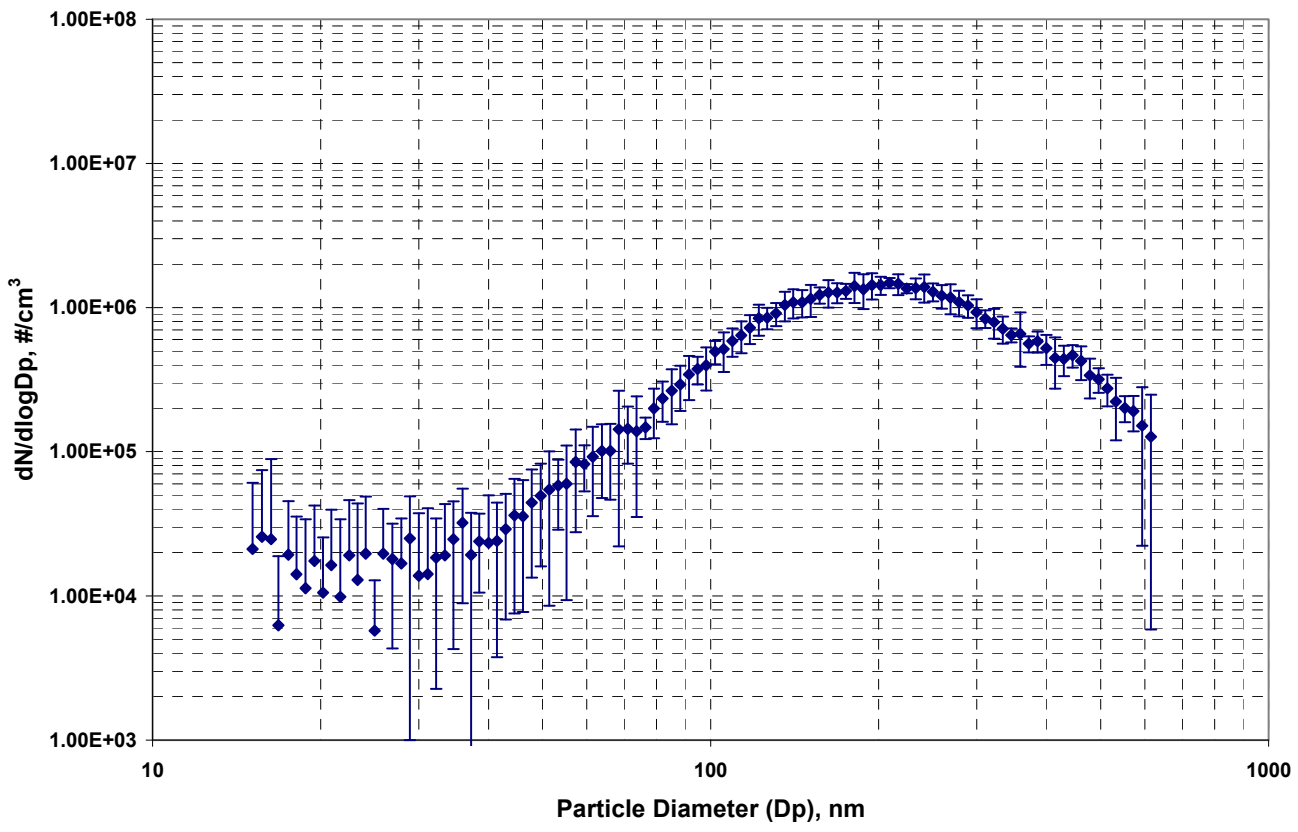

Figure E6 Particle Size Distribution: Synthetic Oil (Speed=15 rps, Phi=0.28, Boost=20 kPa) 


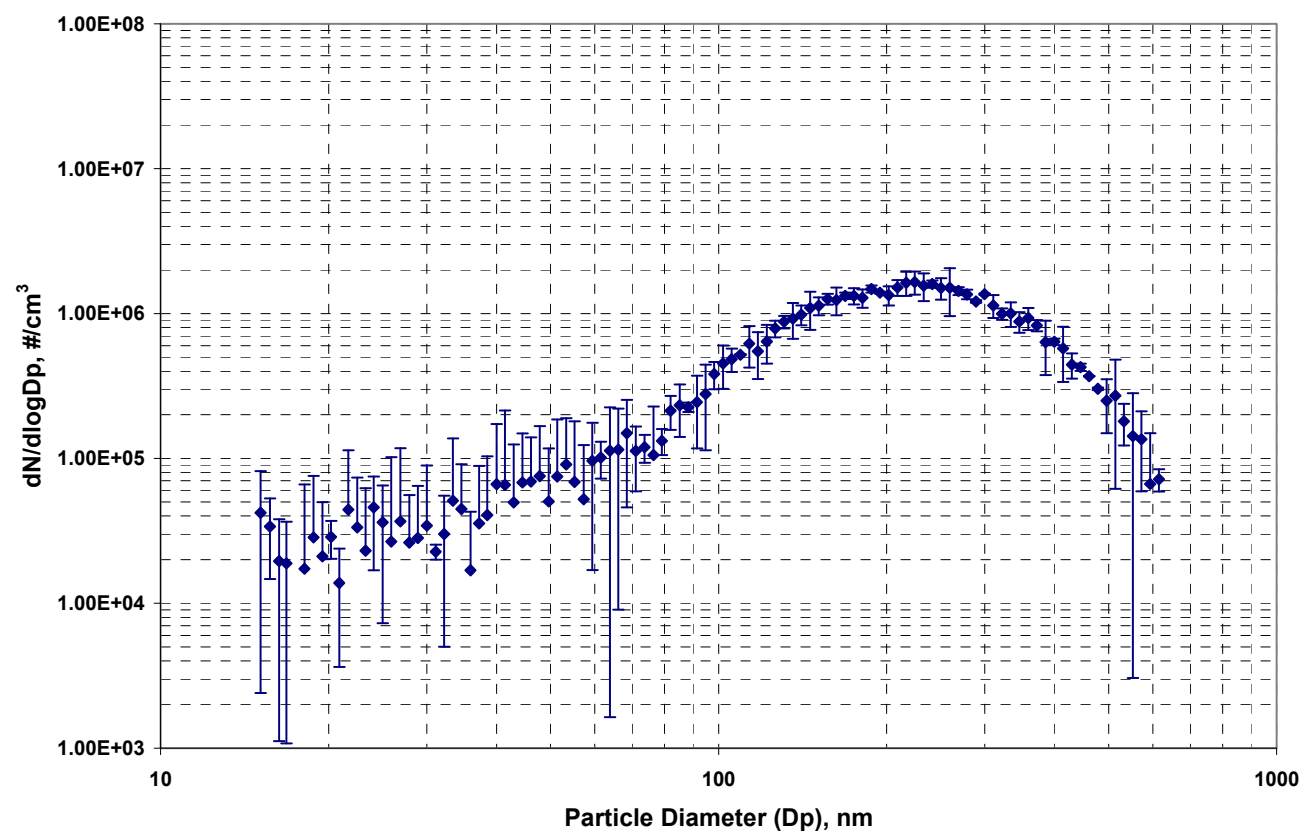

Figure E7 Particle Size Distribution: Synthetic Oil (Speed=15 rps, Phi=0.28, Boost=60 kPa)

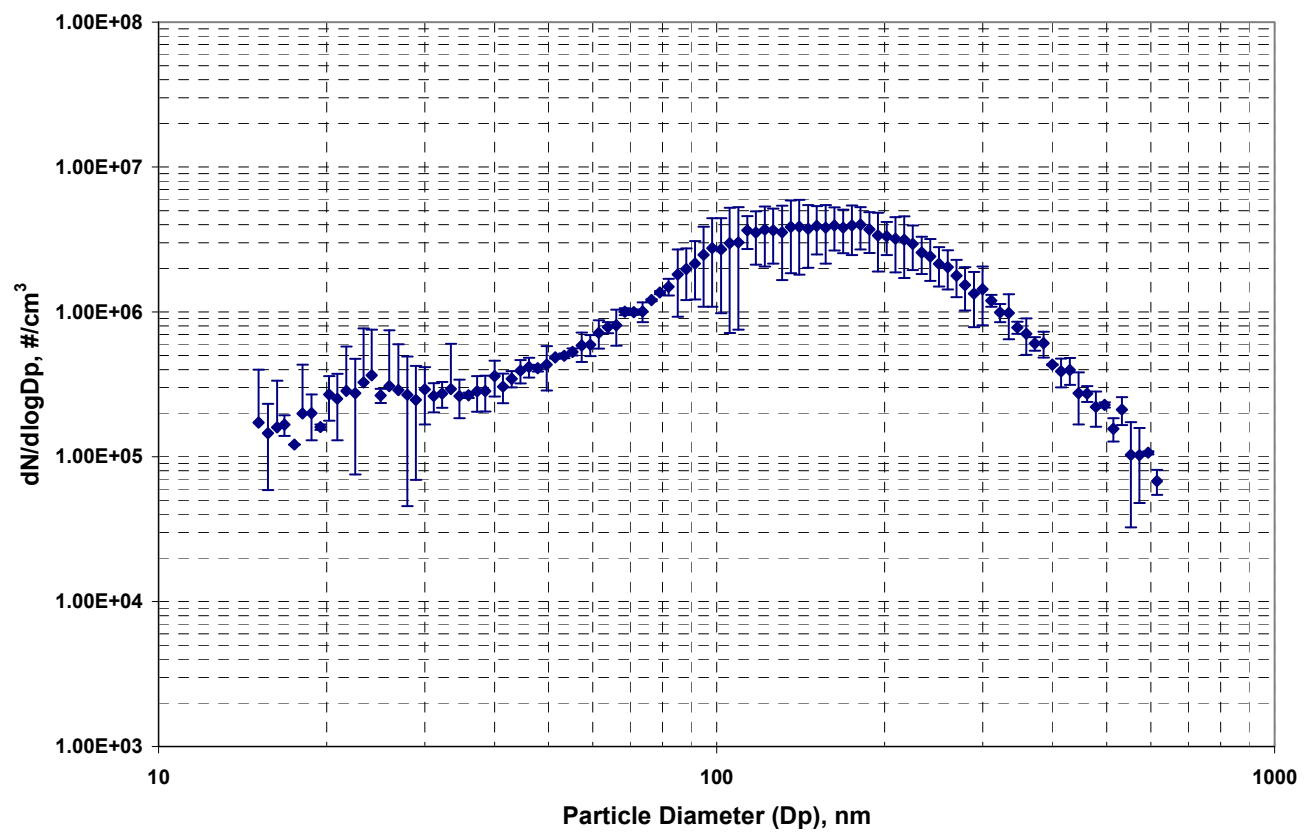

Figure E8 Particle Size Distribution: Synthetic Oil (Speed=15 rps, Phi=0.33, Boost=40 kPa) 


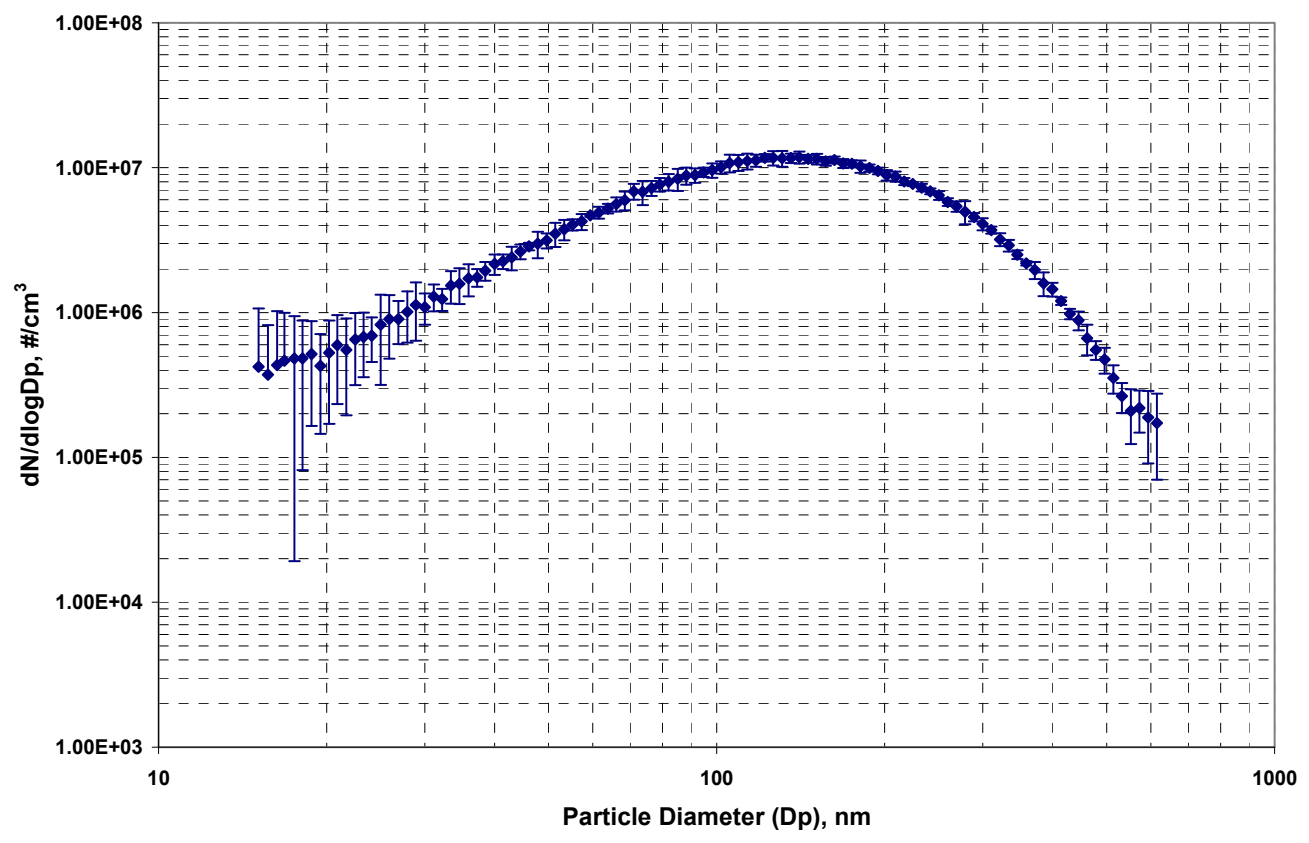

Figure E9 Particle Size Distribution: Synthetic Oil (Speed=15 rps, Phi=0.38, Boost=20 kPa)

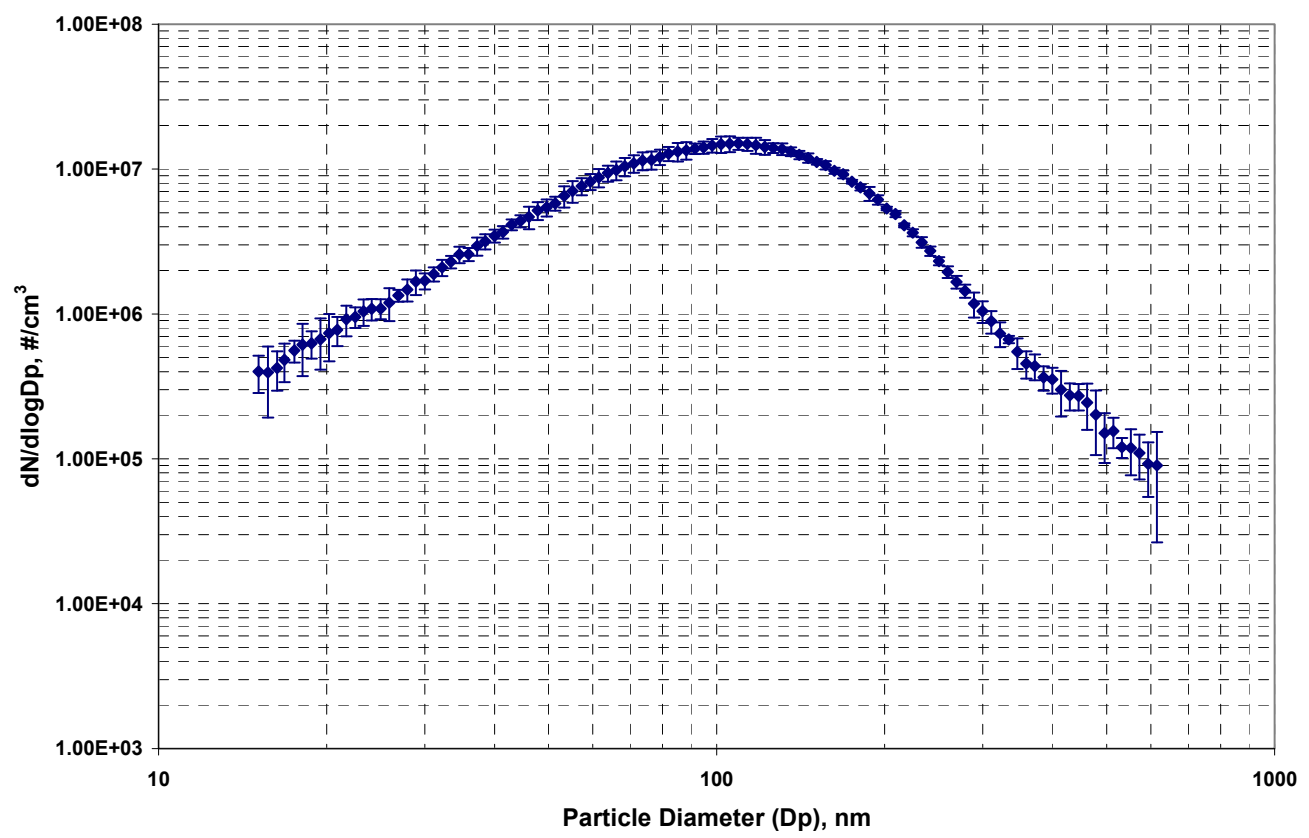

Figure E10 Particle Size Distribution: Synthetic Oil (Speed=15 rps, Phi=0.38, Boost=60 kPa) 


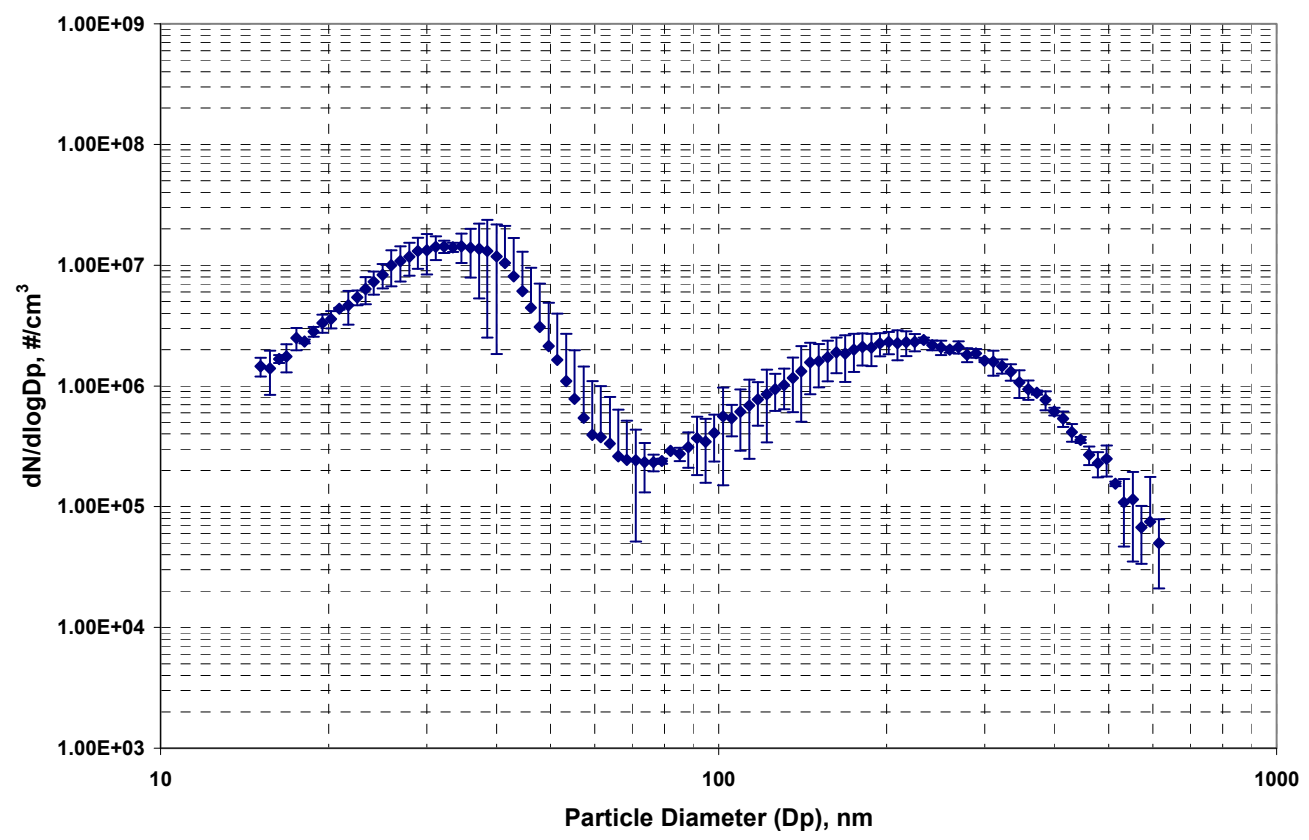

Figure E11 Particle Size Distribution: Mineral Oil (Speed=22.5rps, Phi=0.28, Boost=20 kPa)

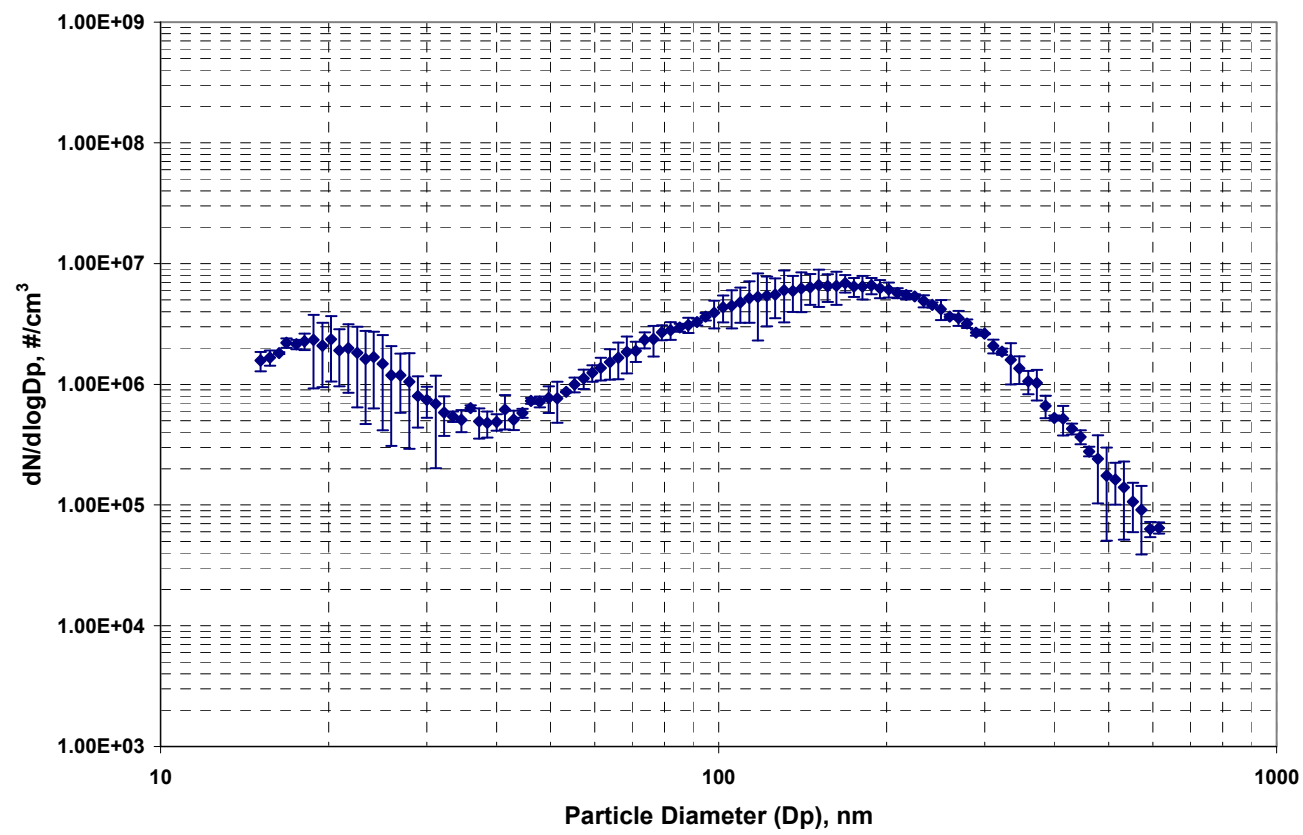

Figure E12 Particle Size Distribution: Mineral Oil (Speed=22.5rps, Phi=0.33, Boost=20 kPa) 


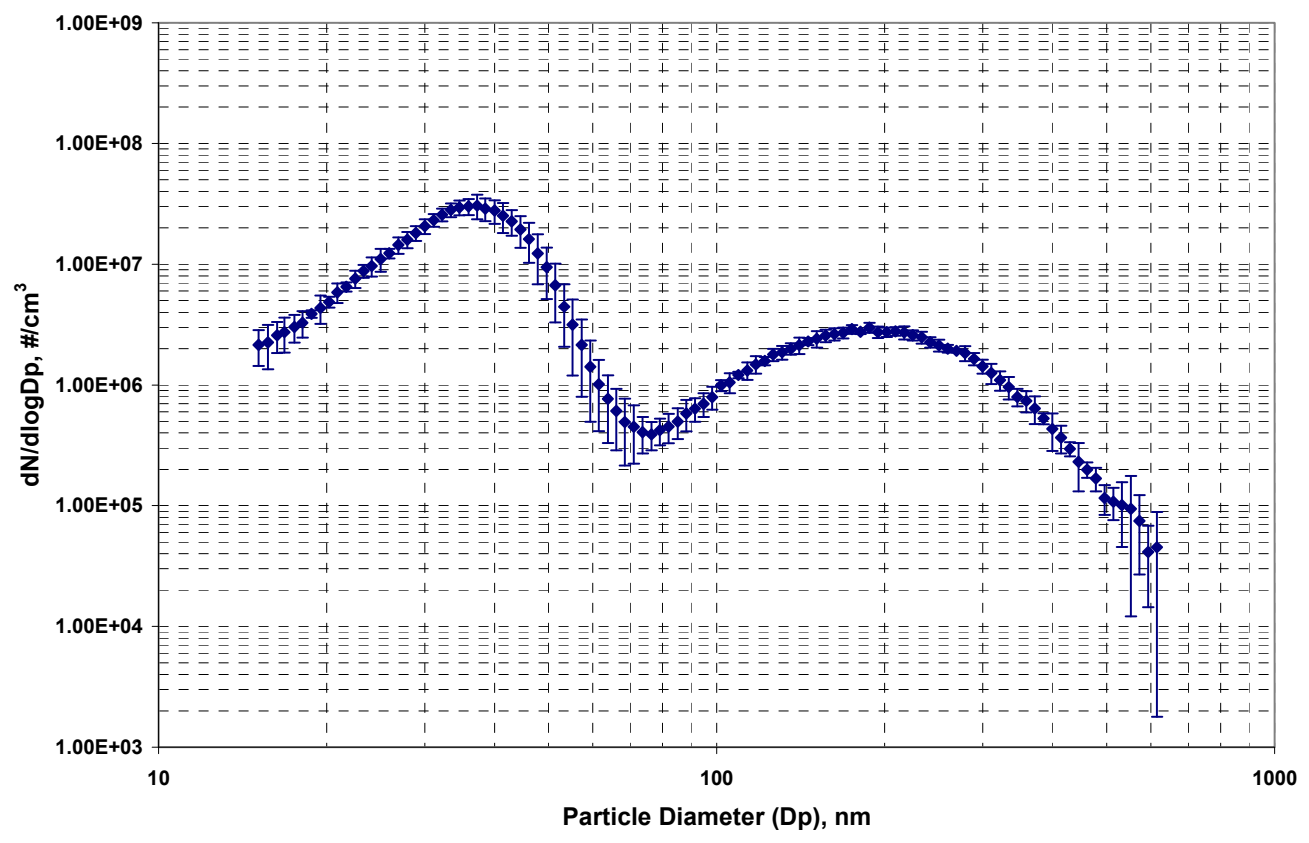

Figure E13 Particle Size Distribution: Mineral Oil (Speed=22.5rps, Phi=0.33, Boost $=40$ kPa)

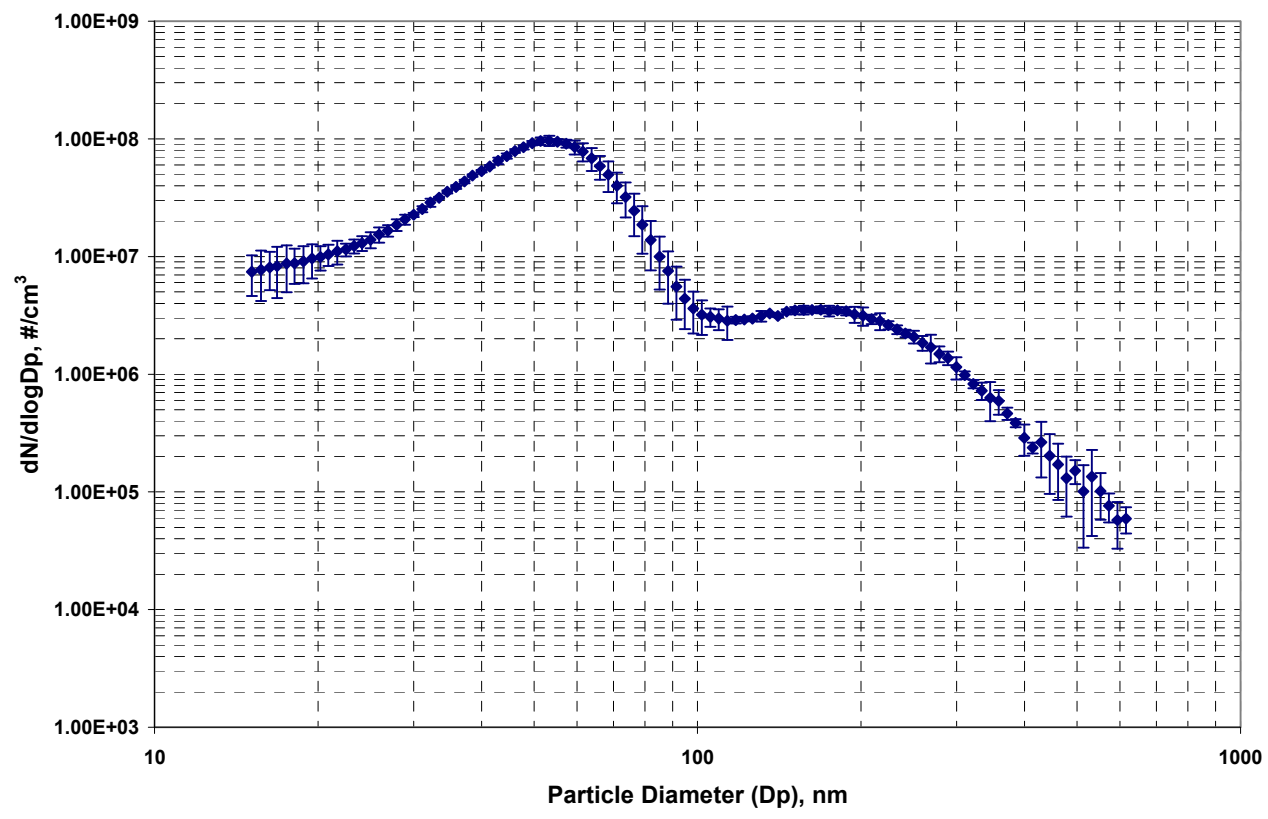

Figure E14 Particle Size Distribution: Mineral Oil (Speed=22.5rps, Phi=0.33, Boost=60 kPa) 


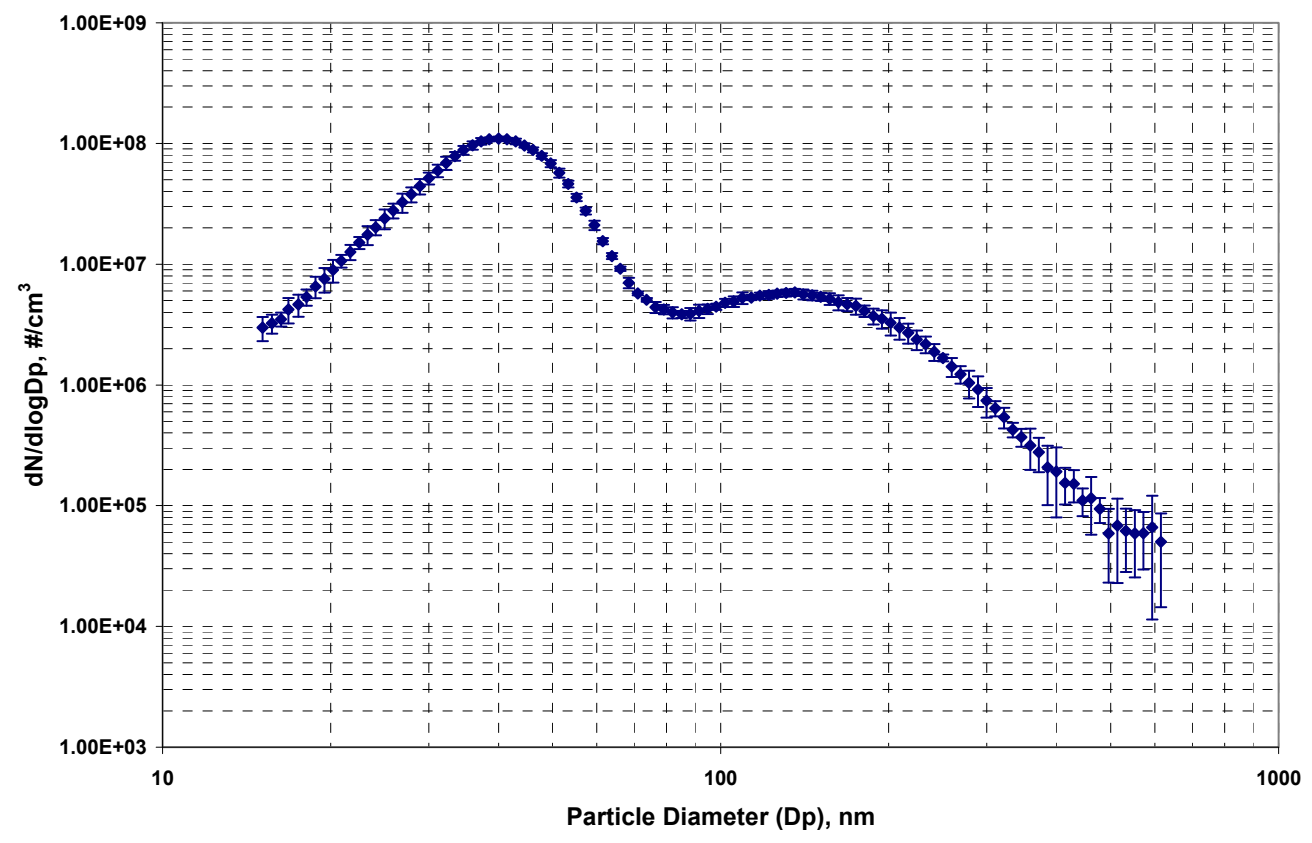

Figure E15 Particle Size Distribution: Mineral Oil (Speed=22.5rps, Phi=0.38, Boost $=40$ kPa)

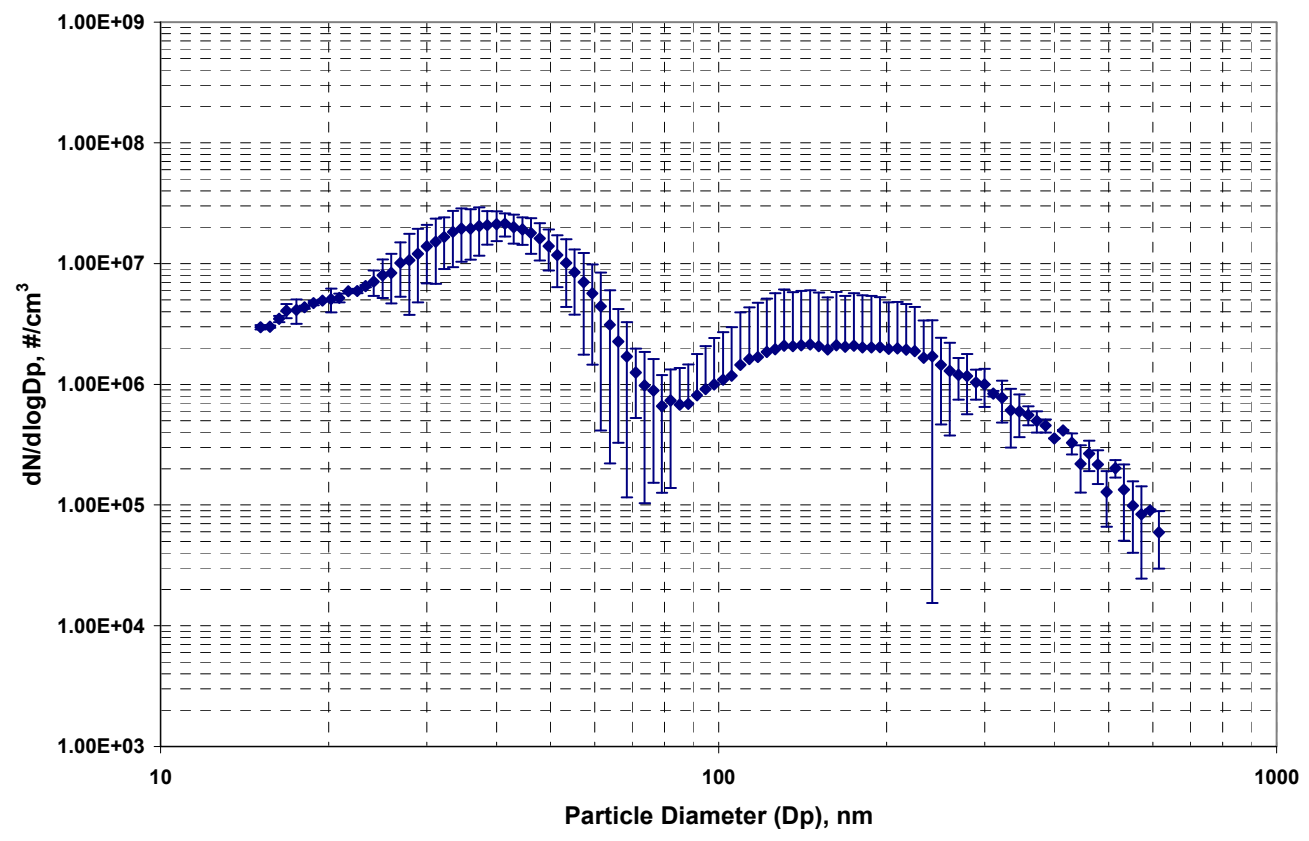

Figure E16 Particle Size Distribution: Synthetic Oil (Speed=22.5rps, Phi=0.28, Boost $=40 \mathrm{kPa}$ ) 


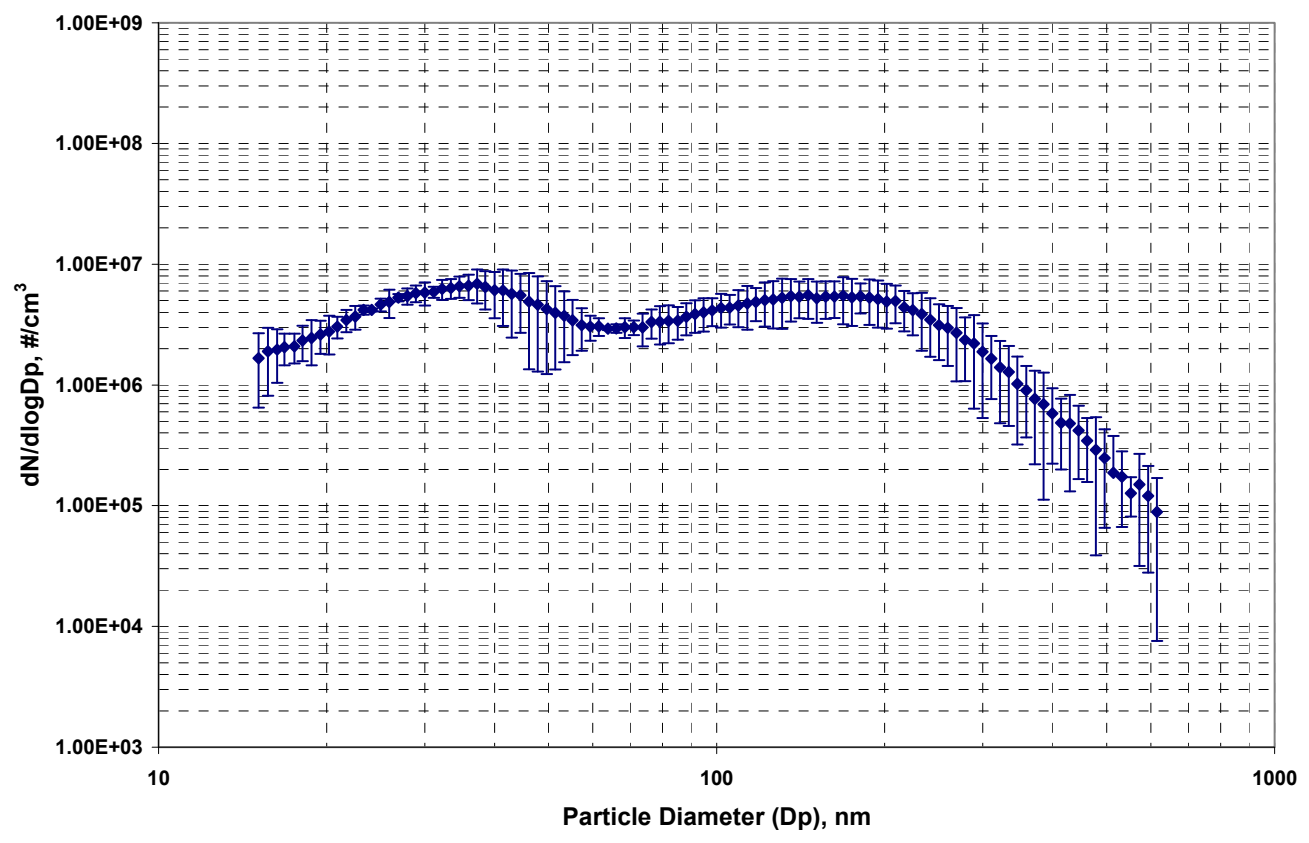

Figure E17 Particle Size Distribution: Synthetic Oil (Speed=22.5rps, Phi=0.33, Boost=20kPa)

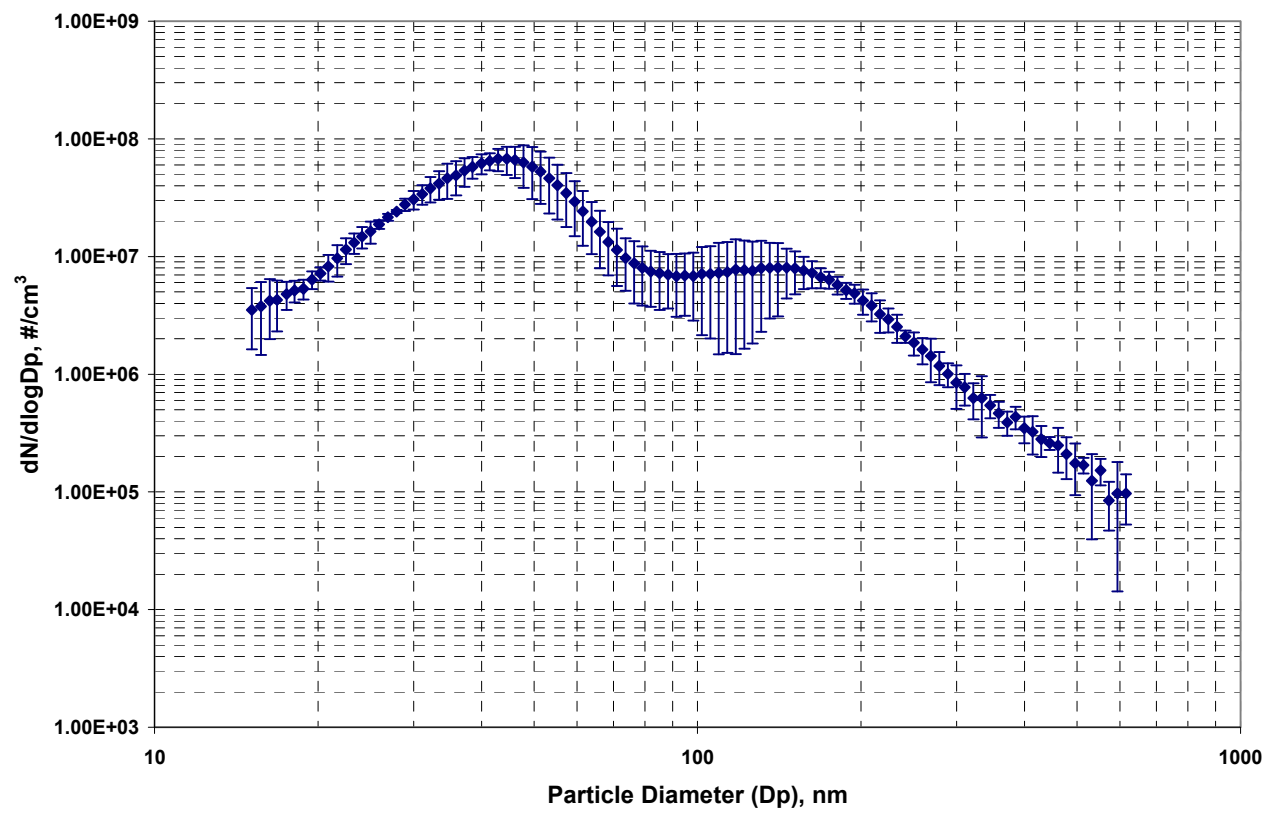

Figure E18 Particle Size Distribution: Synthetic Oil (Speed=22.5rps, Phi=0.33, Boost $=40 \mathrm{kPa}$ ) 


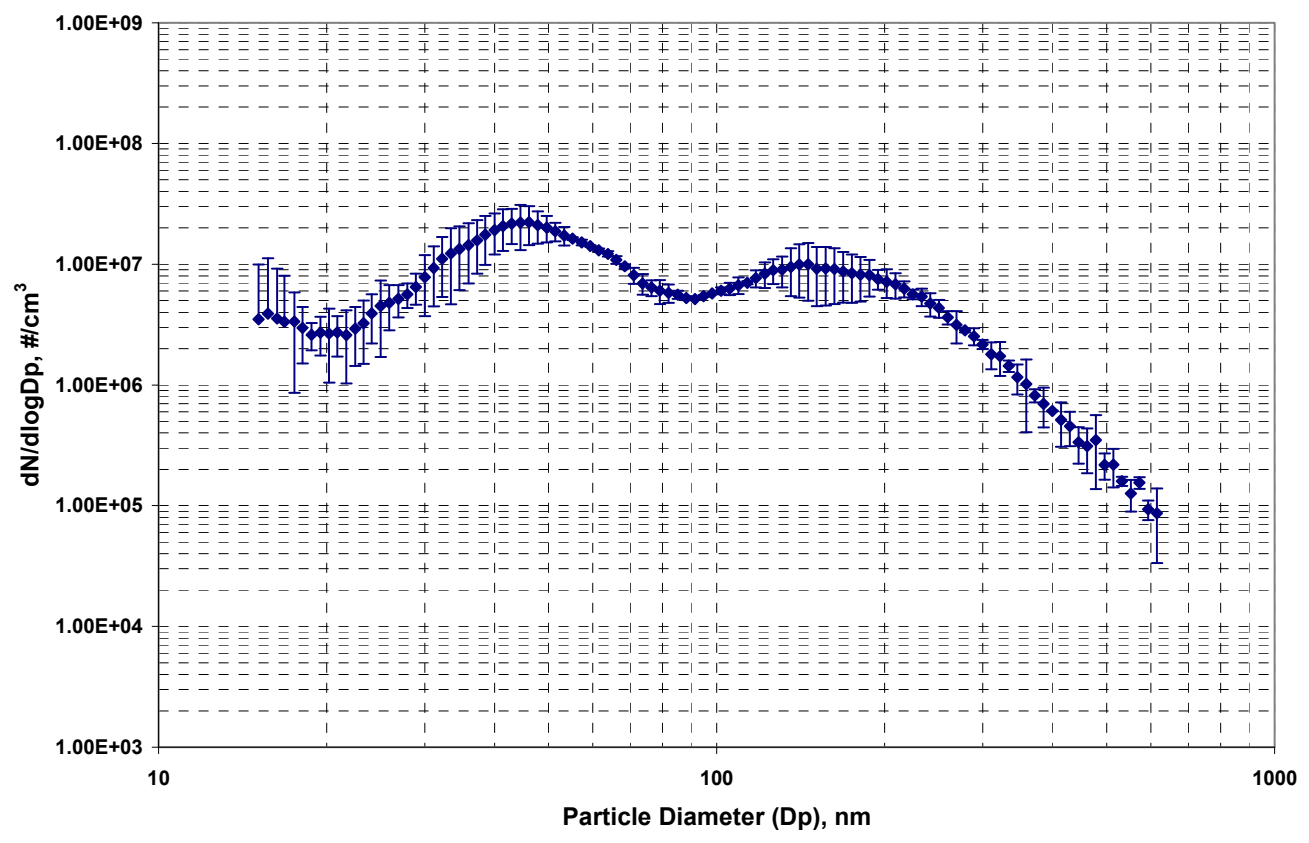

Figure E19 Particle Size Distribution: Synthetic Oil (Speed=22.5rps, Phi=0.33, Boost $=60 \mathrm{kPa})$

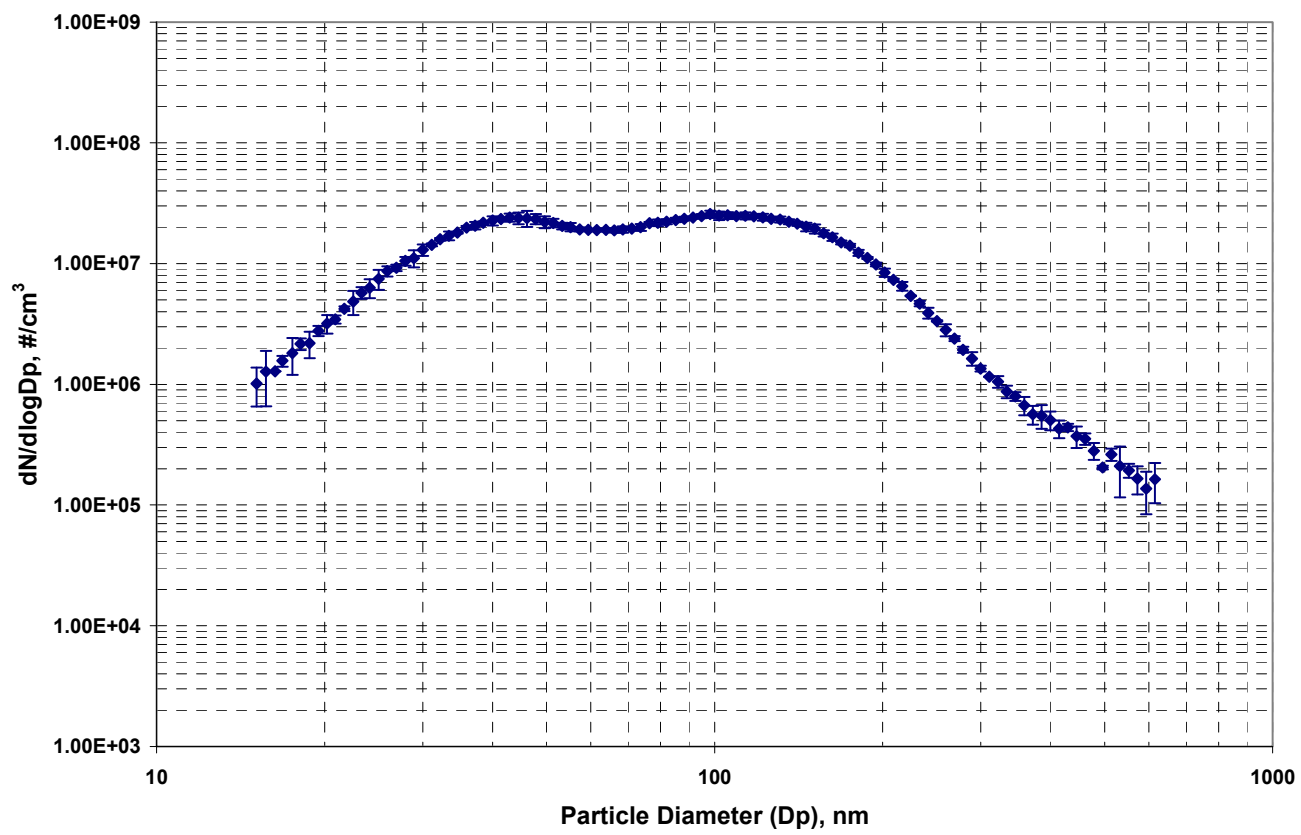

Figure E20 Particle Size Distribution: Synthetic Oil (Speed=22.5rps, Phi=0.38, Boost $=40 \mathrm{kPa})$ 


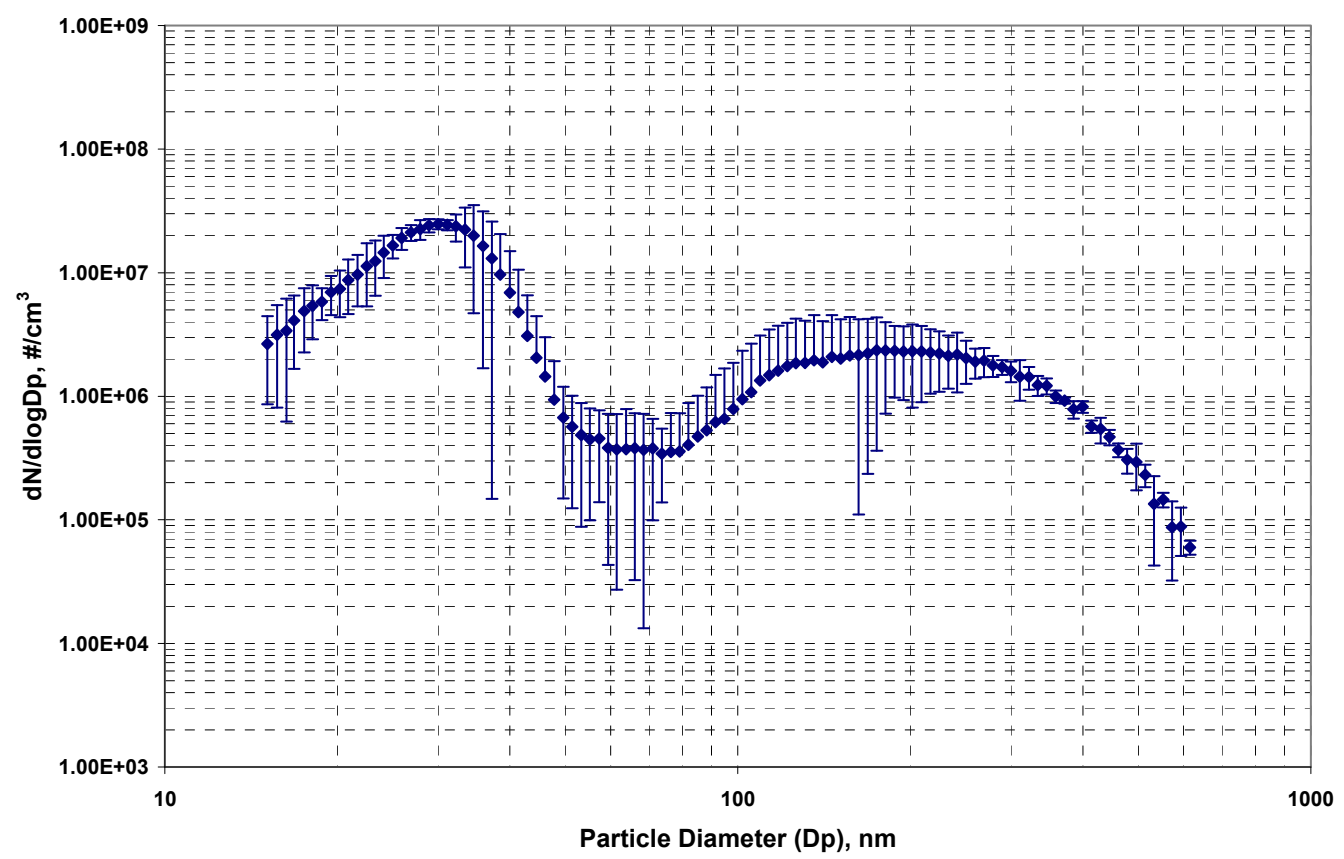

Figure E21 Particle Size Distribution: Mineral Oil (Speed=30 rps, Phi=0.28, Boost=20 kPa)

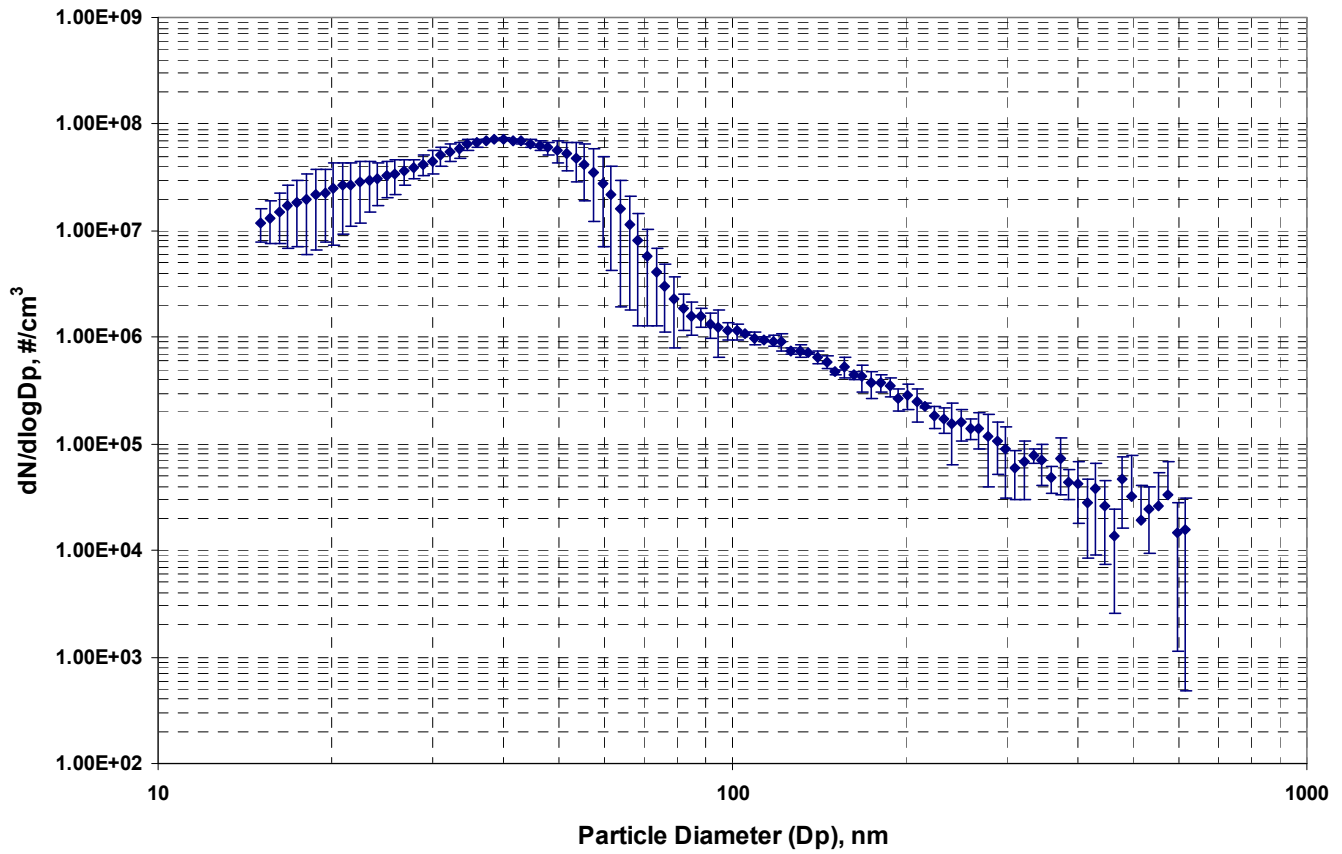

Figure E22 Particle Size Distribution: Mineral Oil (Speed=30 rps, Phi=0.28, Boost=60 kPa) 


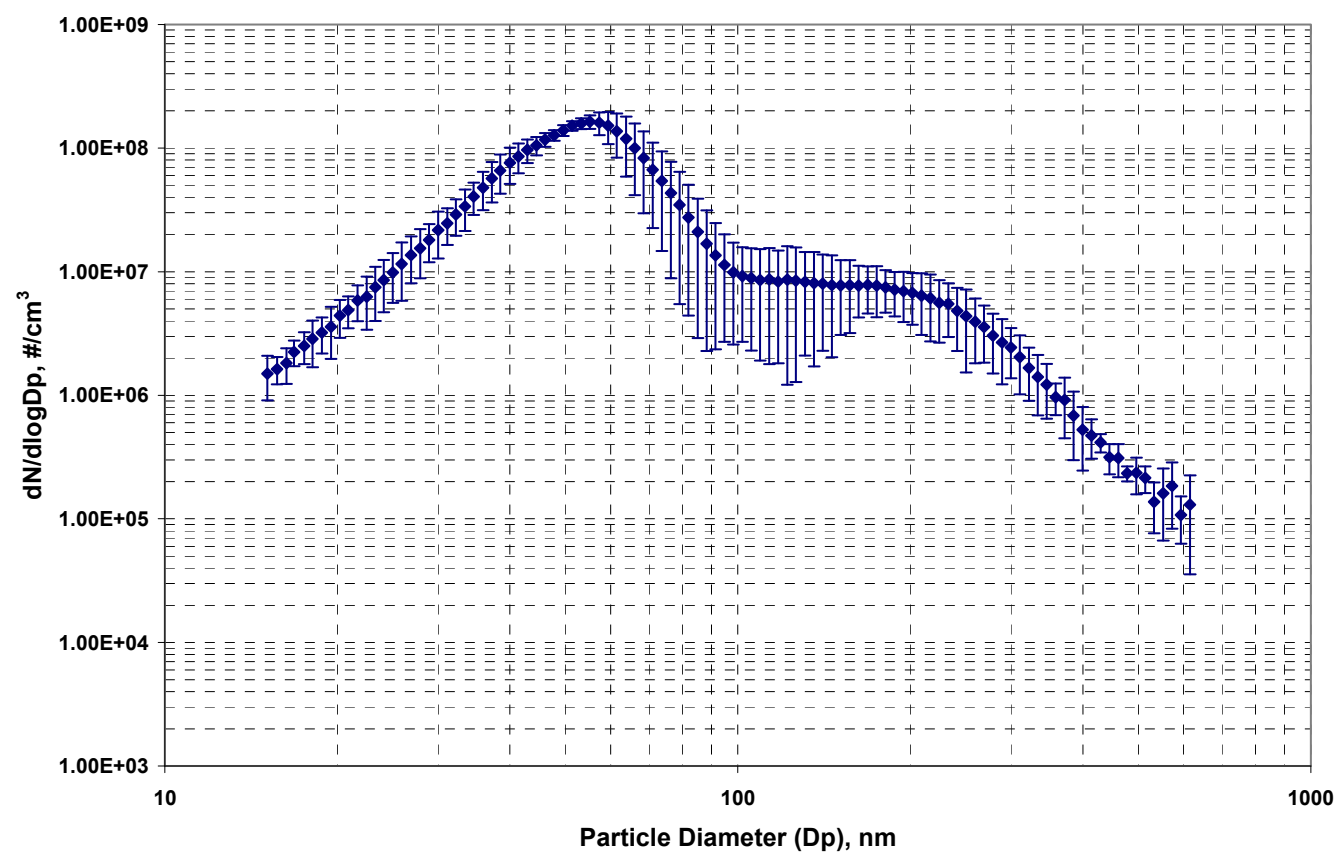

Figure E23 Particle Size Distribution: Mineral Oil (Speed=30 rps, Phi=0.33, Boost=40 kPa)

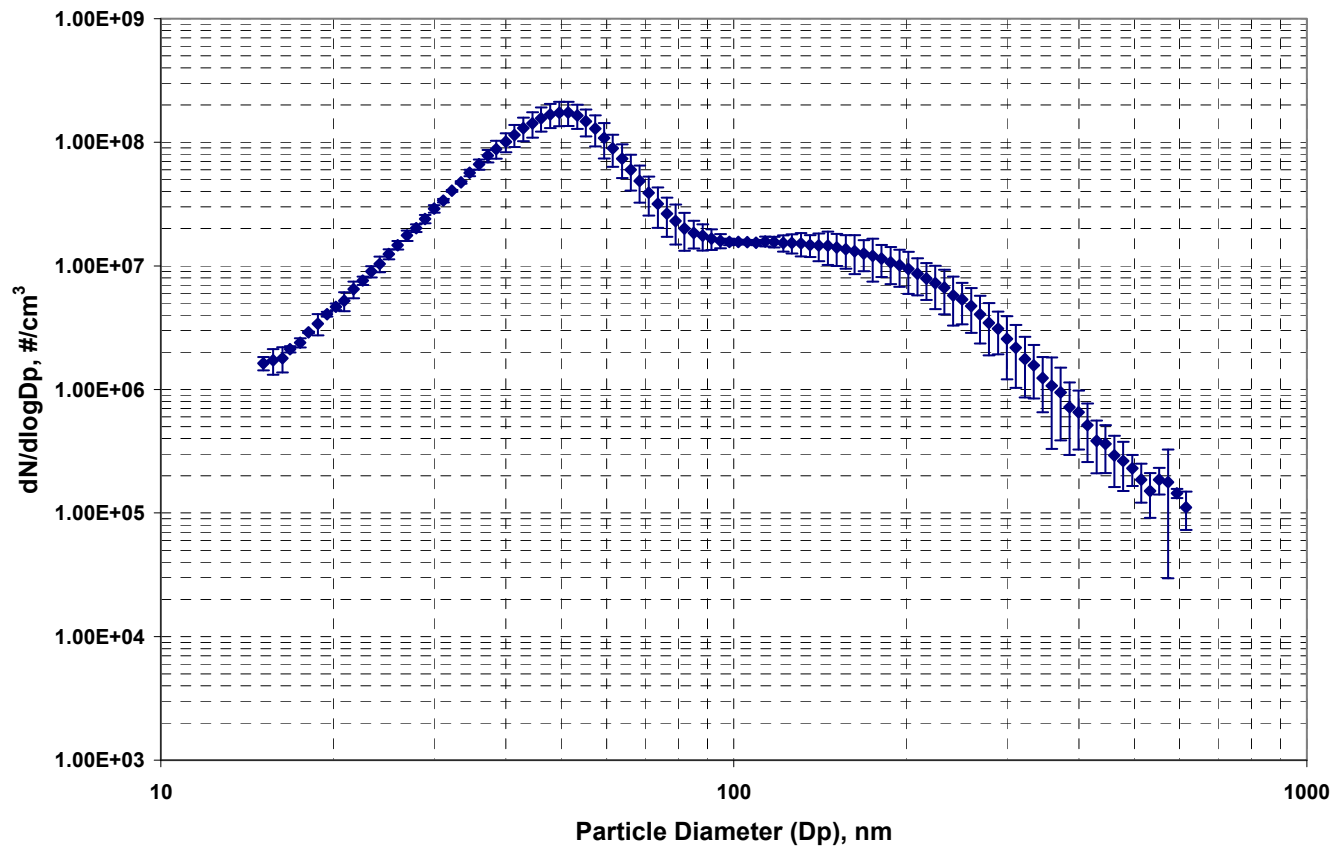

Figure E24 Particle Size Distribution: Mineral Oil (Speed=30 rps, Phi=0.38, Boost=20 kPa) 


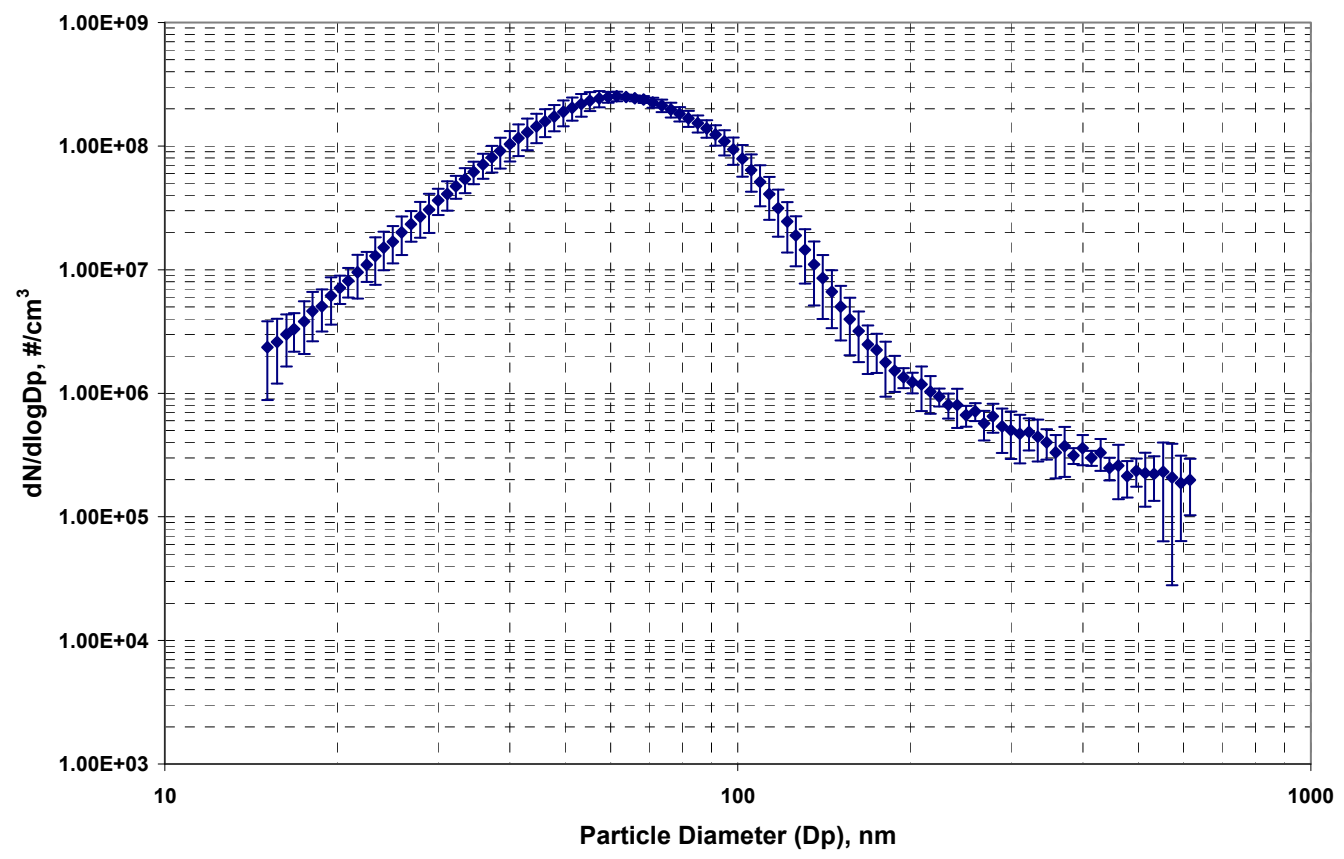

Figure E25 Particle Size Distribution: Mineral Oil (Speed=30 rps, Phi=0.38, Boost=60 kPa)

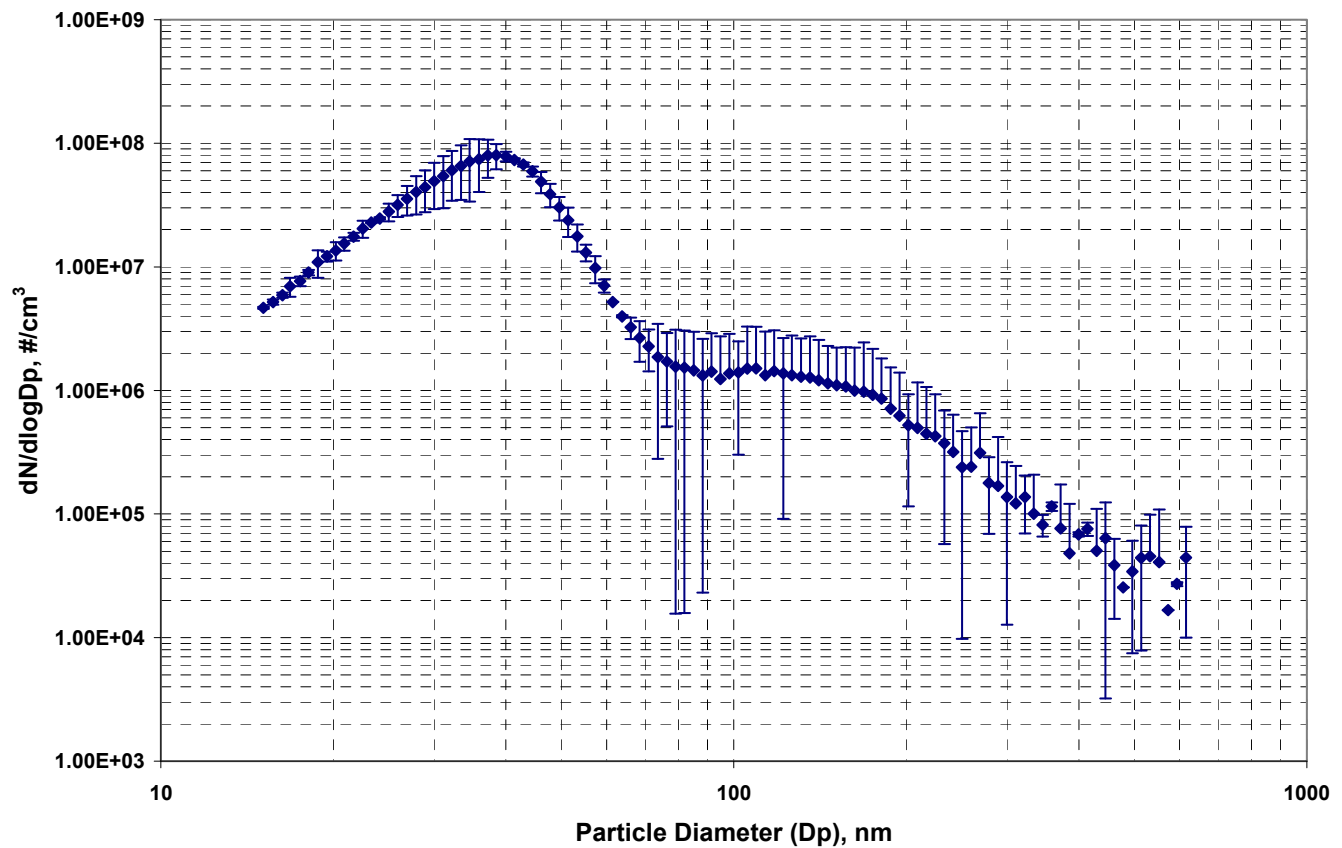

Figure E26 Particle Size Distribution: Synthetic Oil (Speed=30 rps, Phi=0.28, Boost=20 kPa) 


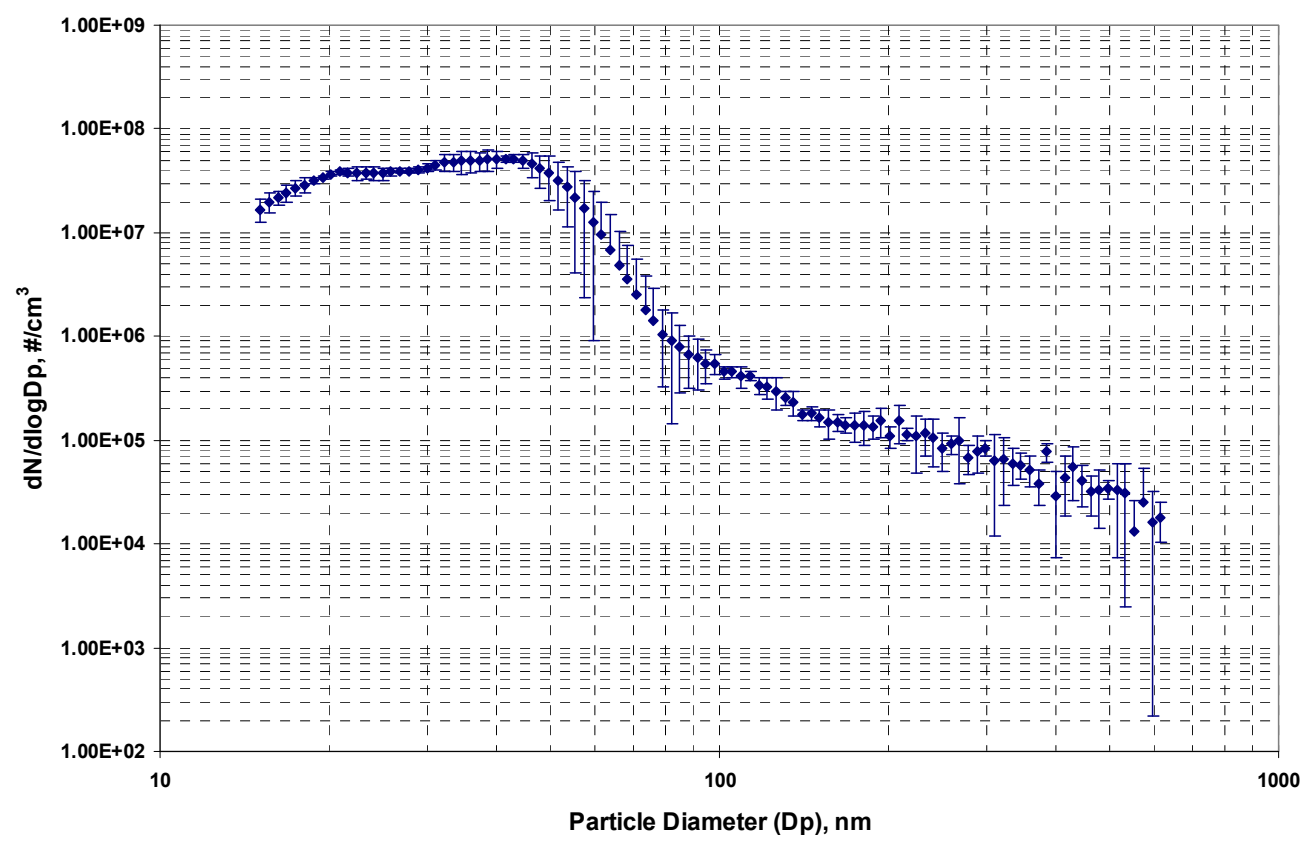

Figure E27 Particle Size Distribution: Synthetic Oil (Speed=30 rps, Phi=0.28, Boost=60 kPa)

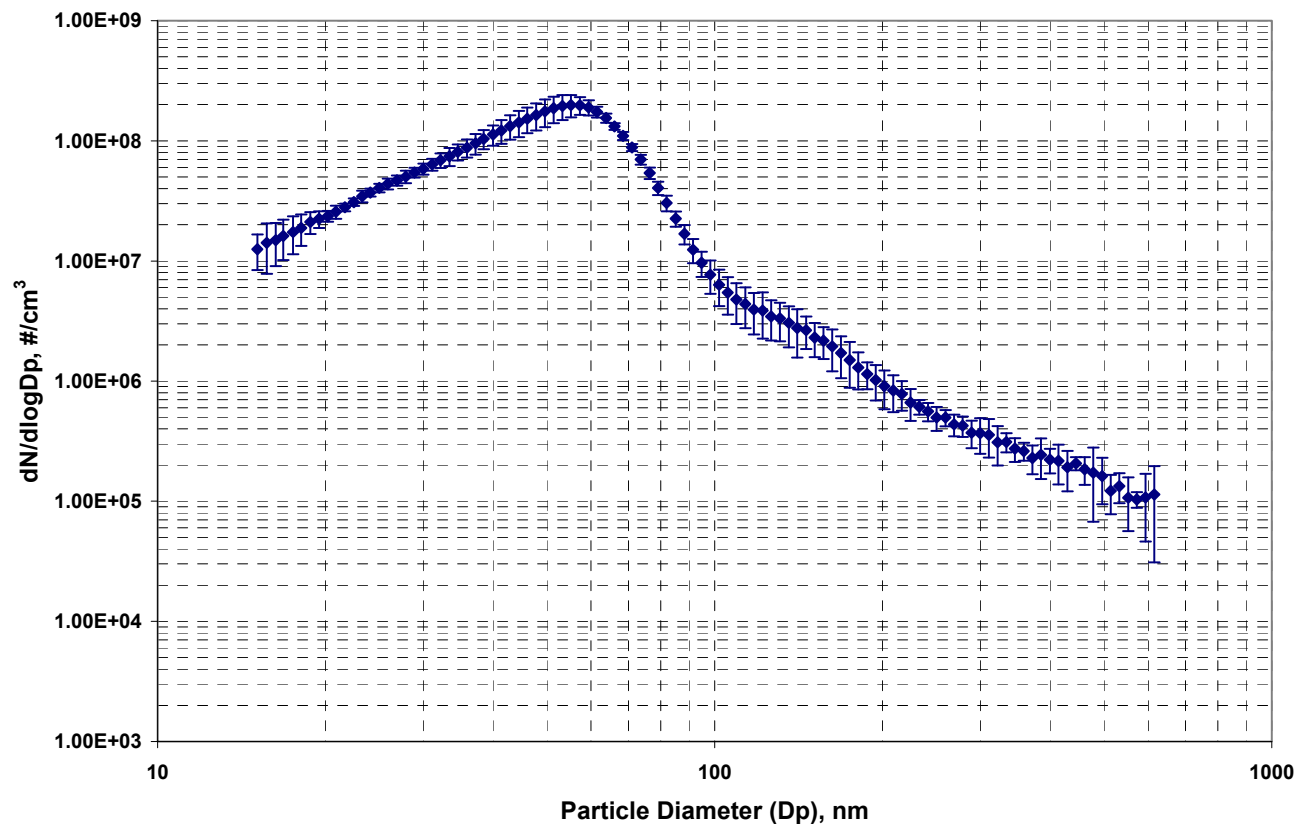

Figure E28 Particle Size Distribution: Synthetic Oil (Speed=30 rps, Phi=0.33, Boost=40 kPa) 


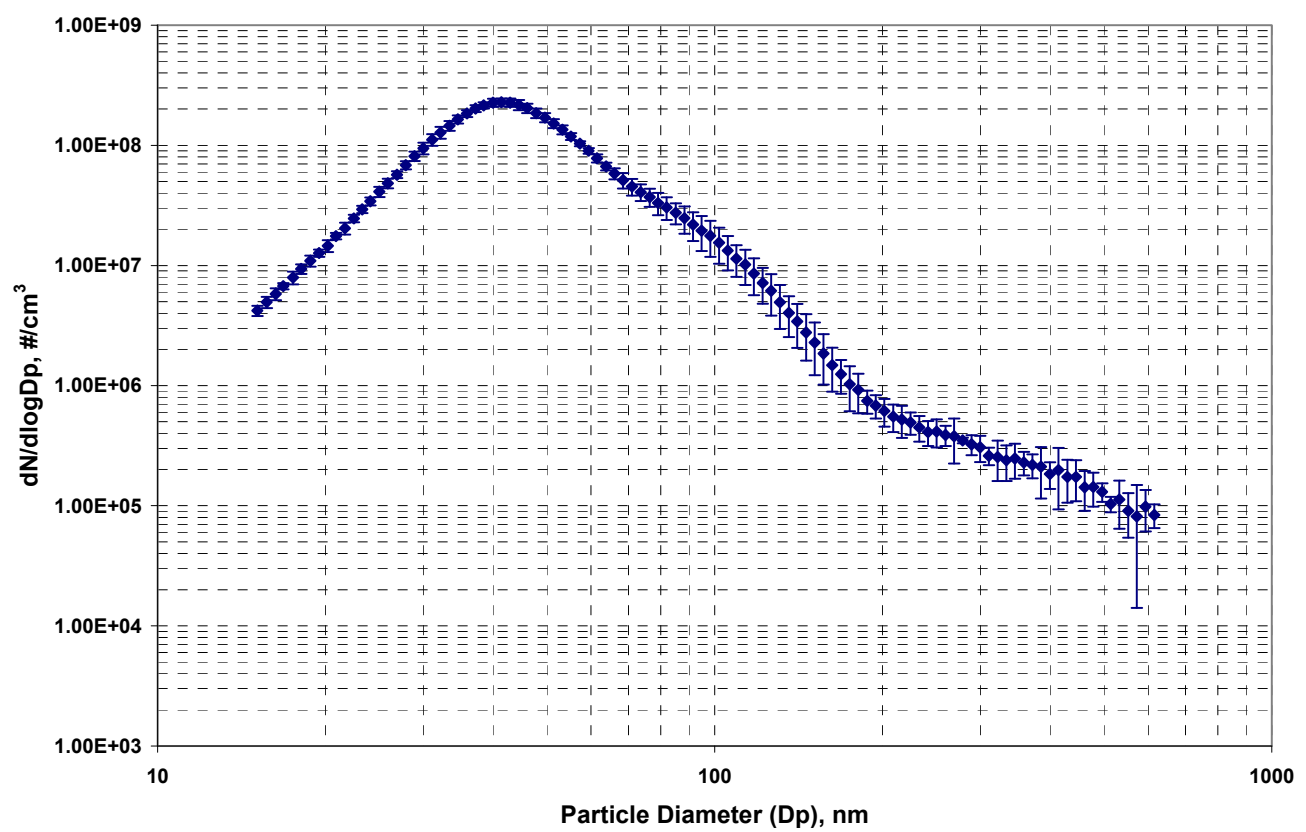

Figure E29 Particle Size Distribution: Synthetic Oil (Speed=30 rps, Phi=0.38, Boost=20 kPa)

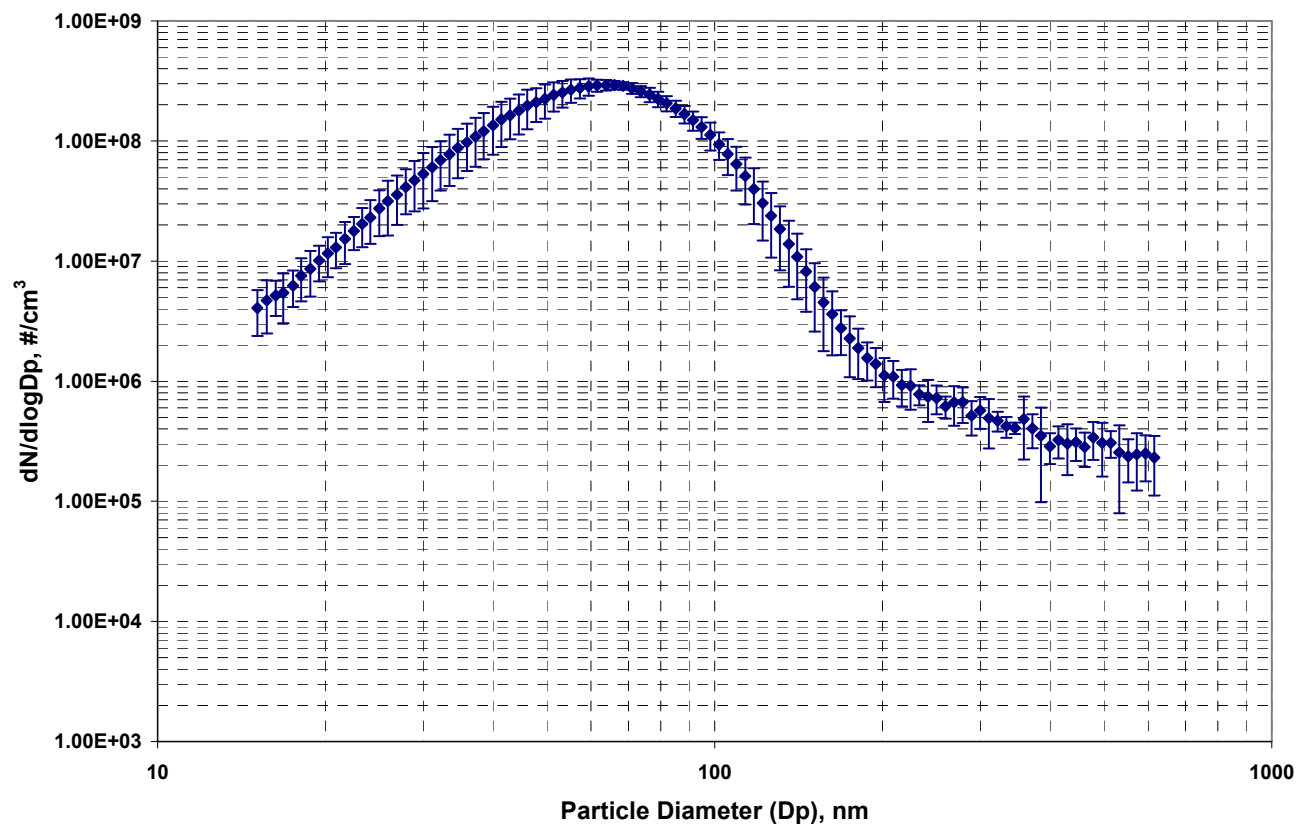

Figure E30 Particle Size Distribution: Synthetic Oil (Speed=30 rps, Phi=0.38, Boost=60 kPa) 


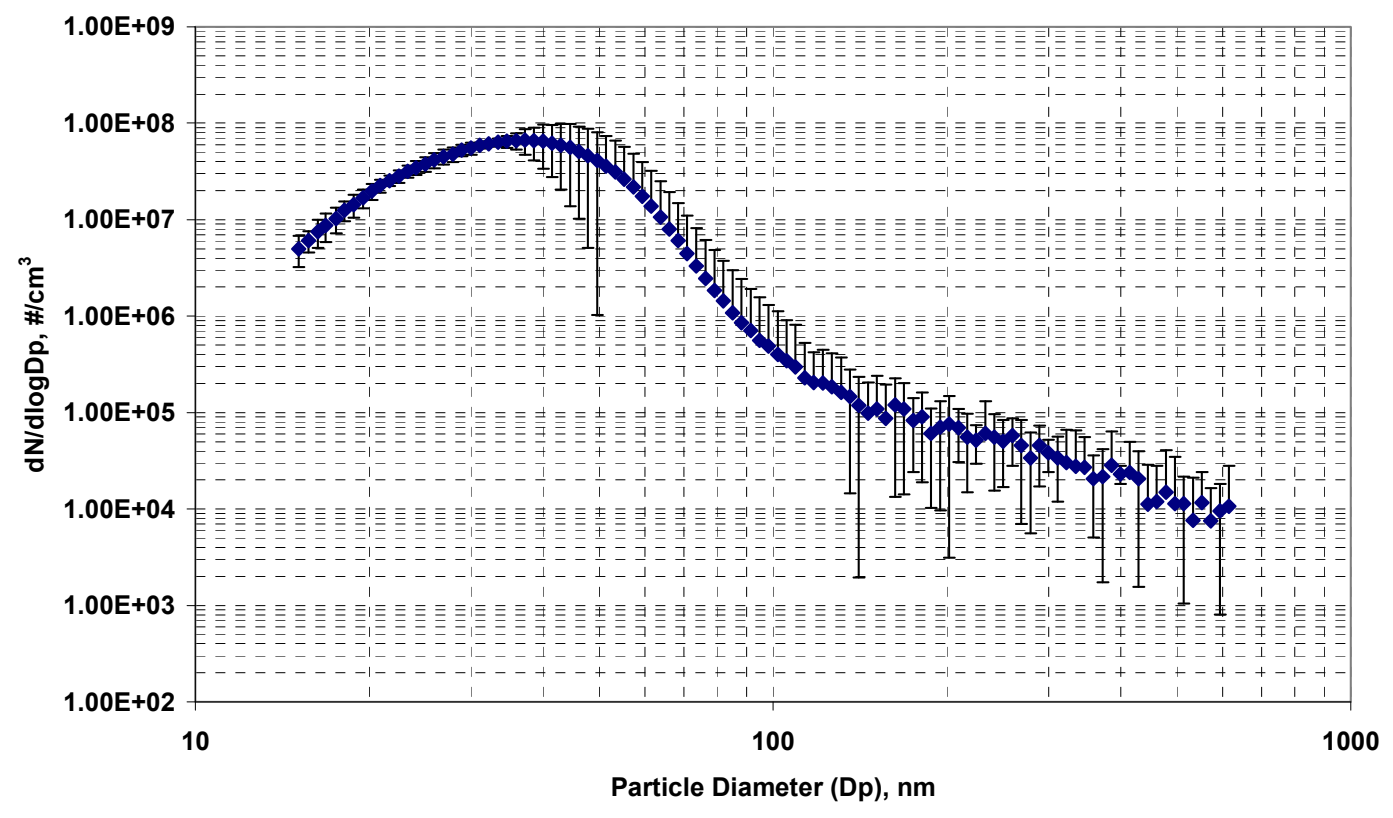

Figure E31 Particle Size Distribution: Motoring Condition (Speed=15 rps, Boost=40 kPa)

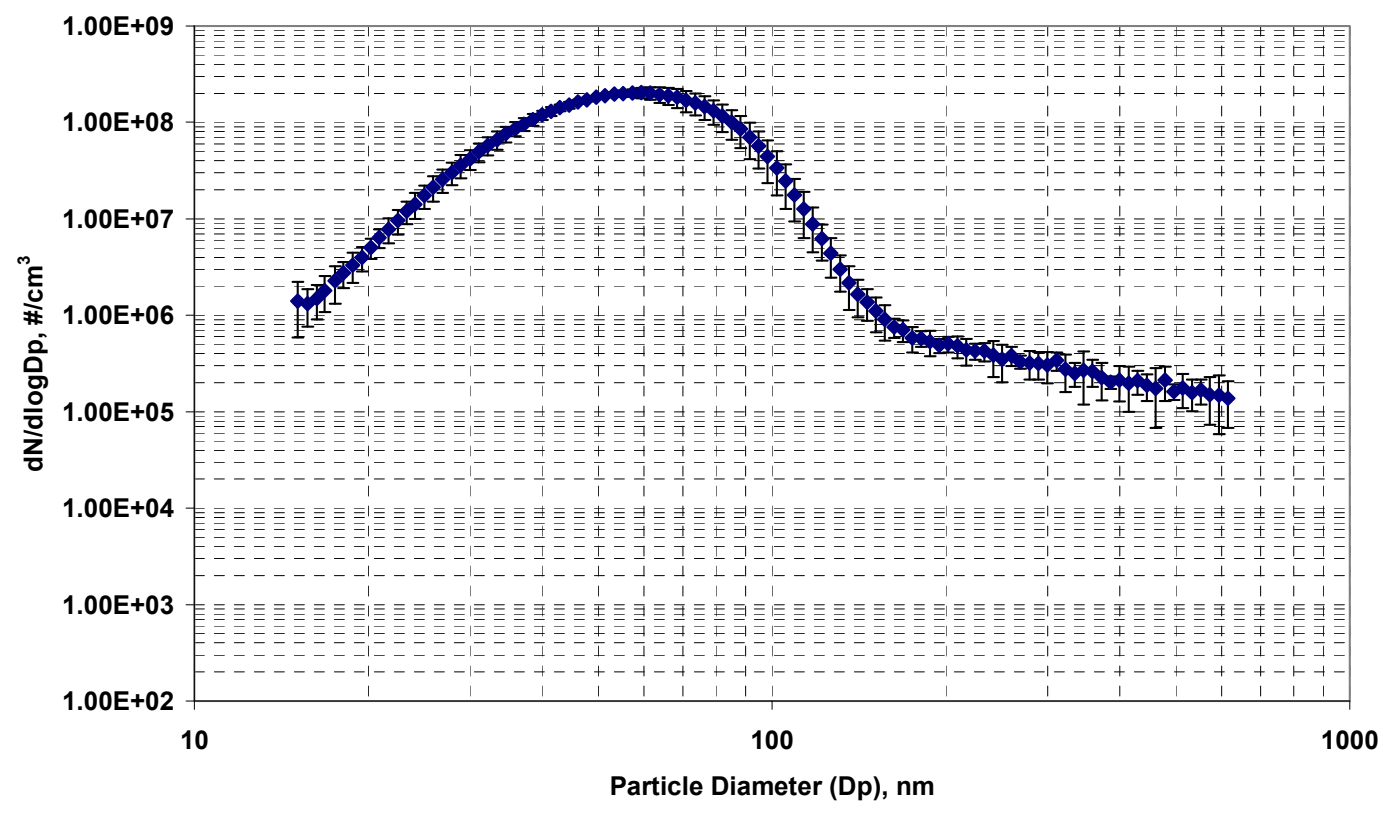

Figure E32 Particle Size Distribution: Motoring Condition (Speed=22.5 rps, Boost=40 kPa) 


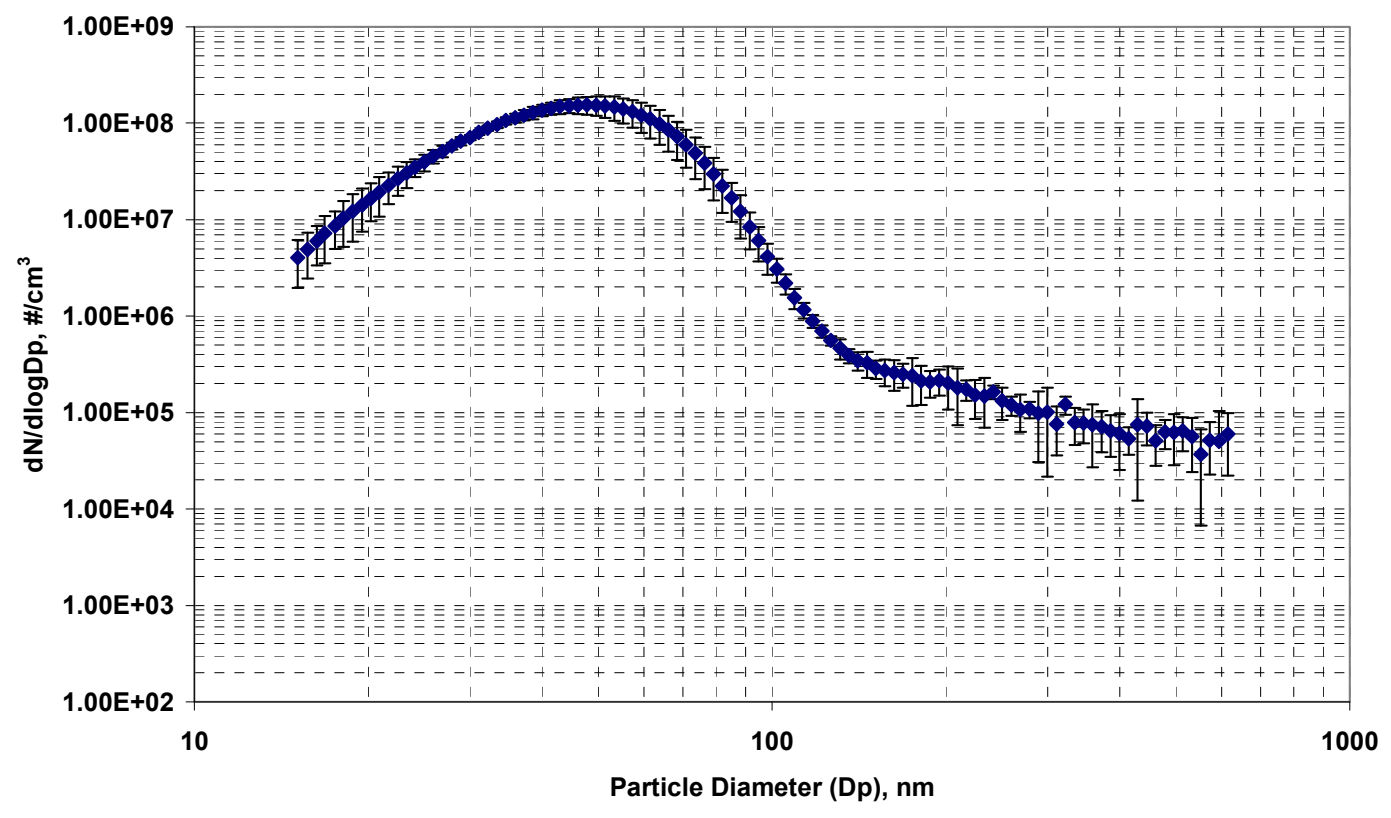

Figure E33 Particle Size Distribution: Motoring Condition (Speed=30 rps, Boost=40 kPa)

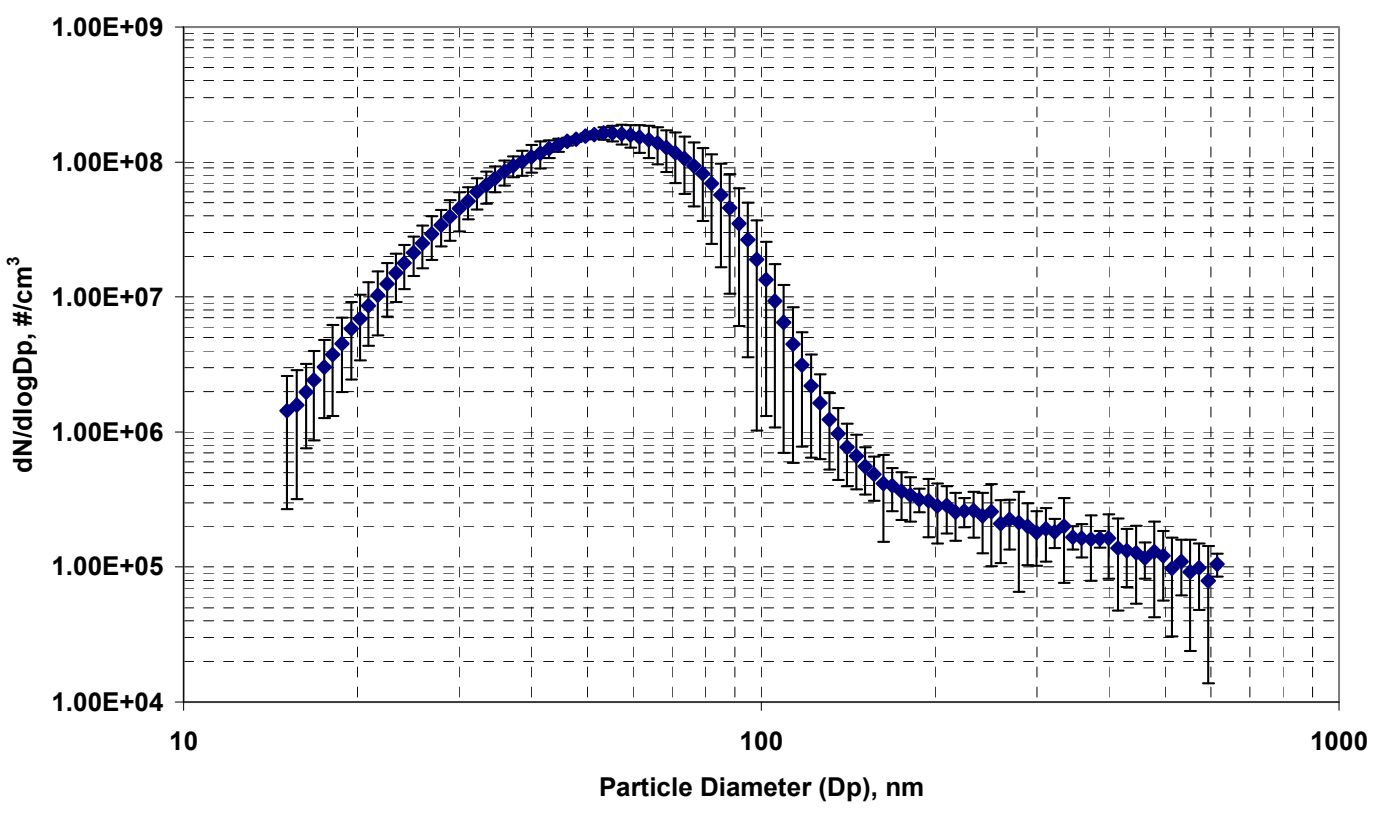

Figure E34 Particle Size Distribution: Motoring Condition (Speed=22.5 rps, Boost=20 kPa) 


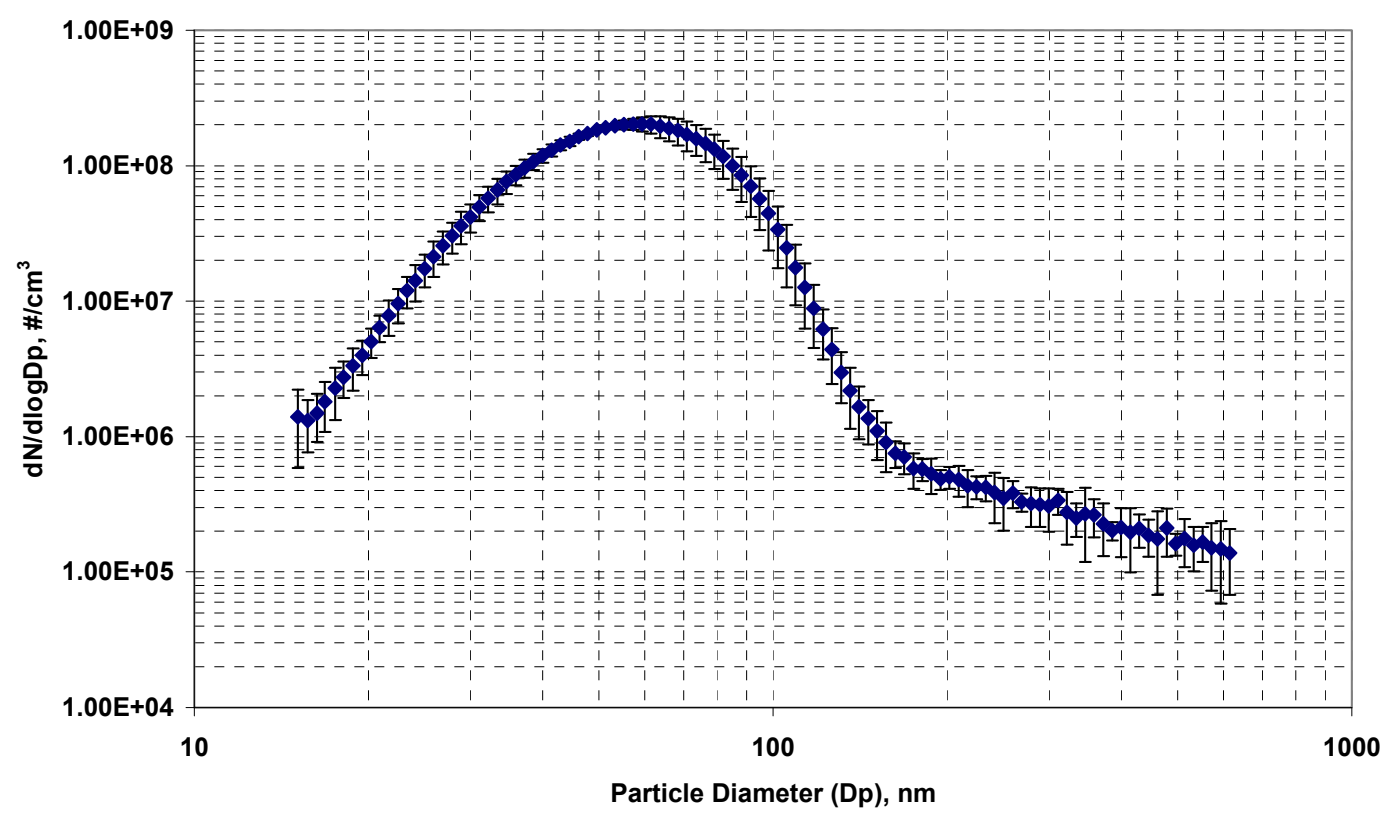

Figure E35 Particle Size Distribution: Motoring Condition (Speed=22.5 rps, Boost=40 kPa)

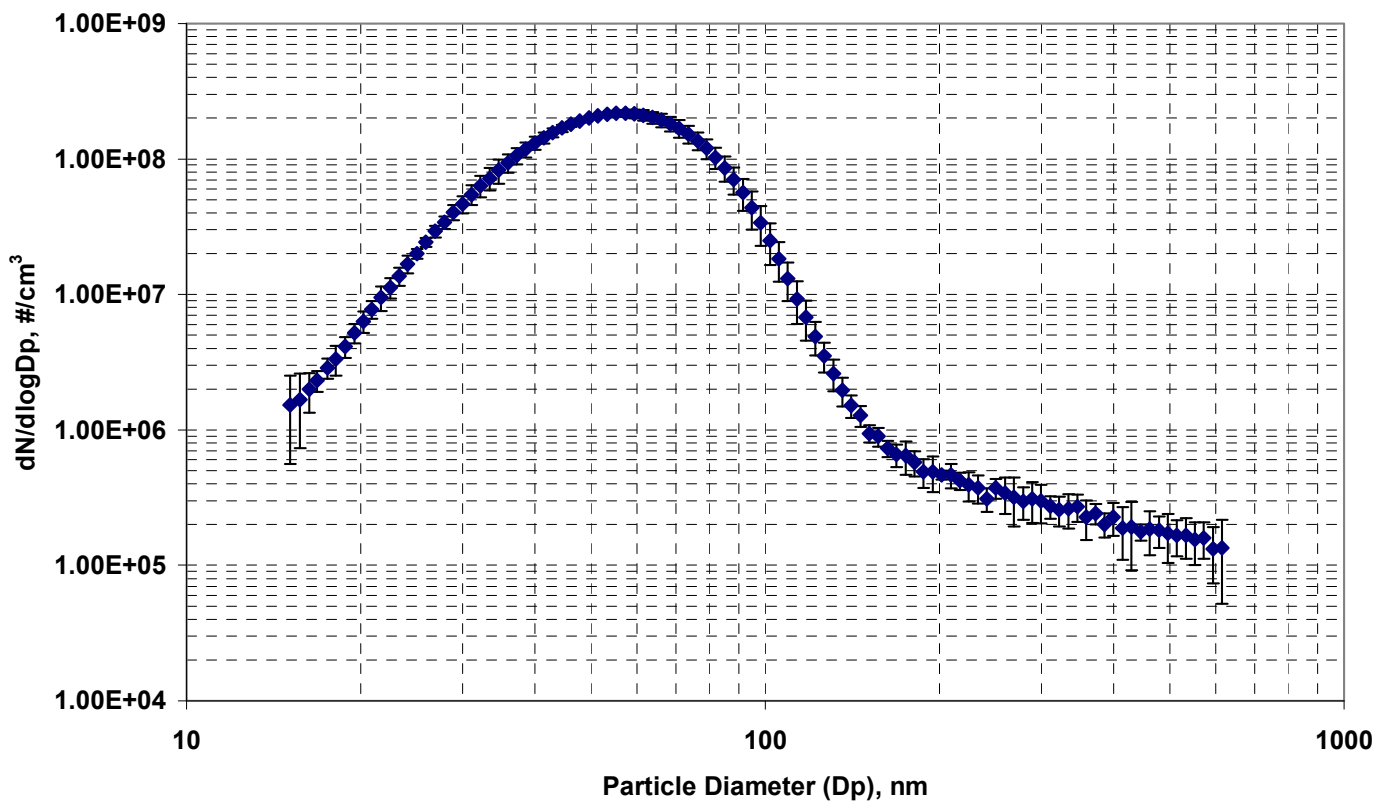

Figure E36 Particle Size Distribution: Motoring Condition (Speed=22.5 rps, Boost=60 kPa) 152 